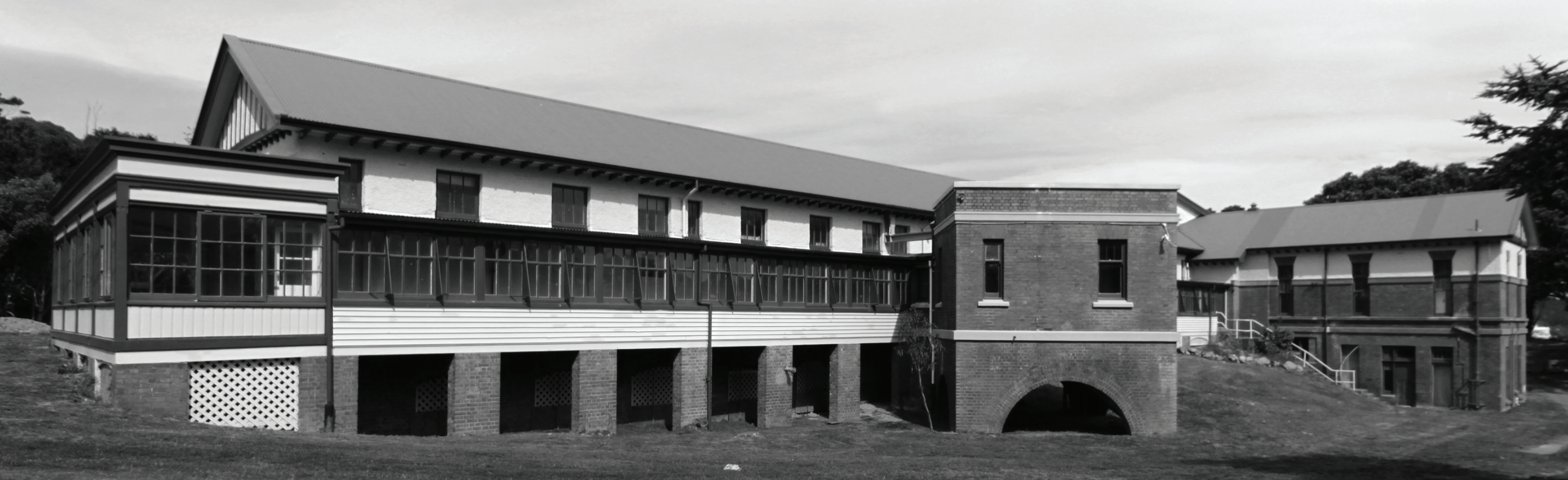

\title{
Activating Intangible Heritage
}




\title{
Activating Intangible Heritage
}

\author{
By \\ Jasper Keats \\ A Thesis Submitted to the Victoria University of Wellington in partial \\ fulfilment of the requirements for the degree of Master of Architecture \\ (Professional)
}

2014 


\section{Acknowledgements}

To both of my supervisors, Simon Twose and Jan Smitheram, your guidance, support and direction was indispensable to the completion of this thesis.

Also, to my friends, family, and particularly Vioula, for your support and patience in listening to my constant progress reports and updates on often trivial aspects of the project, it helped more than you know.

Thank You 


\section{Abstract}

Laurajane Smith argues that traditional approaches to heritage tend to conform to ideas of preservation; privileging tangible and physical connections between past and present. This thesis explores heritage as an experience that can be facilitated by, but not limited to these physical remains; proposing an approach in which intangible characteristics are privileged.

This alternative approach to heritage employs themes of memory, performance and intangibility in order to establish a means of architectural intervention. Within this multi-sensory approach to heritage, reminiscence is achieved by formalising a historical narrative of space, visually evoking feelings in regard to memory of the site. The site of this investigation is the Fever Hospital in Mount Victoria, Wellington, an abandoned heritage building purpose built as an isolation hospital in 1919. Through multiple architectural interventions, this thesis designs the integration of this neglected, forgotten, and isolated site as a significant element of the city. Historical narrative is engaged as a tool to distil intangible conditions and preserve the sites heritage value that would not otherwise be considered. The method of this architectural investigation uses iterative design and critical reflection to test ideas of form, scale, and program. Throughout these tests light, shadow, material, and narrative are employed as mechanisms to accentuate these less tangible elements. Informed by the history of the site, this investigation explores the programs of a bath-house and public performance space. The result being a mixed-use public space that activates the site as a component within the social context of the city, while embodying a sense of reminiscence to intangible heirtage; experienced through the spatial narrative. 
"If place cannot be completely erased, nor can it be unproblematically reproduced, for the mind is not a warehouse where bygone facts and sites slumber passively and intact, but a creative laboratory where the past is tampered with and restored the way buildings are restored, with additions and deletions. Memory is interventionist: it magnifies, diminishes, adjusts, darkens, or illuminates places that are no longer extant, transforming the past anew every time it is called to mind, shorn of undesirable reminiscense, embellished by wishful thinking, coloured by present concerns." ${ }^{1}$

Treib, M. (2009). Spatial Recall: memory in architecture and landscape. New York: Routledge, p187 


\section{Contents}

3 Acknowledgements

5 Abstract

Chapter One: Introduction

12 Background

12 The Scope

$13 \quad$ Aim

13 Approach / Methodology

14 Thesis Structure

Chapter Two: Physical Traces of History

18 Introduction

18 Heritage - A Conventional Understanding

20 The Problem

20 Intangible Heritage

21 The Aesthetics of Remembrance
23 Conclusion

Chapter Three: The Intangible Condition

$\begin{array}{ll}26 & \text { Introduction } \\ 27 & \text { Memory and Architecture } \\ 28 & \text { Atmosphere } \\ 29 & \text { Light } \\ 30 & \text { Shadow } \\ 30 & \text { Materiality } \\ 31 & \text { Spatial Narrative }\end{array}$

32 Conclusion

Chapter Four: Case Study Analysis

36 Introduction

$37 \quad$ Hedmark Museum

42 Therme Vals 
48

Jewish Museum

53 Conclusions

Chapter Five: Site Selection and Analysis

56 Chosen Site

60 Historical Significance

62 Design and Planning

66 Heritage Protection Criteria

66 Programmatic Functions

Chapter Six: Design Exploration

72 Introduction

78 Design Rationale

$78 \quad$ Concept Testing

$79 \quad$ Iteration One

85 Iteration Two
$90 \quad$ Iteration Three

$97 \quad$ Developed Design

143 Design Reflection

\section{Chapter Seven: Conclusions}

146 Reflection on Design Processes and Outcome

147 Limitations and Further Investigations

148 To Conclude

152 Bibliography

156 List of Figures

163 Appendices 


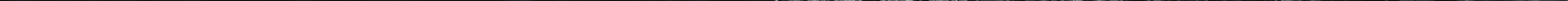




\section{Chapter One INTRODUCTION}

$\begin{array}{ll}1.0 & \text { Background } \\ 1.1 & \text { The Scope } \\ 1.2 & \text { Aim } \\ 1.3 & \text { Approach / Methodology } \\ 1.4 & \text { Thesis Structure }\end{array}$




\subsection{Background}

Rodney Harrison argues that the late twentieth and early twenty-first century has seen a remarkable growth in efforts toward the preservation of traces of history. This proliferation of heritage has been driven by a number of factors, "the increasingly broad definition of heritage, the growth of heritage tourism in the global economy, and the mnemonic or memorial function of heritage in late modern societies". ${ }^{1}$ In addition to preserving the tangible remains of history, these factors have shifted the focus of heritage to new forms of material memory and directed attention toward intangible forms of heritage. ${ }^{2} \mathrm{~A}$ focus toward intangible heritage has emerged within the interdisciplinary field of Heritage Studies; to address questions regarding conservations modern practice, tourism, and museum and site visitation. ${ }^{3}$ Drawing from Heritage Studies, this thesis investigates an approach to heritage that explores how to communicate an active dialogue between the past and present of a site, moving beyond the realms of conventional heritage practice.

\begin{tabular}{ll}
\hline 1 & Harrison, Rodney. Heritage: Critical Approaches. New York: Routledge, \\
$2013, \mathrm{p} 194$ & Harrison, Heritage: Critical Approaches, p166 \\
2 & Smith, Laurajane. Uses of Heritage. New York: Routledge, 2006, p2 \\
3 &
\end{tabular}

\subsection{The Scope}

While this research focuses on the less tangible aspects of history it does not seek to dismiss the physical remains entirely, but merely decentre them as the essence of heritage. Due to the brevity and limited scope of this research, this physical understanding of heritage will not be discussed in length, but briefly touched upon in order to establish the premise and background on which the argument of this thesis is structured. In exploring the possibilities of an alternative approach to heritage, this thesis identifies the capacity of architecture to stimulate a range of physical and sensory experiences in the retrieval of heritage that may otherwise be forgotten. In doing so, the role of atmosphere is investigated as a primary architectural concern. Drawn from prevalent attributes of memorial architecture, this atmospheric exploration focuses primarily on the presence of light, shadow, material, and narrative. 


\subsection{Aim}

The aim of this thesis is to establish an approach to abandoned historic architecture that moves beyond the realms of conventional practice. Within this architectural investigation, intangible heritage is viewed as the history, function, and purpose that underlie a building or site. These elements will be used to inform a contemporary adaption to the site of Wellington's former Fever Hospital, actively communicating its past through a complex layering of program, form, and atmosphere; formalized and experienced through a narrative structure.

\subsection{Approach/Methodology}

This research operates as an architectural investigation, following a design-led research structure. The approach of this investigation is framed through an iterative design process. The format of this thesis follows a relatively linear process; however this does not reflect the design research methods employed throughout the process of the thesis itself. Throughout its length, this design research has followed an iterative working method and employed digital design as a tool for testing theoretical concepts, with each test informing the development and scope of the research. This approach is informed by theorists such as Downton and Jonas, who argue the benefits of a non-linear research approach.
Jonas argues that research through design is "the only genuine research paradigm because it is here that new knowledge is created through an action reflection process."

Within this approach, this thesis uses written research to firstly establish the premise for the proposition, contextualizing the design within current practice. Following which, case study and site analysis are used to construct a theoretical foundation for initial design development and testing. These tests form three separate design iterations, each disrupting the physicality of the existing building and exploring the role of atmosphere and program within a contemporary addition. These form a layered investigation, building upon each other and gaining in complexity. The resolved outcome presented is informed by the multiple streams of theory investigated throughout written research and responsive to the design development within iterative testing. Informed by intangible heritage, it expresses architectures capacity to stimulate a range of emotional responses, visually evoking feelings in regard to the history of the site.

Lois Frankel, M. R. (2010). The Complex Field of Research: for Design, through Design, and about design. Design Research Society, p6 


\subsection{Thesis Structure}

\section{Chapter Two: Physical Traces of History}

Chapter Two begins by defining the word 'heritage' and identifying its development leading into the twenty-first Century. This acts as the premise to this thesis, identifying the argument to which the design responds. The following sections of this chapter identify the material focus of conventional heritage practice, discuss the inherent problems, and present the alternative conceptions that have emerged leading into the twenty-first Century that this research aligns with

Chapter Three: The Intangible Condition

Chapter Three explores the role of architecture in mediating our connection to intangible aspects of history. This exploration begins by examining the traditional role of memory in relation to memorial architecture, followed by an investigation of atmospheric qualities that are prevalent attributes in memorial museums and assist in the representation of history; by focusing on the presence of light, shadow, narrative and materiality.

\section{Chapter Four: Case Study Analysis}

Chapter Four explores the role of atmosphere within the three selected case studies of this research. The common architectural element within these buildings is the dominant presence of atmosphere; used to elicit a specific emotional response within the user. Programmatically these buildings differ, but the powerful presence of atmosphere within each acts as a strong design precedent for this research.

\section{Chapter Five: Site Selection and Analysis}

Chapter Five identifies the chosen site for the design exploration of this thesis. Due to the theoretical context of this research, the history of the site is of key focus, used to construct an understanding of intangible heritage. This analysis will consider historical significance, design and planning, programmatic functions, and existing heritage criteria that the site is currently governed under. 


\section{Chapter Six: Design Exploration}

Within Chapter Six, the atmospheric qualities explored through case study analysis are employed as architectural mechanisms to activate intangible heritage. These design tests follow an iterative working method and develop in complexity toward a resolved architectural outcome.

Chapter Seven: Conclusions - A Critical Reflection on Design Processes

Chapter Seven, the final chapter of this thesis, presents a reflective view on the research, design and approach taken. This critically analyses the iterative design responses and presents them as a speculative solution to the research problem of embodying intangible heritage within an architectural experience.

Given the design-led structure of this thesis, the weighting and emphasis is placed as $25 \%$ toward the theoretical component and $75 \%$ toward the design investigation. This is illustrated within figure 3 , showing the order that this investigation follows.

Figure 3: Diagram illustrating thesis structure and research weighting

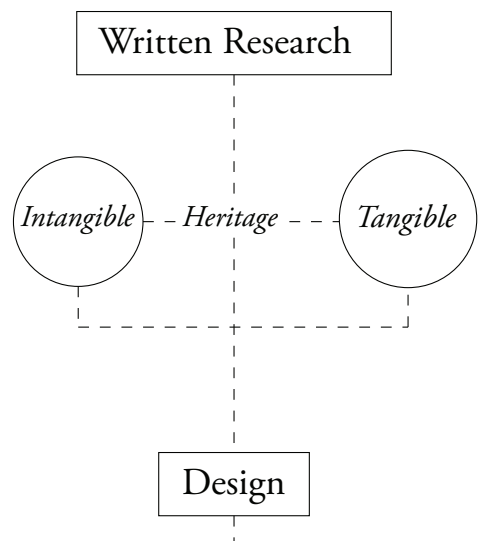

Case Study Analysis

Chosen Site

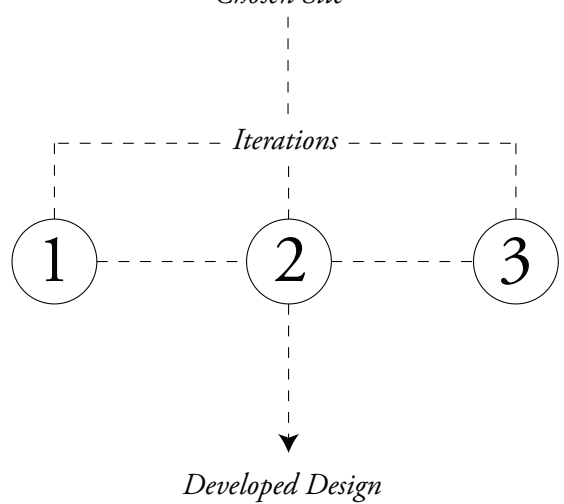




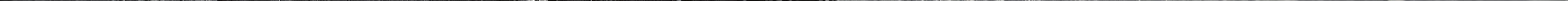




\section{Chapter Two PHYSICAL TRACES OF HISTORY}

$2.0 \quad$ Introduction

2.1 Heritage - A Conventional Understanding

2.2 The Problem

2.3 Intangible Heritage

2.4 The Aesthetics of Remembrance

2.5 Conclusion 


\subsection{Introduction}

Within her book Uses of Heritage, Laurajane Smith argues that the standard approaches to historic buildings and sites privilege materiality as the only source of heritage and apply cultural meaning to their enduring physical traces. ${ }^{1}$ Building upon this relatively recent academic area of Heritage Studies, this research examines intangible heritage in the context of a contemporary architectural intervention, challenging the effectiveness of conventional approaches in communicating an understanding of the past. This chapter identifies the material focus of conventional heritage practice, discusses the problems within the approaches, and presents the alternative conceptions that have emerged leading into the twenty-first century. Due to the brevity of this thesis, this identification of conventional interpretations of heritage acts as a mere summary, only briefing attending to the diverse arguments and positions that surround it.

Smith, Uses of Heritage, $\mathrm{p} 2$

\subsection{Heritage-A Conventional Understanding}

Miles Glendinning notes the long standing history and development of heritage conservation, tracing its origins back to the fifteenth century. However, as a modern architectural movement, he argues that the conservation of heritage did not fully emerge until the eighteenth century; within 'The Enlightenment' period. ${ }^{2}$ Leading into the twentieth century, conservation became heavily impacted by the First World War with the mass destruction acting as a pivotal point within the development of heritage protection standards; prompting attempts for a standardised international approach to heritage treatment able to define protection criteria. ${ }^{3}$ These attempts were channelled through the efforts of professional organisations concerned with the protection of historic buildings, the result being the development of an International Committee

2 'The Enlightenment' was a movement that emerged during the eighteenth Century throughout Europe and fundamentally altered the approaches toward monuments and their conservation. Previously, the treatment of historic buildings had been a matter of practical suitability but The Enlightenment period transformed conservation practice with new interpretations of history. Within the wake of Enlightenment history, and its buildings, began to be intellectually considered and valorised. This generated a new understanding of chronological relativity and altered the process of conservation through a systematic and scientific understanding. See Glendinning, Miles. The Conservation Movement: A history of architectural preservation. New York:Routledge, 2013, p48
Glendinning, The Conservation Movement: A history of architectural preservation, 
on Intellectual Cooperation (ICIC, 1922), followed by the founding of the International Museums Office (IMO, 1926). The development of these International Organisations acted as the forerunner for what would become the foundation for heritage conservation throughout the twentieth century, the Charter of Athens. ${ }^{4}$

The Charter of Athens was officially approved in 1932 . However, due to concerns that merely listing and safeguarding heritage was not enough, it became superseded by the development of various other international legislations throughout the latter end of the twentieth century. ${ }^{5}$ The first of these was in 1964, with the creation of the 'Venice Charter' and the 'International Council on Monuments and Sites (ICOMOS)' ${ }^{6}$ which acts as a non-government organization aimed at preserving sites associated with world heritage. Following these developments, ICOMOS New Zealand was established in 1992; providing a set of guidelines informed by the preceding Athens and Venice charters. The ICOMOS New Zealand Charter was established in order to bring the practice of heritage

\footnotetext{
4 Glendinning, The Conservation Movement: A history of architectural preservation,

p199.

Jokilehto, Jukk A History of Architectural Conservation. Butterworth-Heinemann,

1999, p285

6 These followed the development of 'The First International Congress of Architects

and Specialists of Historic Buildings', 1957, when, in 1964, 'The Second International Congres of Architects and specialists of Historic Buildings' met in Venice and adopted 13 resolutions; the first of which was the 'Venice Charter', and the second the creation of the 'ICOMOS'.
}

conservation to New Zealand, produced with specific intent for local sites of historic value. ${ }^{7}$ Smith argues that this standardised approach to heritage, applied to countries and communities with radically different contexts, has resulted in the archiving of thousands of buildings in a manner that sheds no light on the actual history they serve: ${ }^{8}$

The approach to heritage conservation that treats materiality as an end in itself effects a deformation of place. The excision of the material past from its social context, past and present, hollows it out and deforms it. What you are left with are things minus feelings. ${ }^{?}$

Smith outlines the inflexible material focus that conventional heritage practice tends to conforms to; being inherited from the Charter of Athens. $^{10}$
7 ICOMOS 'New Zealand Charter for the Conservation of Places of Cultural Heritage Value: Revised 2010. Auckland, NZ: ICOMOS New Zealand, 2010.

8 Akagawa, Laurajane Smith and Natsuko. Intangible Heritage. New York: Routledge, 2009, p230

$9 \quad$ Akagawa, Smith, Intangible Heritage, p231

10 Smith, Uses of Heritage, $\mathrm{p} 3$ 


\subsection{The Problem}

Miles Glendinning argues that heritage practice is often used to merely exploit the physical remains of the past for modern and aesthetic purposes, shedding little to no light on the history it has served. ${ }^{11}$ Jennifer Hill supports this position presented by Glendinning and notes that the last 15 years have seen discussions arise regarding the relevance and applicability of the Venice Charter within contemporary conservation practice of the twenty-first Century. She argues that relationships, associations and meanings that contribute to the value of a site should not be dismissed in favour of physical remains, stating: "The Venice charter has never been revised to reflect the wider understanding of what we now understand to be described as heritage or to address some of the issues arising from this." ${ }^{12}$ Harrison builds upon this argument, discussing the general nature of the Venice Charter and its tendency to foster architectural mimicry as a means of revitalising historic buildings, lacking an in-depth appreciation of the less tangible characteristics of history. ${ }^{13}$ While extensive research exists around the interdisciplinary field of Heritage Studies, Smith notes that these less tangible approaches struggle to gain firm footing within conventional practice:
In the present day, the field of heritage is almost entirely concerned with the tangible. Notwithstanding the inprinciple acknowledgement by many heritage agencies and practitioners of the importance of intangible heritage, one continues to find that on-ground heritage practice is almost exclusively focused on conserving the physicality of architecture and archaeological sites. ${ }^{14}$

This thesis argues, similar to Smith, that these less tangible characteristics of history are pivotal in conveying a dialogue between past and present. To find alternative treatment methods that engage with historic background more actively than mere preservation this research explores the potential role of intangible heritage. The following sections of this chapter will further explore the notion of intangible heritage and identify its increasing prominent role in memorial architecture.

\subsection{Intangible Heritage}

Harrison identifies the current changing interpretations of heritage from physical to immaterial, writing: "This modern period has seen heritage increasingly shift away from a concern with 'things' to a concern with cultures, traditions and the 'intangible.".'15

\footnotetext{
$14 \quad$ Akagawa, Smith, Intangible Heritage, $\mathrm{p} 243$
} 
The increasing emphasis on intangible rather than physical heritage reached a critical point in 2003, when the general conference of UNESCO (United Nations Educational, Scientific, and Cultural Organization) adopted the 'Convention for the Safeguarding of Intangible Cultural Heritage'. The aim of this convention was to shift heritage interest away from historical monuments, archaeological sites, and natural parks and toward more intangible characteristic's such as living traditions, embodied skills, and oral expressions. ${ }^{16}$ This relatively new area of research is undertaken by a range of disciplines and investigates the more intangible characteristics present in heritage; addressing questions regarding the modern practices of conservation, tourism, and museum and site visitation. ${ }^{17}$

While the term intangible heritage can be used to refer to a diverse range of characteristics, this thesis investigates it through an architectural lens. As such, this research focuses on the prominent role the museum has come to play in preserving these less tangible aspects of history. While UNESCOS's inclusion of intangible heritage is a relatively recent development in the long standing history of conservation, the museum has long been concerned with preservation of living traditions, embodied skills, and oral expressions. ${ }^{18}$ However, the role of intangible heritage in recent years has seen a change in the fundamental nature of the

\footnotetext{
16 Alivizatou, Marilena. Intangible Heritage and The Museum. Left Coast Press, 2012,

museum, aimed at generating an atmospheric and spatial environment of reminiscence. ${ }^{19}$ Paul Williams asserts this powerful role of museum architecture, stating; "As a user navigates a museum, they are able to gain equal meaning from the size, character and evocative nature of space as they are from the objects and texts contained within it." ${ }^{20}$ This evocative atmosphere of the museum is of key focus to this research, explored as a mechanism to activate the memory of the past. Focusing on the memorial museum typology, the following section further explores the use of architectural aesthetics in the activation of intangible heritage.

\subsection{The Aesthetics of Remembrance}

As a site of commemoration, the memorial museum is given the task of not only conserving artefacts and objects but also ideas and memories. ${ }^{21}$ The degree to which exhibition design can achieve this is limited. However, as an abstract form of expression, architecture assumes the dominant role in conveying historic values that could not otherwise be expressed. ${ }^{22}$ Architectures ability to construct a physical connection

\footnotetext{
19 Hawkes, Dean. The Environmental Imagination:Technics and poetics of the architectural environment. London: Taylor and Francis, 2008, p158

20 Williams, Paul. Memorial Museums: The Global Rush to Commemorate Atrocities. New York: Berg, 2007, p77

21 The use of the museum as a site of commemoration, while common in today's society, is a relatively recent development in the long standing history of museum culture. See Rotem, Stephanie Shosh. Constructing Memory: Architectural Narratives of Holocaust Museums. New York: Peter Lang, 2013, p13

22 Rotem, Constructing Memory: Architectural Narratives of Holocaust Museums, p23
} 
to that which is intangible is illustrated by the environment of the memorial museum. This is described by Dean Hawkes who writes:

The common ingredient in these buildings is environmental imagination. This being the combination of form and material, set within a specific climate and locale, which aim to enhance the meaning and identity of a building. ${ }^{23}$

This statement illustrates the capacity of memorial museums to stimulate ones imagination and generate reminiscence to immaterial aspects that underlie its exhibit.

Within the memorial museum typology, a common strategy for achieving this sense of reminiscence is the use of spatial narrative. ${ }^{24} \mathrm{~A}$ highly acclaimed example of which occurs within Holocaust Museums; users follow a spatial narrative to learn about the Holocaust, to experience a sense of empathy, and dwell on the moral issues presented within the space. ${ }^{25}$

\footnotetext{
23 Hawkes, The Environmental Imagination:Technics and poetics of the architectural environment, $\mathrm{p} 200$

24 Rotem, Constructing Memory: Architectural Narratives of Holocaust Museums, p14 $25 \quad$ Hansen-Glucklich, Jennifer. "Evoking The Sacred: Visual Holocaust Narratives In National Museums." Journal of Modern Jewish Studies: Volume 9, No. 2 (2010): 209-232, p210.
}

Within the narrative of Holocaust Museums; Light, shadow, and materiality are employed as pivotal elements in constructing a sense of environmental imagination. ${ }^{26}$ Paul Williams argues that narrative allows the visitor to move from knowing, in a factual sense, to experiencing as a witness. He states that: "The age of the memorial museum has coincided with the tactic among urban planners of establishing museological 'event spaces' in which historical narratives are given an aesthetic architectural form. ${ }^{27}$ This concept of enabling a user to witness intangible heritage is supported by Smith who, in reference to her descriptions of the Tuol Sleng Genocide Museum in Phnom Penh, Cambodia, writes;

What I have described here is the possibility of experiencing, at second hand and through the medium of a heritage site, the suffering of past individuals, the possibility of bearing witness to their individual lives and deaths, the possibility of making the intangible tangible..$^{28}$

26 Hansen-Glucklich, "Evoking The Sacred: Visual Holocaust Narratives In National Museums." p221

27 Williams, Memorial Museums: The Global Rush to Commemorate Atrocities, p78

28 The museum marks the location at which 17,000 Khmer Rouge accused of treason were imprisoned, tortured and executed between 1975 and 1979. Before being executed 'mug shot' photographs were taken of each individual. These photos are now exhibited at the museum as a spatial experience to recuperate a sense of individuality for the victims who would otherwise be lost amongst the mass death and suffering. Within the museum, visitors are propelled into the past as they progress the narrative of the exhibition. See Akagawa, Laurajane Smith and Natsuko. Intangible Heritage. New York: Routledge, 2009, p244 
Rather than merely preserving the physical remains of a site, the memorial museum is able to construct an environment that provides reminiscence to the sites intangible heritage. This thesis draws on aspects prevalent in memorial museum architecture; using narrative, lighting, and materiality in order to constitute an appropriate architectural setting of environmental imagination.

\subsection{Conclusion}

This chapter has briefly introduced the changing interpretations of heritage that have emerged leading into the twenty-first Century. This began with a brief introduction to conventional heritage practice, tracing the development of standardised approaches governed by international legislation. While this thesis does not focus on these approaches, their background and evolution is important to understanding the role of intangible heritage within the context of this research; focusing on the mnemonic and memorial function that heritage has acquired within recent years. The discussion on aesthetics of remembrance illustrates the emotive power presented by the memorial museum typology. The following chapter will explore how light, shadow, material, and narrative aid in constructing intangible heritage in further detail; focusing on the role of memory in relation to these atmospheric conditions. 
$-3$

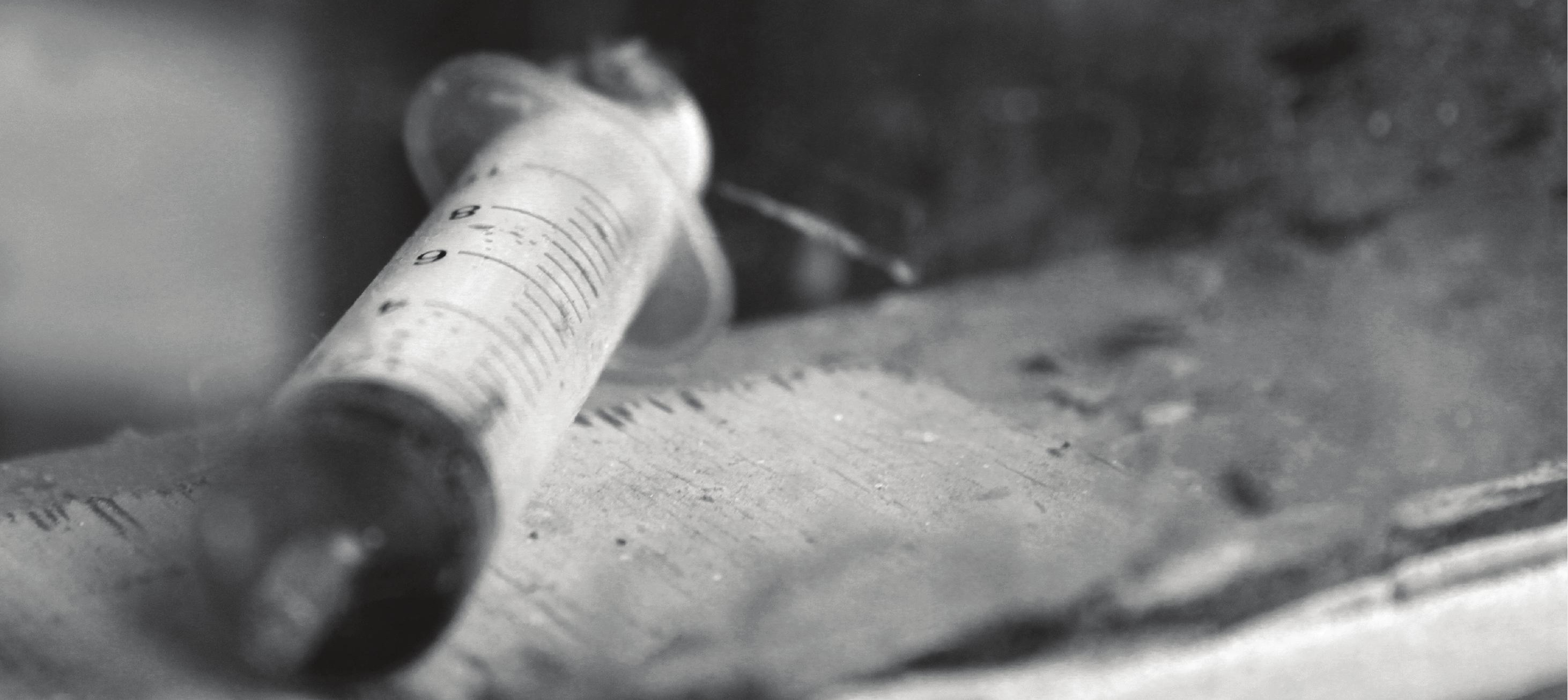




\section{Chapter Three THE INTANGIBLE CONDITION}

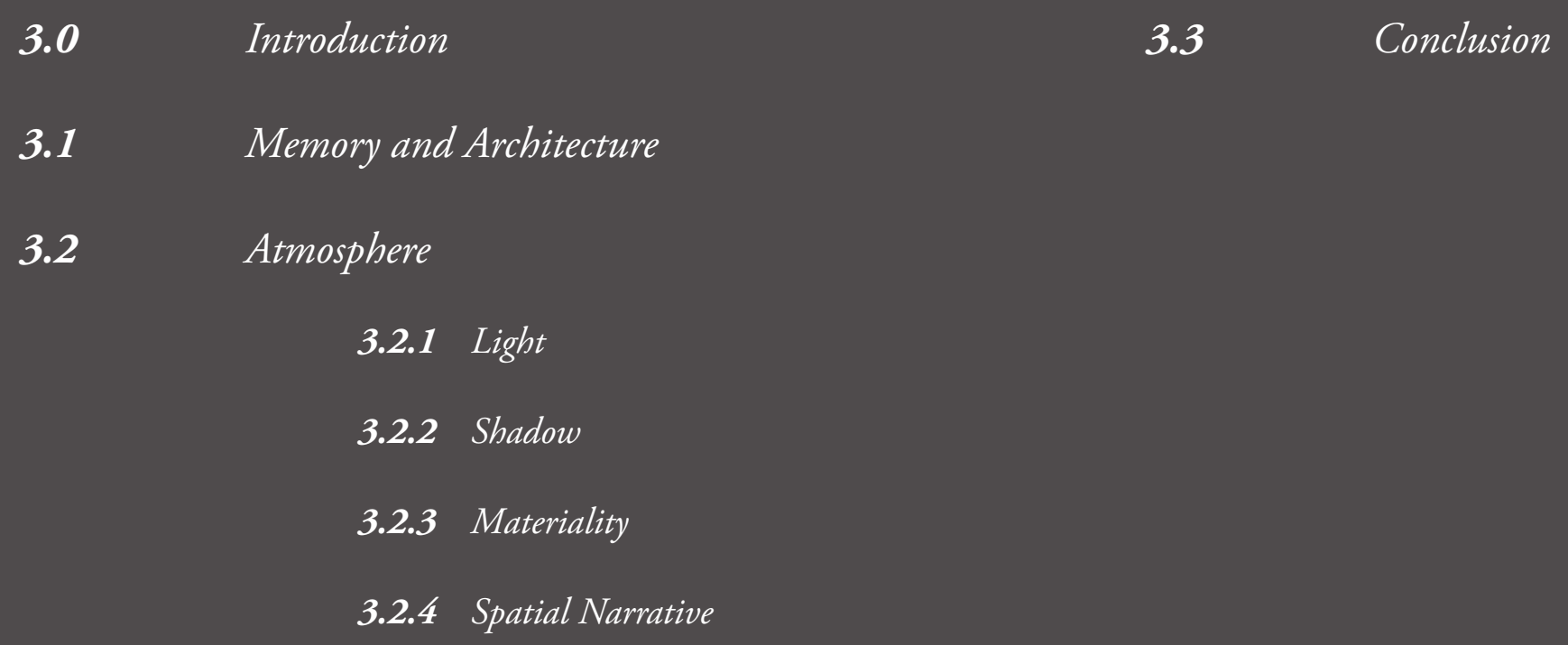




\subsection{Introduction}

Following a brief introduction to conventional interpretations, the previous chapter presented heritage through an intangible lens and identified the memorial museum as a strong precedent for this research. This chapter investigates the role of the memorial museum typology in further detail, exploring the common strategies used in constructing a sense of remembrance to intangible heritage. This construction of remembrance is discussed by Ernst Van Alphen, who argues:

Our access to the past is no longer mediated by the account of a witness or a narrator, or by the eye of a photographer. We will not respond to a re-presentation of the historical event, but to a presentation or performance of it. $^{1}$

Rotem, Constructing Memory: Architectural Narratives of Holocaust Museums, p1 1
Smith describes this presentation of history in a similar manner and depicts these aesthetics as "experienced within a layering of performative qualities that embody remembrance and commemoration and aim to construct a sense of place and understanding within the present." This chapter identifies ways that architecture is used to construct a sense of reminiscence; embodying qualities remembrance and commemotration. This will communicate architectures capacity to stimulate a range of physical and sensory experiences in the retrieval of heritage that may otherwise be forgotten. ${ }^{3}$ This exploration begins with a brief introduction to the background of memorial architecture, elaborating on ideas presented by the previous chapter. This is followed by an exploration of atmospheric qualities presented by the memorial function of the museum; focusing on the presence of light, shadow, narrative and materiality.

Smith, Uses of Heritage, $\mathrm{p} 3$

Bagnall, Gaynor. "Performance and Performativity at Heritage Sites." Museum and Society 2003: 87-103 


\subsection{Memory and Architecture}

Robert McCarter argues that architecture is too often viewed under a futurist bias, stating that:

Architecture is often seen in futurist terms; significant buildings are understood to probe and project an unforeseen reality, and architectural quality is directly associated with its degree of novelty and uniqueness. ${ }^{4}$

Similarly Marc Treib writes; "the appreciation of newness has probably never been as obsessive as in today's cult of spectacular architectural

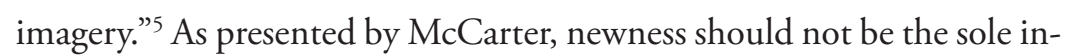
tent of architecture; buildings constitute our most important externalizations of memory and should also maintain an understanding of the durations of time, culture and tradition. ${ }^{6}$ There are particular buildings types, such as monuments, memorials, commemorative sites, and museums, which have been conceived as a direct attempt to communicate this understanding of history. ${ }^{7}$ These buildings, constructed with the

\footnotetext{
$4 \quad$ McCarter, Robert. Understanding Architecture: a primer on architecture as experience London: Phaidon Press Limited, 2012, p329

5 Treib, Spatial Recall: memory in architecture and landscape, p17

$6 \quad$ McCarter, Understanding Architecture: a primer on architecture as experience, p329

7 These buildings aim to preserve and evoke specific memories and emotions in regard to public memory, aimed at allowing a more active engagement with history than

physical remains that merely freeze the past as an object; preserved and protected. See Huyssen, Andreas. Present Pasts: urban palimpsests and the politics of memory. Stanford, California: Stanford University Press, 2003, p94
}

sole intent of reminiscence, communicate the separations of past and present like no other; "they assert themselves as witness", writes Jennifer H. Glucklich. ${ }^{8}$

The memorial museum uses spatial configuration in order to construct sensations of belonging or rejection, inclusion or isolation, tranquillity or despair. ${ }^{9}$ In regards to the representation of public memory, Huyssen notes that the most compelling and successful buildings are those which act as an intervention to urban space. ${ }^{10}$ The memorial as a site of intervention allows this history to not only be embedded within urban space, but experienced as an environment of reminiscence. This physical embodiment of memory within space is described by Eleni Bastéa, who writes: "architecture can transform words, needs, and desires into space. It can capture fleeting or insistent memories into tangible, buildable, or unbuildable forms." 11 This description presented by Bastéa outlines architectures capacity to not only preserve, but reconstruct and create a tangible memory.

\footnotetext{
$8 \quad$ Hansen-Glucklich, "Evoking The Sacred: Visual Holocaust Narratives In National Museums." p210

$9 \quad$ McCarter, Understanding Architecture: a primer on architecture as experiencep331 10 Huyssen argues that once remembrance is embodied within a memorial site that acts as a component of the existing urban fabric, reminiscence of traumatic events becomes less susceptible to the ficle atributes of memory. With the me of to as a site of in memory is able to be inscribed into the physcal realm, codifed into natonat consciousess. See Huyssen, Andreas. Present Pasts: urban palimpsests and the politics of memory. Stanford, California: Stanford University Press, 2003, p10

11 Bastéa, Eleni. Memory and architecture. University of New Mexico Press, 2004, p1
} 
As described by McCarter, architecture aimed at reminiscence should not be merely a mental activity but engage aspects of the entire body. He argues that all of the human senses aid in the construction of an experience, with memories not only being hidden in the processes of the brain. ${ }^{12}$ Pallasmaa affirms this concept of body memory, argueing that; "human memory is embodied, skeletal and muscular in its essence, not merely cerebral."13

This research explores the immersive capabilities of atmosphere as a tool to stimulate intangible heritage. Informed by the spatiality of memorial museum architecture, this exploration employs light, shadow, narrative and materiality as pivotal elements in the construction of intangible heritage.

\subsection{Atmosphere}

According to Mark Wigley, the term atmosphere refers to a variety of intangible characteristics of space; he describes these as: "some kind of sensuous emission of sound, light, heat, smell, and moisture; a swirling climate of intangible effects generated by a stationary object." ${ }^{14}$ While advocating its important role within architecture, Wigley identifies the

\footnotetext{
12 McCarter, Understanding Architecture: a primer on architecture as experience, $\mathrm{p} 331$

13 Treib, Spatial Recall: memory in architecture and landscape, p21

$14 \quad$ Wigley, Mark. "Architecture of Atmosphere." Daidalos 68 (1998): 18-27, p18
}

elusive nature of atmosphere and presents it as a concept that lacks definition. In contrast, Juhani Pallasmaa argues that every architectural experience is informed by atmosphere. He identifies the presence of atmosphere as a multi-sensory experience controlled by matter, writing;

Every touching experience of architecture is multi-sensory; qualities of space, matter, and scale are measured equally by the eye, ear, nose, skin, tongue, skeleton and muscle....architecture involves several realms of sensory experience which interact and fuse into each other. ${ }^{15}$

Peter Zumthor approaches atmosphere in a similar manner to Pallasmaa, identifying it as a complex and varying arrangement of sensory stimuli. ${ }^{16}$ Within his book Atmospheres, Zumthor presents nine categories of atmosphere separated into brief and illustrated chapters. Of these nine, three categories are of particular interest to this research; Light on Things, Material Compatibility, and Between Composure and Seduction. These run parallel with the primary atmospherics presented by the memorial museum. Informed by an understanding of atmosphere by Zumthor, Pallasmaa and Wigley, this research assumes the position

$15 \quad$ Pallasmaa, Juhani. "Hapticity and Time: notes on fragile architecture." The Architectural Review (London). Vol. 207 (2000): 78-84, p78

16 Within his book Atmospheres, Zumthor sets about explaining what, to him, constitutes architectural atmosphere. Within nine brief and illustrated chapters framed as a process of self-observation he sets about describing his personal processes in the construction of atmosphere. These chapters follow the structure of; The body of architecture, Material Compatibility, The Sound of a Space, The Temperature of a Space, Surrounding Objects, Between Composure and Seduction, Tension Between Interior and Exterior, Levels of Intimacy and The light on things. See Zumthor, Peter. Atmospheres: architectural environmentd; surrounding objects. Birkhäuser, 2006. 
that atmospheric conditions are able to contribute to the embodiment of meanings that exceed standard perceptions of architectural space. As such, atmosphere plays a dominant role in the design-led research of this thesis and is explored in further detail throughout the remainder of this chapter.

This exploration will briefly present the characteristics of atmosphere that this thesis focuses on; later employed throughout case study analysis and applied to design exploration. These follow the order of light, shadow, materiality, and narrative.

\subsubsection{Light}

As described by McCarter, the temporal dimension of light can express deep, subtle and extreme emotions; ranging from melancholy to joy, grief to ecstatic, and sorrow to bliss. ${ }^{17}$ Within Western architecture light has become increasingly dominated by an obsession with brightness; leaving interiors void of shadow. ${ }^{18}$ These homogenous artificial lighting standards for McCarter are: "a result of the modern era's association of lightness and whiteness with health and vitality." ${ }^{19}$ Hervé Descottes disputes this purely functional understanding of light, argueing that light

\footnotetext{
17 McCarter, Understanding Architecture: a primer on architecture as experience, $\mathrm{p} 151$ 18 Steane, Mary Ann. The Architecture of Light: Recent Approaches to Designing with Natural Light. New York: Routledge, 2011, p

19 McCarter, Understanding Architecture: a primer on architecture as experience, $\mathrm{p} 153$
}

has a powerful mnemonic presence able to construct an understanding of space beyond its physicality: "light can effect emotions and trigger memories, giving rise to specificity of place. What we often recall of a space is its feeling or sense of atmosphere, not its formal details." ${ }^{20}$ Informed by this understanding, the design of this thesis employs light as a strong architectural component in the activation of intangible heritage; used to trigger memories specific to the history of the site.

Perhaps the most powerful example of this form of light is that which falls from above; illuminating interior space from either an opening in the roof or a window placed high on a wall. Within his aptly titled book Zenithal Light, Elias Torres identifies the theatrical and representational capacity of this form of light, stating:

They are spaces that give rise to the creation of spaces akin to stage sets where light, although intangible, is the main actor and an essential ingredient for imagining with form. ${ }^{21}$

This form of light, Torres argues, allows architectural space to be separated from its exterior reality, creating a detached environment that acquires a dramatic dimension stimulated by intensity and form. ${ }^{22}$

\footnotetext{
20 Descottes, Hervé. Architetcural Lighting: Designing with Light and Space. New York: Princeton Architectural Press, 2011, p8

21 Torres, Elias. Zenithal Light. Barcelona: Collegi d'Arquitectes de Catalunya, 2005,

22 Torres, Zenithal Light, p96
} 
As argued by both Descottes and Torres, light has an experiential quality that is generally ignored throughout Western architecture. This thesis assumes the position that these experiential qualities discussed are not merely present in light, but its dualistic opposite; shadow. These are identified within the following section.

\subsubsection{Shadow}

Light mediates ones connection to the temporal qualities of shadow and in doing so becomes an inseparable ingredient in its use. As identified by Torres, this powerful relationship that exists between light and shadow is able to construct an experiential realm separated from any exterior reality. Arden Reed identifies this powerful relationship, stating "the differences that we perceive between light and dark embody meanings that exceed perception." ${ }^{23}$ He suggests that shadows belong to an experiential dimension and identifies their connection to the inherently intangible nature of memory:

Because a shadow is always adjacent to and verging on, but not precisely where one stands, it delineates the spot where at present or in the present one is not. Metaphorically then a shadow falls on either side of the present, be it past or future, and signifies the obscurity either of what is

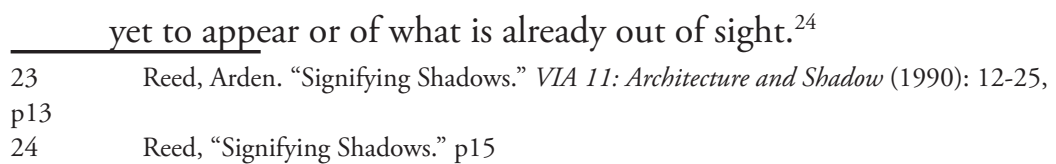

Shadows have a powerful connection to memory; their expression within architecture allows meanings to be attached to buildings. Marco Frascari argues that, "Shadows make tangible what is intangible", ${ }^{25}$ and suggests that within architetcure shadows provide a glimpse into an occult dimension, a theatre of representation:

On the stage of this theatre, shadows are the required sustenance for our memory. Shadows describe objects at rest making possible projections which speak of absent objects, objects which belong to memory and therefore to the power of imagination. ${ }^{26}$

Descottes asserts an understanding of space influenced by both materials and light, arguing that an interdependence exists between light, shadow, and material. This is explored within the following section, addressing the role of materials.

\subsubsection{Materiality}

Descottes argues that: "this interdependence between material and light, form and intangible atmospheres, defines the visual environments we inhabit." ${ }^{27}$ As discussed by McCarter, materials possess a haptic and

\footnotetext{
25 Frascari, Marco. "A Secret Semiotic Skiagraphy." VIA 11: Architecture and Shadow (1990): 32-51, p35

26 Frascari, "A Secret Semiotic Skiagraphy." p36

27 Descottes, Architetcural Lighting: Designing with Light and Space, p8
} 
tactile aesthetic that is able to intimately engage the senses. He argues that it was this aesthetic that informed a departure away from the reductive visual and form driven architecture of modernism, toward a more sensuous architecture aimed at the senses. ${ }^{28}$ Within this haptic and sensuous approach to architecture the interior and tactile intimacy of an atmosphere became the driving influence, presented by McCarter who writes:

Materiality and a sense of tradition evoke experiences of natural duration and temporal continuum. We are not only obliged to dwell in space, we also inhabit a continuum of culture and are surrounded by material memory. ${ }^{29}$

Both Descottes and McCarter argue materials have a language of their own able to construct a dialogue with time and its processes. A dialogue between materials, time and process that for McCarter, enable a deeper understanding of experiences, recollections, associations and emotions. ${ }^{30}$ The following section presents the role of narrative; used to enhance this dialogue between the processes of time.

$28 \quad$ This approach was initiated during the early modern era by architects of the other tradition'; notably Erik Gunnar, Asplund, Sigurd Lewerentz and Alvar Aalto. The predominant player in this movement toward architecture as a multi-sensory engagement was Alvar Aalto; who rejected the universal ideal of modernity, choosing to explore regionalist, organic, historic and romantic matters. See Pallasmaa, Juhani. "Hapticity and Time: notes on fragile architecture." The Architectural Review (London). Vol. 207 (2000): 78-84, p82

29 McCarter, Understanding Architecture: a primer on architecture as experience, $\mathrm{p} 84$ $30 \quad$ McCarter, Understanding Architecture: a primer on architecture as experience, p81

\subsubsection{Narrative}

Descottes argues that our cognitive capacities interpret patterns easily, but are confused by elements connected without a specific sequence or order. ${ }^{31}$ Stephanie Shosh Rotem presents the crucial role of narrative within her descriptions of the memorial museum, stating:

Walking through a museum, visitors enter on a journey that recreates significant and meaningful events - the museums structure, circulation route, lighting, and architectural design constitutes the theatrical setting, while the visitors are its active actors. Narrative museums, like conventional ones, provide the setting for the performance, but they are unique in that they also provide its sequence. Visitors follow a path designed by the museums' curators and architects that dictates the route, mood, and rhythm of their progression. ${ }^{32}$

This description outlines the potential within the structure and atmosphere of the museum, able to provide the user with a performative conncection to the less tangible propereties of history. The metaphor of visitors as actors or active participants, following a specific path, plays a strong role in the resolved design of this thesis; discussed in further

\footnotetext{
31 Descottes, Architetcural Lighting: Designing with Light and Space, p67 32 Rotem, Constructing Memory: Architectural Narratives of Holocaust Museums, p15
} 
detail throughout design exploration. Within this narrative structure of the museum, Henry Plummer describes the most powerful environment as being that which moves up or down in relation to the ground plane. He describes the process of descending below ground as a subterranean journey; a journey associated with caverns, tunnels, crypts and carved by memory. ${ }^{33}$ This descent below the ground plane is further explored within case study analysis, acting as a strong precedent within the desing exploration of this thesis.

\subsection{Conclusion}

This chapter began by presenting the traditional understanding of memory in architecture and its presence within the memorial museum. Following this, atmosphere was explored as a tool able to construct reminiscence, analyzing the role of light, shadow, material and narrative; used to stimulate a range of sensory responses in regards to intangible heritage. Informed by an understanding of light presented by Descottes and Torres, this thesis follows an experiential interpretation of light; exploring the role of zenithal light in constructing an architectural experience of reminiscence. Aligning with theories presented by Reed and Frascari, shadow is employed as a representational tool to construct a theatre of memory; dedicated to that which would otherwise remain hidden. Following Descotte's discussion on narrative, the implementation of light, shadow and materiality is to be structured around a specific circulation pattern; creating a theatrical setting or performance experienced by the user. The following chapter will identify the chosen site for the design of this research; outlining its historical significance, design and planning, and heritage protection criteria. This will provide insight into the intangible heritage of the site and inform the relationships, program, and structure of the design exploration. 


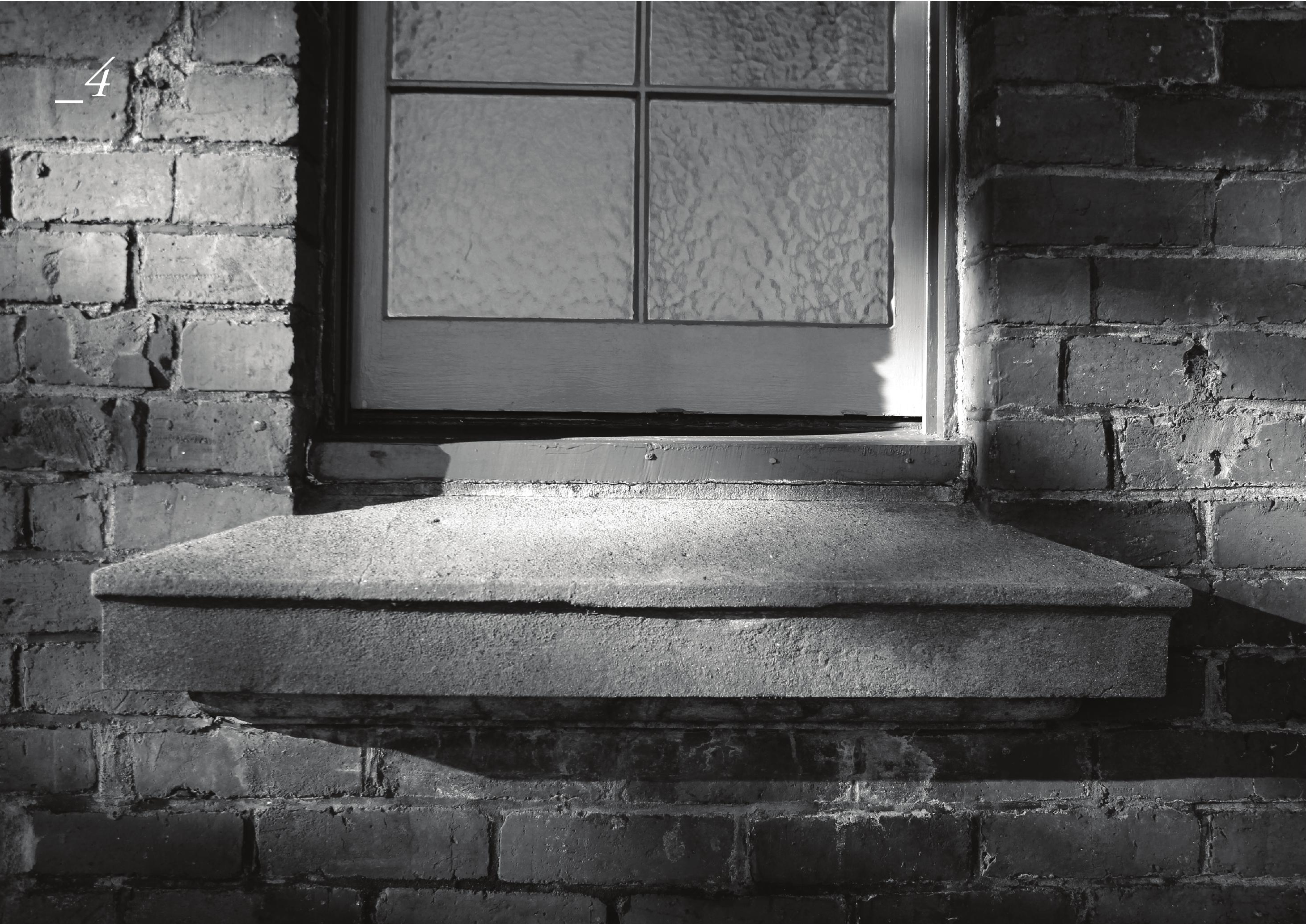




\section{Chapter Four CASE STUDY ANALYSIS}

4.0 Introduction

$\begin{array}{ll}\text { 4.0.1 } & \text { Hedmark Museum } \\ \text { 4.0.2 } & \text { Therme Vals } \\ \text { 4.0.3 } & \text { Jewish Museum }\end{array}$

$4.1 \quad$ Conclusions 


\section{4}

\subsection{Introduction}

As presented within the previous chapter, this research positions atmosphere as an essential ingredient within the exploration of this design; employing light, shadow, material, and narrative. In order to analyse the character of these within the built environment, this chapter begins by exploring their role within the three selected case studies. The common ingredient within these case studies is environmental imagination, this being the combination of form and atmosphere, used to actively enhance the meaning and identity of the building. ${ }^{1}$ These buildings differ programmatically, but the powerful presence of atmosphere within each acts as a strong precedent for design.

Hawkes, The Environmental Imagination:Technics and poetics of the architectural environment, p200
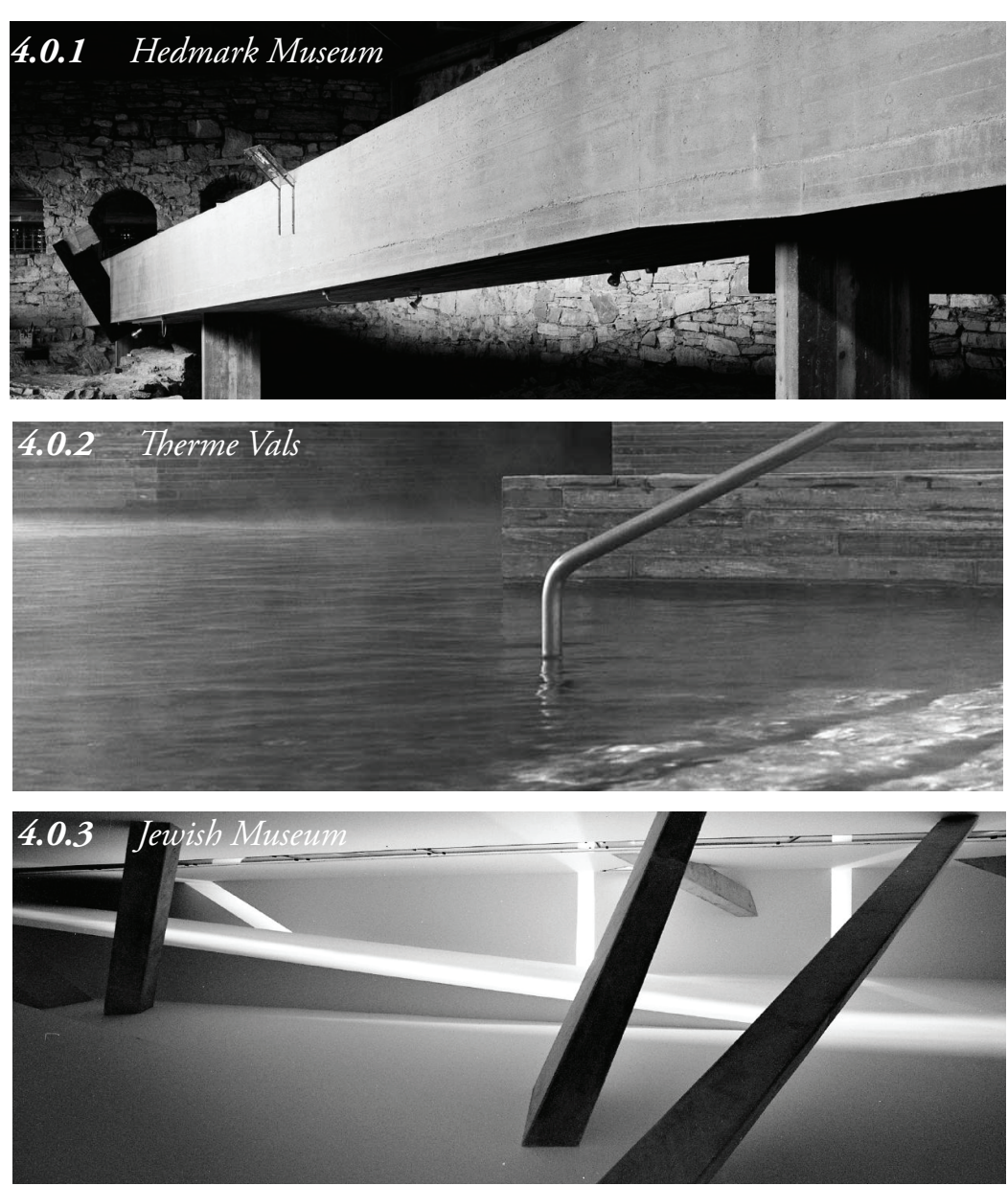

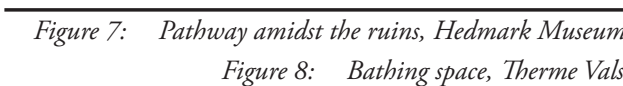
Figure 9: Chaotic struts-cum-beams, Jewish Museum 


\subsubsection{Hedmark Museum, Sverre Fehn}

Within this project, Sverre Fehn constructed a contemporary museum within the remains of a barn from the nineteenth century. The existing barn sits on top of the ruins of a medieval bishop's fortress from the twelfth century, traces of which are still visible. ${ }^{2}$ Fehn's proposal followed discussion on demolition of the site due to a state of disrepair and neglect, within which he sought to not merely preserve but recreate an experience of history, "Rather than working with history as information, Fehn approaches history as memory." 3 This de-privileging of quantifiable information in favour of immaterial aspects of history holds strong relevance with the intent of this thesis. This case study analyses the methods employed by Fehn in evoking these memories of local history, focusing on the atmospheric qualities of light, shadow, material and narrative.

\footnotetext{
2 Norberg-Schulz, C. (1997). Sverre Fehn : works, projects, writings, 1949-1996. New York: Monacelli Press, p129

3 Fjeld, P. O. (2009). Sverre Fehn : the pattern of thoughts. New York: Monacelli Press, p116
}

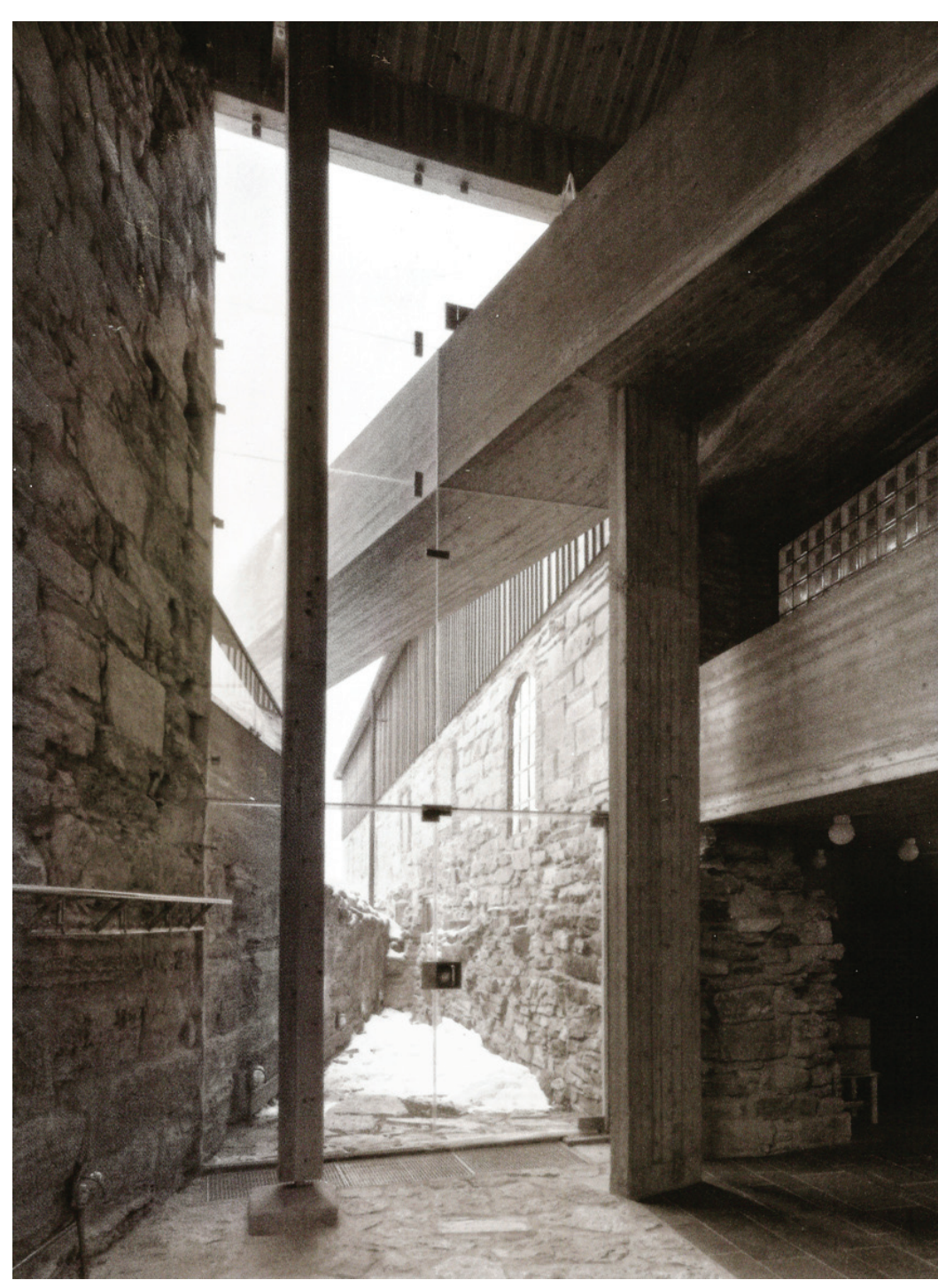

Figure 10: Suspended walkway into existing building 


\section{Atmosphere}

The atmosphere of the Hedmark Museum provides the user with a continual dialogue between interior and exterior, old and new, and light and dark. This dialogue is communicated as a procession that spans the centuries. Following a series of suspended walkways, the user is guided throughout the building; through an ethnographic museum, raised gallery space, and contemporary auditorium before descending a second ramp across the courtyard of the former monastery. ${ }^{4}$ The interior and exterior ramps provide a spatial sequence that constantly adjusts ones perception of the horizon, moving up and down in relation to the ground plane. The subterranean environment of this allows the imagination of the user to calmly wander and, assisted by the display of objects above and below ground, provides the user with the connected feeling of a journey through time. 5 "The museum is open ended, and the past continues to be questioned there by the present; it is a museum that echoes time." 6

Fjeld, The workings of Sverre Fehn, 52

Plummer, Nordic Light: Modern Scandinavian Architecture, 76

6 Fehn, S. (1993). Blending The Old And The New. Architecture Aujourd Hui, 94

\section{Light and Shadow}

Within the building, natural lighting plays the dominant role. The only source of light within the wings of the barn is provided by shafts of natural light that filter between the ruins and the contemporary roof addition. However, as shown in figure 8 , within the concrete blocks that line the central path of these wings and house the museum displays, a glazed roof structure allows light to flood and illuminate the room. These confined blocks allow the museum display to slowly unfold, following a specific historic narrative "organized like voyages to instances and situations at different points in history."

\footnotetext{
7 Lawrence, R. (2009). Sverre Fehn: the architect who built on the horizon. Architectural Research Quarterly, Vol. 13, 11-15, p12

$8 \quad$ Norberg-Schulz, Sverre Fehn : works, projects, writings, 129
}

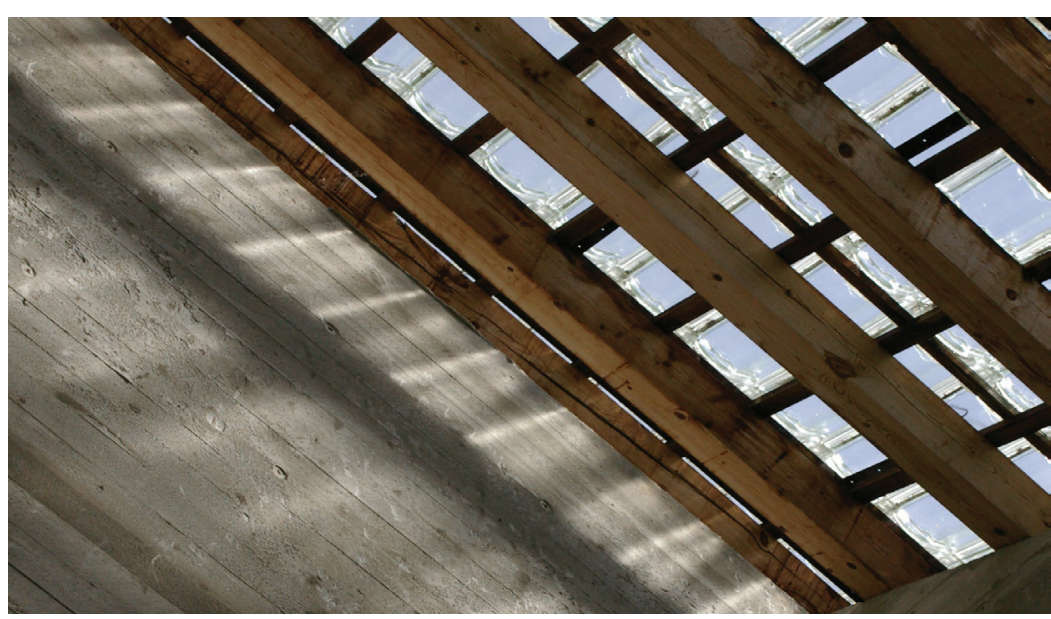

Figure 11: Glazed roofing above concrete blocks containing displays 


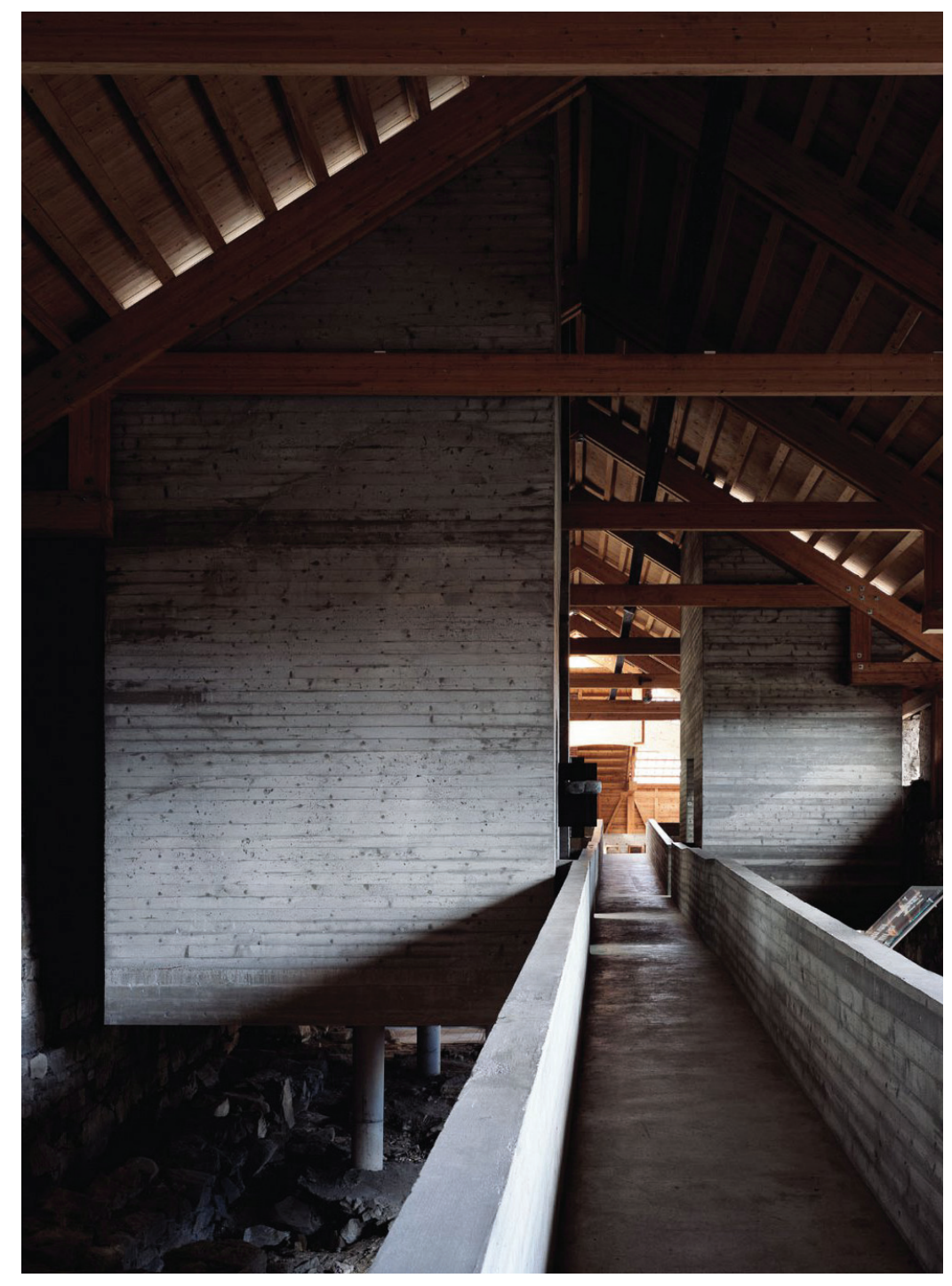

\section{Spatial Narrative}

As argued by Plummer, within narrative architecture the most powerful environment is that which moves up or down in relation to the ground plane. He describes the process of descending below ground as undertaking a subterranean journey; a journey carved by memory and associated with history. ${ }^{9}$ The Hedmark Museum takes full advantage of these associations, and provides its narrative with the connected feeling of a journey through time. ${ }^{10}$ Within this journey, the user is effortlessly guided up and down among the ruins of the existing building, with the ramps and plateaus of the museum creating a varied spatial sequence; "The architect can establish places under the ground, and these become the new way to travel into the past..." ${ }^{11}$ Within its underground spaces, the materiality of the museum aims to enhance the experience of the user, focusing attention inward.

\section{Materiality}

The museum employs a relatively limited material palette, consisting primarily of exposed concrete, glulam timber, and un-framed glass. The architect aims to contrast those of the barn, standing clearly separated from the existing structure. Above the wings of the barn, the glulam

\footnotetext{
Plummer, Nordic Light: Modern Scandinavian Architecture, 75

10 Plummer, Nordic Light: Modern Scandinavian Architecture, 76

11 Fjeld, Sverre Fehn : the pattern of thoughts, 108
}

Figure 12: Suspended walkway approaching blocks 

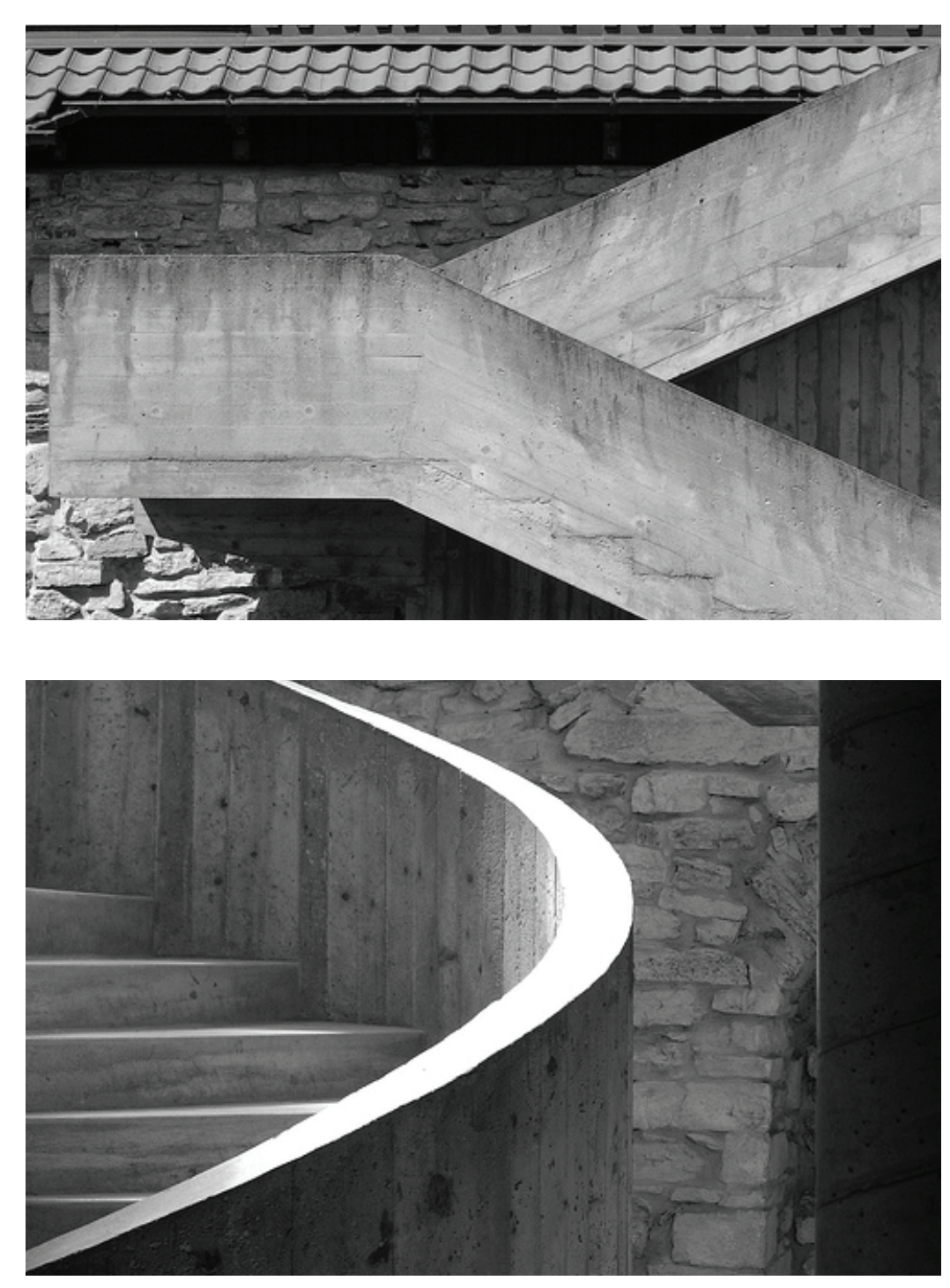

Figure 13: Ramp providing access to wings of barn

Figure 14: Rough exposed concrete of pathway structure asserts its simplicity by discreetly sitting on the top of the thick exterior stone walls. ${ }^{12}$ Within his approach, Fehn has not attempted to repair or restore any aspects of the existing building and materials. Time is not suspended, but made to progress; the existing building and its materials continue their natural process of decay. ${ }^{13}$ This reinforces the historic dialogue within the museum, "The past is suddenly present, the stones come close to you, the ruins look more material and more real, because they make up a story at the same time as they are attacked." ${ }^{14}$

\section{Conclusion}

Within his design of Hedmark Museum, Fehn displays an approach to heritage that goes beyond the bounds conventional practice, or traditional notions of conservation. He employs architecture as an experiential tool, actively engaged with the identity of the site and processes of time; both past and future. ${ }^{15}$ As an addition to an existing heritage building, the Museum acts an exemplary precedent for the design of this thesis. It identifies architectures capacity to stimulate and evoke the memories within a site, using a layering of atmospheric and spatial conditions to achieve a sense of reminiscence to the history that underlies

\footnotetext{
12 Fehn, Blending The Old And The New, 103

13 Fjeld, Sverre Fehn : the pattern of thoughts, 116

14 Fehn, S. (1992). The poetry of the straight line. Helsinki: Museum of Finnish Architecture, p48

15 Fjeld, The workings of Sverre Fehn, 51
} 
the building. The intimate connection that the building shares with the ground plane and horizon is pivotal to the historic narrative and experience within the space. These will be adopted as elements in the iterative design process of this thesis, exploring a subterranean journey informed by the identity and intangible heritage of the site.

Figure 15: Glulam structure within existing barn

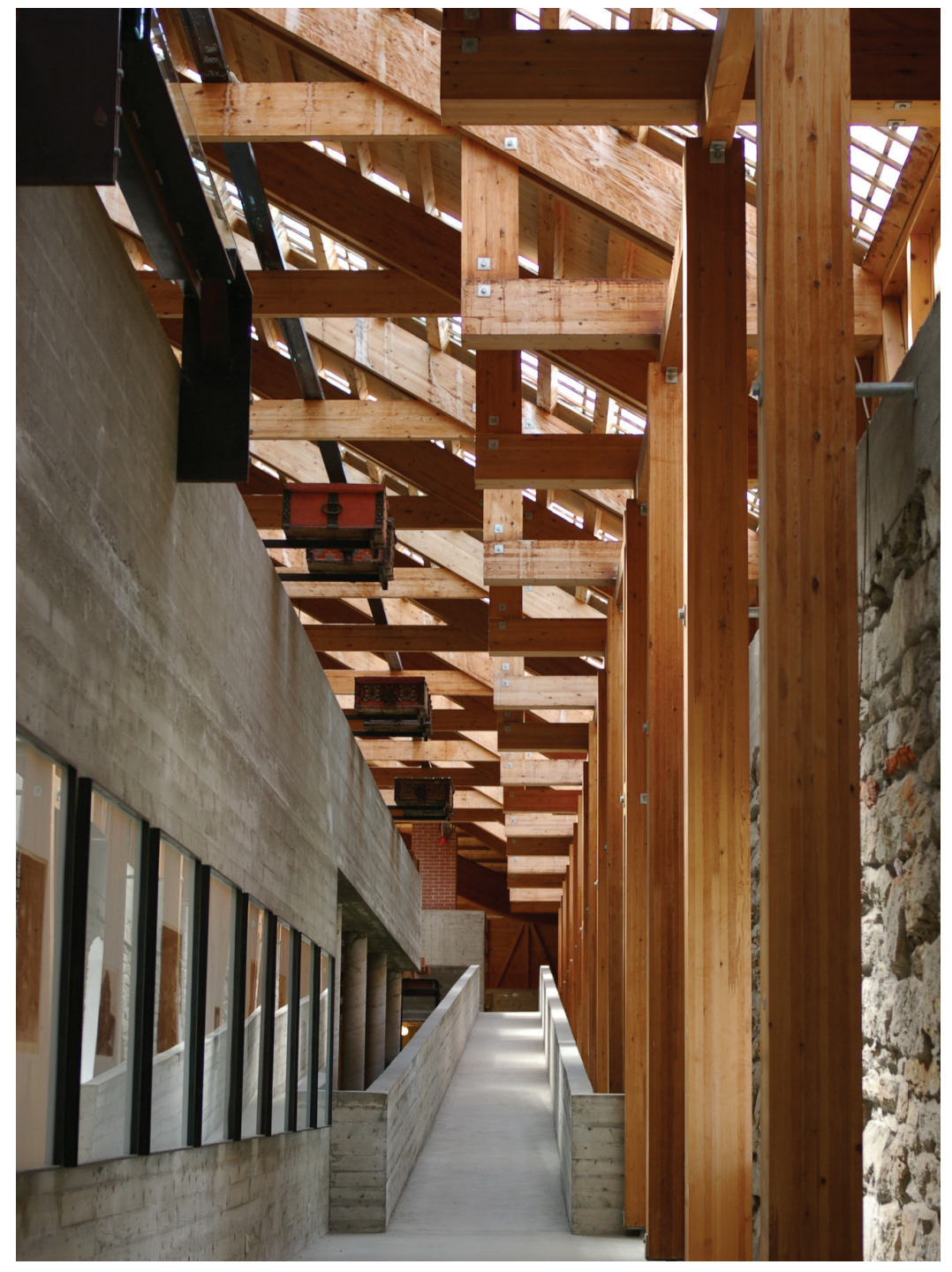




\subsubsection{Therme Vals, Peter Zumthor}

Therme Vals is a thermal bath complex located in the isolated mountain village of Vals, Switzerland. The building was designed as a selfcontained addition to revitalize the failing fortunes of a 1960s hotel spa which, by the mid-1980s, was verging on bankruptcy. ${ }^{16}$ Although this building does not deal with heritage, it aligns with the primary programme explored within the design of this thesis and provides insight into the atmospheric considerations within the bath-house typology. The ways in which thermal, acoustic and visual characteristics are used in order to create a sensory experience are of key focus. This case study analyses the mechanics employed to construct this atmosphere; focusing on the role of light, shadow, spatial narrative and materiality.

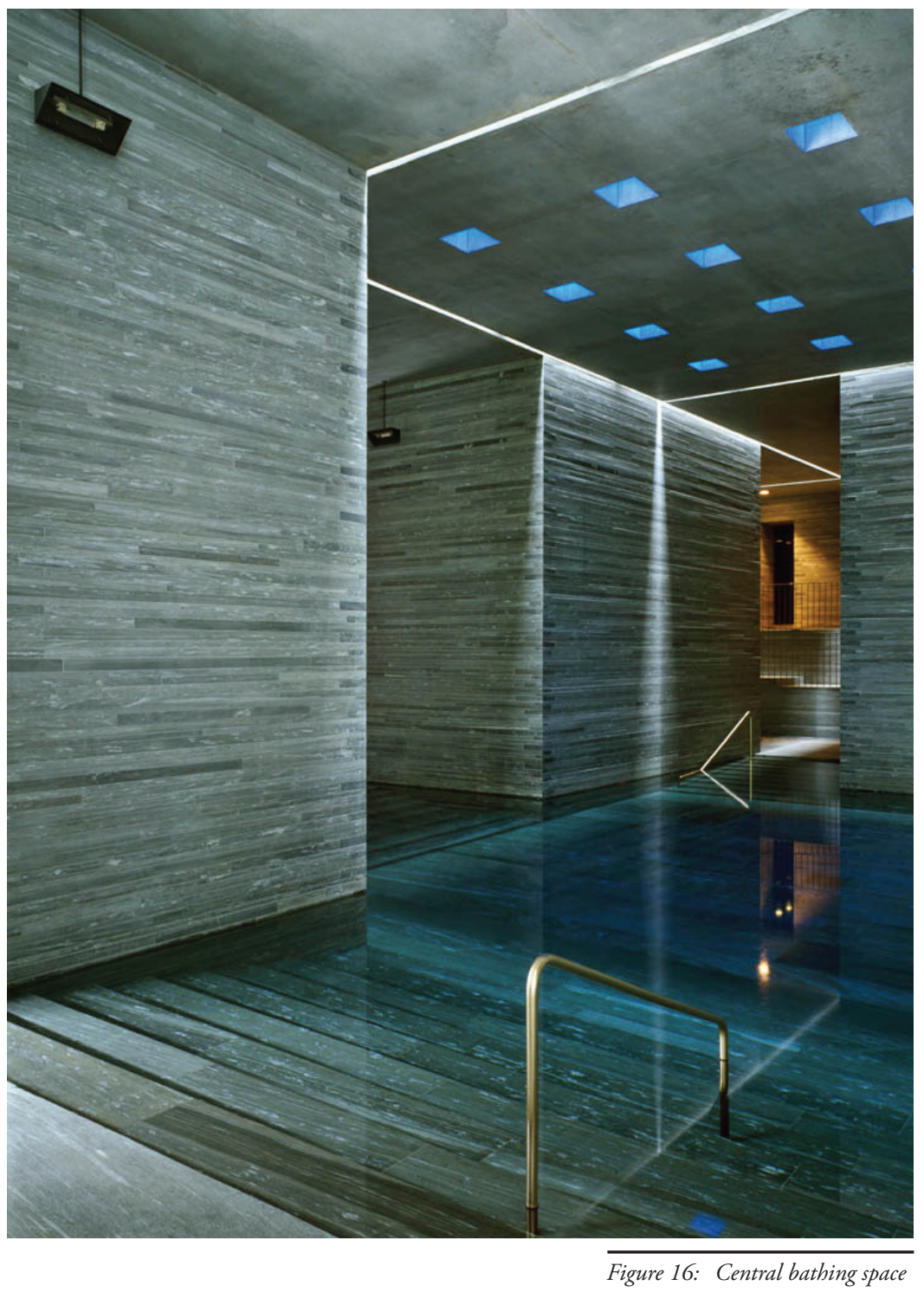




\section{Light and Shadow}

This complex employs both natural and artificial light in the construction of its sensory experience. Natural lighting is carefully orchestrated using narrow shafts of light that penetrate through slits within the roof slabs and against wall to ceiling connections. ${ }^{19}$ Suspended lamps are used to artificially light the circulation routes and poolside spaces, but

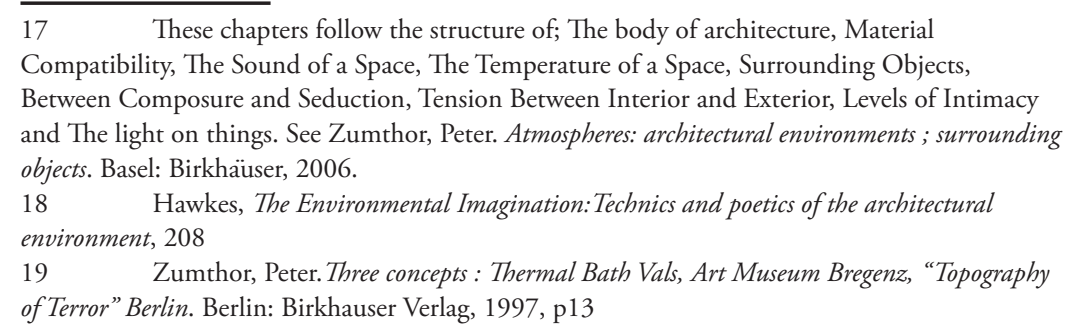
of Terror" Berlin. Berlin: Birkhauser Verlag, 1997, p13

\section{Atmosphere}

Within his book Atmospheres, Zumthor sets about explaining what, to him, constitutes architectural atmosphere. Within nine brief, illustrated chapters framed as a process of self-observation he sets about describing his processes in the construction of atmosphere. ${ }^{17}$ These are evident within his design of Therme Vals. The spaces within the building have been designed and organized meticulously in order to offer the user a complex and varying arrangement of sensory stimuli; creating tactile, visual, aural and olfactory qualities that influence the atmospheric environment. ${ }^{18}$
\end{abstract}

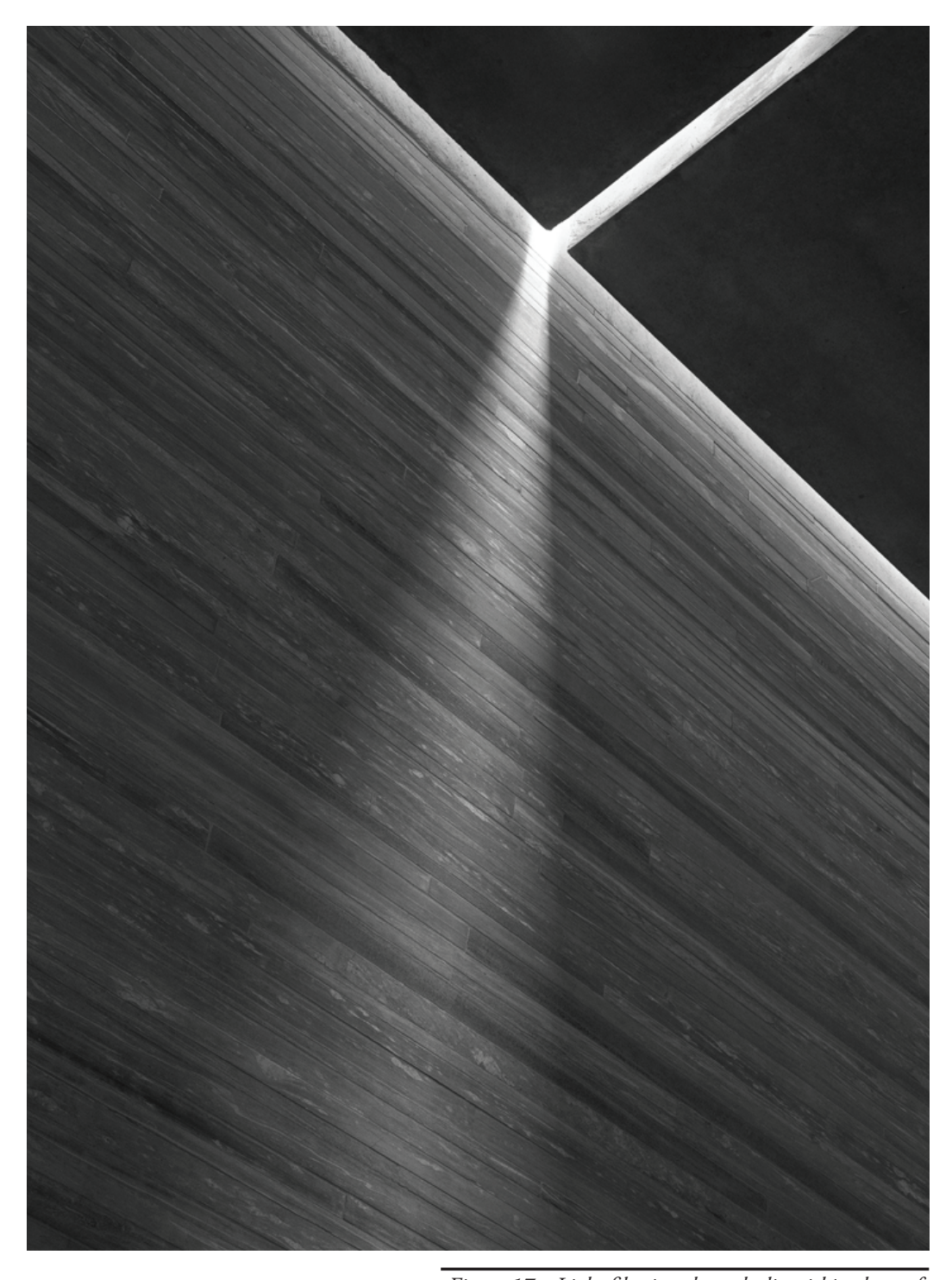

Figure 17: Light filtering through slit within the roof 

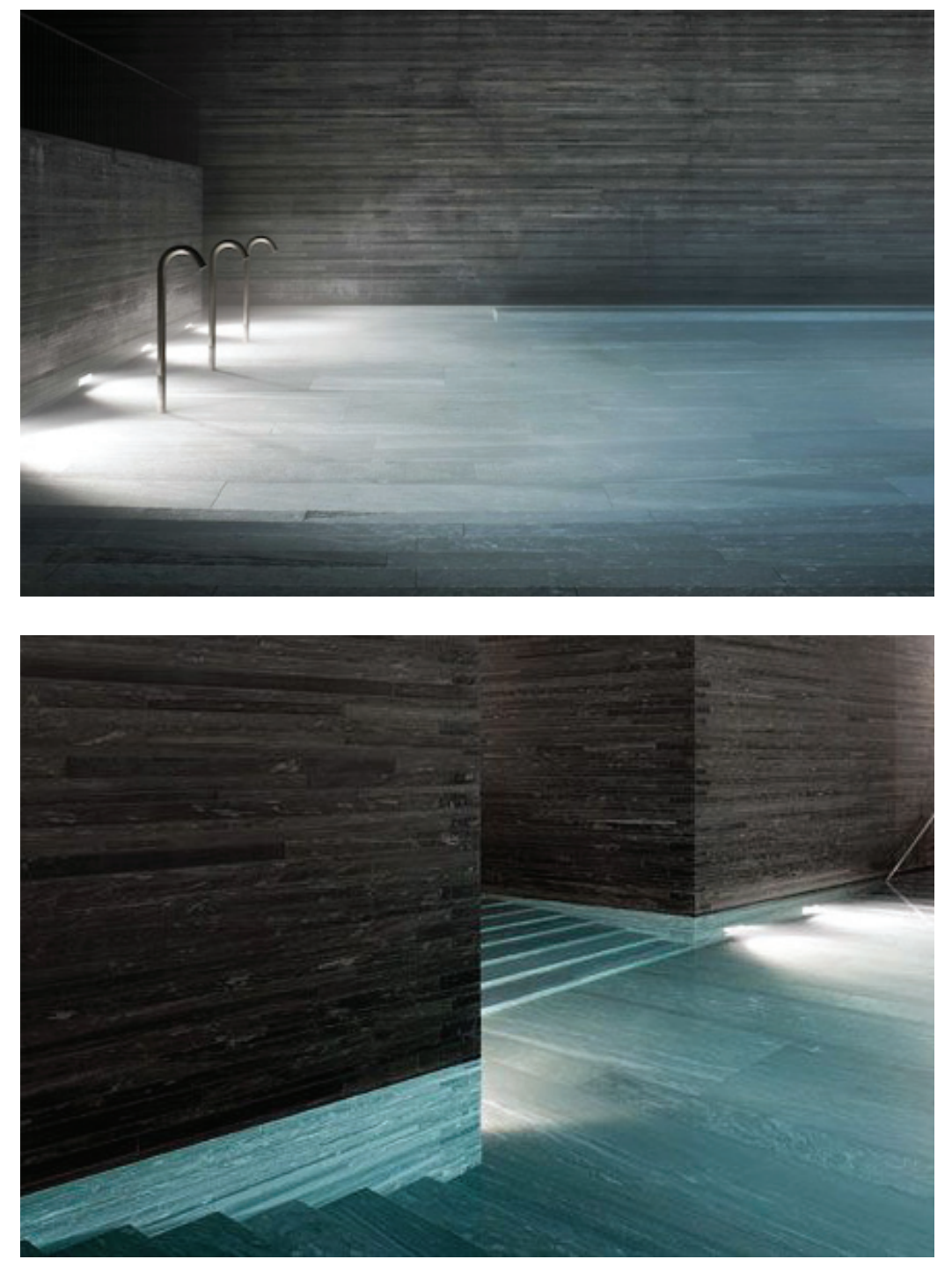

Figure 18: Recessed lights illuminating the pools

Figure 19: Recessed lights illuminating the pools the primary source of artificial illumination is provided by the pools themselves. Lamps, recessed below water level, push shafts of light through the water; softening and gently illuminating the rough stone of surrounding walls.

\section{Spatial Narrative}

The building, while open in plan, is separated into 'blocks' that have acquired names in accordance with their function: sweat stone, shower stone, massage block, drinking fountain stone, rest space, fire bath, flower bath, cold bath, sounding stone. ${ }^{20}$ Underlying Zumthor's seemingly informal plan is a carefully constructed circulation pattern that leads the user throughout predetermined points while still allowing a sense of freedom. ${ }^{21}$ As illustrated within figure 20, the only pre-determined movement path of the complex is its entry, leading toward the bathing space. This notion of self-endeavoured discovery was something Zumthor hoped to achieve within the buildings open yet concealed and fragmented plan; "I can never see it all at once. I have to

20 Zumthor, Peter. Peter Zumthor works : buildings and projects 1979-1997. Baden, Switzerland : Lars Muller Publishers, 1998, p160

21 As a bather, you arrive at the back of the hotel complex; set deep within the mountain. After emerging from the changing rooms, the user is placed upon a raised balcony overlooking the large central bathing hall. From this point, the internal environment opens up and allows the user to navigate the sensory experiences that the complex has to offer; progressing through constantly changing environments toward the more open eastern and southern corners of the building. See Zumthor, Peter. Three concepts: Thermal Bath Vals, Art Museum Bregenz, "Topography of Terror" Berlin. Berlin: Birkhauser Verlag, 1997, p13 


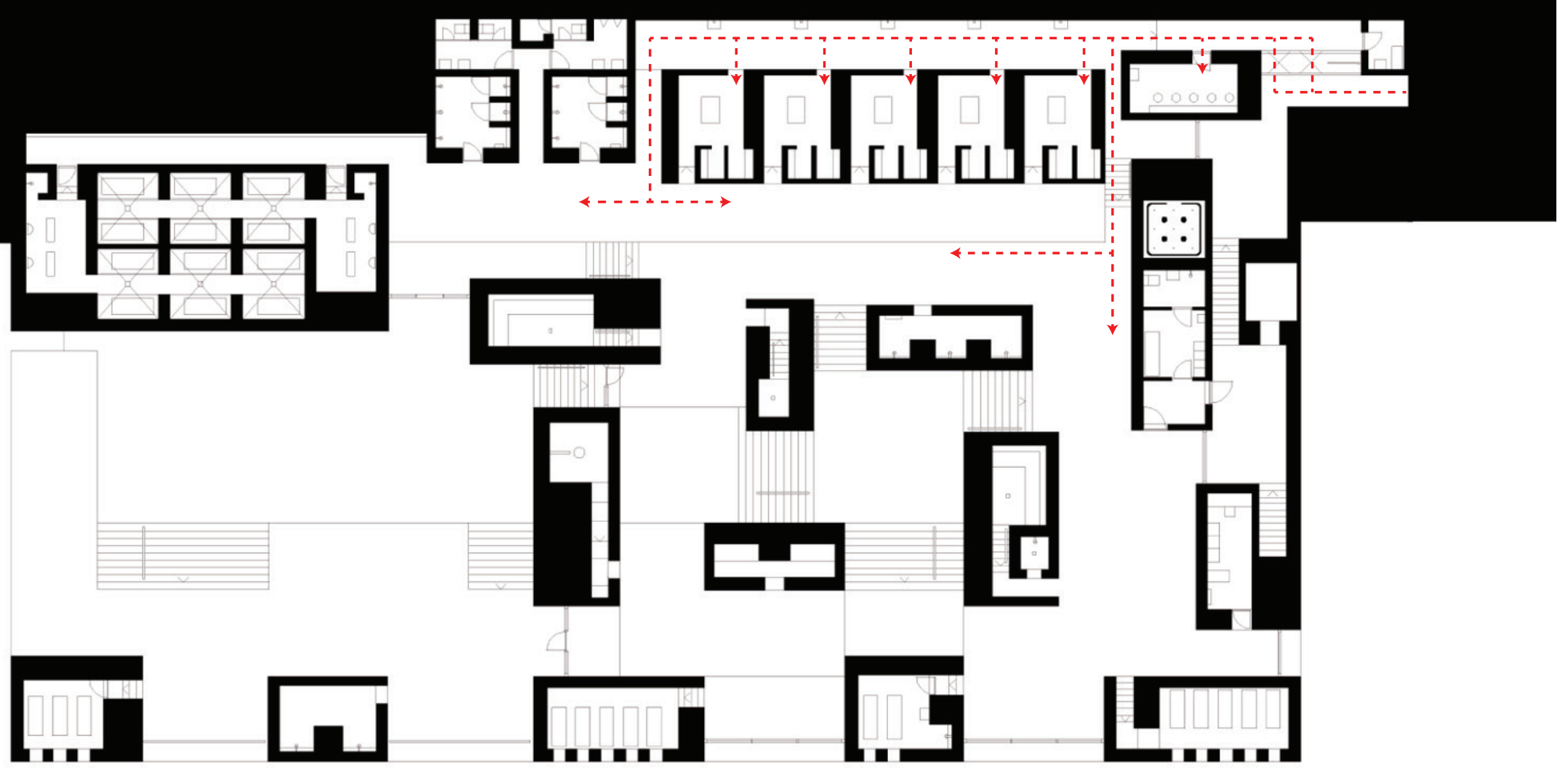


walk through it, discover it step by step. I experience it as image upon image, as a sequence of spaces." ${ }^{22}$ This allows the user to intimately connect with each space, fully emersed and seperated from any surrounding context. The large and dominant material mass of the building restricts movement and visibility, enclosing these intimate spaces.

\section{Materiality}

The building follows a relatively simple and limited palette, employing only four principal materials to define its internal bathing spaces; stone, concrete, glass and water. ${ }^{23}$ The most dominant of these is the grey gneiss stone, found locally within the village of Vals. ${ }^{24}$ This local stone lines the majority of the building's interior bathing space, making its relationship with water crucial to the design; "in architecture, stone and water can enter into a natural, and even charmed relationship. Stone loves water and water loves stone, perhaps even more than any other material." 25

\footnotetext{
$\begin{array}{ll}22 & \text { Hauser, Sigrid. Peter Zumthor therme Vals. Zurich: Scheidegger \& Spiess, 2007, p38 } \\ 23 & \text { Hawkes, The Environmental Imagination:Technics and poetics of the architectural }\end{array}$ environment, 208

24 In order to allow this materiality to have such an impact on the space, all elements that would seek to disrupt its continuity are masterfully integrated into the mass of the building. From both the interior and exterior the mechanics of the structure are hidden; leaving a seamless and sensuous internal environment unobstructed by mechanical services. See Zumthor, Peter. Three concepts : Thermal Bath Vals, Art Museum Bregenz, "Topography of Terror" Berlin. Berlin: Birkhauser Verlag, 1997, p12

25 Hauser, Peter Zumthor therme Vals, 140
}

\section{Conclusion}

Therme Vals is a world of stone, water, darkness and light. Zumthor's design offers a rich and complex architectural experience that caters to the human body and its sensory stimuli. The technical expertise and spatial configurations used by Zumthor provide insight into the immersive power of atmospheric conditions; to construct an experience that stimulates the senses. The ways in which light, movement, and materiality are controlled to elicit specific emotional responses is of key importance to this research. These atmospheric qualities that contribute to the sensuous environment of Therme Vals act as an exemplary precedent for the design of this thesis. 


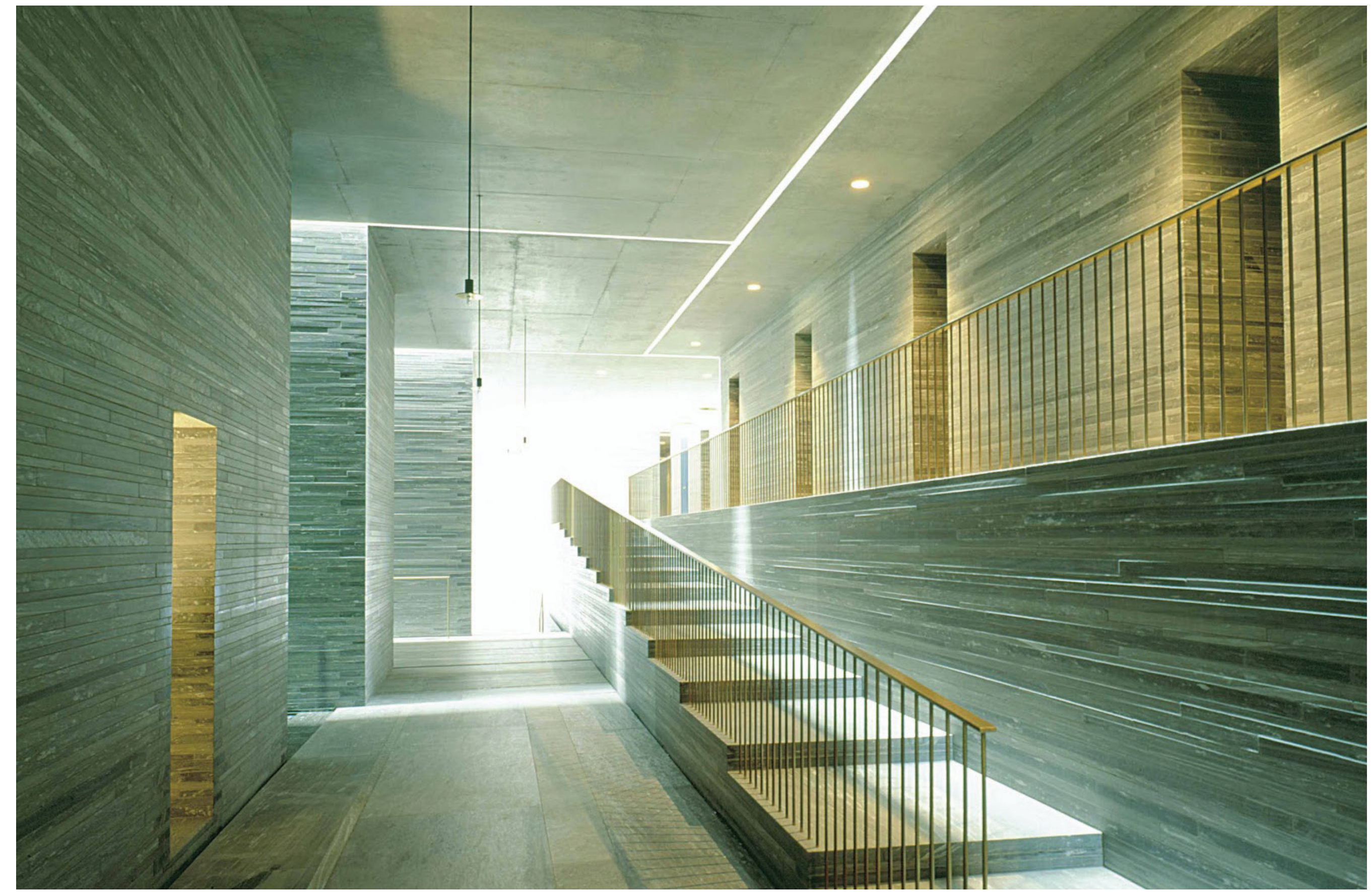

Figure 21: Below raised balcony - approaching pools 


\subsubsection{Jewish Museum, Daniel Libeskind}

The original Jewish Museum in Berlin was founded in 1933, but forcibly closed shortly after in 1938 by order of the Nazi regime. ${ }^{26} \mathrm{~A}$ competition for a contemporary revitalisation of the building was held in 1989; its intent being to generate a critical reconstruction of the original plan through contemporary architectural means. An international jury reviewed the 165 proposals submitted, with Daniel Libeskind's design being awarded first prize due to its "radical and innovative character... and its convincing interpretation of the indissoluble interweave of Jewish history with that of the city in general." ${ }^{27}$ Within his design, Libeskind sought to architecturally articulate and narrate the intangible characteristics of Jewish history. In this construction of intangible heritage, atmosphere is evident as a pivotal tool. This case study examines the mechanisms of light, shadow, narrative, and materiality that Libeskind employed in an attempt to make the architecture itself represent historical meaning.

26

Young, James E. "Daniel Libeskind's Jewish Museum in Berlin: The Uncanny Arts of Memorial Architecture." Jewish Social Studies, Volume 6, Number 2 (2000): 1-23. p4

27 Schneider, Bernhard. Daniel Libeskind: Jewish Museum Berlin . Prestel, 1999.

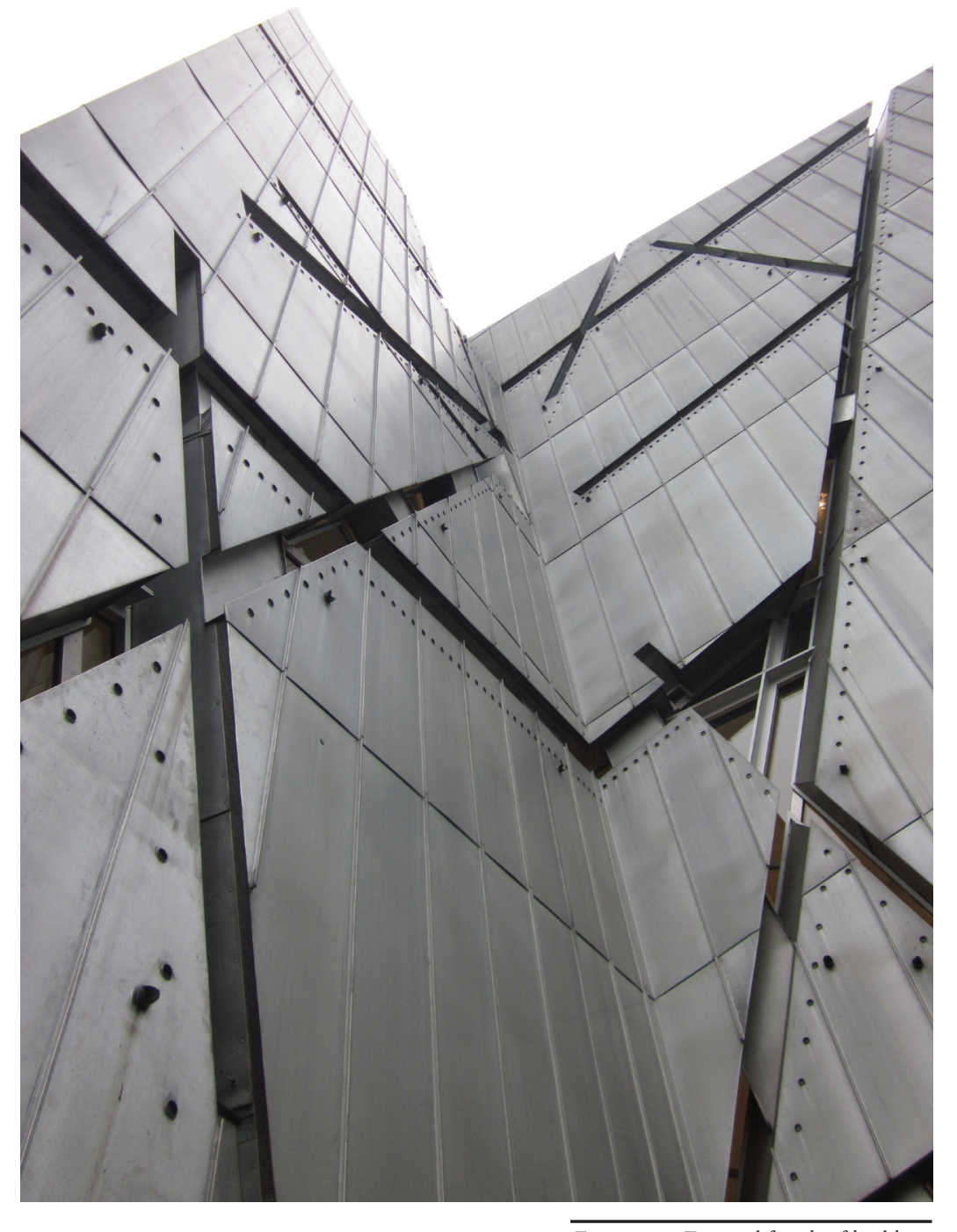

Figure 22: External facade of building 


\section{Atmosphere}

Rather than merely housing its collection, the design aims to estrange and defamiliarize the objects and historical chronology within the museum; using oblique angles, fragmented lines, and slanting floors to disorientate the users. ${ }^{28}$ This is experienced within the museums voids and ruptured lines that break any sense of linearity; representing the Holocaust through absence, fragmentation and loss. ${ }^{29}$ The points at which these lines intersect form voids that penetrate through the building,

28 Hansen-Glucklich, Jennifer. "Evoking The Sacred: Visual Holocaust Narratives In National Museums." Journal of Modern Jewish Studies: Volume 9, No. 2 (2010): 209-232. p220 29 Within the plan of the building, these voids can be seen as forming at the intersections of two primary lines; the first being straight but fragmented, and the second long and complex. resulting in six irregularly spaced cuts through the museum on both horizontal and vertical planes. ${ }^{30}$ Through its use of evocative architecture and visual form, this internal environment acts as belated witness; able to elicit feelings in regard to the horror of an event that gradually withdraws into the past. ${ }^{31}$ While the event itself that this museum represents is in no way comparable to the chosen site of this research, the architectural mechanism and spatial qualities that Libeskind employs in referencing immaterial aspects of the past is of key focus to this research.

30 Libeskind, Daniel. Extension to the Berlin Museum with Jewish Museum department. Berlin: Ernst \& Sohn, 1992 p63

31 Young, "Daniel Libeskind's Jewish Museum in Berlin: The Uncanny Arts of Memorial Architecture", 2

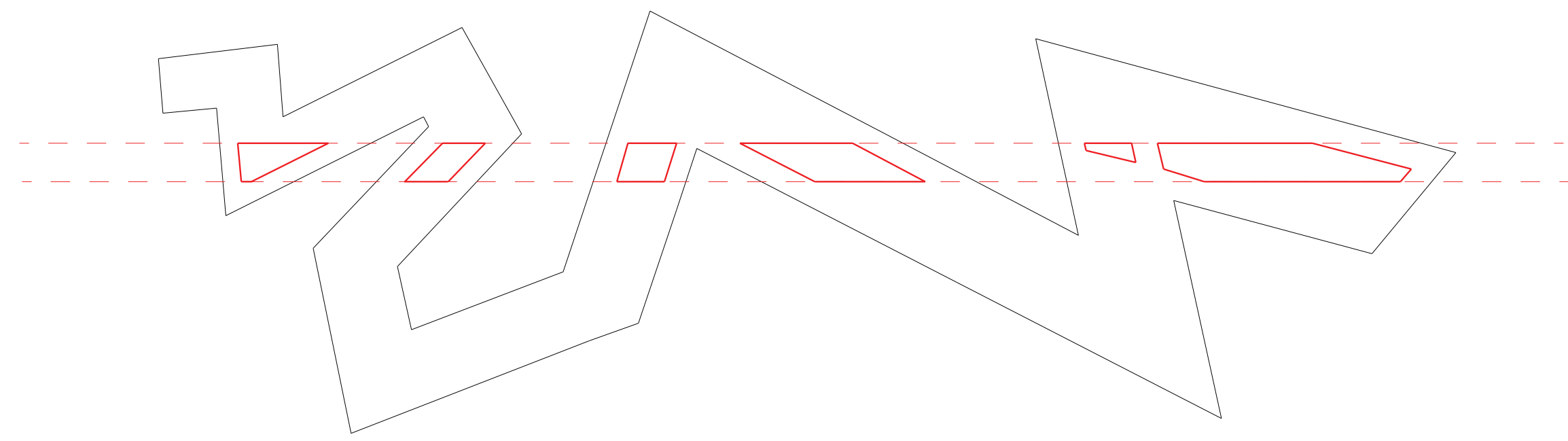

Figure 23: Diagrammatic plan illustrating void placement 


\section{Light and Shadow}

The Jewish museum relies on both natural and artificial lighting. The irregular window openings and apertures that scatter the building's façade allow a variety of natural lighting qualities within its interior. These external apertures, while seemingly random, conform to the programmatic functions of the building's interior; increasing in size toward the fourth floor which houses the offices, workshops, and the library, and decreasing on the lower floors which accommodate the exhibition rooms and require large continuous surfaces with limited natural illumination. ${ }^{32}$ Light and shadow are employed as pivotal elements in the buildings narrative of absence, the most powerful instances of which occur within the six voids that extend vertically through the entire structure and illuminate the lower floors from above. ${ }^{33}$ As discussed by Torres, the theatrical dimension of this form of light is able communicate abstract and alternative realities. Within his extension to the Jewish Museum, Libeskind uses this evocative power of vertical light to communicate the absence of the Jewish community within Berlin, Germany.

32 Schneider, Daniel Libeskind: Jewish Museum Berlin, 45

33 The most dominant of these voids, the Holocaust Tower, is a 24 metre high space constructed of raw concrete which only receives a small strip of light from above. The aim of this space is to create a place for the user to reflect on the absence that underpins the building and allow for a moment of pause in which memory and mourning can occur. As described by Libeskind, "The void is the central structure of the building; aiming to give spatial and material Libeskind, "The void is the central structure of the building; aiming to give spatial and material
expression to the trauma of that loss". See Hansen-Glucklich, Jennifer. "Evoking The Sacred: Visual Holocaust Narratives In National Museums." Journal of Modern Jewish Studies: Volume 9, No. 2 (2010): 209-232. p221

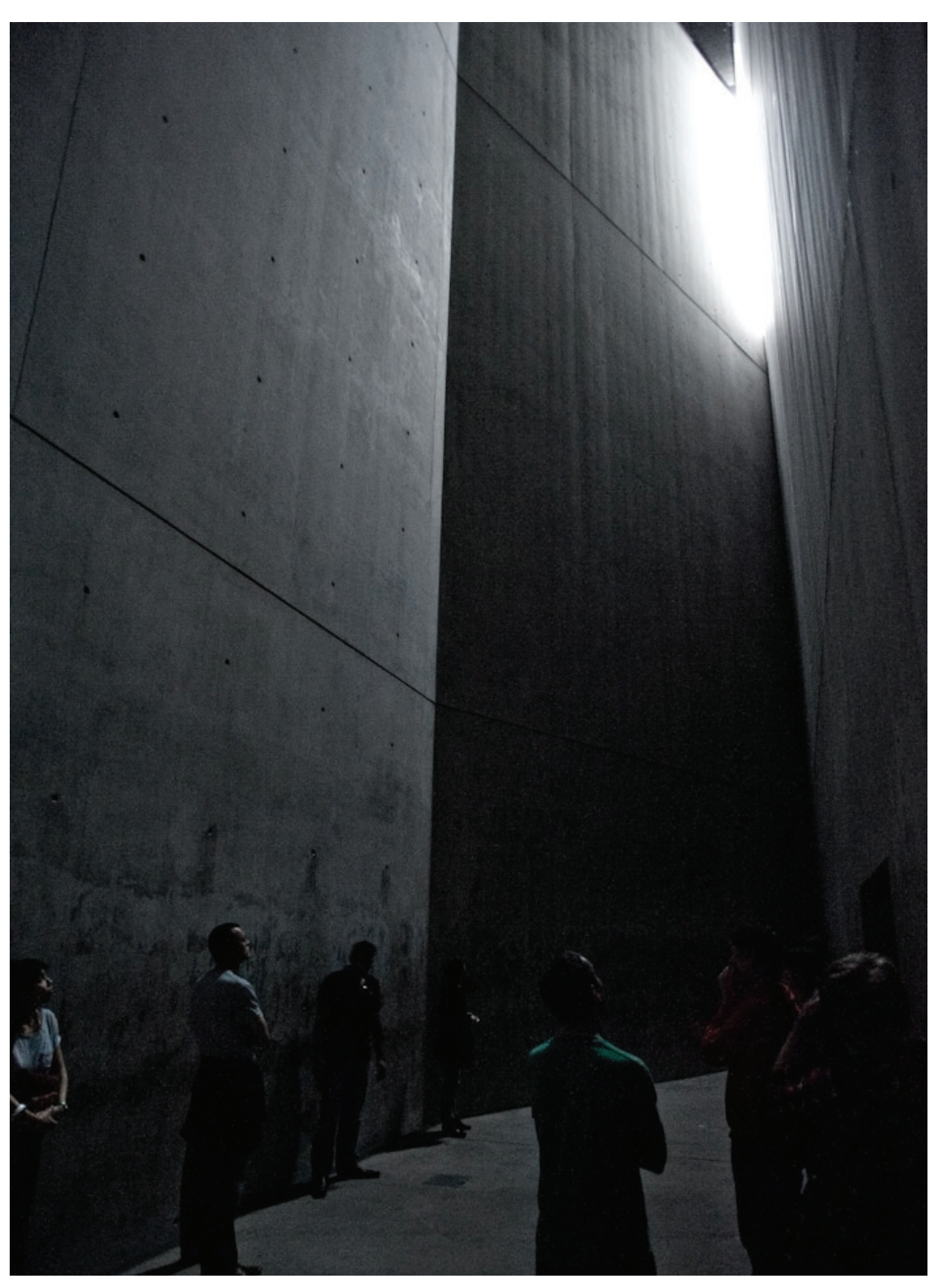

Figure 24: Small strip of light within the Holocaust Tower 


\section{Spatial Narrative}

While commonly described as a narrative, the spaces of the museum do not need to be viewed in any specific sequential order; six auxiliary lifts and staircases, as well as the main central stairs, allow a variety of connections and circuits between floors. ${ }^{34}$ This is underpinned by the museums attempt to estrange and disorientate its user. ${ }^{35}$ This open and free-flowing spatial narrative has only one pre-determined circulation path; its entry. As illustrated in figure 25, in order to access Libeskind's extension to the museum one must first enter through the existing 1933 Baroque building, the Kollegienhaus, where a void stretches from the roof into a subterranean tunnel. Libeskind describes this link as an em-

$34 \quad$ Schneider, Daniel Libeskind: Jewish Museum Berlin, 58

35 Regardless of their navigation choices, on all floors of the museum the user is repeatedly confronted with the negative spaces of the voids. This is seen within the dominating presence of the Holocaust Tower which, in order for a user to navigate the length of the building must be crossed via one the 30 bridges that penetrate through it. See Libeskind, Daniel. Daniel Libeskind and the Contemporary Jewish Museum : new Jewish architecture from Berlin to San

Francisco . San Francisco: Contemporary Jewish Museum, 2008, p63

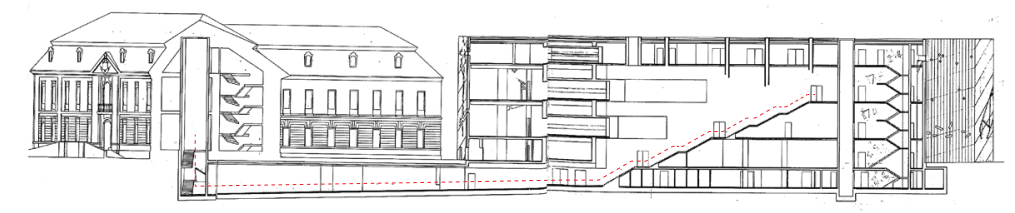

Figure 25: Entry from existing building through subterranean tunnel bodiment of the connection between the two that is no longer visible, but buried in memory; "The void contains a stair that descends beneath the existing foundations and connects to the new building above, preserving the contradictory autonomy of both and permanently binding them together." ${ }^{36}$ This connection is illustrated within figure 24, showing the journey from the existing building to within Libeskind's addition.

\section{Materiality}

The materials used within the building were chosen in an attempt to reinforce the symbolism present throughout the entire project, the most dominant of these being reinforced concrete, which comprises the structure, and its zinc façade panelling. ${ }^{37}$ Internally, concrete is used to contribute to the user's spatial experience. This is seen within the concrete struts-cum-beams that cross chaotically above the main stairwell, leading down to the exhibition galleries. These symbolize the historical dislocations and horrors experienced by the German Jews.

\footnotetext{
36 Libeskind, Daniel. Daniel Libeskind and the Contemporary Jewish Museum : new Jewish architecture from Berlin to San Francisco. San Francisco: Contemporary Jewish Museum, 2008, p63

37 Exposed concrete is used to reinforce moments within the buildings internal narrative, while the exterior zinc panelling allows perforations that act independent of internal floor layout. This independent façade contributes to the buildings disorientating internal experience, making aspects of the building appear distorted, "From several vantage points one begins to doubt whether the exterior wall is truly perpendicular to the ground, or whether it might in fact incline forward or inward." See Schneider, Bernhard. Daniel Libeskind : Jewish Museum Berlin
} . Prestel, 1999, p45 


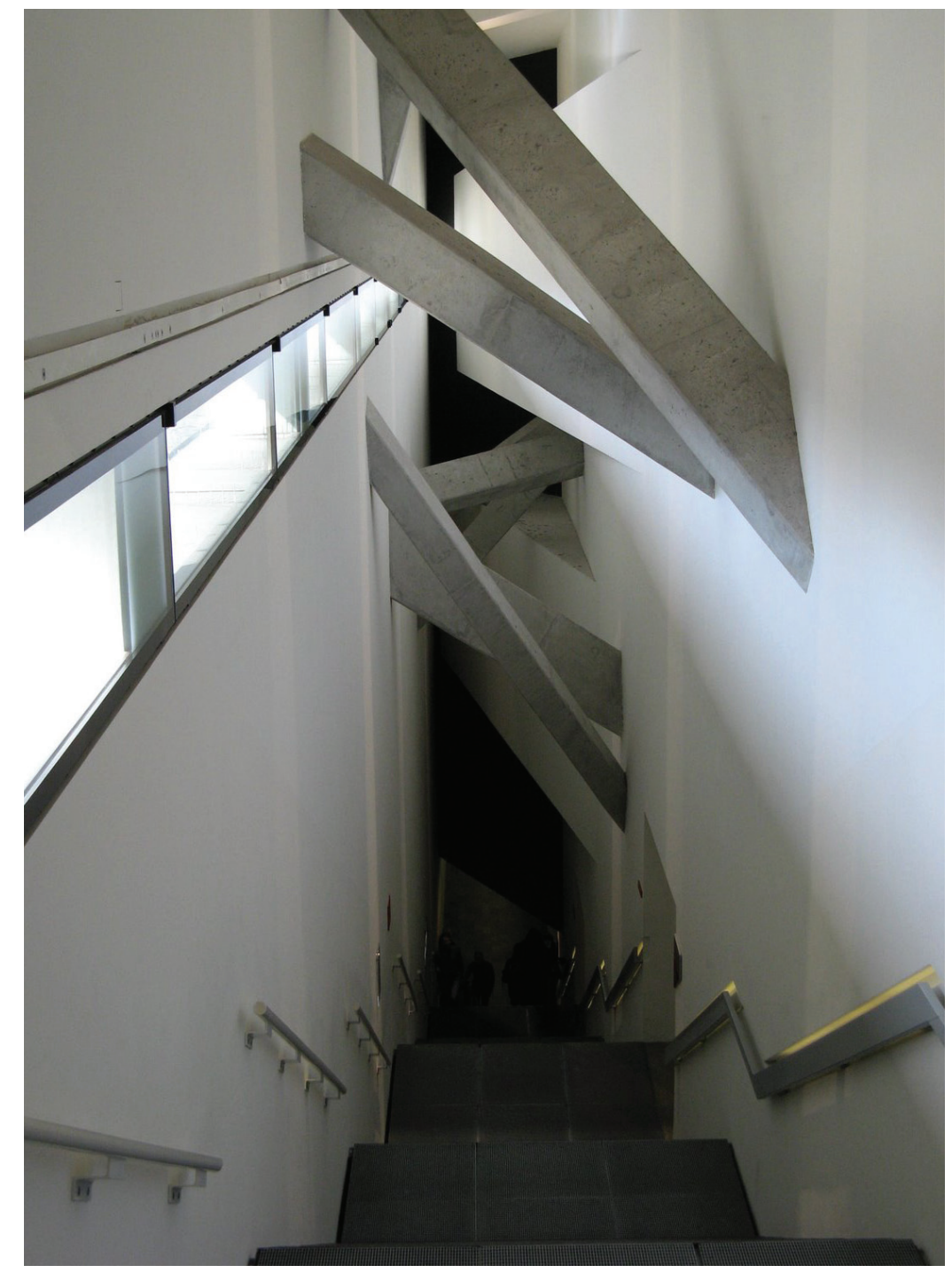

Figure 26: Concrete struts-cum-beams above main stairwell

\section{Conclusion}

The atmosphere of Daniel Libeskind's Jewish Museum addresses the social structure of Berlin and the absence of its Jewish community, being experienced through an atmospheric dialogue between past and present. The history embodied within this design goes far beyond that of the chosen site. However, the approaches employed by Libeskind throughout the journey of the space are of key importance. Within this journey, the use of voids and dramatic natural lighting in order to conjure moments of reflection act as a pivotal precedent for the design of this research. Aligning with theories presented by Plummer, Libeskind's use of a subterranean journey to elicit memories acts as a strong precedent, tested throughout design exploration. 


\subsection{Conclusions}

This section has analysed the atmospheric presence of light, shadow, narrative, and materiality within three case studies. These case studies help identify architectural strategies to approach the activation of intangible heritage. They articulate the atmospheric qualities presented throughout preceding chapters and illustrate their potential role within the built environment. The Jewish Museum and Hedmark Museum act as pivotal design precedents for the implementation of a historic narrative able to communicate aspects of history. Each serves a dramatically different function to the other, but both have similarities within their approach. Subterranean space plays a dominant role within the narrative of both, used as a crucial element in the representation of history. The design of this research will investigate similar methods, creating a subterranean journey within the abandoned and ruinous site of Wellington's former Fever Hospital. Infomed by the intangible heritage of the site, the bath-house typology will be explored as the primary programme of this underground environment. As such, the atmosphere and programme of Therme Vals is used as a precedent for this design. The proposed program of this design will be further explained within the following chapter, presenting a historical analysis of the chosen site. 


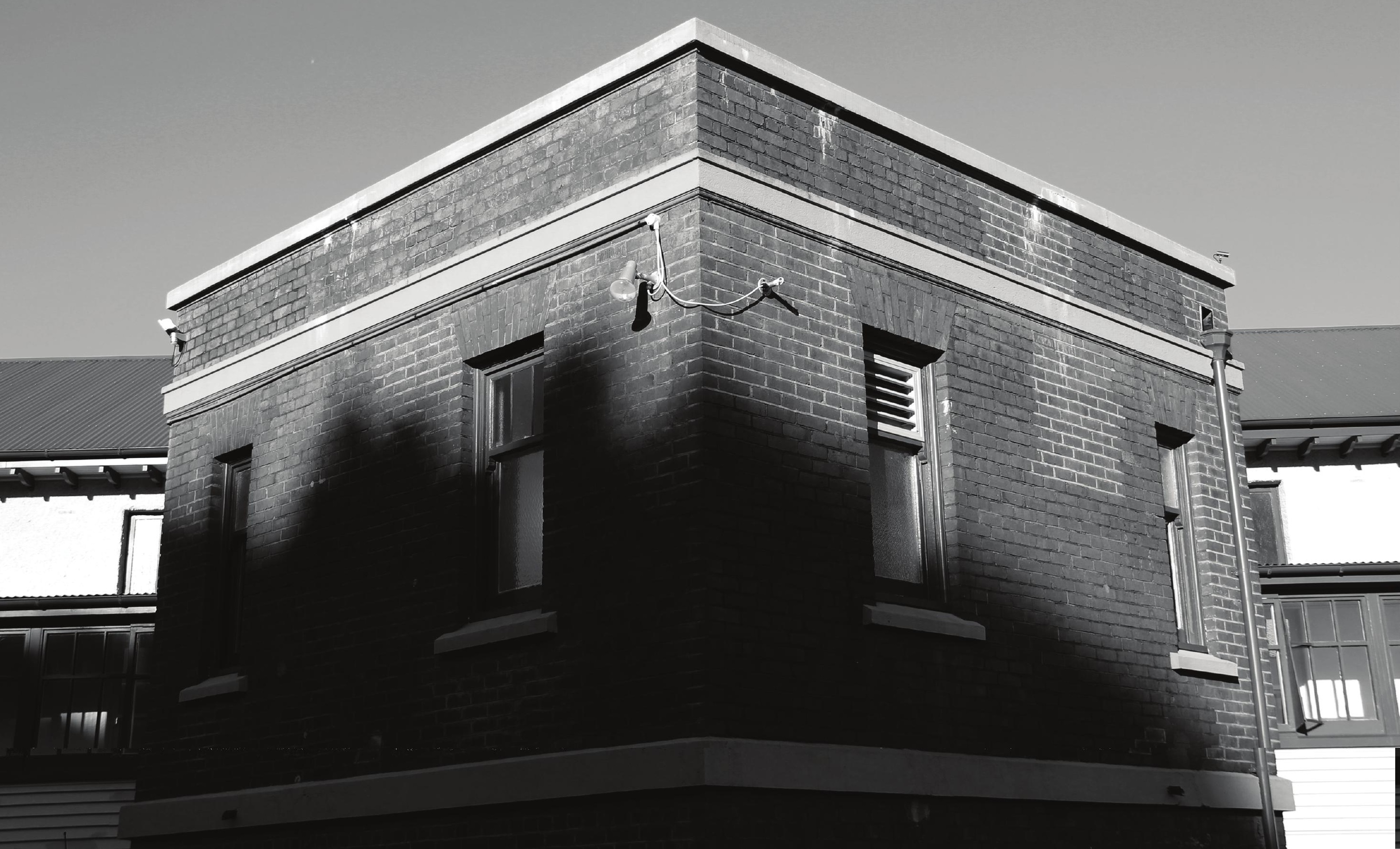




\section{Chapter Five SITE SELECTION AND ANALYSIS}

$\begin{array}{ll}5.0 & \text { Chosen Site } \\ 5.1 & \text { Historical Significance } \\ 5.2 & \text { Design and Planning } \\ 5.3 & \text { Heritage Protection Criteria } \\ 5.4 & \text { Programmatic Functions }\end{array}$




\section{5}

\subsection{Chosen Site}

The chosen site for the design of this thesis is an abandoned heritage complex located on the top of Mount Victoria, Wellington. The buildings were constructed in 1919, designed by Crichton and McKay; purpose built as an isolation hospital for those suffering from infectious diseases. In order to avoid the spreading of infection, the hospital was located far from the city and main hospital and was accessible only by foot. The facility has become obsolete as a hospital, but is still preserved under the Wellington City Council District Plan as being "nationally significant heritage buildings individually and, more especially as a group." ${ }^{1}$ However, under the current preservation tactics governed by the New Zealand ICOMOS Charter for the Conservation of Places of Cultural Heritage, both buildings remain neglected, abandoned and deteriorated. The New Zealand Historic Places Trust identifies the urgent need for a revitalisation of the site, writing; "Hopefully, there is a solution not too far away; otherwise the unthinkable alternative is demolition." ${ }^{2}$ The primary source of information throughout this chapter is from newspaper articles and reports from the Heritage Building Inventory; all accessed through the Historic Places Trust, Wellington.

1 Geden, Bruce. Chest Hospital Heritage Inventory. Architectural Heritage. Wellington: New Zealand Historic Places Trust, 2004, p13

$2 \quad$ Heritage at Risk: Fomer Fever Hospital Building, Wellington. Background Note.

Wellington: New Zealand Historic Places Trust, 2009, p1

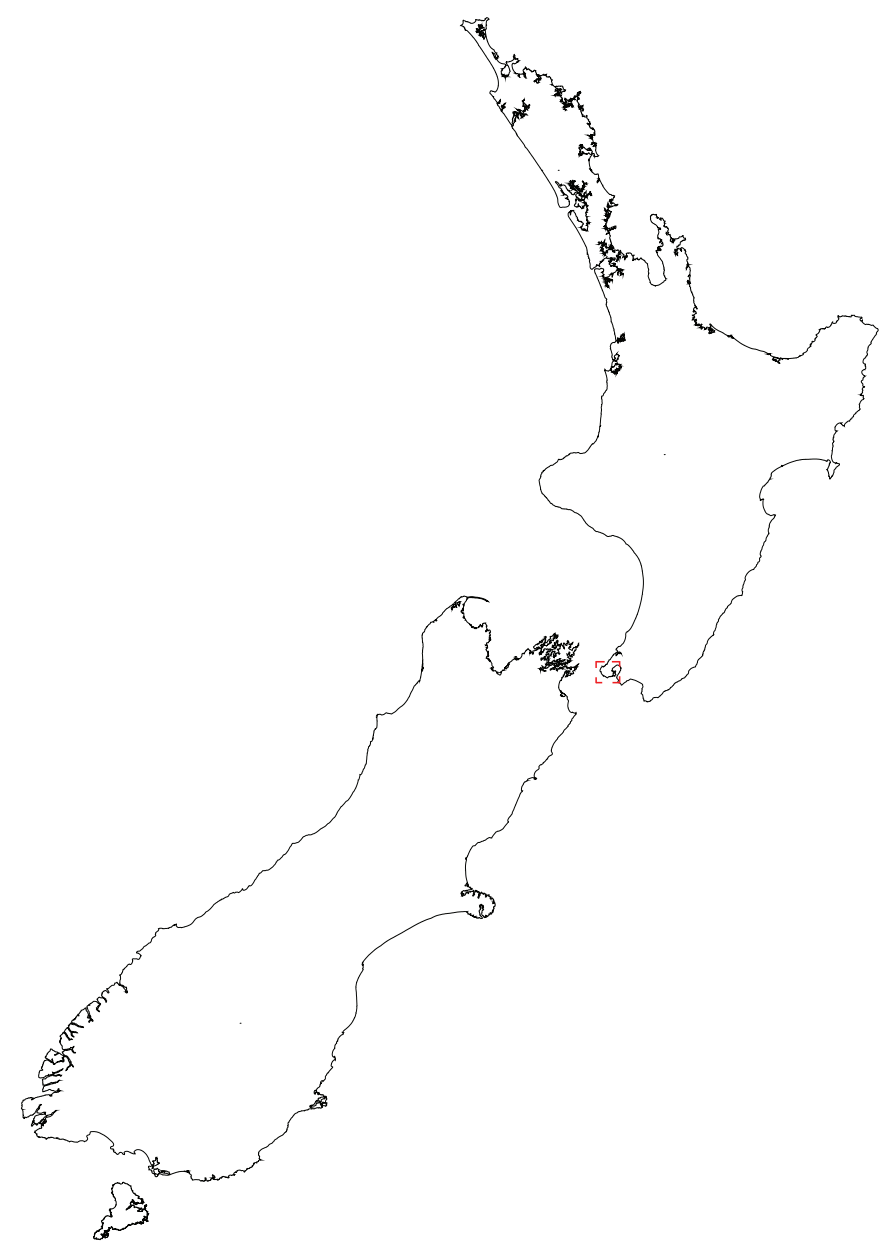

Figure 28: Wellington, New Zealand 


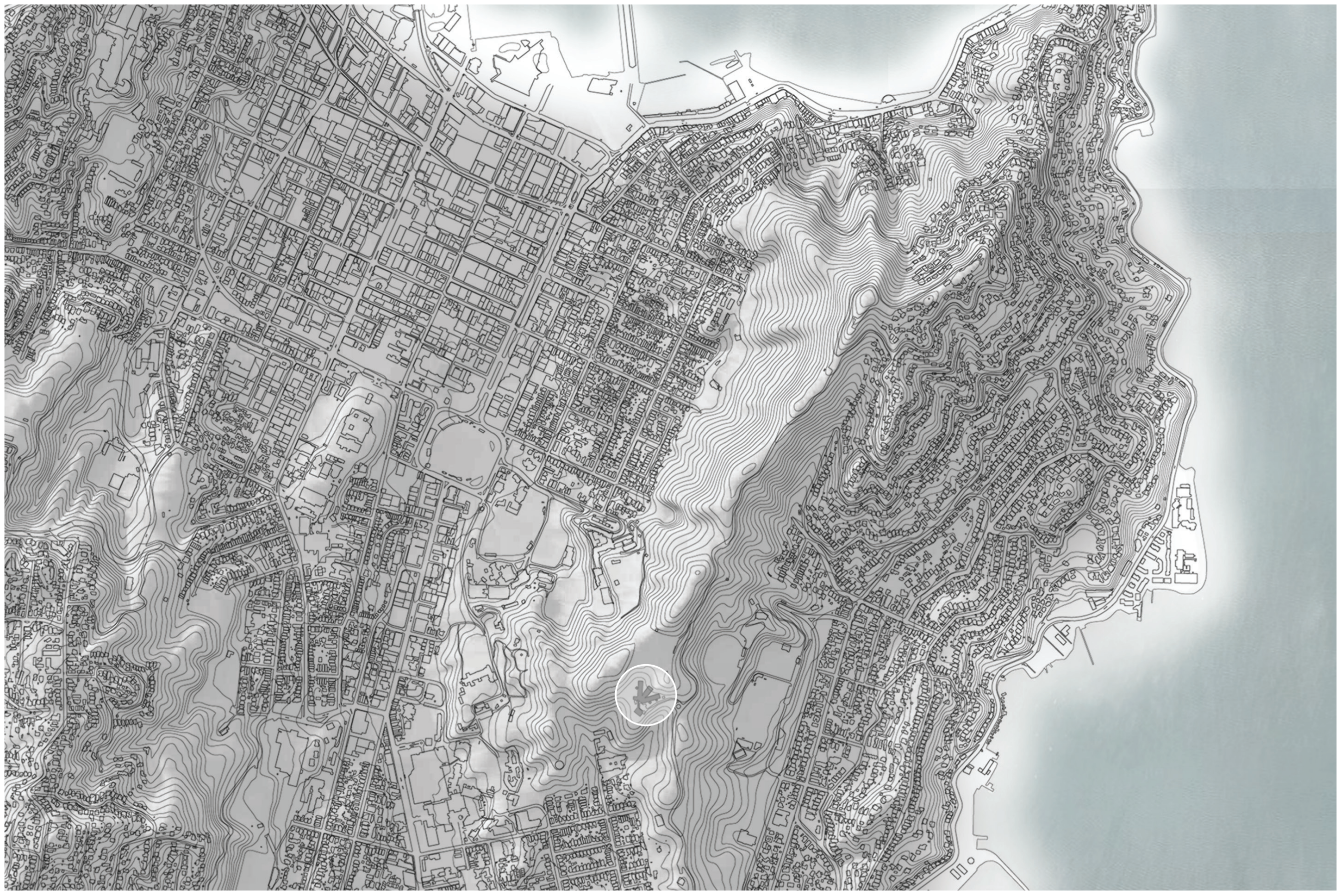



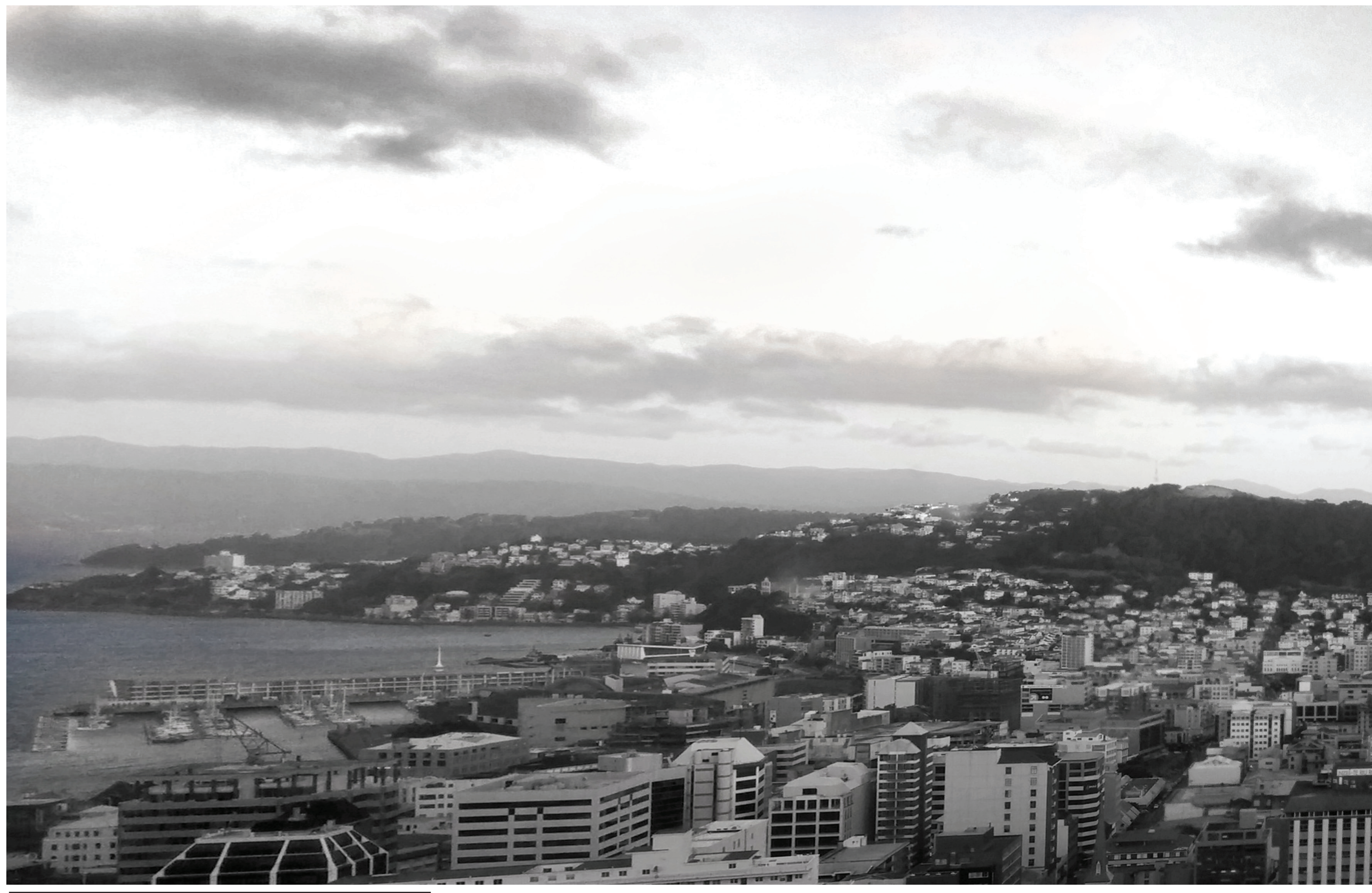

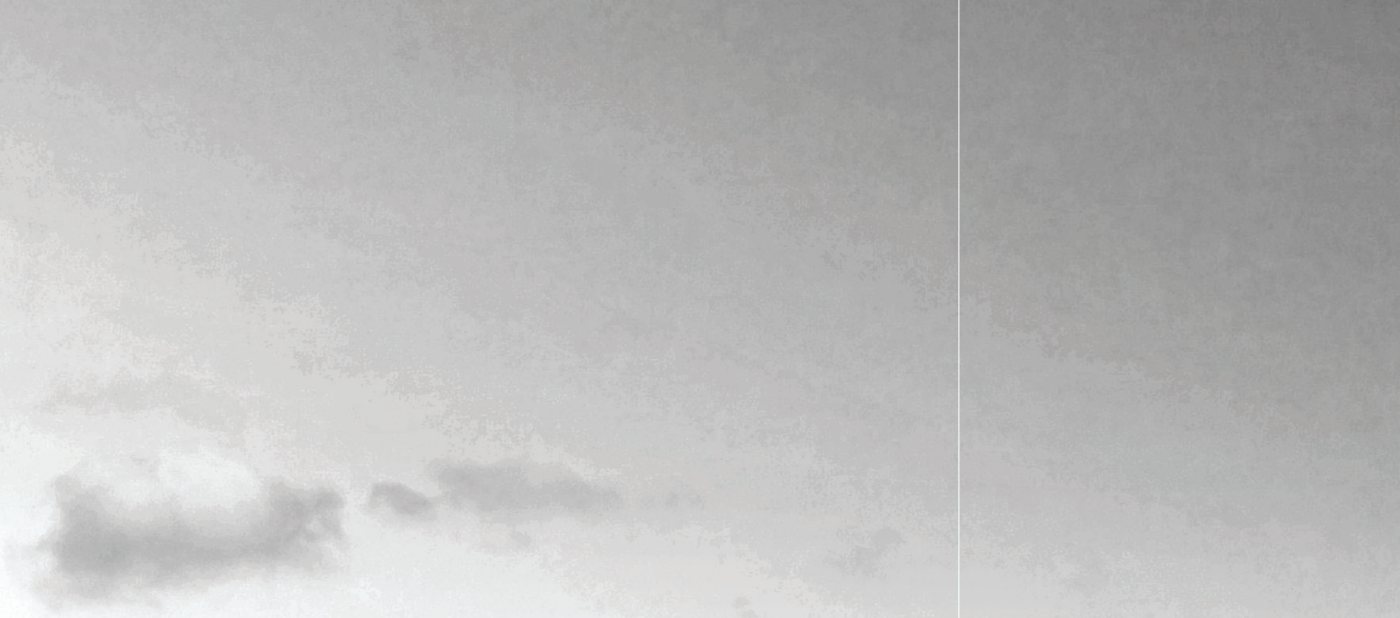

$\operatorname{tin}_{-1}=$

\section{ti} Y.

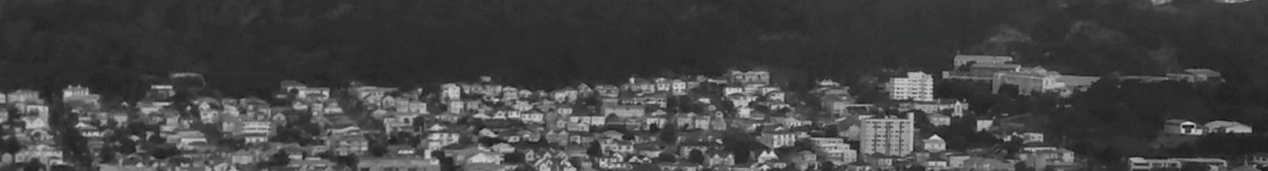

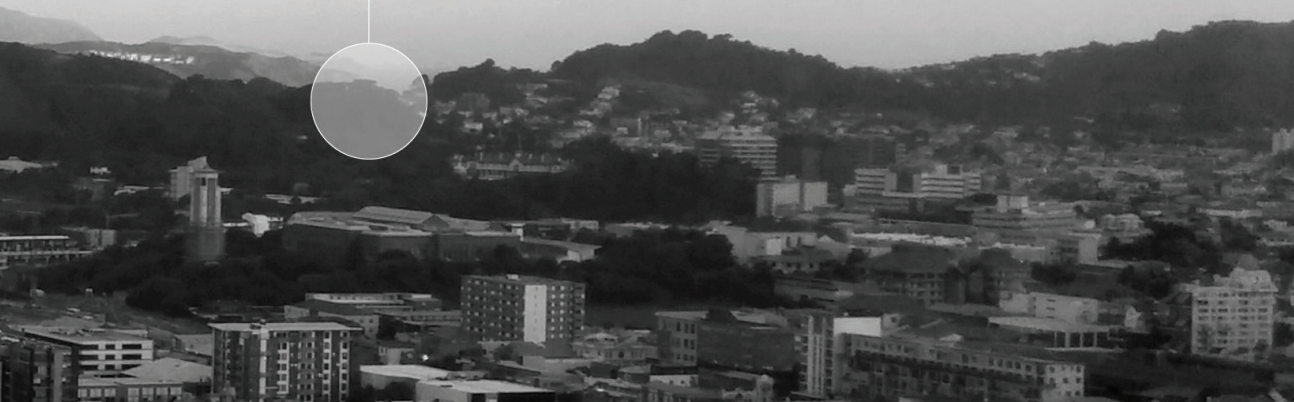

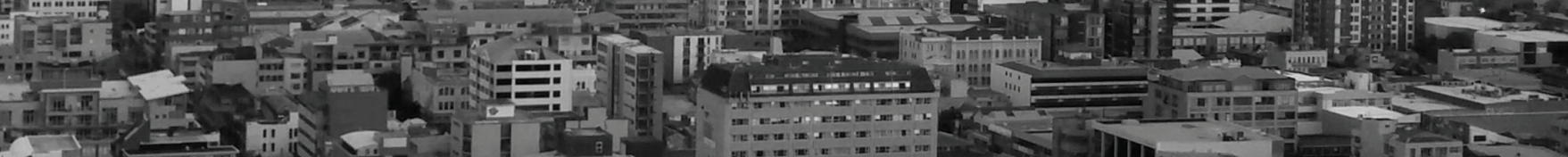
Fi: 1 in 플 


\subsection{Historical Significance}

The hospital was built immediately following the First World War, purpose built to isolate ill returning soldiers suffering from highly infectious diseases such as scarlet fever, measles, influenza and chicken pox. ${ }^{3}$ The severity of these diseases required that both patients and nurses remain on site. A nurse's home was constructed alongside the hospital with rigorous decontamination processes required for staff and visitors to come and go. With advances in medicine and changes toward health treatment isolation of diseases for which the hospital was originally constructed was no longer needed and by 1953 only four patients remained. ${ }^{4}$ This was shortly followed by the closing of the hospital complex. However, soon after it was re-opened as the "Temporary Chest Ward" with its primary function being the treatment of tuberculosis; which had replaced infectious diseases as the principal threat to community health. In 1973 an addition was constructed in order to accommodate excess patients from the main hospital, however this relocation was short-lived and the hospital complex soon became redundant, officially closing in $1981 .{ }^{5}$ In 1987, after considerable refurbishment, the building was given the role of accommodating the Wellington Polytechnic School of Music but this was another temporary relocation

\footnotetext{
3 Geden, Chest Hospital Heritage Inventory, $\mathrm{p} 4$

Heritage at Risk: Fomer Fever Hospital Building, Wellington. Background Note.

4 Heritage at Risk: Fomer Fever Hospital Building
Wellington: New Zealand Historic Places Trust, 2009, p1
}

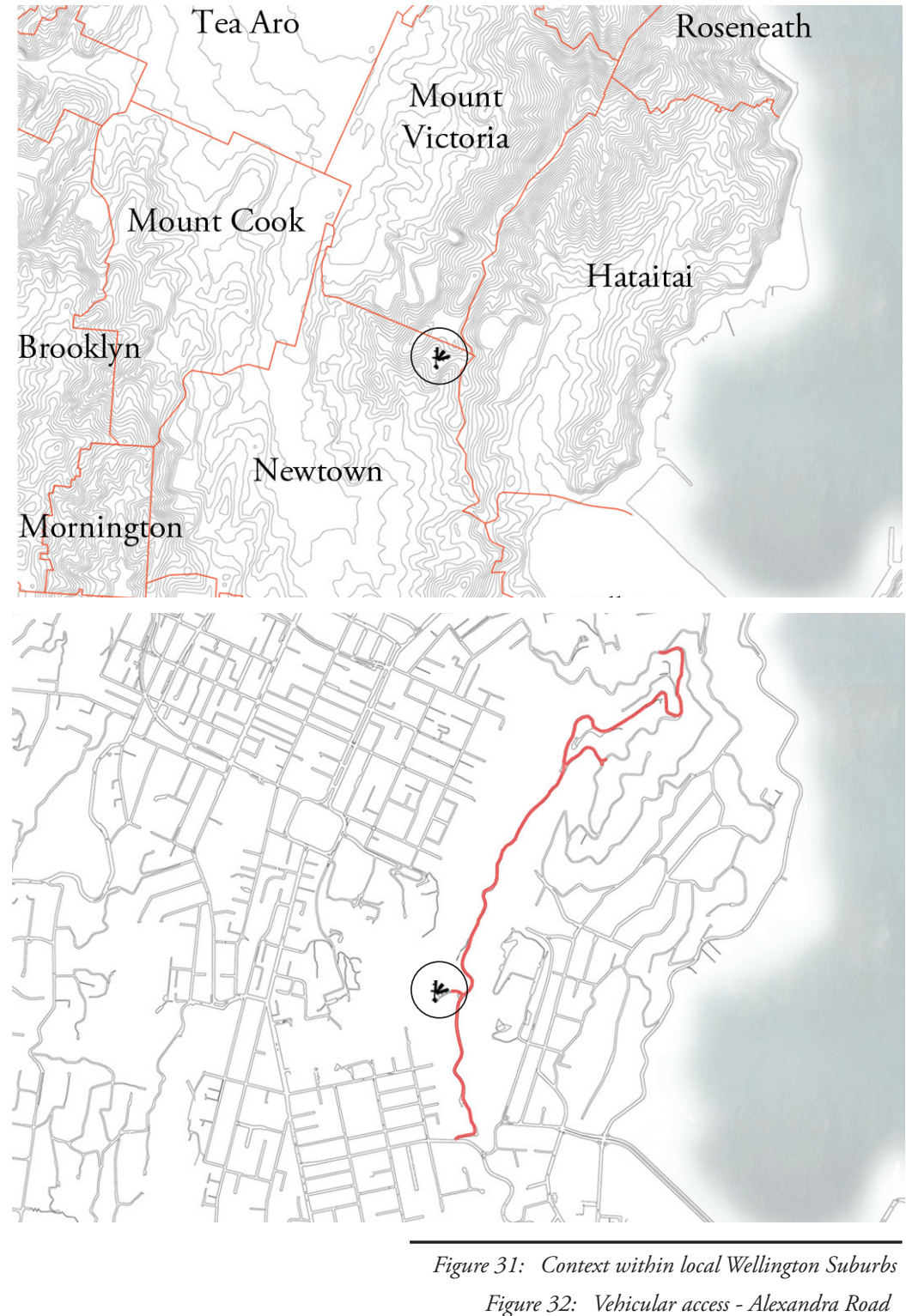

Figure 32: Vebicular access - Alexandra Road 


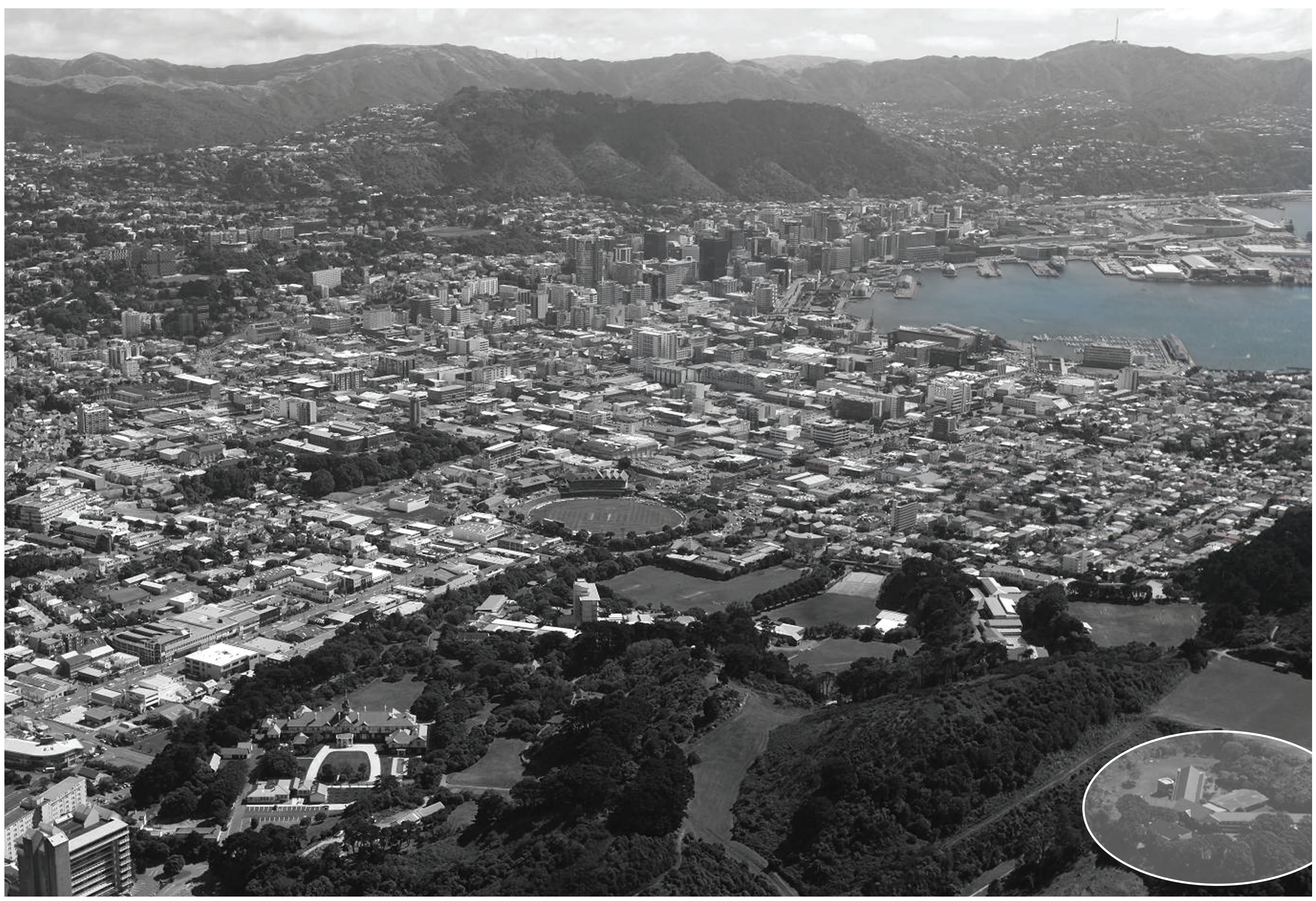


and by 1997 the Buildings were again closed, this time for good. ${ }^{6}$ The Hospital and Nurses Home have since been abandoned and although they originally consisted of aesthetic value, today there is an air of neglect with the buildings becoming increasing dilapidated. While its setting is pleasant, located in an open space bordering the town belt, the overall impression is not assisted by the heavy and ruinous state the complex has attained over its years of neglect. As presented within the Chest Hospital Heritage Inventory, "the hospital building is a rare New Zealand example of an Edwardian 'Fever Hospital', with most, if not all, other specifically designed infectious disease hospitals having been demolished." As such, the identity and history of the building should be preserved.

\subsection{Design and Planning}

During the period in which the Hospital was designed open air was seen as vital for improving health. ${ }^{8}$ On this basis, the hospital was designed with large opening windows spanning its length and veranda's from which patients could gain fresh air. The siting of the hospital, within a large open park setting, also allowed patients to walk among the garden-space. The hospital is designed in an Arts and Crafts version

\footnotetext{
$6 \quad$ Heritage at Risk: Fomer Fever Hospital Building, Wellington. Background Note.

Wellington: New Zealand Historic Places Trust, 2009, p1

7 Geden, Chest Hospital Heritage Inventory, 12

$8 \quad$ Ibid., 11
}

of the Queen Anne style; being a revival of late $17^{\text {th }}$ and $18^{\text {th }}$ Century architecture popularised by British architects Richard Norman Shore and William Eden Nesfield. ${ }^{9}$ The layout and planning of the hospital gives the building a sense of openness that integrates with its goal of easily accessible fresh air. The original building plan is designed in a ' $\mathrm{V}$ ' shape with the reception, staff area and administration at its base. The two main wings are one room wide and each housed four large open wards, with toilets and amenities being located off the wings in brick pavilions. ${ }^{10}$ Both buildings consist of painted corrugated steel roofing, painted solid brick with cavity brickwork, exposed brick lintels, and painted timber joinery and decorative elements. ${ }^{11}$

\footnotetext{
$9 \quad$ This style was part of the picturesque movement; known for its asymmetrical building designs consisting of conical towers and tall chimneys that aim to generate an interesting non-standard skyline and interplay of complex forms. This Queen Anne style was known for its use of both Gothic and Classical elements. The hospital also reflects aspects of Edwardian implementation in its planning, of which Edward Prior was a major influence with his exploration of new plans and forms that were able to integrate architecture more with nature. See Geden, Bruce. Chest Hospital Heritage Inventory. Architectural Heritage. Wellington: New Zealand Historic Places Trust, 2004, p6

10 Geden, Chest Hospital Heritage Inventory, 6

11 Ibid. ,7
} 

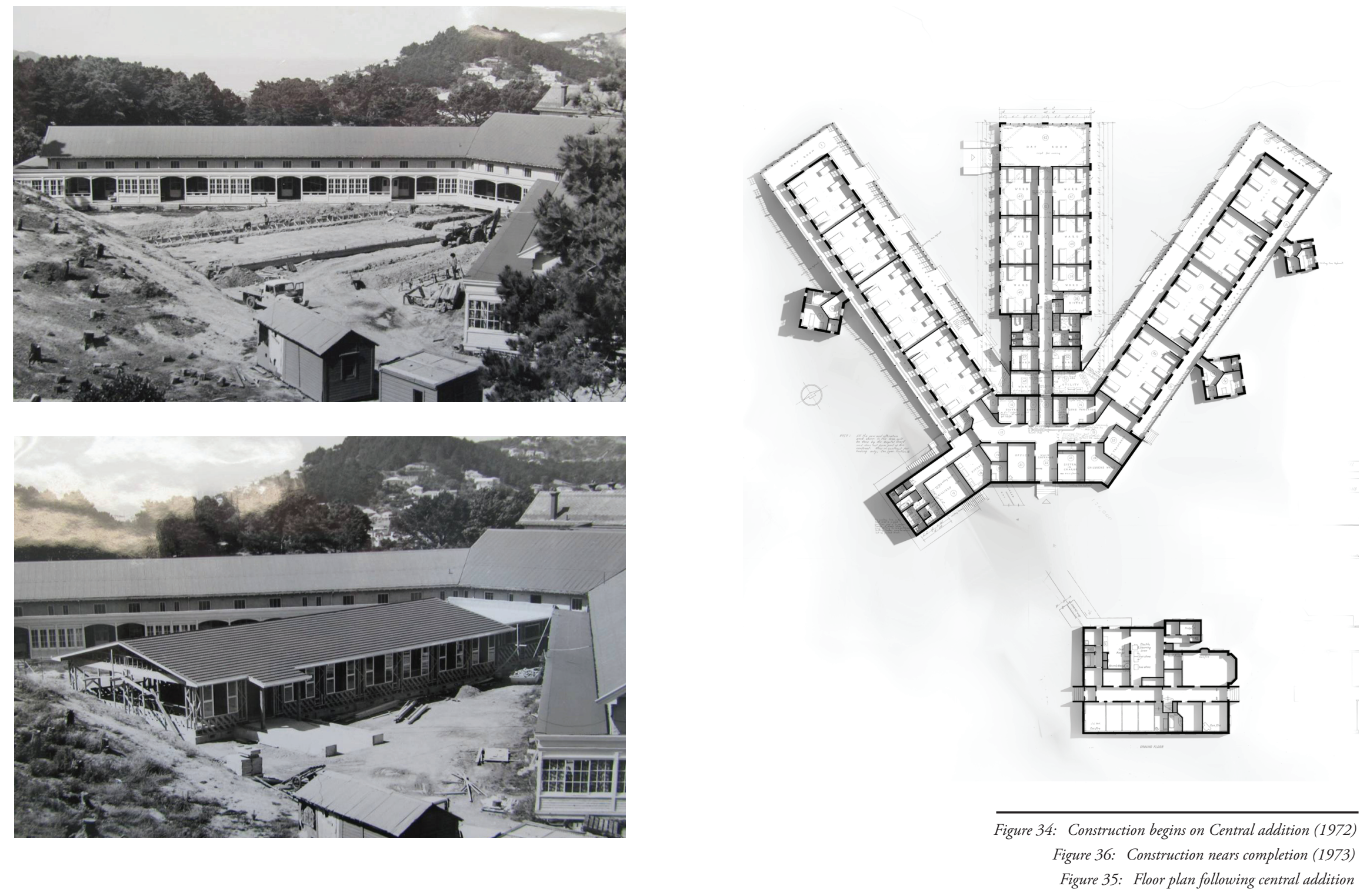


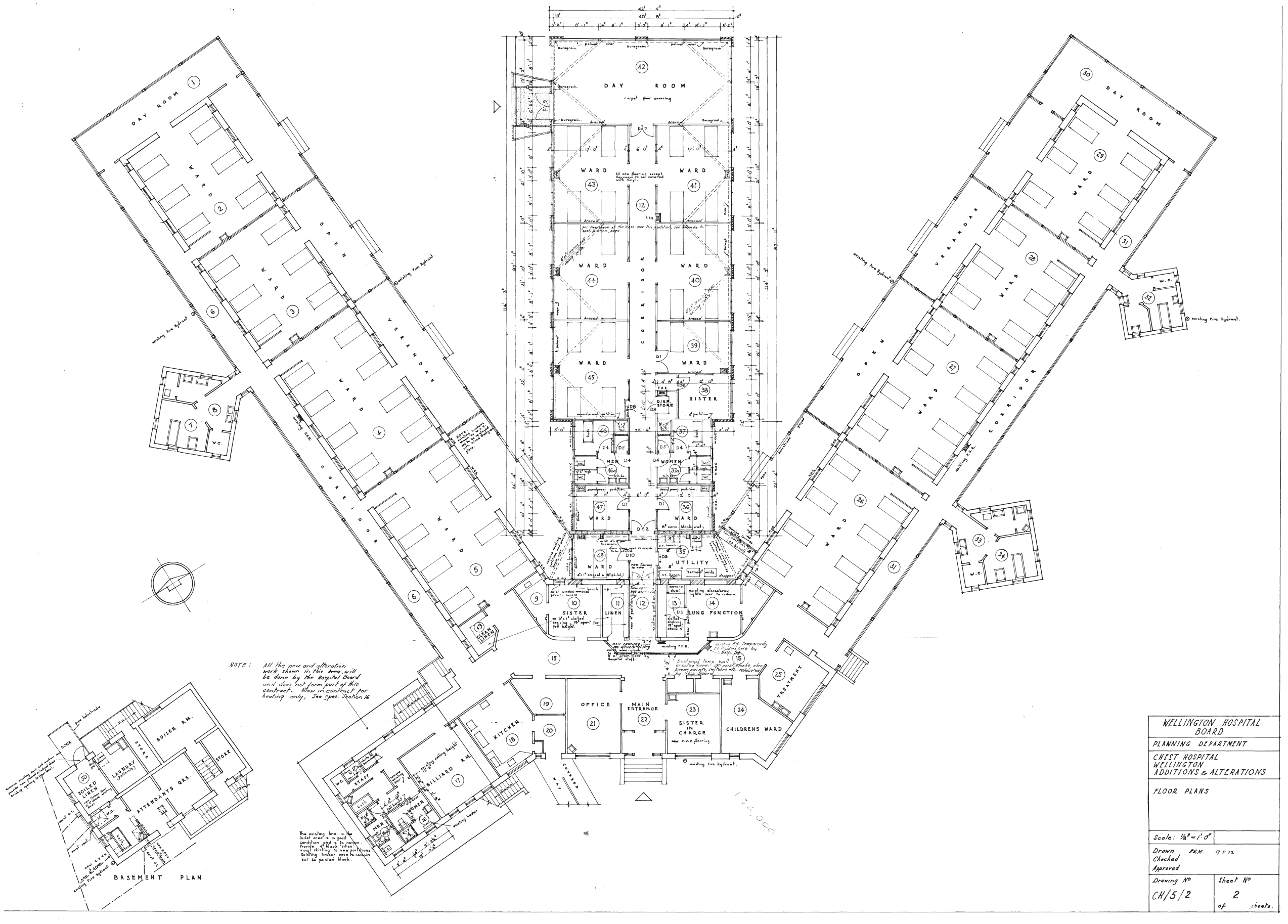




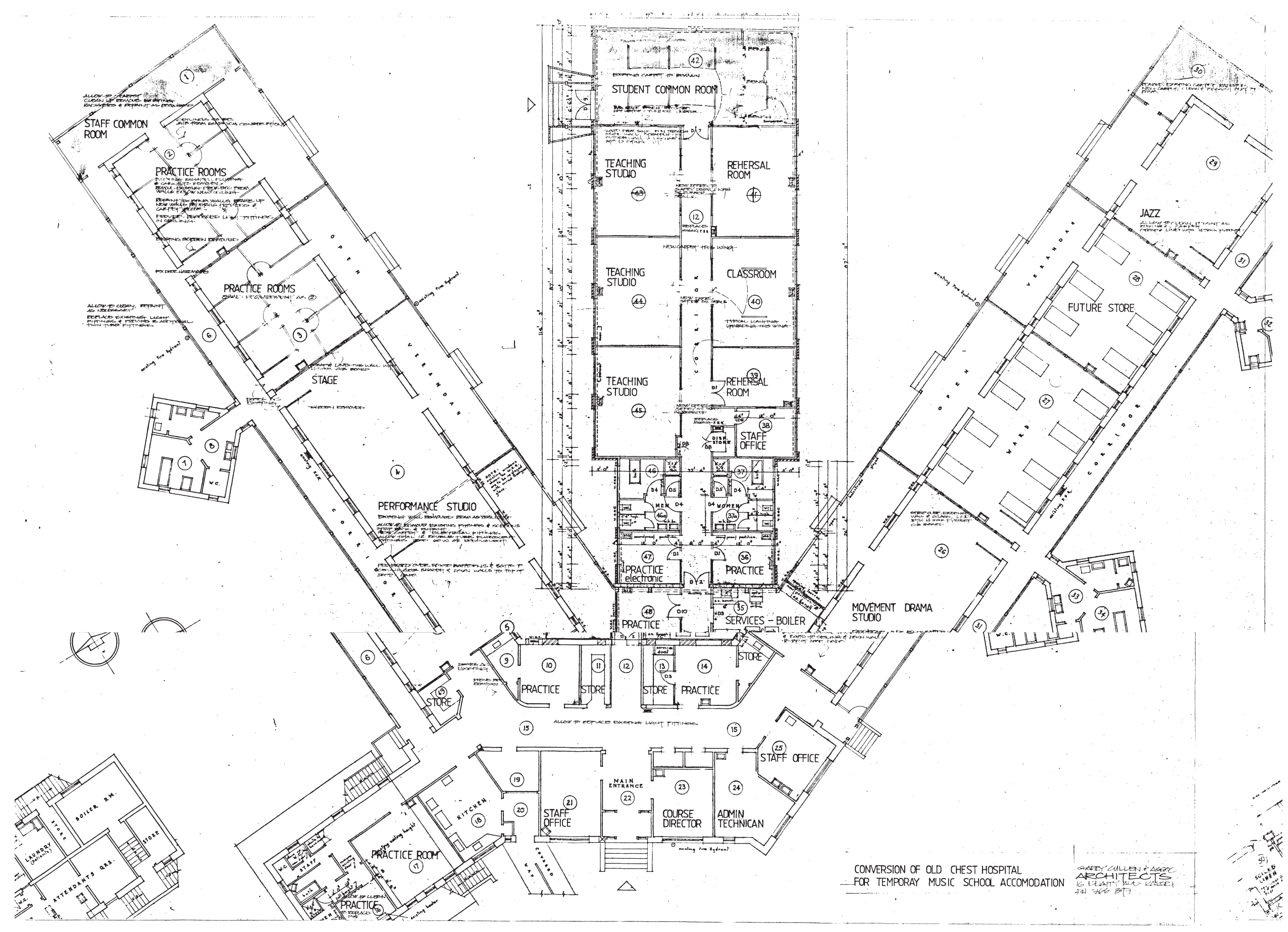




\subsection{Heritage Protection Criteria}

The current protection guidelines for the buildings are outlined in the 'Identification of Places of Heritage Value' within the Wellington City Council District plan. This inventory follows the format, topic categories, and sequences described in the 'Cultural Significance' section of James S. Kerr's The Conservation Plan: A guide to the preparation of conservation plans for places of European cultural significance. ${ }^{12}$ These are broadly outlined by the ICOMOS New Zealand Charter for the Conservation of Places of Cultural Value, broken down into three primary criteria; cultural values, use values, and contextual values. ${ }^{13}$ In this inventory, within 'cultural values', the historical value of the site is summarised as;

Both buildings are associated with medical practice of the time where isolation and fresh air were seen as the main means of treatment. Isolation was also required for nursing staff while on duty for six week periods. Such specifically designed hospitals are no longer considered necessary with the improvement in medicines and treatments available today. The building is, therefore, significant as an example of a redundant hospital building type in the history of hospital building in New Zealand. ${ }^{14}$

\footnotetext{
12 Bowman, Ian. Wellington Hospital for Infectious Diseases Heritage Assessment Wellington: Wellington City Council, 1998, p3

13 Geden, Chest Hospital Heritage Inventory, 9

14 Bowman, Wellington Hospital for Infectious Diseases Heritage Assessment, 11
}

This Historic New Zealand landmark, following Bowman, should not be severed from its surrounding context, but integrated into public consciousness as a memorial to the history it has served. Due to the history of events that have occurred within them, both buildings are now a rare building type which responded to the health concepts of the time. They require an architectural modification that is able to activate the rich history underlying their construction and the subsequent uses that they accompanied over the years.

\subsection{Programmatic Functions}

As illustrated within Figure 39 and 40, the buildings of Wellingtons abandoned Fever Hospital have accommodated two primary programs; the intended function as an isolation hospital and the subsequent use as a school of music. During its operation as an isolation hospital the site was heavily separated from all surrounding city function both symbolically and physically; with vehicular access not being built until 1933 . Decontamination was a standard procedure during these times, with bathing units being placed throughout the hospital. Due to a lack of medical treatment, this process of bathing, in combination with fresh air and isolation, was seen as the primary means of treatment for those 
suffering from infectious diseases. ${ }^{15}$ While the original function of the building served to quarantine those on site, the subsequent use by Wellington's Polytechnic School of Music did the opposite; scheduling, performances and open-rehearsals in an attempt to integrate public participation on site. This thesis draws upon these disparate functions the building has served, using them to inform the programmatic functions explored through design testing.

As the main functions the buildings have served, these two programs are used to inform the relationships, program, and structure of design exploration. This is explored within the following chapter, reinstating aspects of these initial functions as contemporary programs.

Geden, Chest Hospital Heritage Inventory, 11

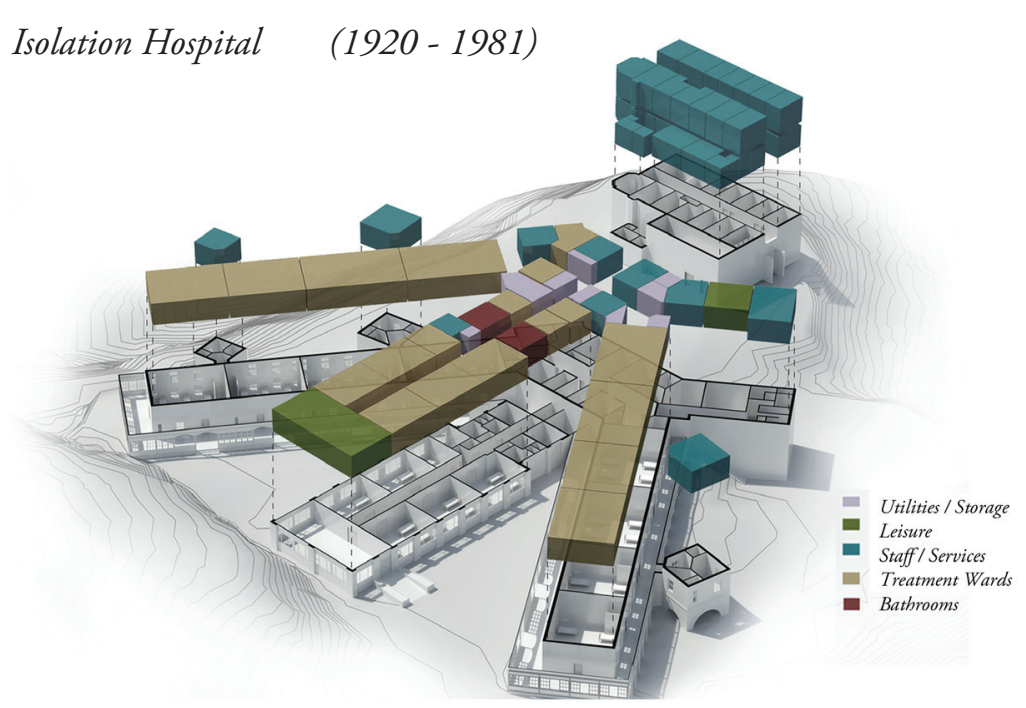

Wellington Polytechnic School of Music $\quad$ (1987-1997)

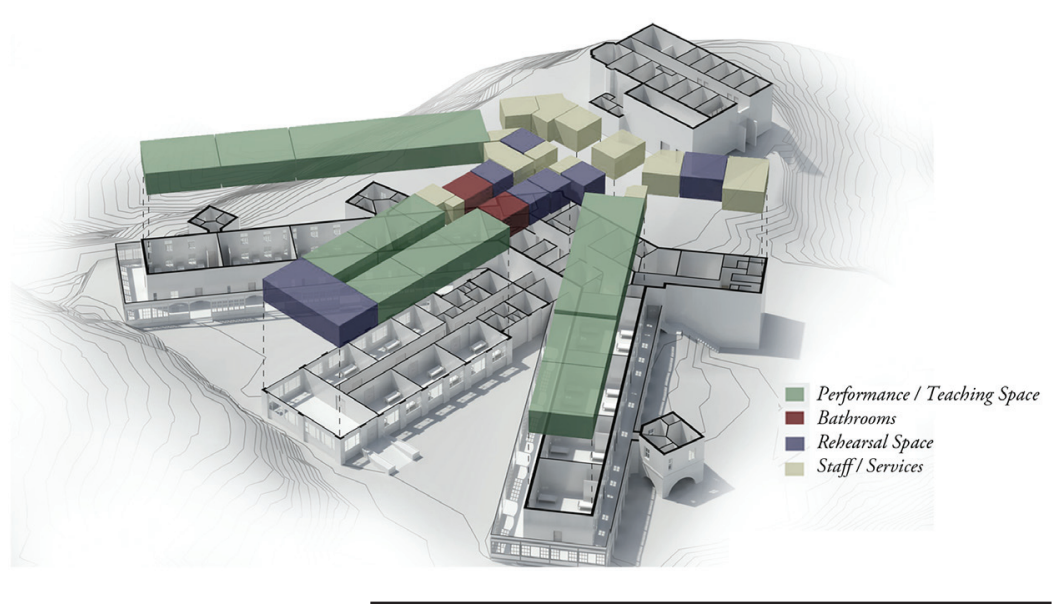

Figure 39: Isometric illustrating building use - Isolation Hospital Figure 40: Isometric illustrating building use - School of Music 


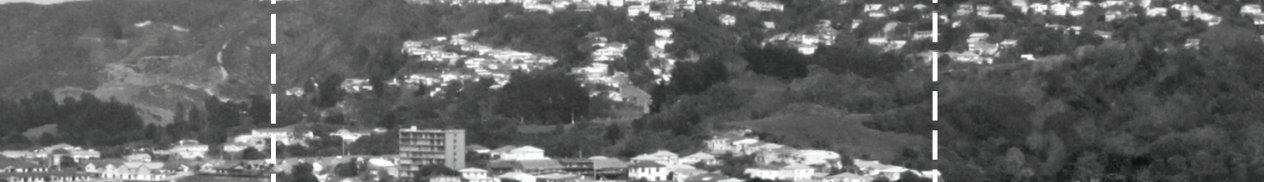

$10=1$ 1 inting $4 x^{2}+x^{3}$ E. THE $\frac{1}{4}$ thing thas

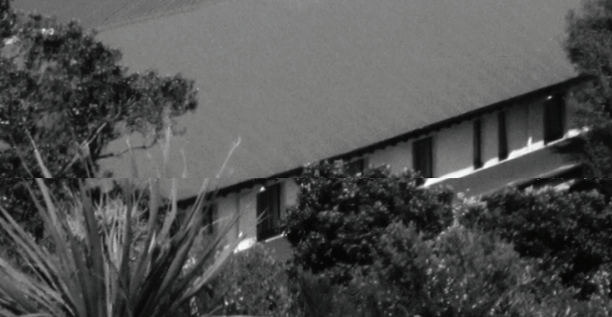

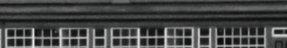
$=1\left(\frac{1}{2}\right.$

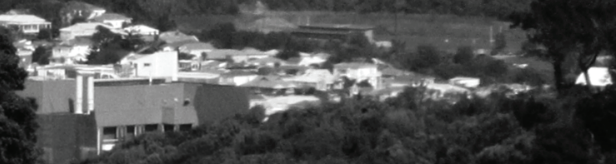

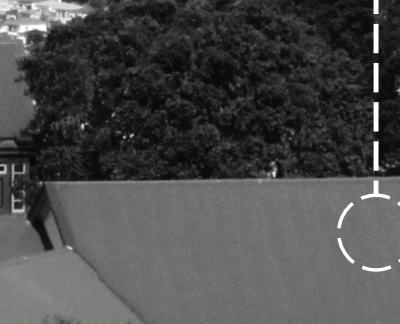

1.:
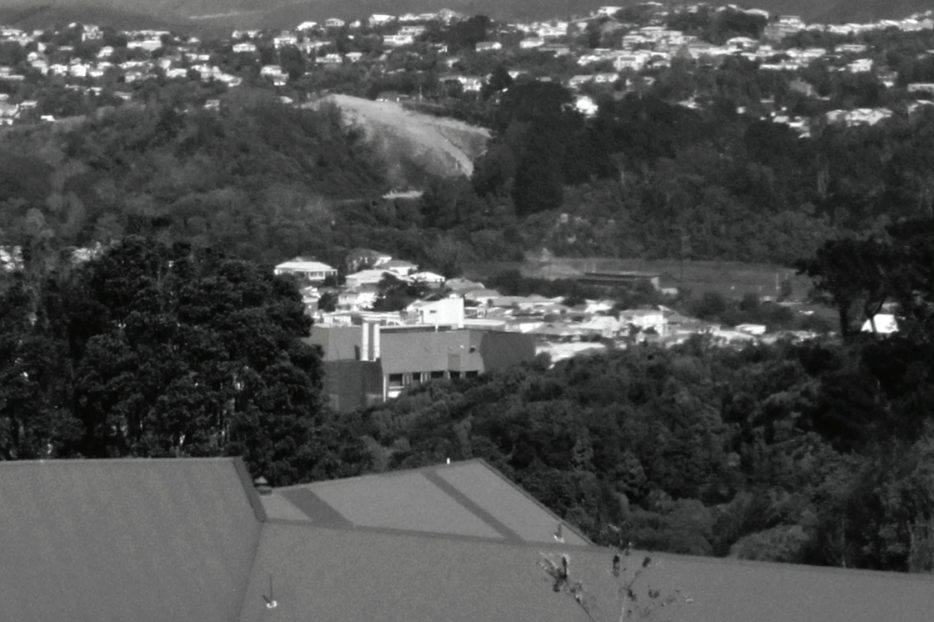

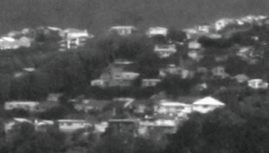

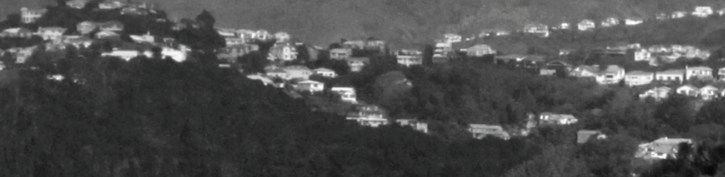

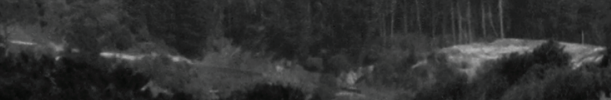
ar 
$-6$
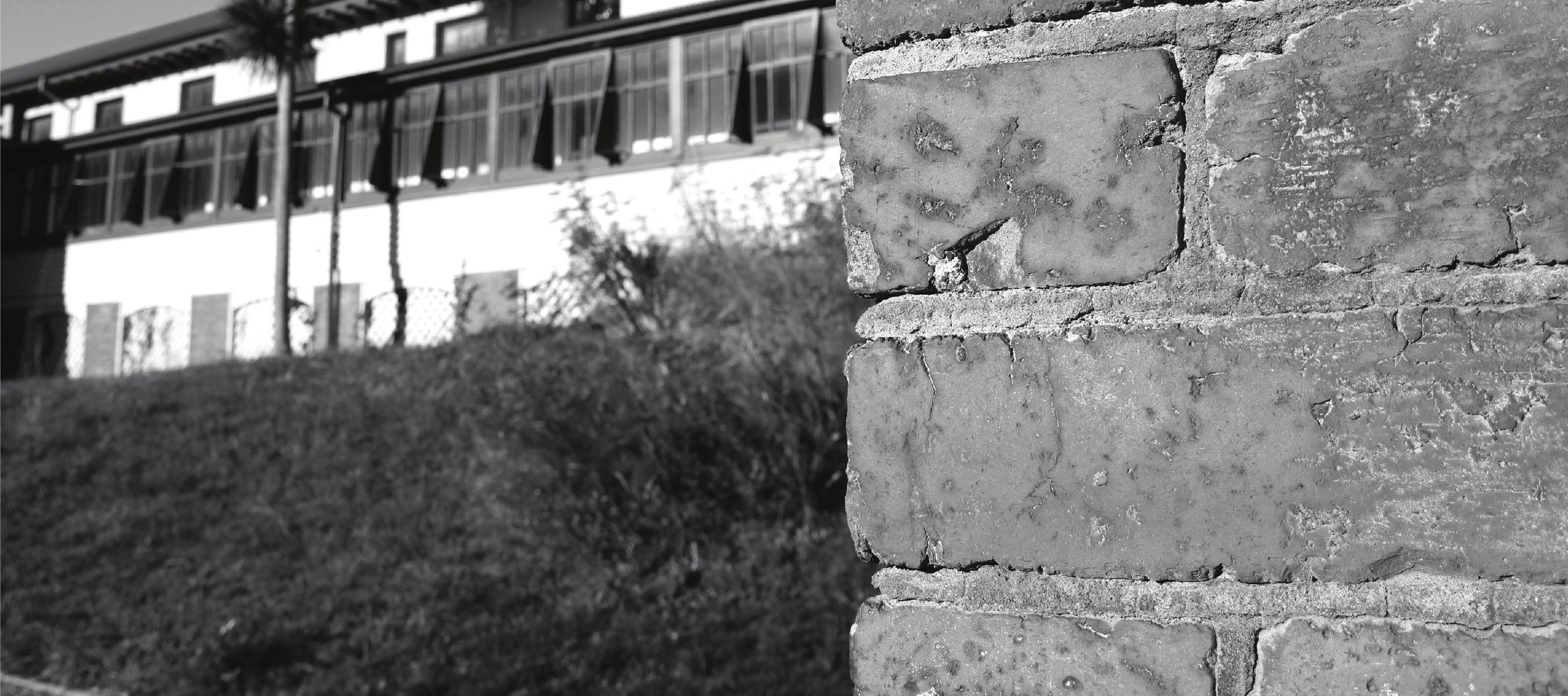


\section{Chapter Six DESIGN EXPLORATION}

$\begin{array}{llll}6.0 & \text { Introduction } & 6.3 & \text { Developed Design } \\ 6.1 & \text { Design Rationale } & 6.4 & \text { Design Reflection } \\ 6.2 & \text { Concept Testing } & & \\ 6.2 .1 & \text { Iteration One } & & \\ 6.2 .2 & \text { Iteration Two } & & \\ 6.2 .3 & \text { Iteration Three }\end{array}$




\section{6}

\subsection{Introduction}

As presented within the preceding chapters, this research positions atmosphere as an essential ingredient within the activation of intangible heritage; employing light, shadow, material, and narrative as the four primary considerations. This chapter of the thesis explores research through design in activating intangible heritage, constructing aesthetics of remembrance in order to communicate an understanding of the less tangible aspects within the history of Wellington's former Fever Hospital. Through this process the past, as it exists in current awareness, is to be spatially reconstructed using a complex mixture of research and imaginative representation; enabling a feeling of reminiscence to the history the site has served. This architectural investigation follows an iterative working method, presenting three tests that build upon each other and lead toward a developed architectural outcome. This chapter first presents a rationale for the programmatic decisions within the design, followed by concept testing through iterative design, leading toward the developed architectural outcome of the thesis.
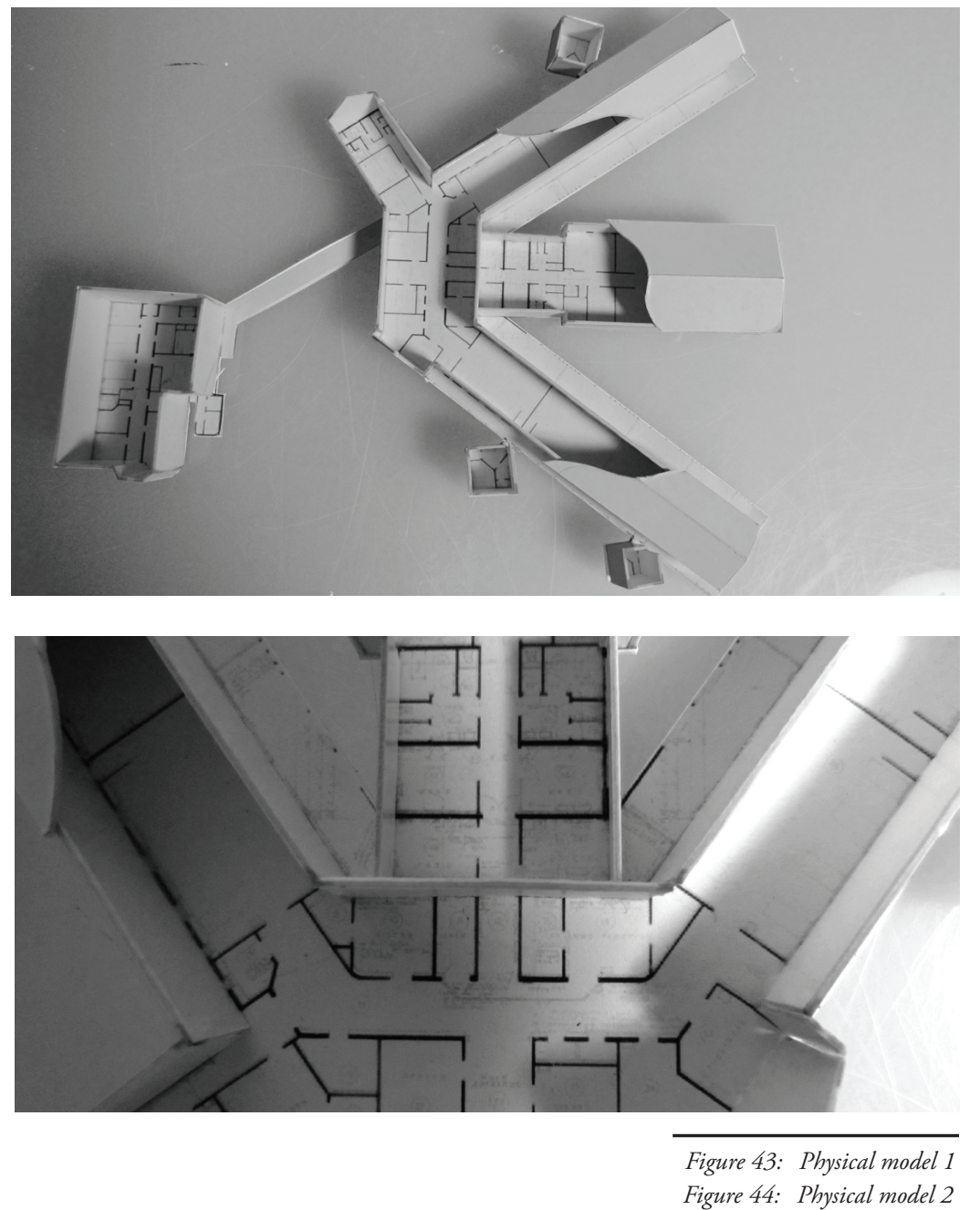
The initial development of this thesis explored atmosphere as expressed through photographs and imagery. This investigated the photographic representation of abandoned spaces by three photographers; Jeremy Barnard, Heidi Johnson, and Christopher Payne. Following this, imagery was used to analyse the spatial conditions and atmosphere of the abandoned Fever hospital. This established a starting point for the investigation of atmospheric conditions and their implementation within a contemporary function.

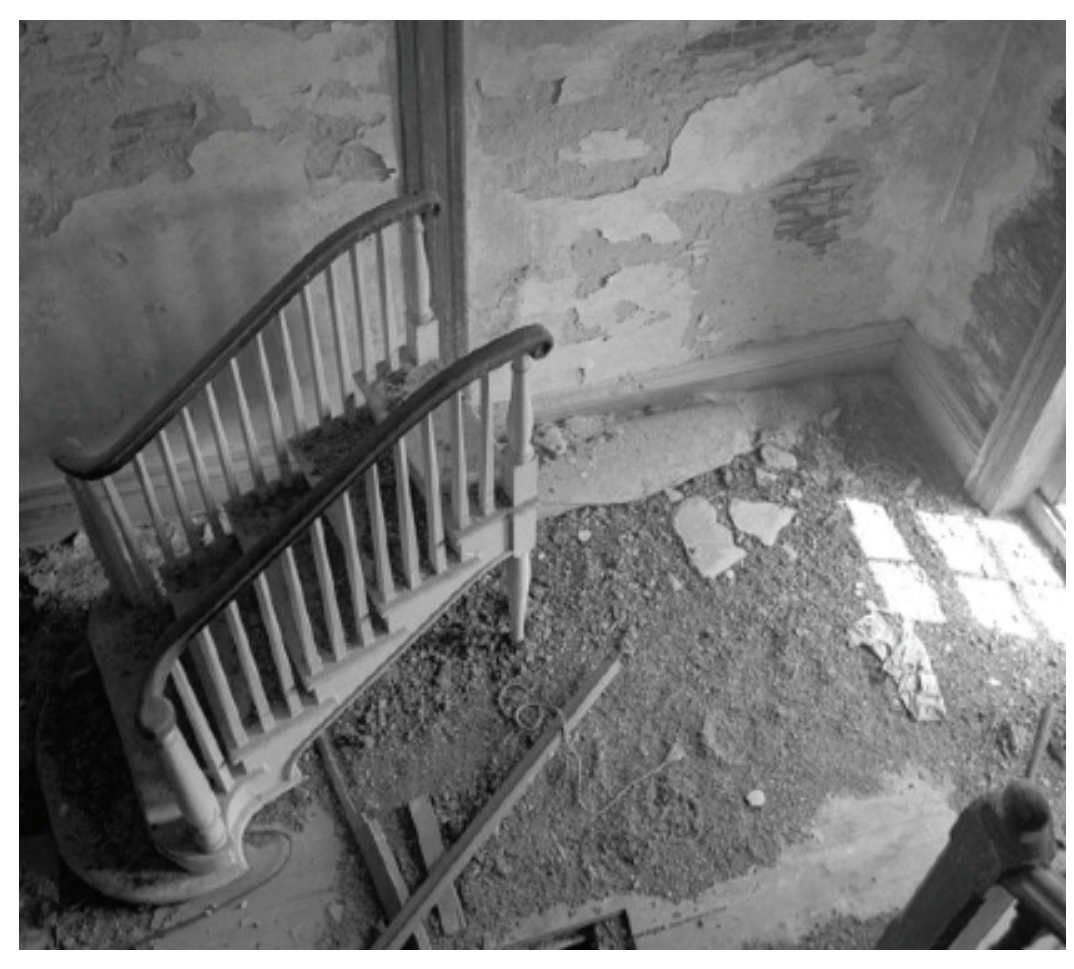

Figure 45: Jeremy Barnard - Danvers State Lunatic Asylum

Figure 46: Heidi Johnson - former Traverse City State Hospital

Figure 47: Christopher Payne - Taunton State Hospital, Massachusetts
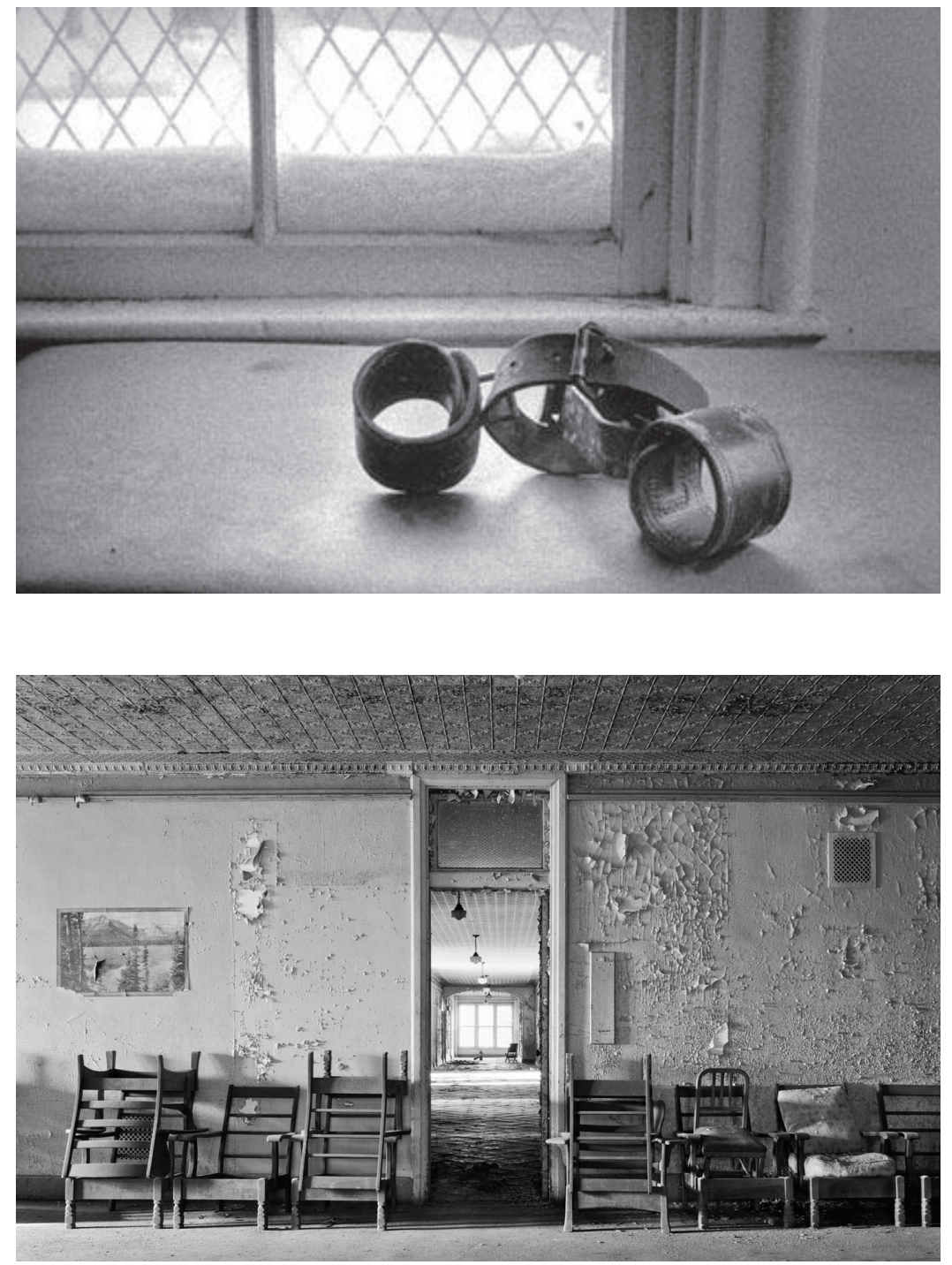


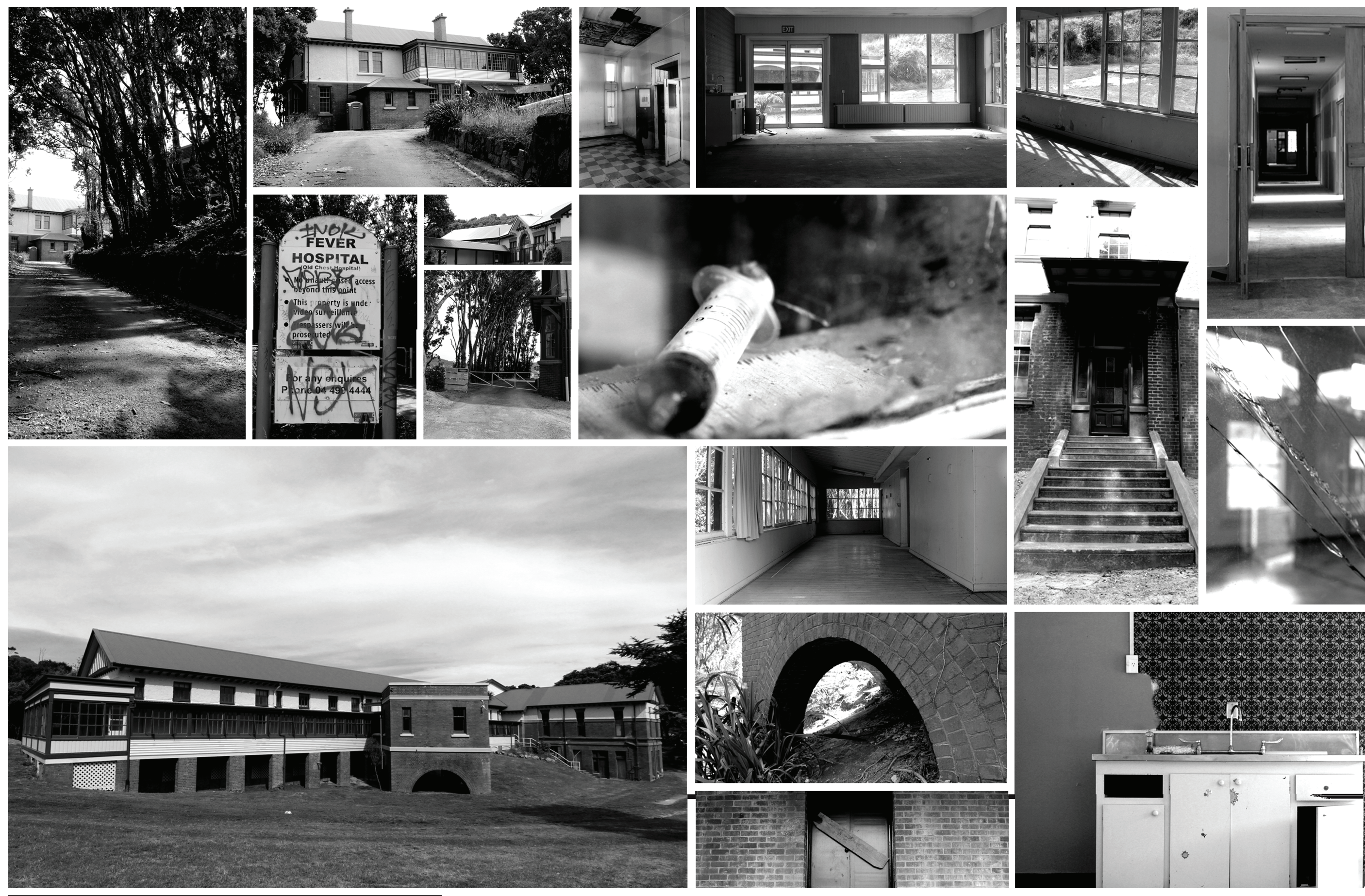




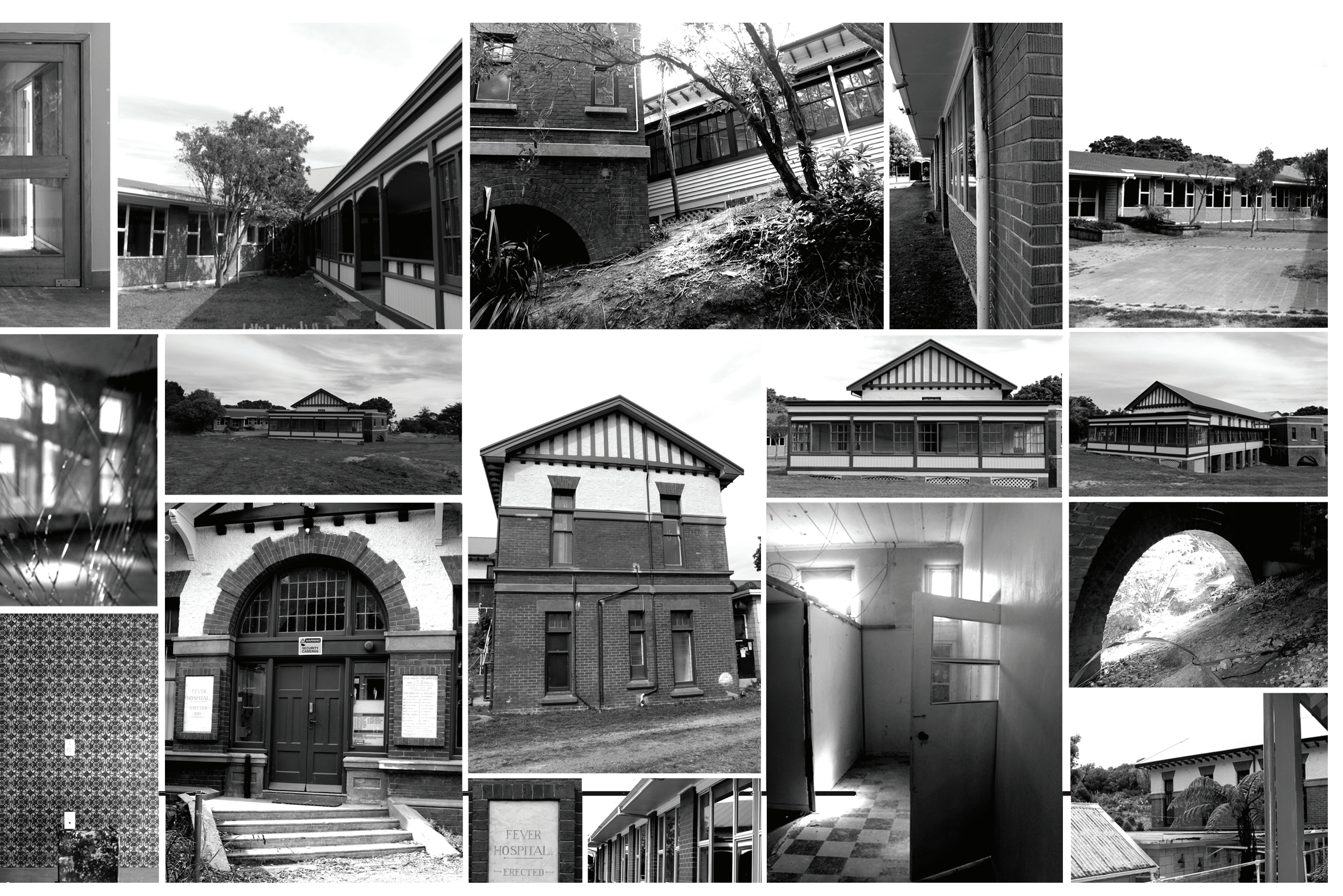



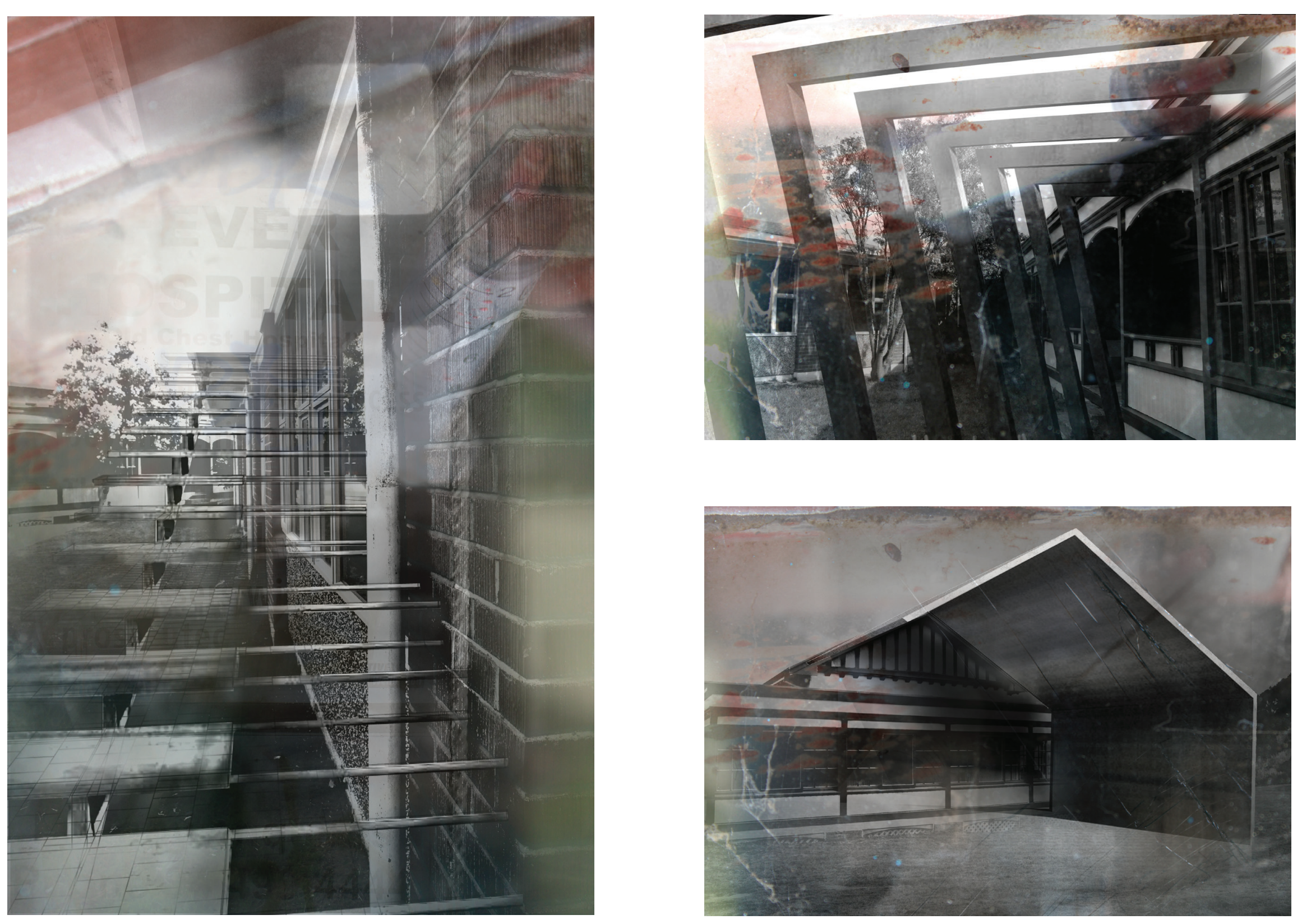

Figure 49: Initial design exploration experimenting with intervening form and geometries: 1 Figure 50: Initial design exploration experimenting with intervening form and geometries: 2 Figure 51: Initial design exploration experimenting with intervening form and geometries: 3 


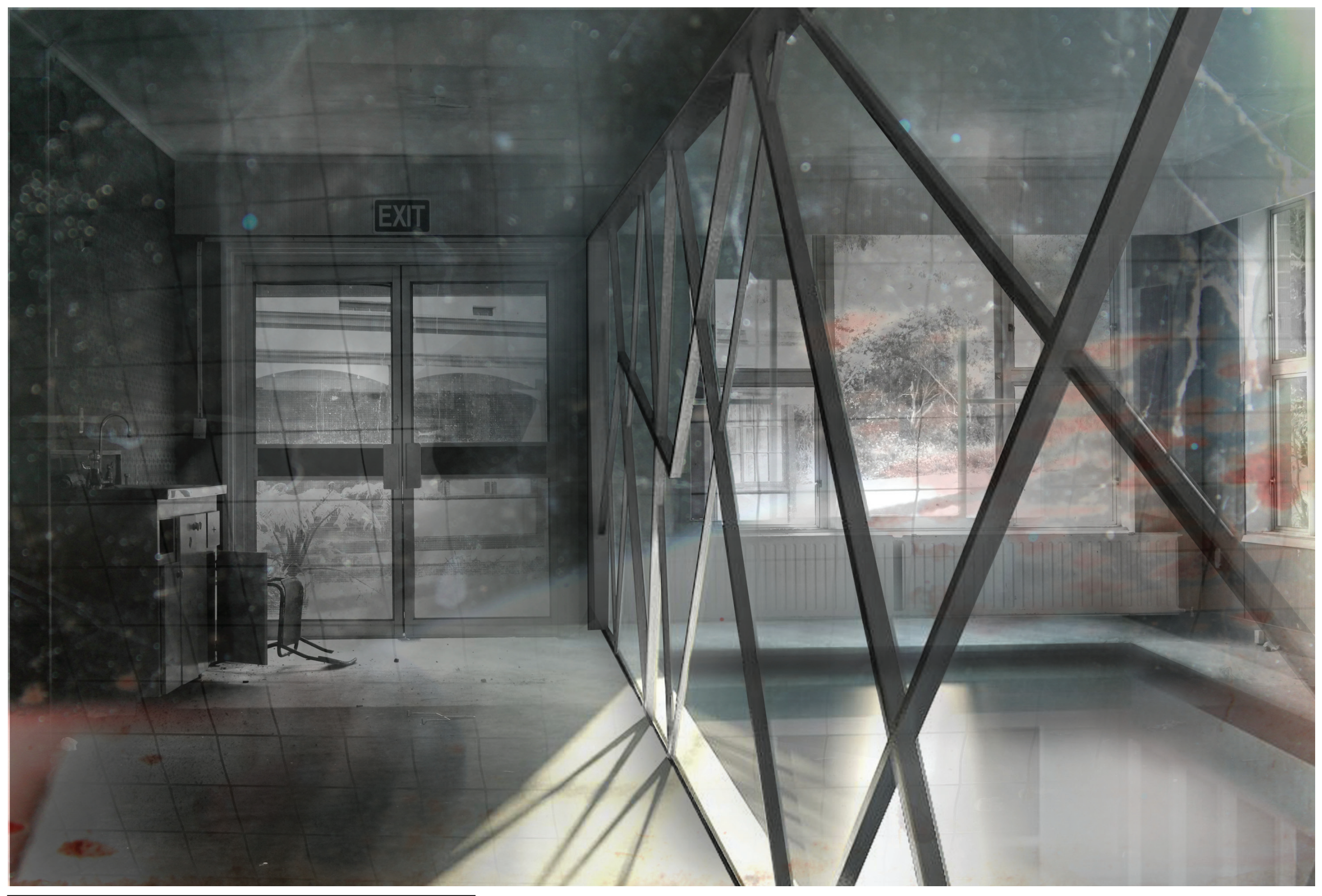




\subsection{Design Rationale}

Both buildings of Wellington's former Fever Hospital are associated with medical practice of the time; during which isolation, segregation, bathing and fresh air were seen as the main means of treatment. These principals shaped the design and placement of the hospital and have become the driving influence behind the implementation of a contemporary program; employing them as the framework for the design of a memorial to the sites history. In this understanding, intangible heritage is treated as the totality of all historically relevant occurrences within the site that remain hidden from public consciousness. The activation of these intangible characteristics will be structured around the design of a spatial narrative; within which experience of isolation, bathing and fresh air stimulate a whole range of physical and sensory experiences. This investigation explores the programs of a bath-house and public performance space, with their disparate relationship being experienced through the spatial narrative. This is intented to activate the site as a component within the social context of the city, while embodying a sense of reminiscence to intangible heirtage; experienced through the spatial narrative.

\subsection{Concept Testing}

This section of the thesis presents the iterative testing methods that this thesis has followed, using each design iteration to test certain charectaristics within the intangible heritage of the site. Peter Downton describes how the value of this iterative and design-led structure lies in its ability to explain ideas, describing it as "a vehicle for aquiring and shaping knowing” able to inform future design. ${ }^{1}$

Throughout these tests light; shadow, material, and narrative are employed as mechanisms to accentuate these less tangible elements. Due to the design-led structure of these thesis, the initial tests of this exploration represent an early period of the research. As such, their programme and function is displayed in a generalised manner. The following sections of this chapter explore these programmatic functions through iterative design testing; using their disparate relationship to enhance the atmospheric experience. 


\subsubsection{Iteration One}

This initial test is structured within the left wing of the Hospital complex, acting as a representation of the two primary programs that have occupied the site. As presented within the previous chapter, the majority of these tests explore an intervention as a subterranean condition. Within this test cross-programming is employed to express the sites intended separation from Wellington's social context; with bathing below the footprint of the existing building, and public space above within the confines of the wing. The relationship between these two disparate programs operates on a vertical axis, employing Zenithal light as a tool to enhance the meaning and identity of the space. As illustrated within figure 53 , this test uses the placement of treatment beds within hospital wing to inform the location at which cuts occur within the floor. These Cuts provide a visual connection between the two spaces. Those within the above space are provided a glimpse into the sensuous climate of heat, moisture, and shadow, while those below are separated from the more public occurrences within the site; both physically and symbolically. The swirling climate of intangible effects within the bathing space acts as an internalized environment, connected to its surrounding context through the faint echoes of sound and shafts of zenithal light.
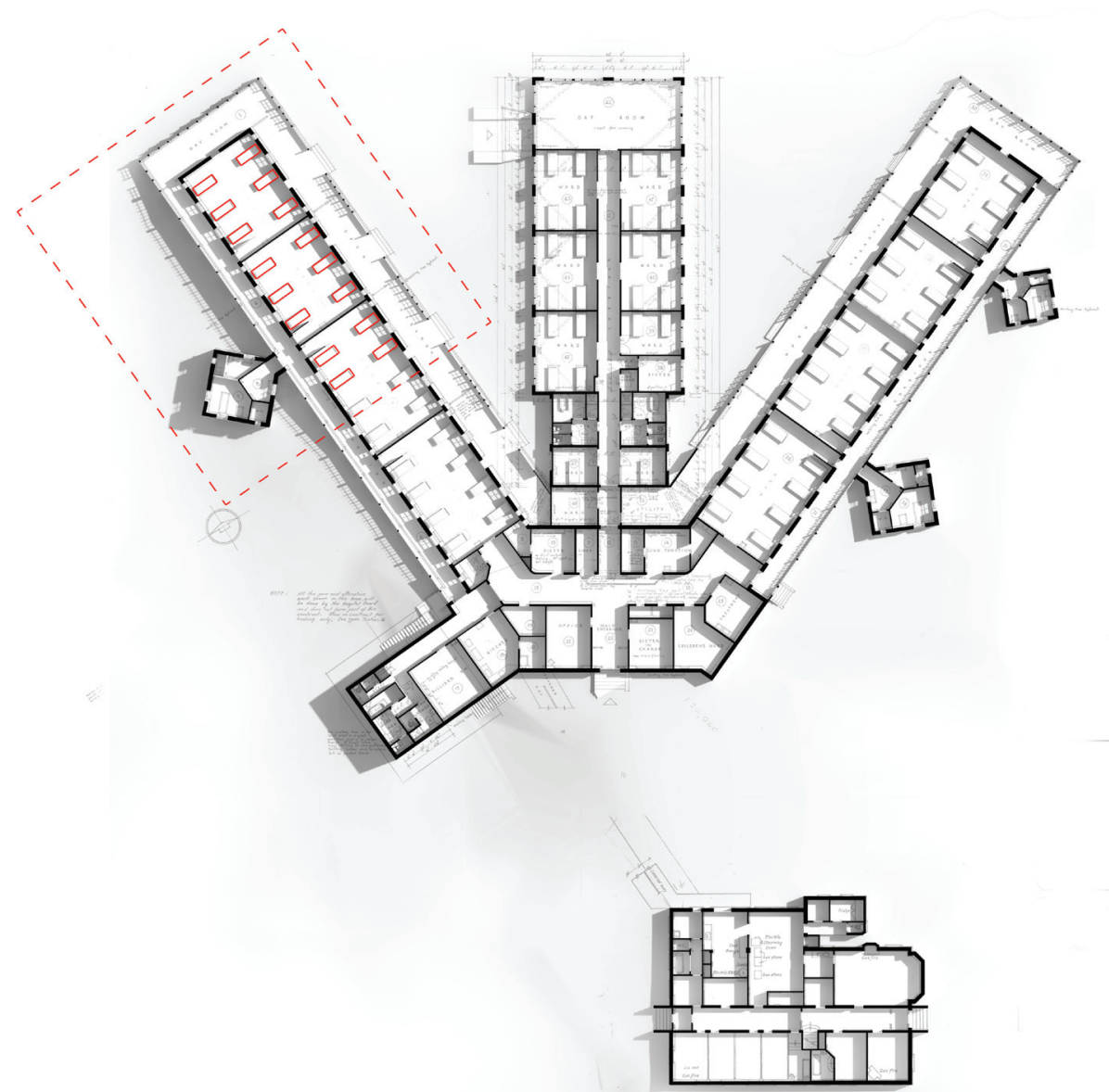

Figure 53: Dotted line outlining test location within existing wing 

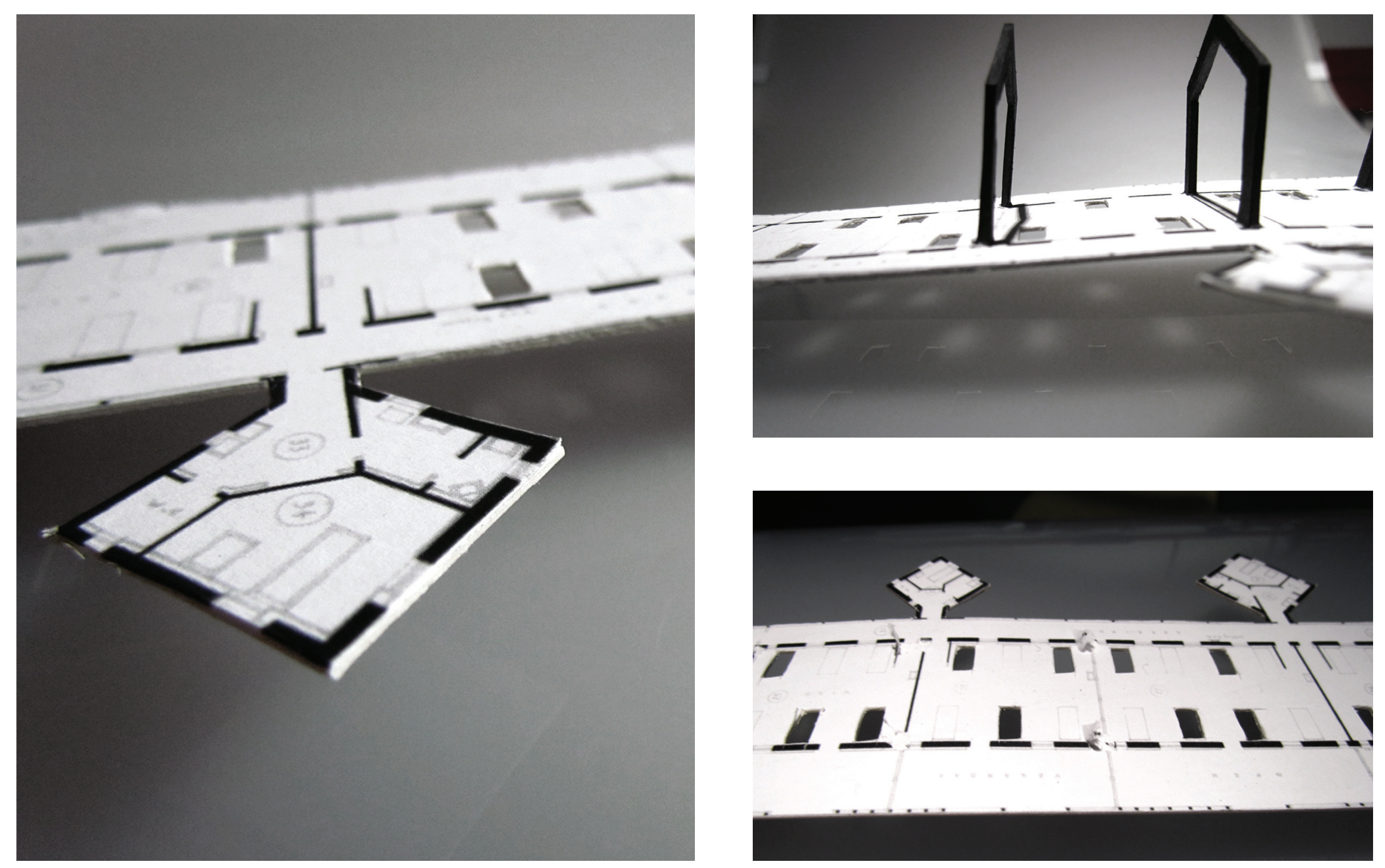

Figure 54: Physical model exploring perforations in floor: 1 
As an early test within the development of this thesis, the programs of this iteration are explored in a generalised manner. The space within the existing wing is represented as a public library, using its civic function to contrast against the sensuous bath-house below.
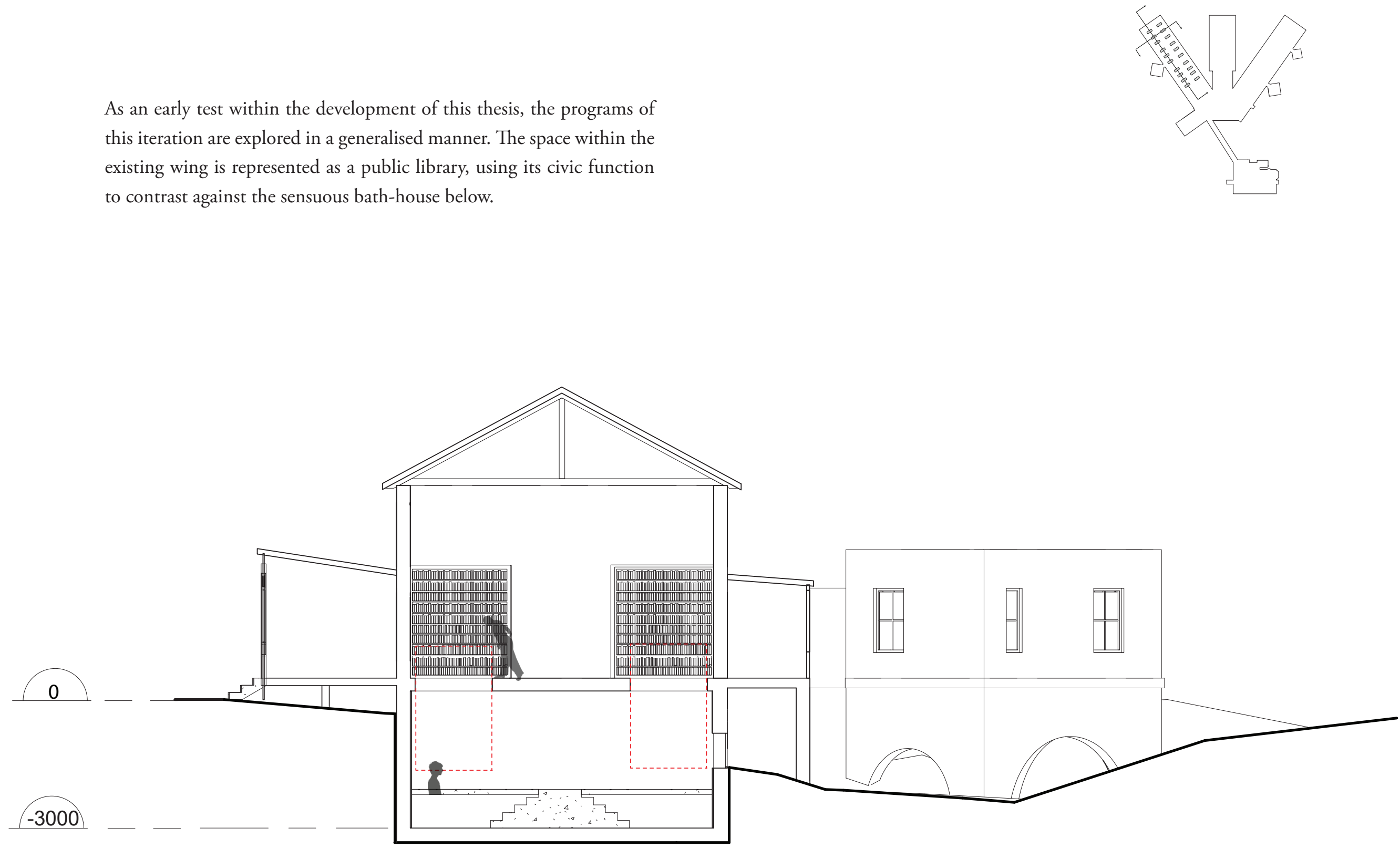


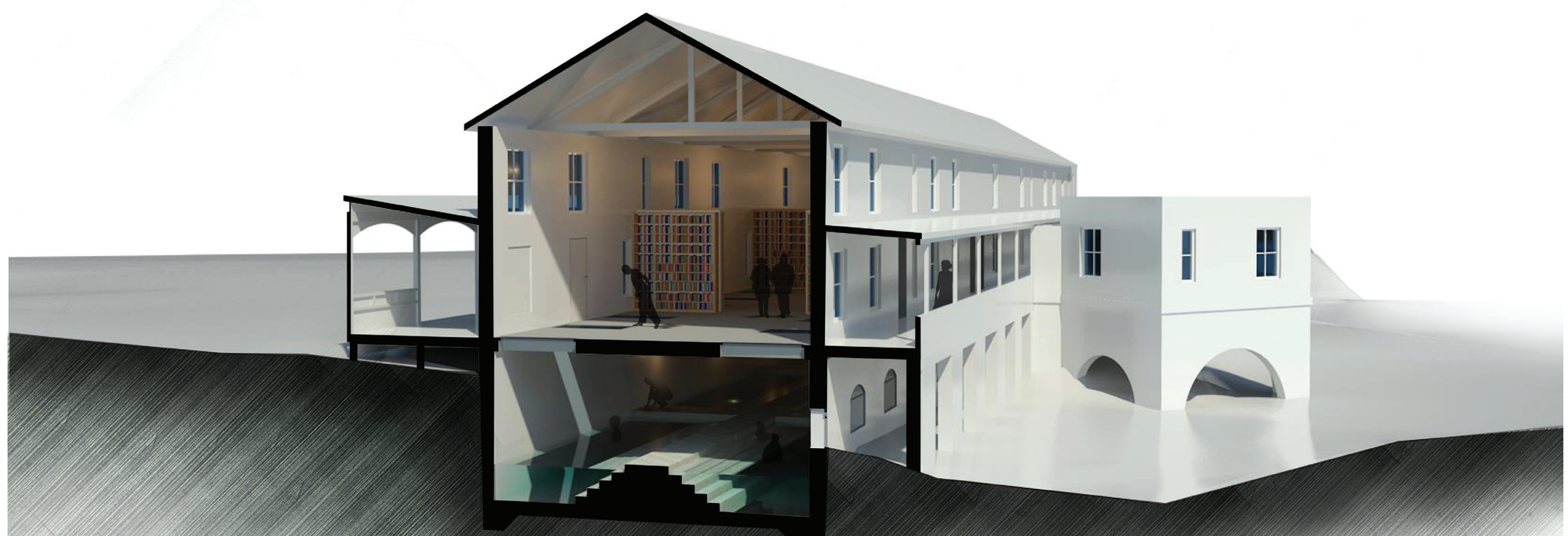




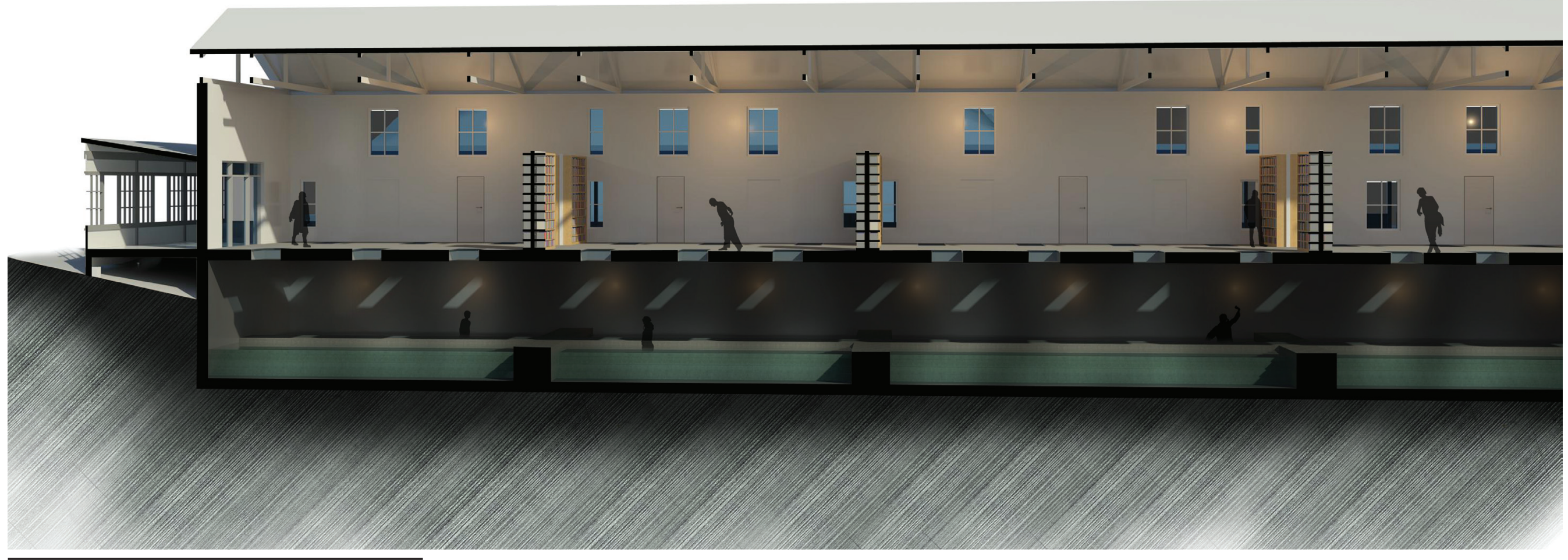




\section{Discussion}

As an initial test within the development of this thesis, this design acts as a brief introduction to the context under which proceeding iterations operate. The approach and spatial layout of this test was influenced by Plummer's discussion on the symbolic nature of spaces that descend below the ground plane; creating a journey informed by memory. Within this subterranean environment, zenithal light is used as a theatrical tool, reinforcing the symbolic and physical isolation that users experience within the sensuous bathing environment. The juxtaposition between light and dark, public and private is intended to establish a programmatic relationship reminiscent of the sites disconnection. This notion of disparate programs will be further explored throughout design development, with the bath-house typology being tested against various civic programs that aim to integrate a public and social dimension to the site.

Figure 60: View from detached underground space up to civic environment

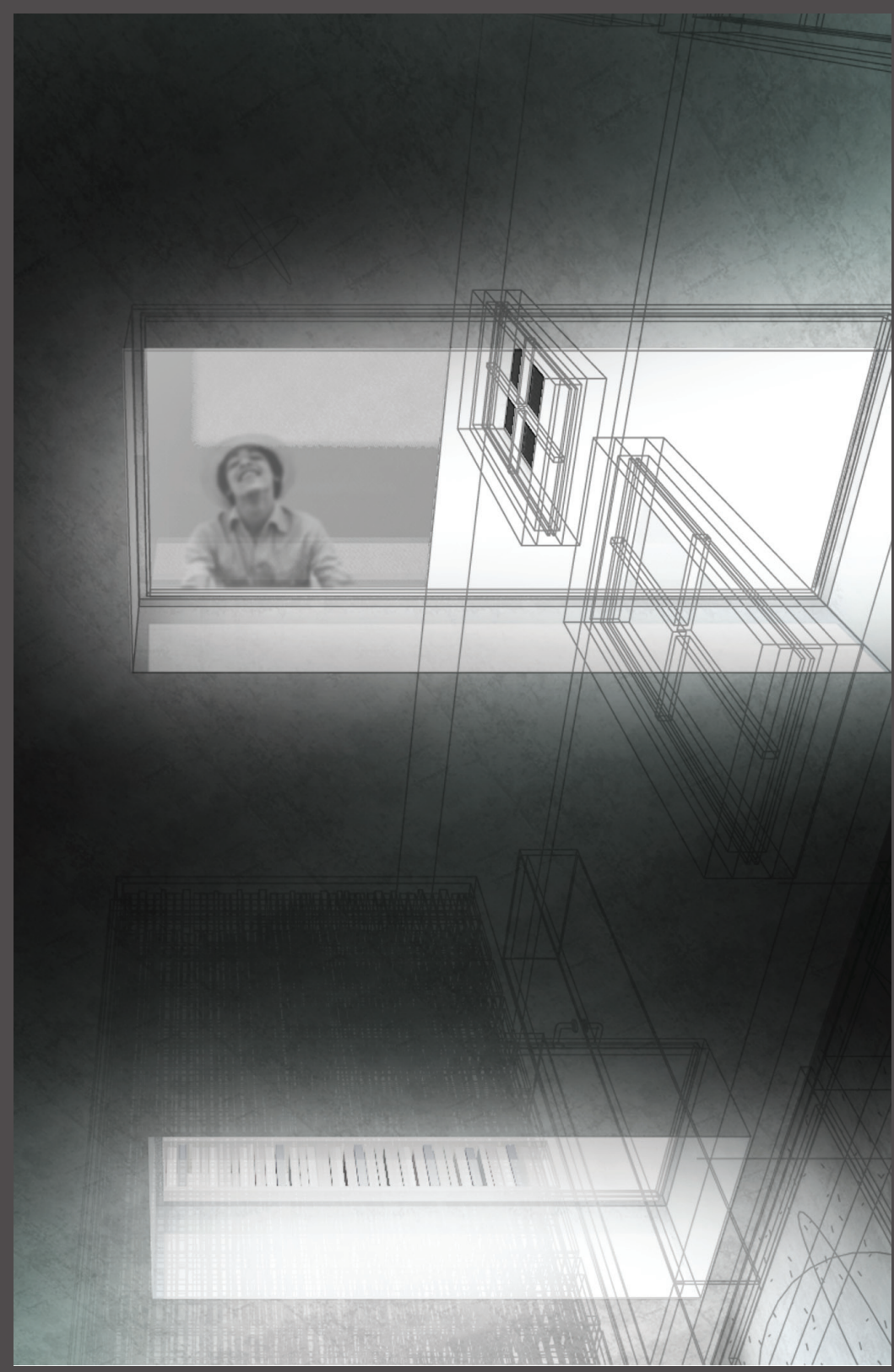




\subsubsection{Iteration Two}

Developing from the first test, this iteration is structured around the design of a spatial narrative; incorporating experiences of isolation, bathing and fresh air in order to stimulate a sense of reminiscence to these charectaristics within the buildings history. Descottes argues that our cognitive capacities interpret spatial patterns more easily, being confused by elements connected without a specific sequence or order. Informed by this understanding, this test employs similar methods to that of the prior, but incorporates narrative in order to actively guide the user through the space. Within this journey, light and shadow play the dominant role in dictating the progression of the user. As illustrated within figure 61, two of the four existing treatment wards are used to inform vertical penetrations through the fabric of the building. The voids created by these penetrations allow zenithal light to filter downwards into the bathing space below; constructing a theatrical setting that leaves the city and its social context as a distant reality. The first of these voids directs attention to the access point, inviting the user downwards into the subterranean space. Within the space the second of these voids is visible but inaccessible, in order to enter the second void one must first descent another level below the existing building; the void acts as the climactic point within the journey. Informed by the spatiality of Libeskind's Jewish Museum, this void provides space for the user to reflect on the intangible heritage that underpins the building.
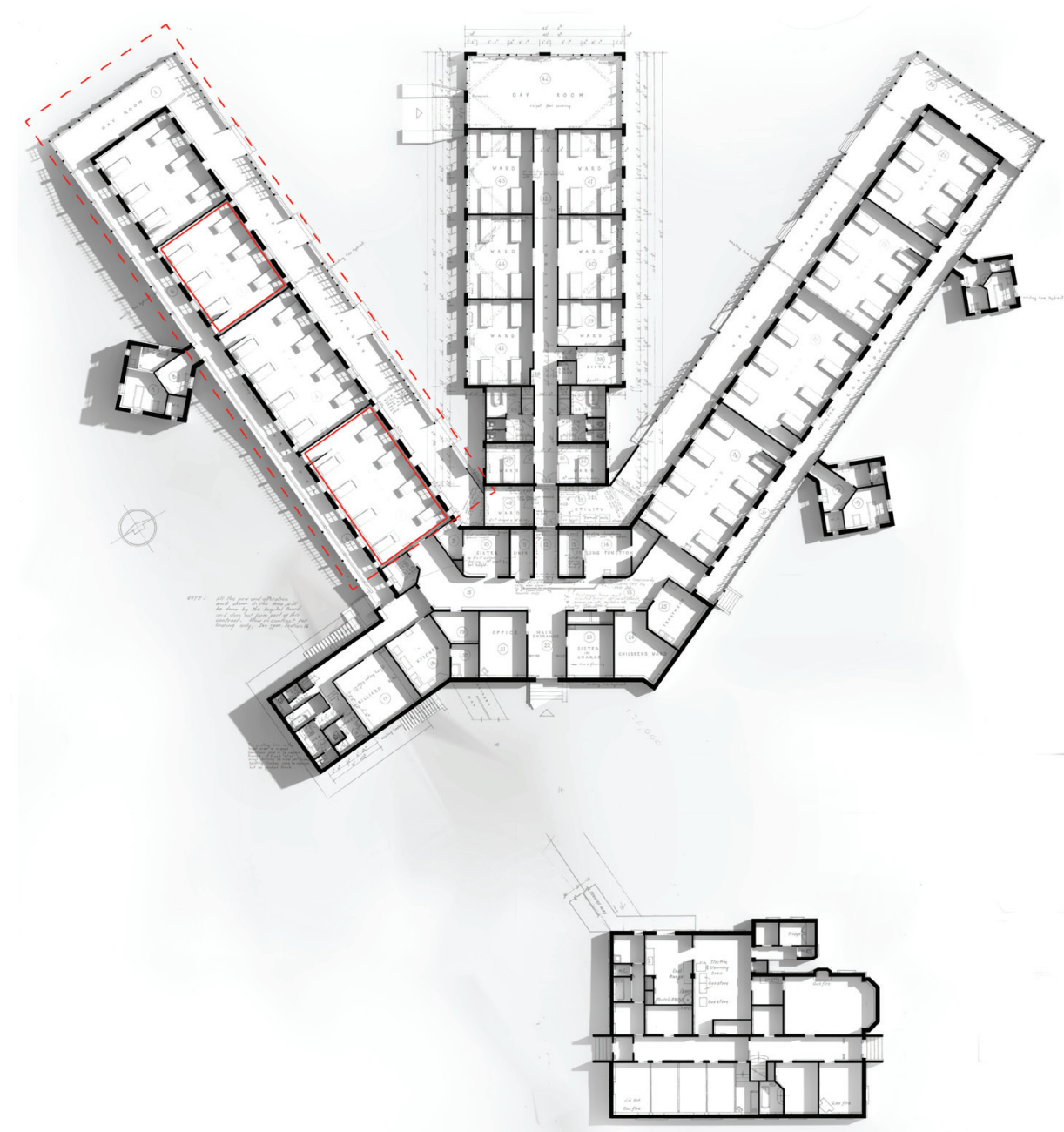

Figure 61: Test lcation diagram 


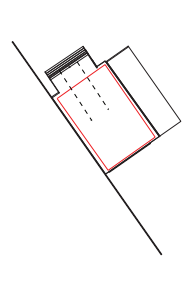

Level -02

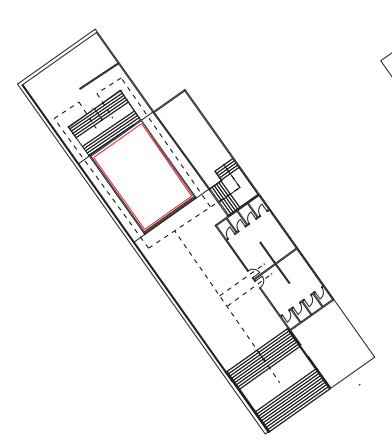

Level -01

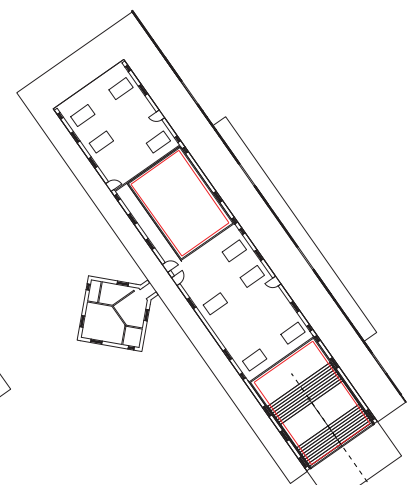

Level 00

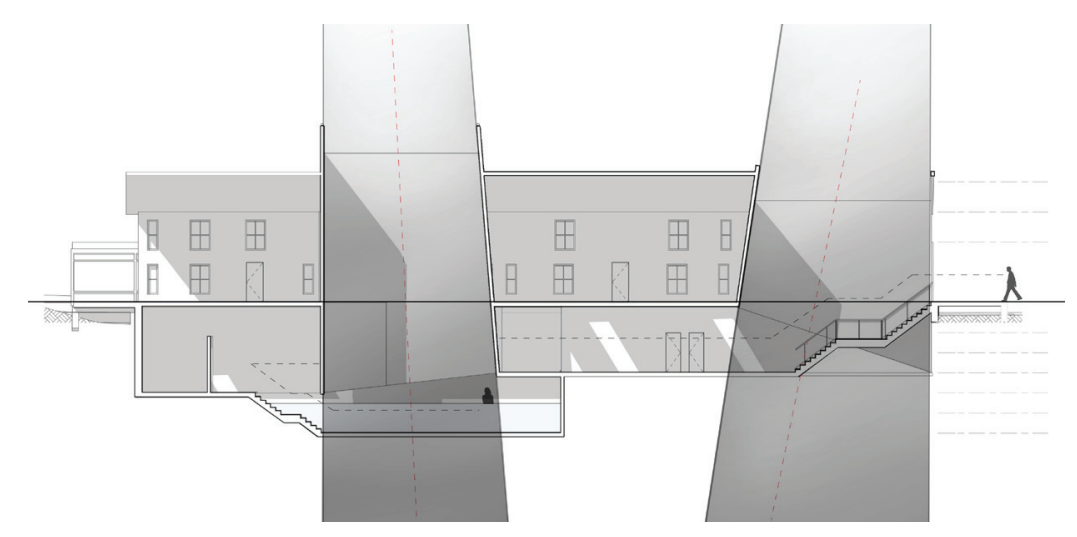

Figure 62: Floor plans illustrating location of voids

Figure 63: Diagramatic longitudinal section
Informed by the concrete blocks within Fehn's design of the Hedmark Museum, these voids penetrate vertically through the structure and act as the primary source of natural illumination. Existing windows illuminate the ground level, while the voids cut through the roof and provide zenithal lighting for the subterranean space. These follow the gable form of the existing roof structure, but extend above and remain unglazed in order to admit air and sound within the below space. 


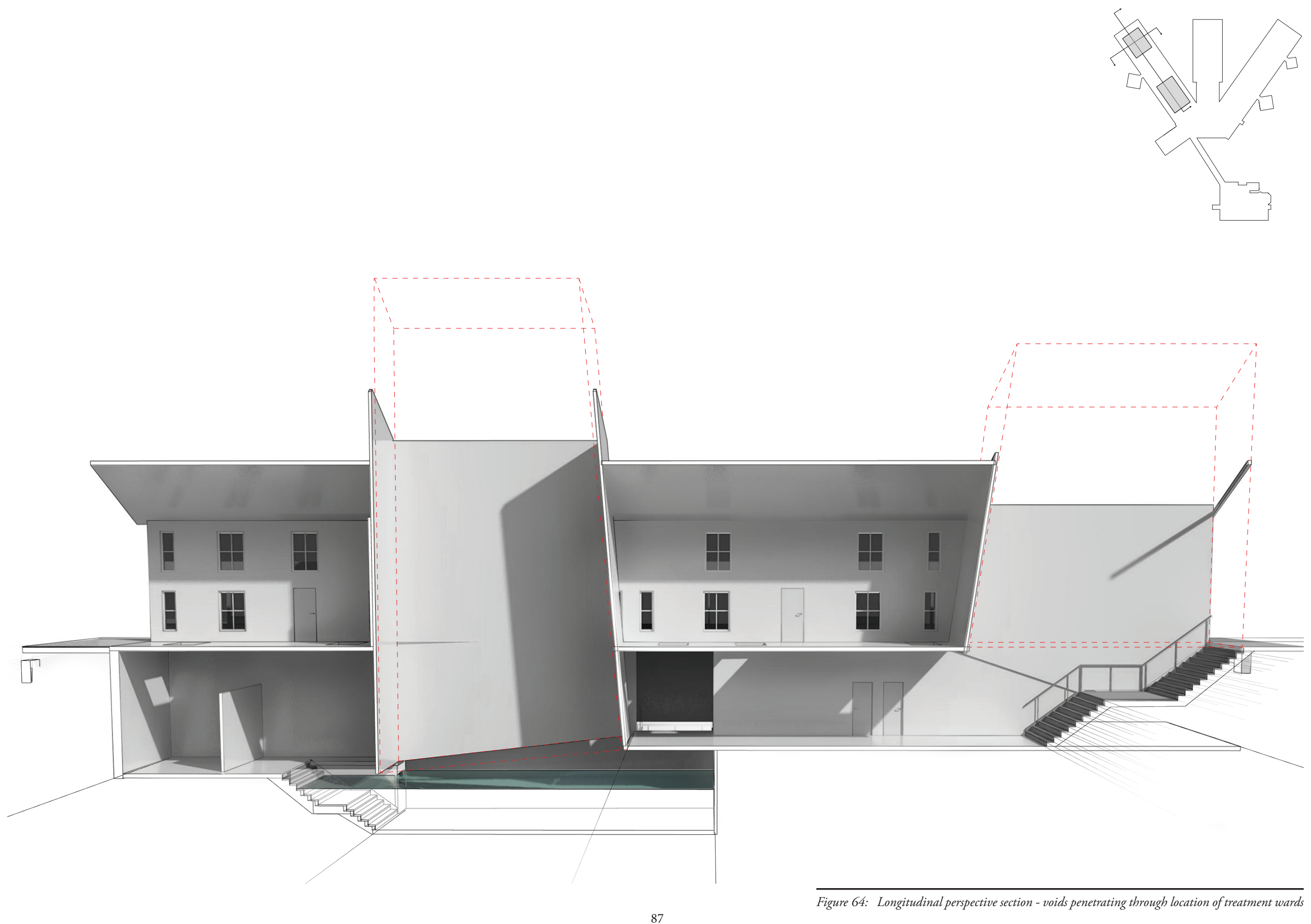




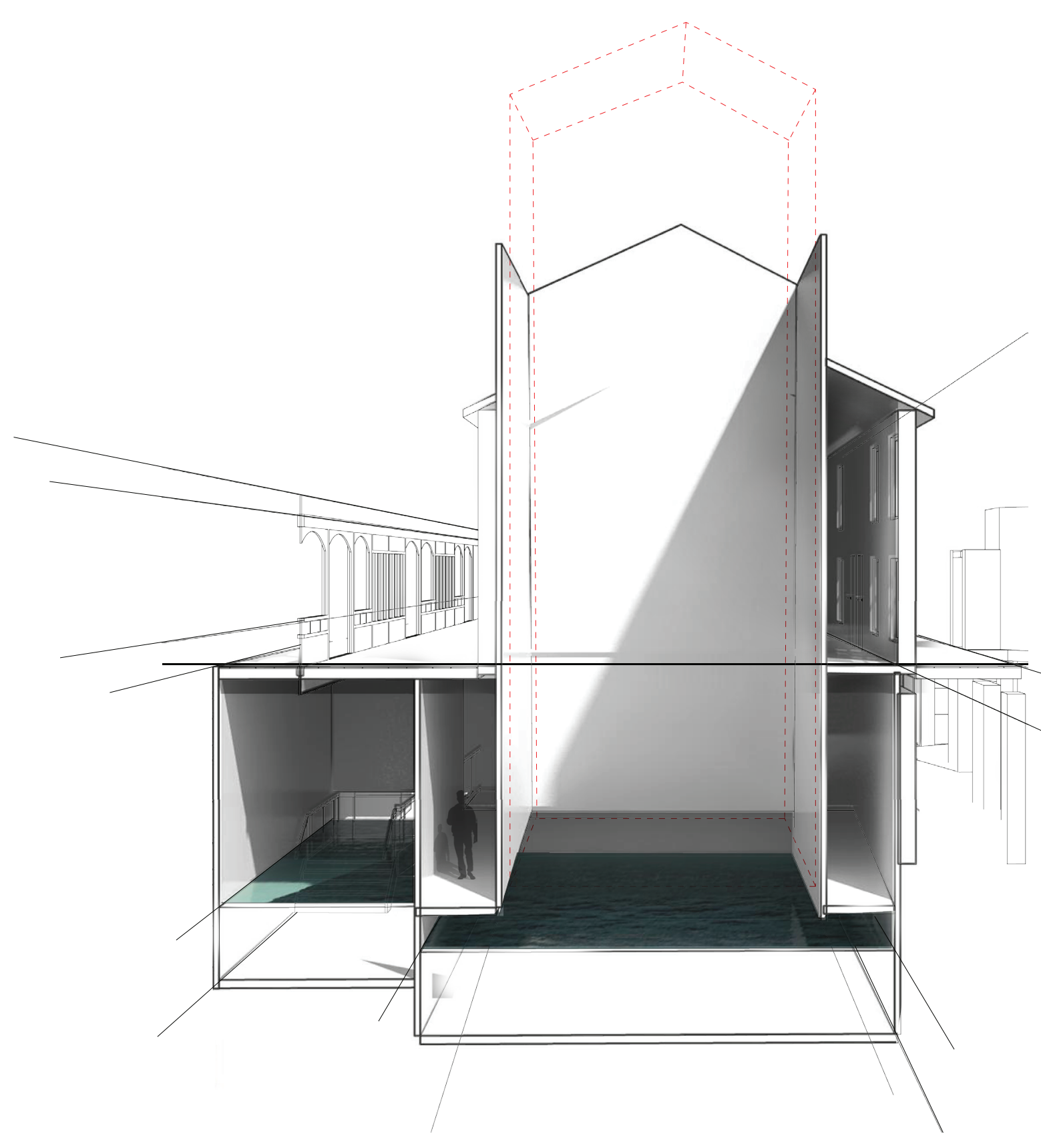

Figure 65: Cross-sectional perspective section showing descent into climactic space 


\section{Discussion}

Within this second test the experiential dimension of bathing was explored using atmospheric conditions of narrative, light, and shadow. The spatial layout within this was informed largely by Libeskind's Jewish Museum, testing the vertical connectivity between the site and the space that lies beneath the footprint of the building. However, differing from Libeskind's approach, within this iteration the spatial layout conforms to the dimensions outlined by the footprint of the existing building. This aims to generate spatial conditions that are reminiscent of the narrow and confined circulation patterns within the treatment wings of the original Fever Hospital. This test has explored bathing as a subterranean experience informed by atmospheric qualities of light, shadow, and narrative. The proceeding iterations will continue to explore the role of bathing within the construction of aesthetic remembrance, but address the role of material and aim to progress in resolution and complexity.

Figure 66: Climactic point within the journes

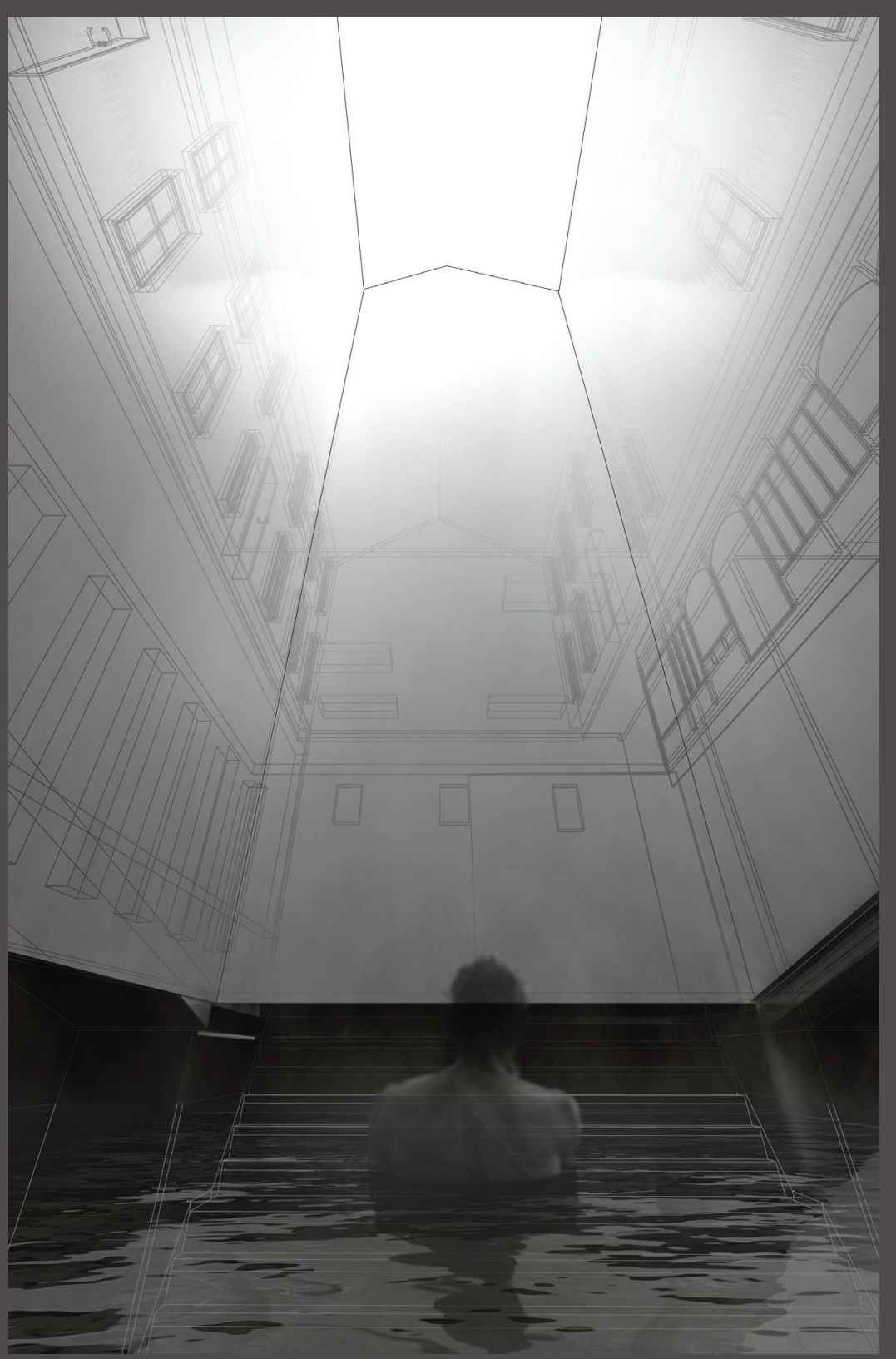




\subsubsection{Iteration Three}

Developing from the previous test, this third iteration explores the wider context of the site and establishes movement patterns that guide the user toward the primary access point of the design. This journey aims to separate itself from the existing linear patterns of the site and impose a progression that follows the movement of both staff and patients within the original Fever Hospital. As illustrated within figure 69, these movement patterns are segregated with patients able to access the surrounding outdoor space of the building but confined to the wings of the hospital. This design is placed within the confines of these two primary treatment wings, using the central addition of 1973 that sits between their span to inform a dramatic descent that leads below their footprint.

Informed by Plummer's position on narrative and case study analysis, this iteration inscribes a subterranean journey within the enduring physical traces of Wellington's abandoned Fever Hospital. Within this test fragmentation is used as a design tool to disrupt the linearity of the existing site. This method is informed by Juhani Pallasmaa who argues that the architectural fragment acts as a powerful tool in the recovery of memory. "Ruins and eroded settings have an especially evocative and emotional power; they force us to reminisce and imagine." In this understanding, when constructing reminiscence within an existing site
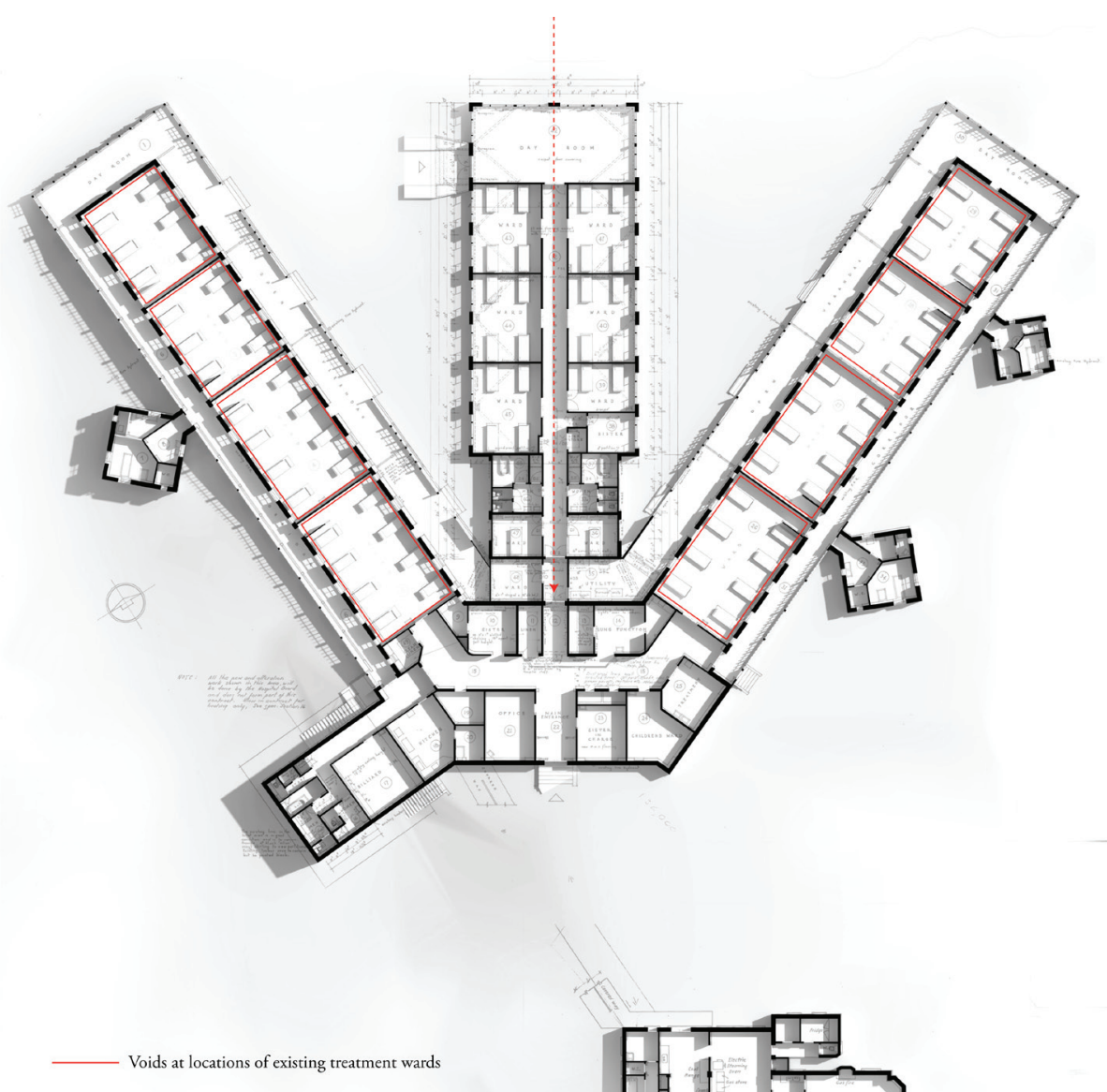

Descent informed by central corridor of late additio

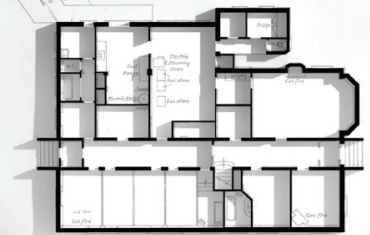

Treib, M. (2009). Spatial Recall: memory in architecture and landscape. New York: Routledge, p21 
the enduring physical traces and fabric of the building aid in the activation of intangible heritage, used as a prop to expand and reinforce the memory created.

The path of this journey creates a curvaceous form that cuts between the two buildings and navigates around the border of the site, communicating the fragmented remnants of the building before directing the user inward between the wings of the hospital. At this point, the user is faced with the long descent below ground level toward the apex of the two wings, entering the stage on which intangible heritage is to be performed; stimulated by atmosphere and architectural form. This subterranean environment is connected to the site through seven vertical voids that sit within the remnants of the building, placed at the locations of the treatment wards. Informed by the treatment methods of the hospital, these voids articulate experiences of isolation, bathing, and fresh air. The materiality of this environment consists of large exposed concrete surfaces, creating a cold and detached atmosphere that prompts users to seek solace within the warmth of the pools. The sensuous and swirling climate of these isolated bathing spaces acts as the climactic end to the journey. As one sits within this detached environment, isolated from the social context of the site, they are confronted with the intangible heritage that underpins the design; reinforced by dramatic conditions of light, shadow, and material.

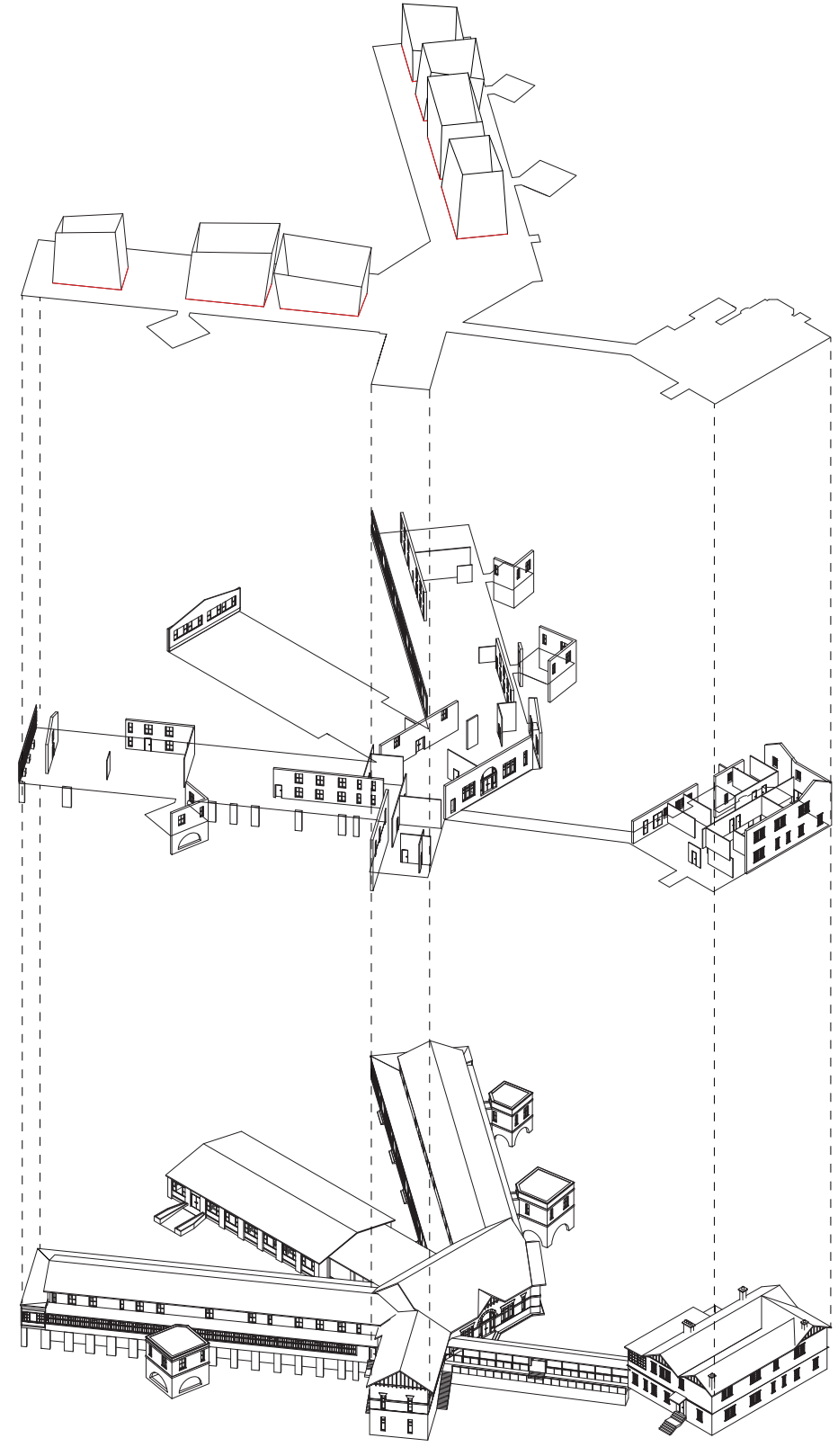

Figure 68: Exploded isometric - fragmentation and voids 

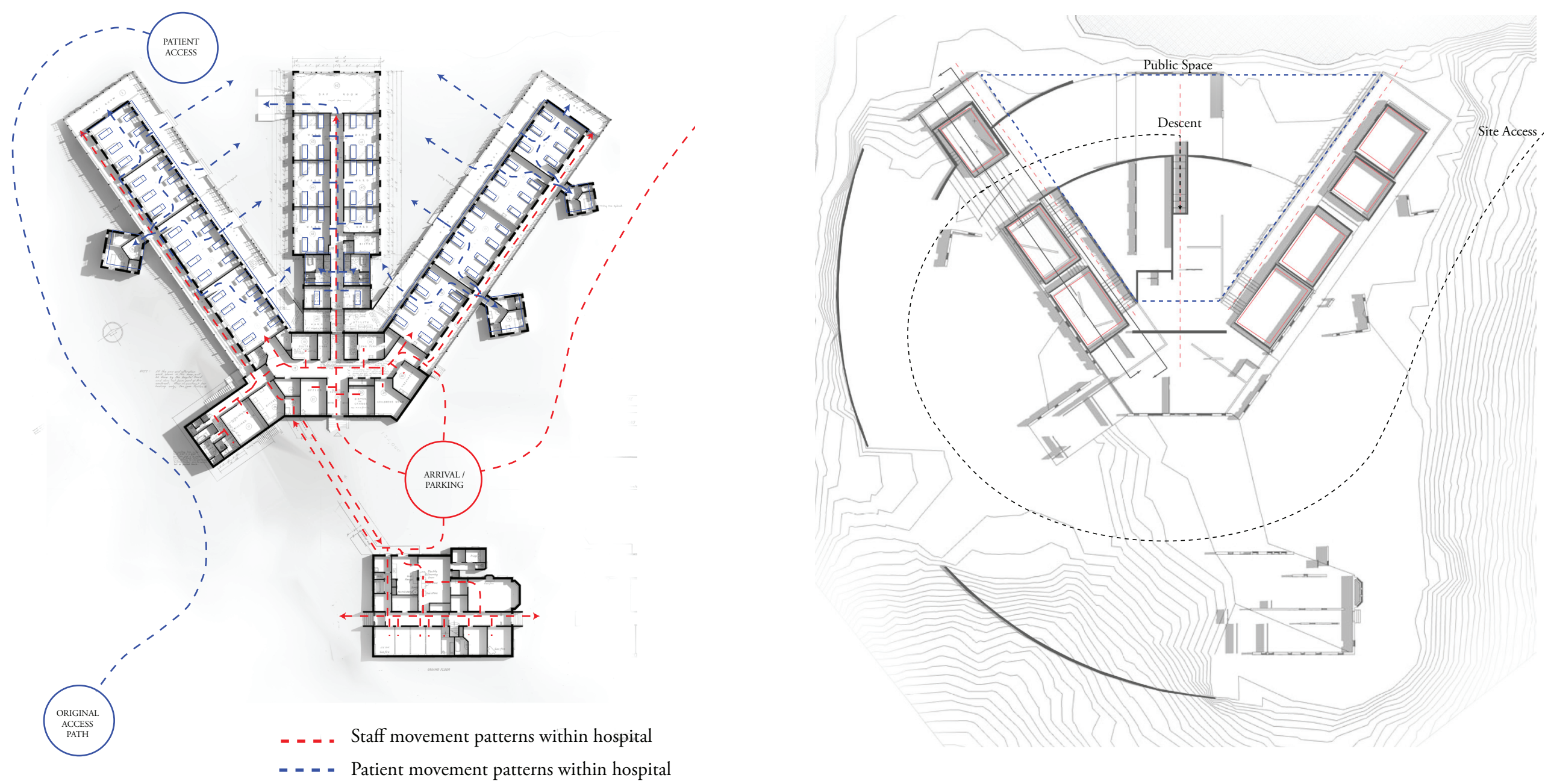

Figure 69: Movement patterns - informing progression around building

Figure 70: Diagramatic plan illustrating curvacious walls and access 

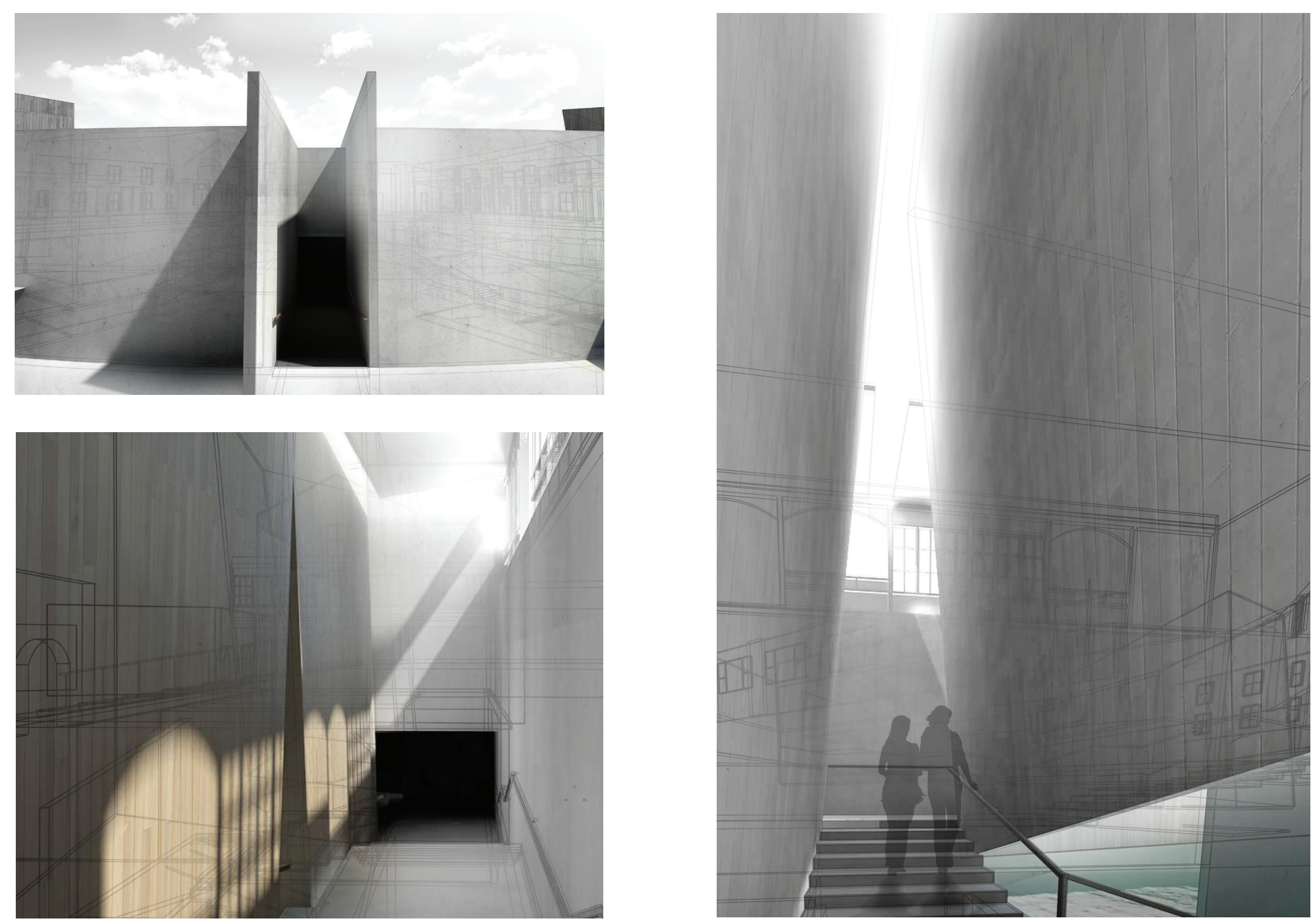

Figure 71: Descent pathway to subterranean space

Figure 72: Shadows cast downward by existing building

Figure 73: Access to bathing space 


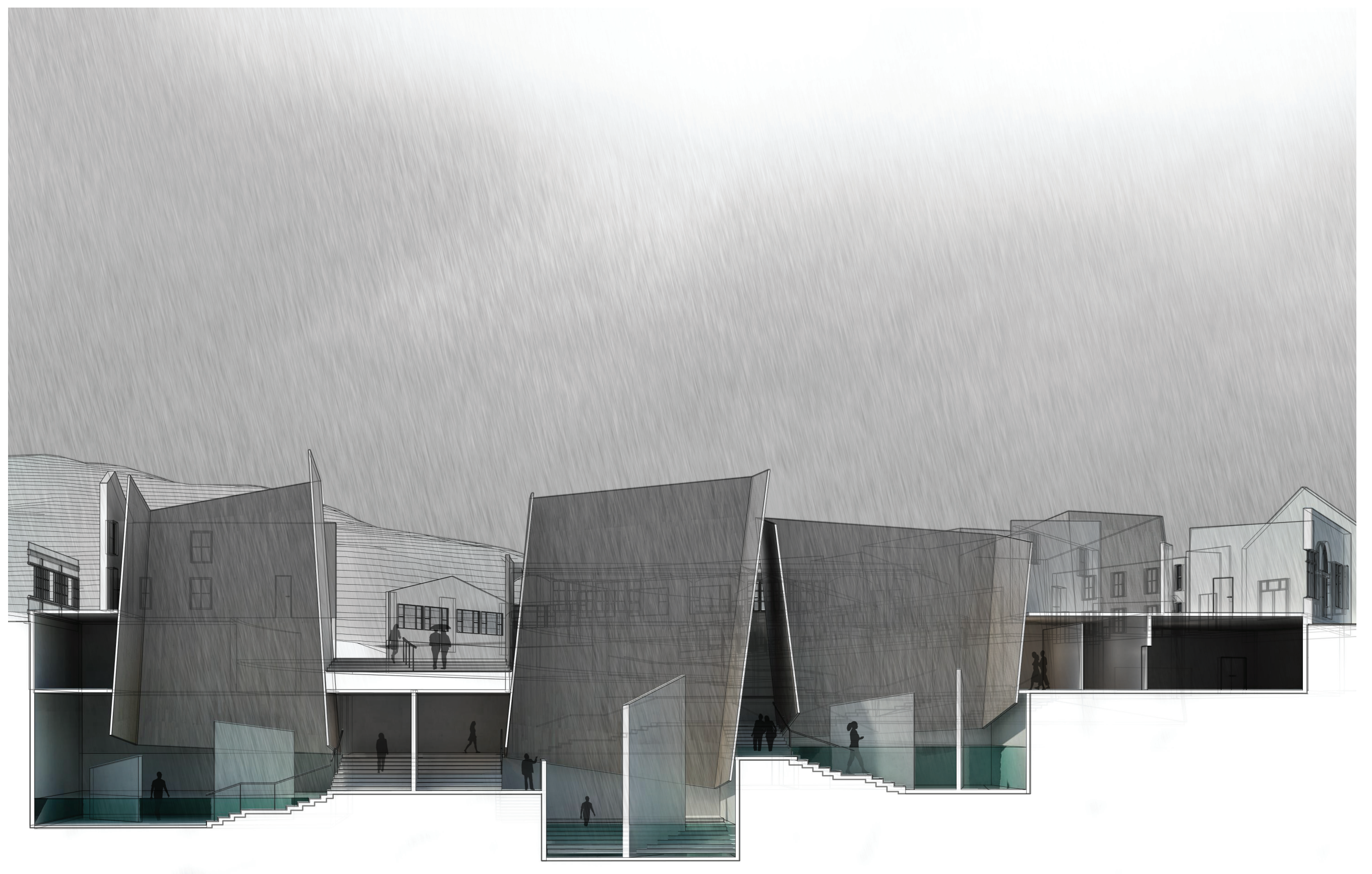




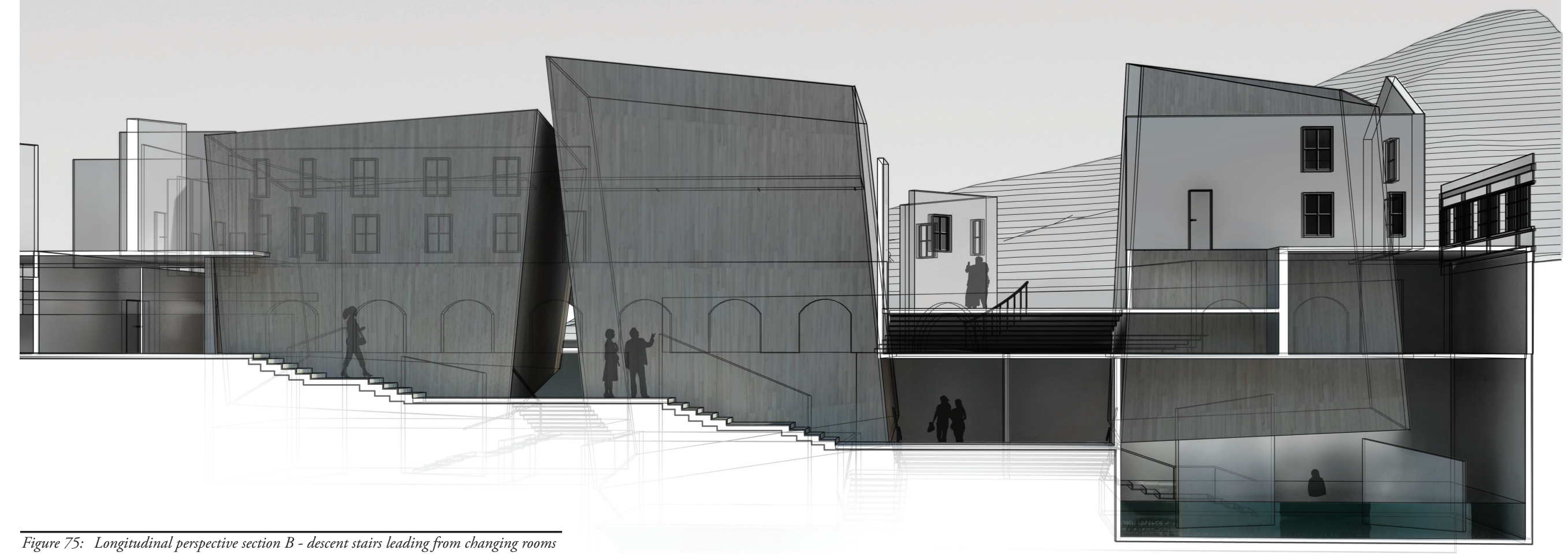




\section{Discussion}

This third iteration provides a spatial experience focused toward a specific journey. The approach to site is an expression of this. Upon arrival, the user is immediately drawn into a progression that slowly moves around the existing building. This movement pattern shifts the experience of site from a meandering and interrupted interpretation of both existing and intervening form to a formal expression of the relationship between the two that slowly unfolds. Within the activation of intangible heritage, this formal narrative allows the user to interpret the reminiscence attached to the design more easily. The fragmented approach to the existing building allowed this journey to infiltrate its fabric, but lacked an intimate relationship to the experience. While this research seeks to de-privilege the tangible remains of the building, this fragmented approach left the building far removed from its original state. Following this, the existing fabric will remain intact at points that intervening design does not interfere. This iteration acts as the final development within the testing of design strategies. The following section will present the developed design of this research, informed by qualities of light, shadow, materiality, and narrative discussed throughout iterative testing.

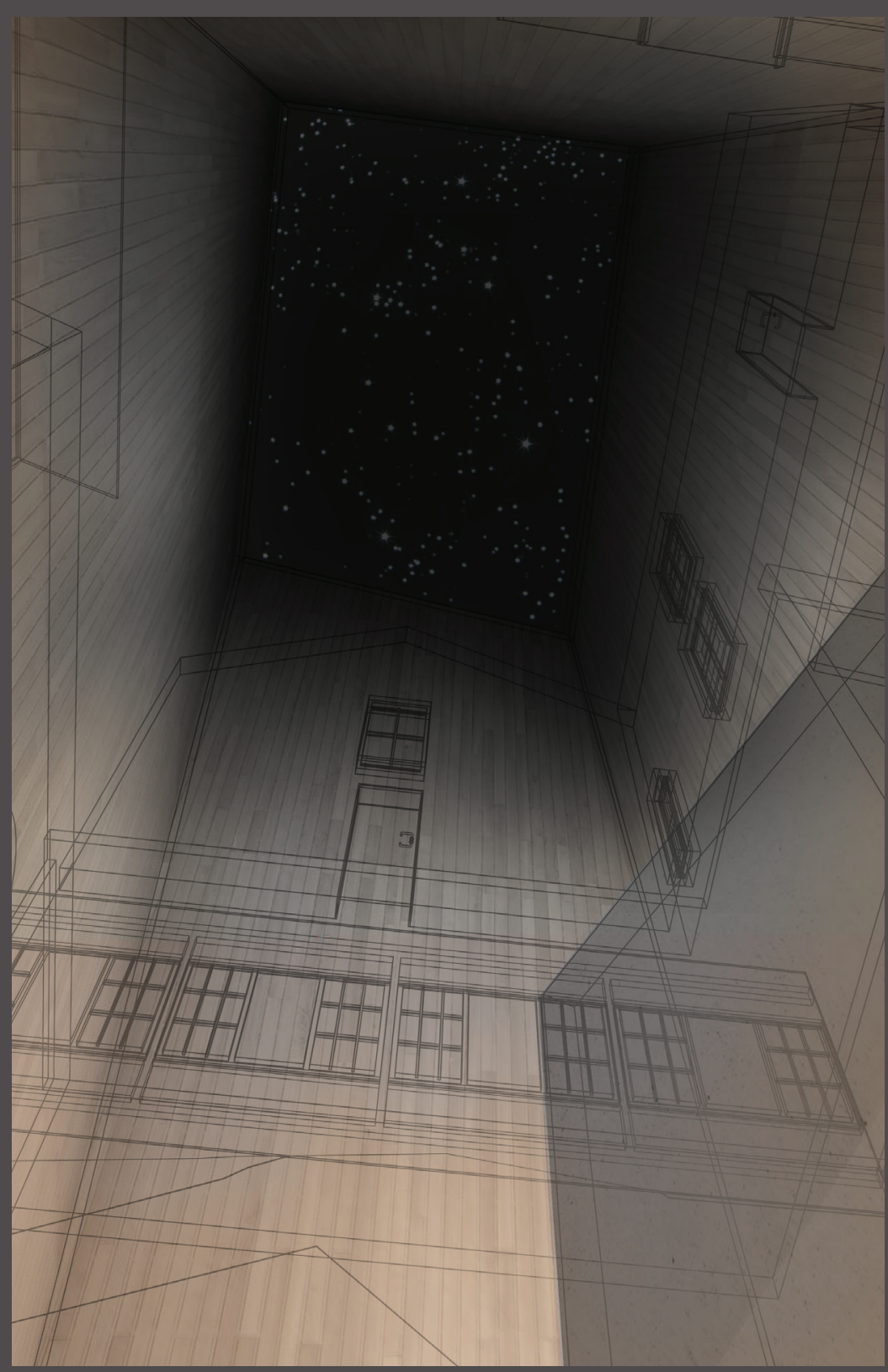




\subsection{Developed Design}

This section of the thesis presents the resolved outcome of the design as informed by previous iterations; employing light, shadow, material, and narrative as key elements in the activation of intangible heritage within Wellington's abandoned Fever Hospital. Informed by the previous iterations, this design focuses on programmatic disparities and veritcal disconnection, structured around a formal journey, in order to construct an experience of reminiscence. Within Erratic: visual impact in current design the narrative of modern museums is presented through the dramatic structure of a classical play, divided into five parts, or acts; exposition, rising action, climax, falling action, and denouement. ${ }^{1}$ These five acts allow the story to follow a linear progression and maintain the focus of the audience. The design of this thesis adopts this dramatic structure, seperating its atmospheric experience into five distinct acts. Within this narrative programmatic function plays a prominant role, used to construct reminiscence to the disconnection that underpins the site. This is achieved through a mixed-use civic space, integrating a public realm to the abandoned site of Wellington's former Fever Hospital that is currently neglected, forgotten, and fully separated from all city function. A multi-purpose open air auditoria space sits between the existing wings of the building; accomodating the social dimensions of dance, music,

$\overline{1}$ Robert Klanten, F. S. (2011). Erratic: visual impact in current design. Berlin Gestalten, p5 drama, and film. While a public bath-house occupies the subterranean space below the footprint of the building.

While these programs operate independant of one another and provide access points specific to their use, the dramatic narrative leads the user throughout aspects of both and uses their disparate relationship to generate reminiscence. It is the dynamic journey that one follows that activates the intangible heritage of the site, experienced through the progression of varying atmospheric qualities and spatial conditions. Visual connection to the physical traces of history is used to enhance this historical narrative. This section of the thesis first briefly illustrates the primary elements of this design, before presenting the final journey; a progression through the intervening elements of the design, seperated into five distinct acts.

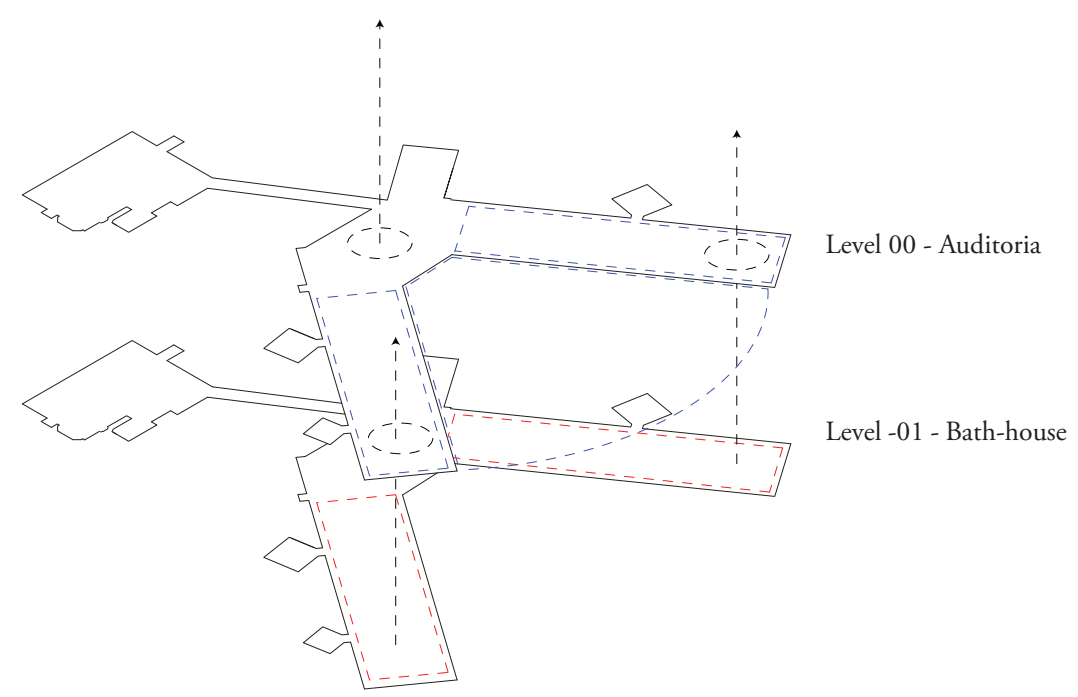

Figure 77: Isometric illustrating programmatic placement 



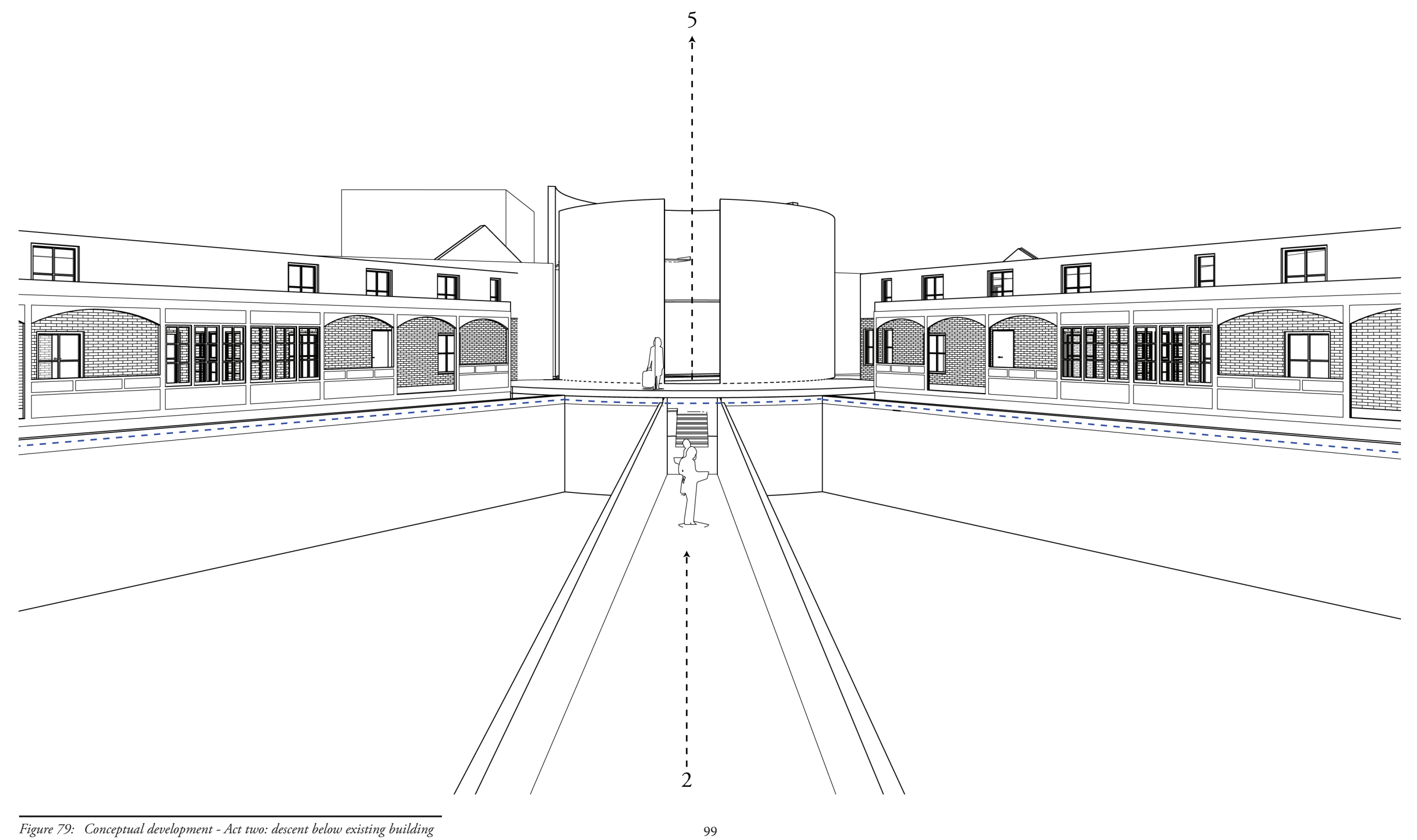



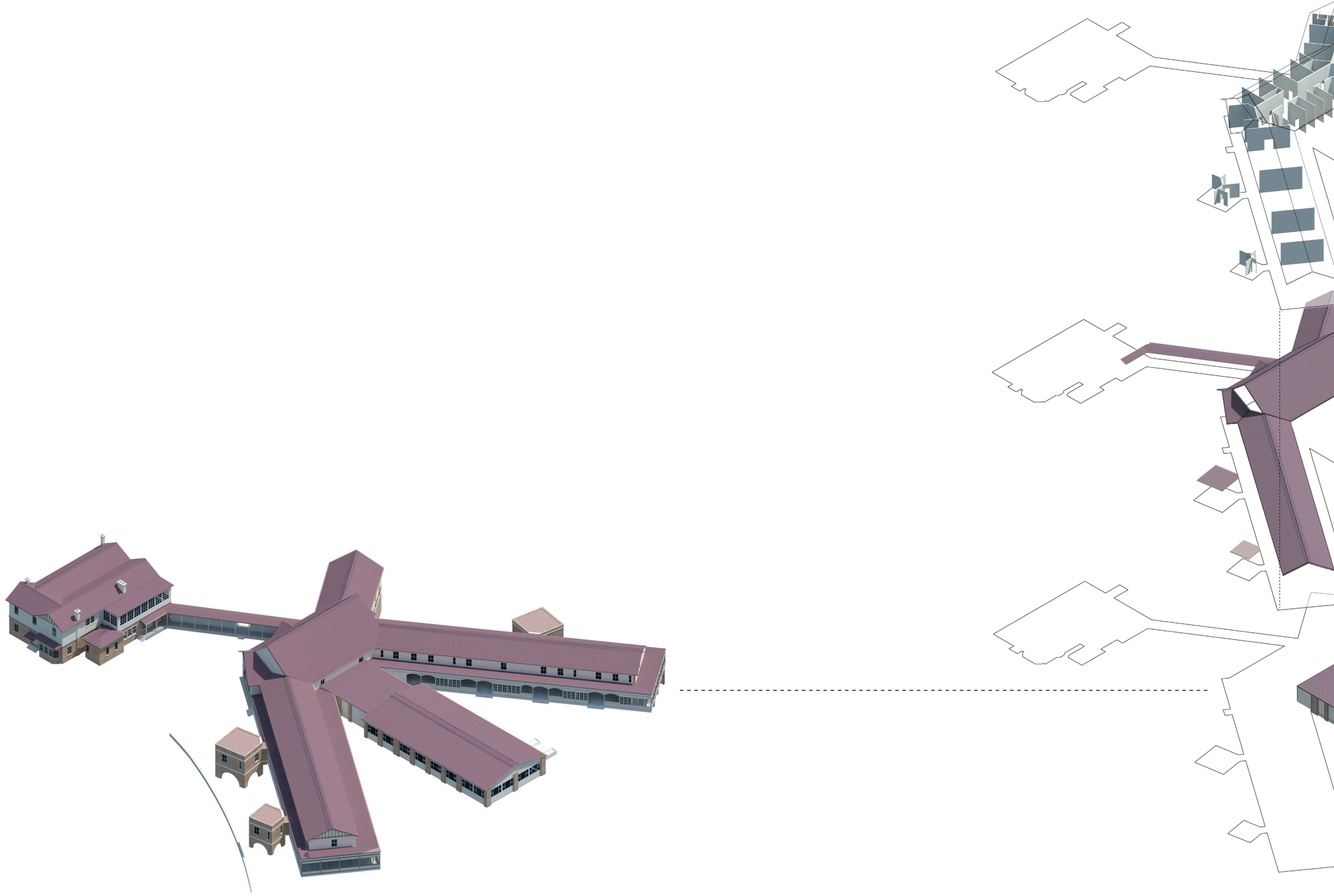

Existing building complex 


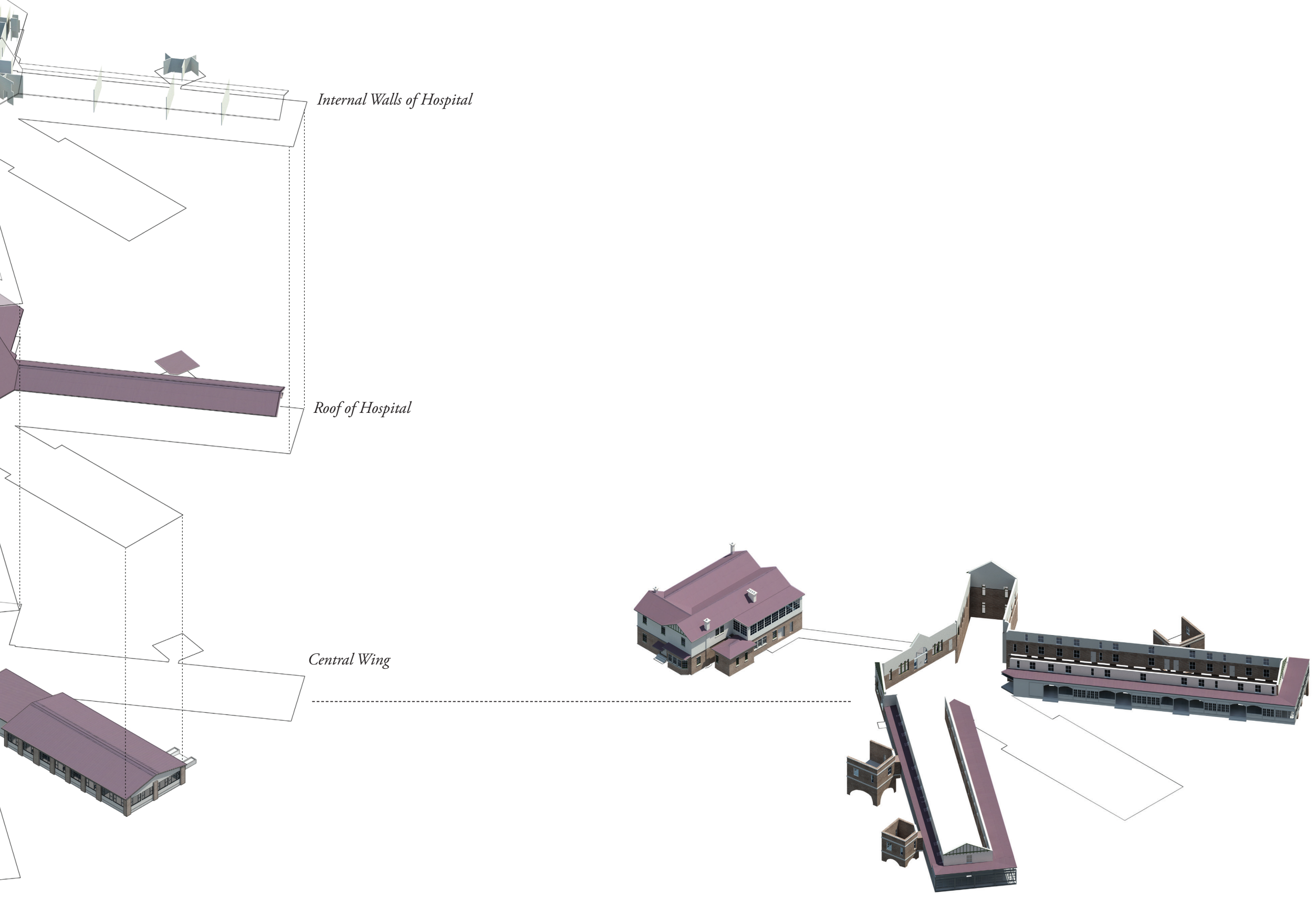



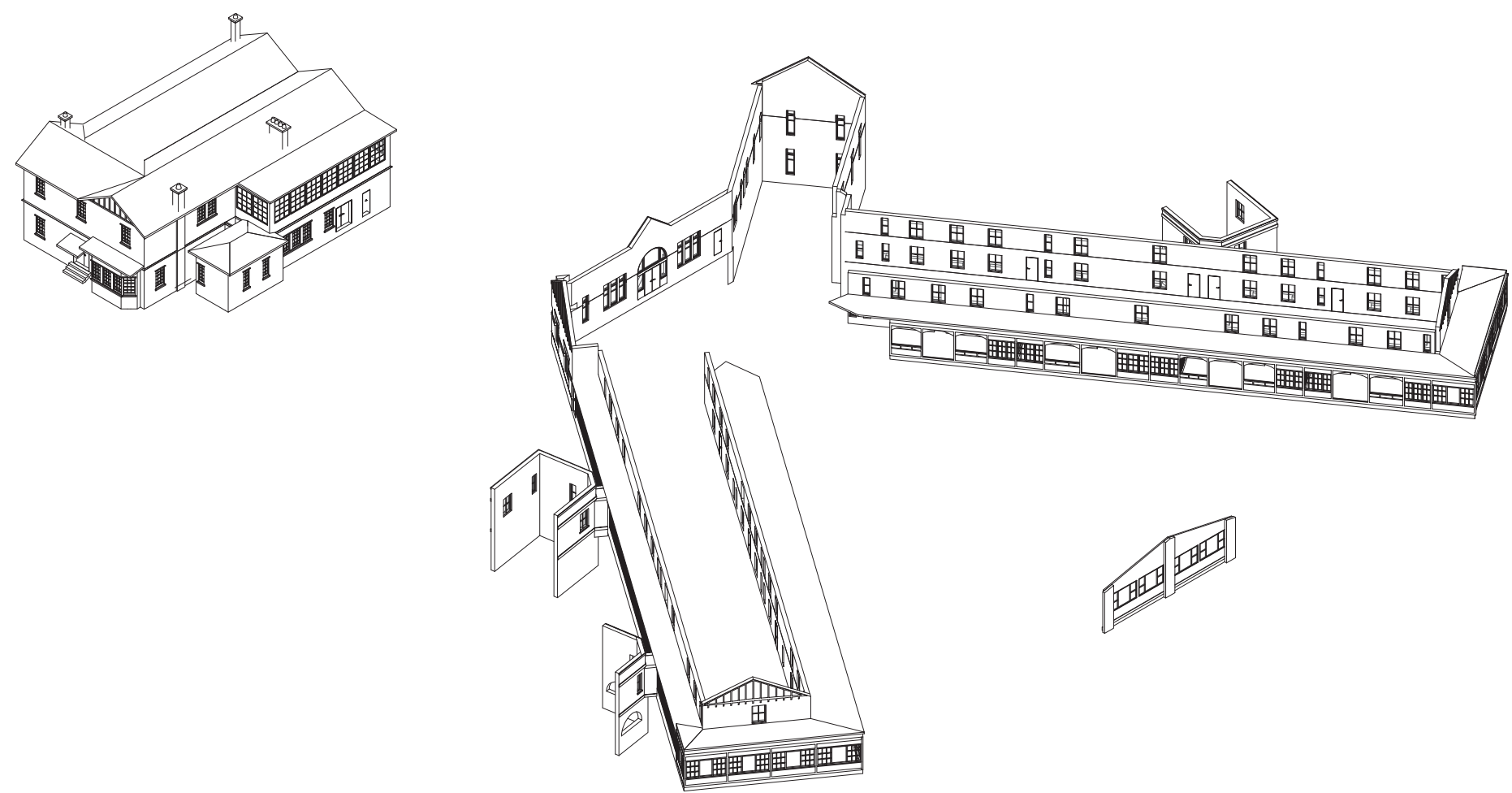


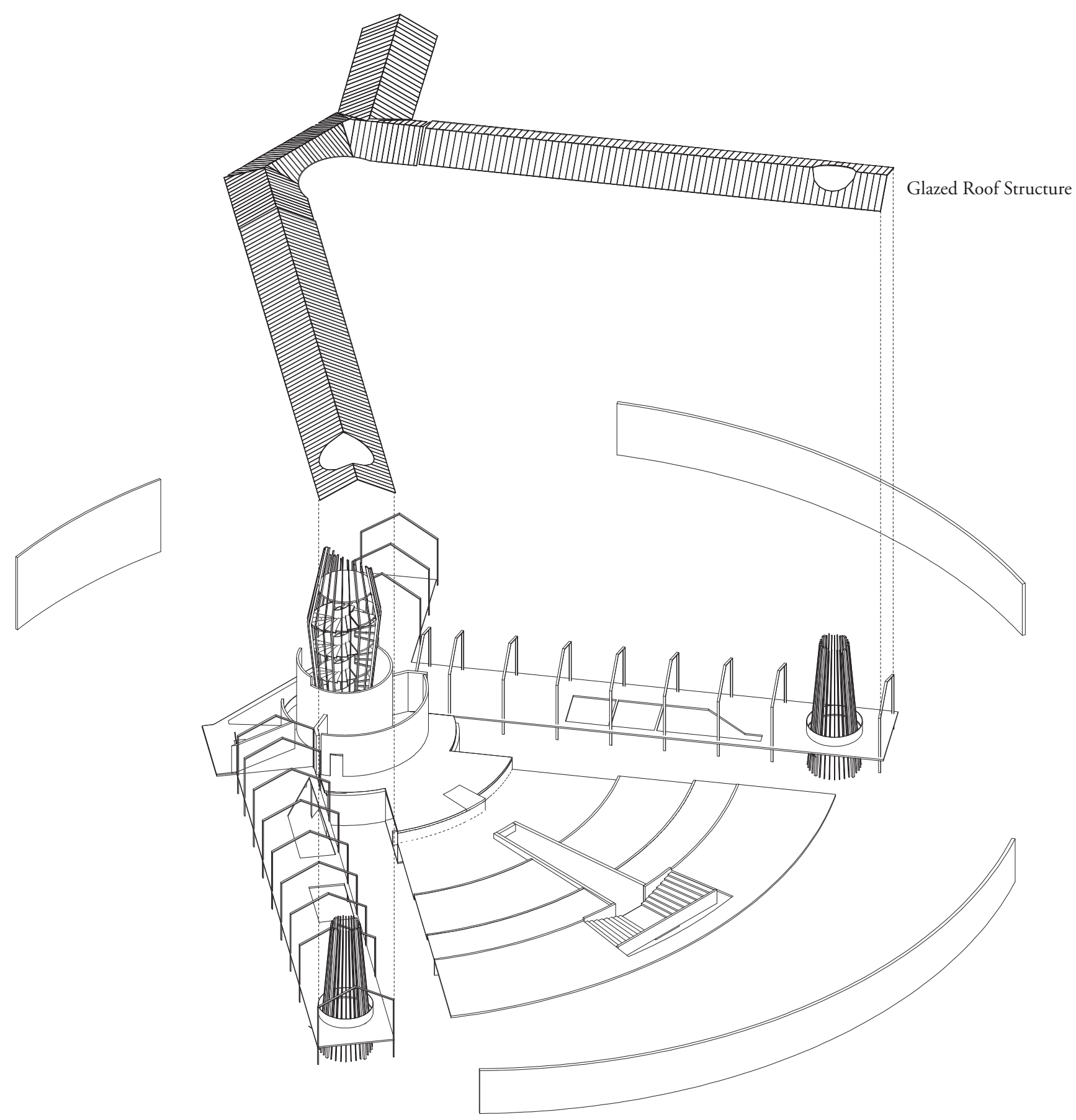

Intervening: Above Ground Level 

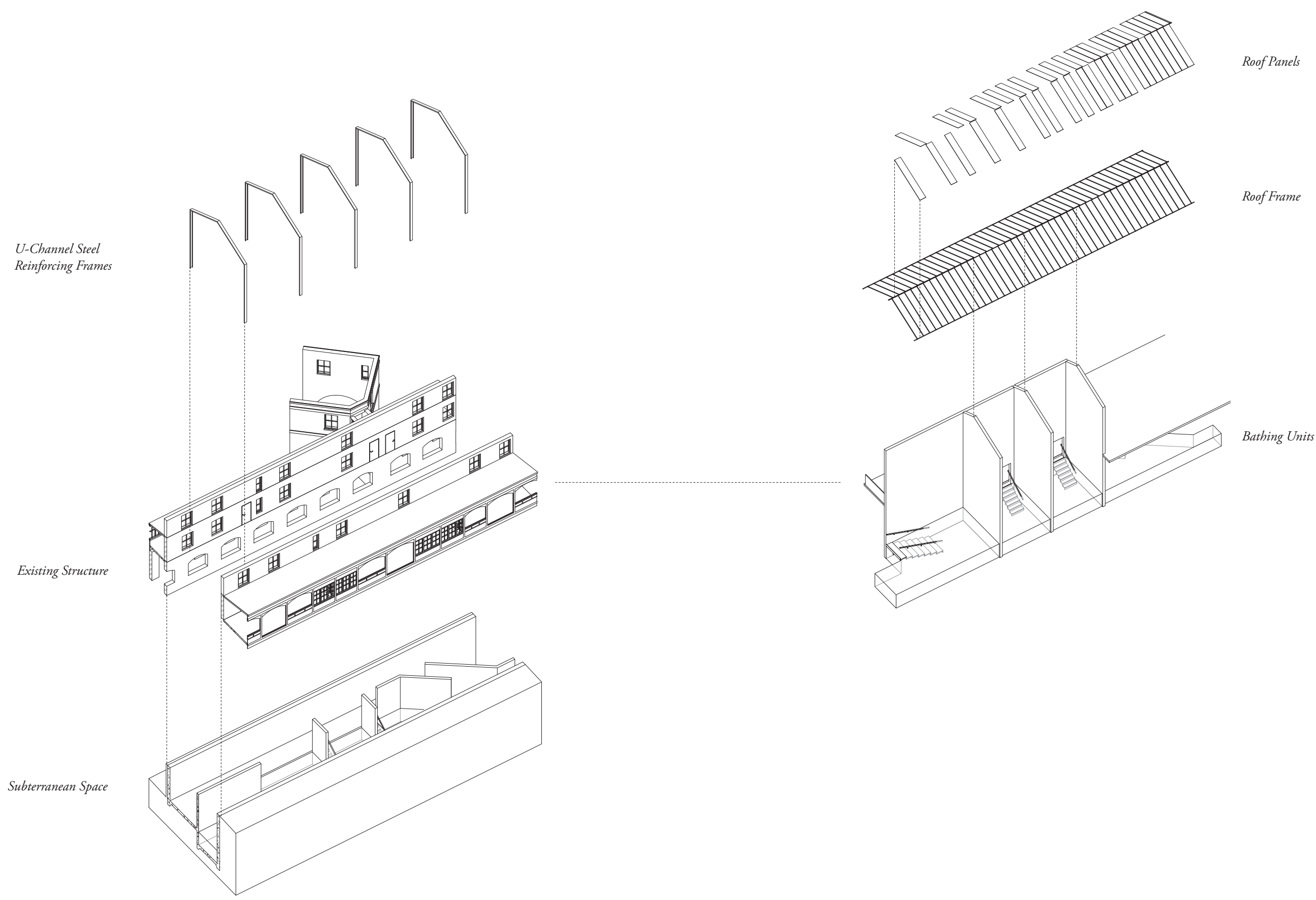

Figure 82: Exploded isometric showing primary elements of structure - left wing 


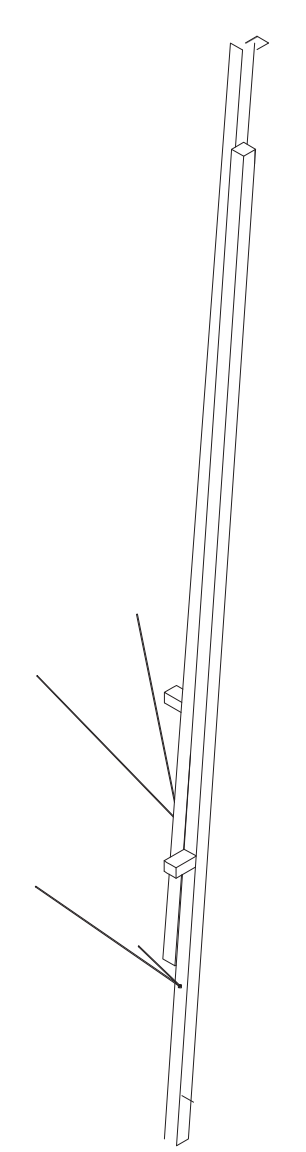

Primary structure - beams and tension cables connected to floor

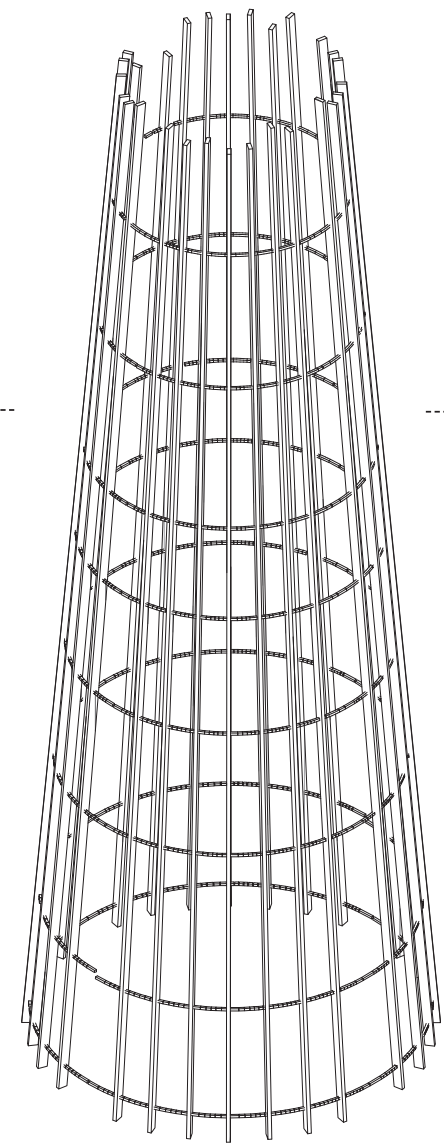

Secondary support structure

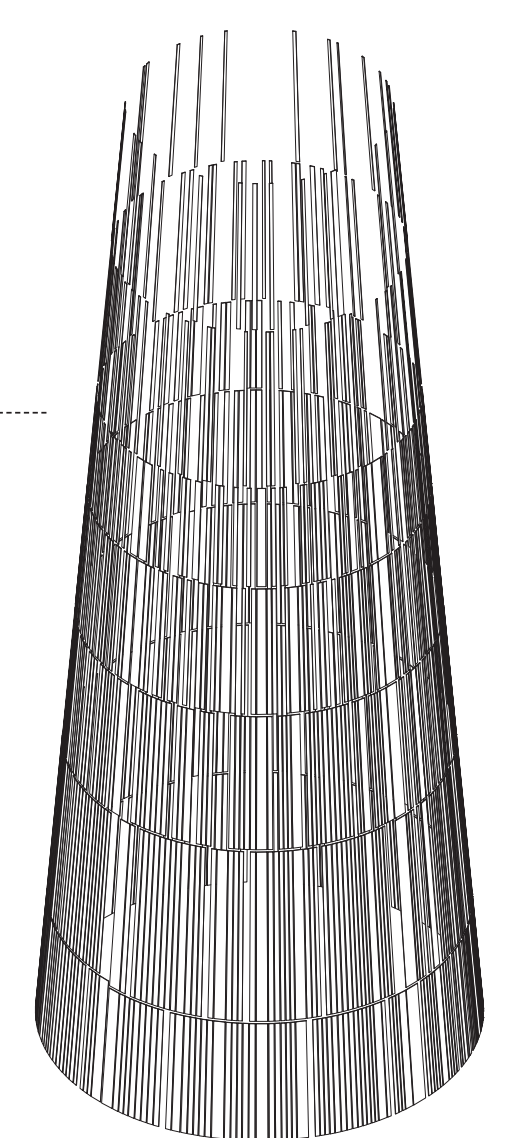

Panels within frame of structure - dissipate upward

Figure 83: Exploded isometric showing primary elements of the vertical voids 


\subsubsection{The Final Journey}

As illustrated within figures 84 and 85 , the final journey of this design is structured around a specific journey, organized around the structure of five acts. Throughout this journey the user is introduced to a range of spatial and atmospheric quailties that aim to enable a sense of reminiscence to the intangible heritage of the site. This is experienced through a layering of atmosphere, program, and form. The following sections of this chapter will present this journey as experienced by the user, seperated into the five acts and presented as a narrative.

Exposition - Site access and progression around building

2 Rising Action - Descent below remains of existing structure

3 Climax-Progression through subterranean bath-house

$4 \quad$ Falling Action - Ascent to within external corridors of existing building

5 Denouement - Ascent above site, providing views of surrounding context

Figure 84: Floor plan outlining acts and progression, Level 00

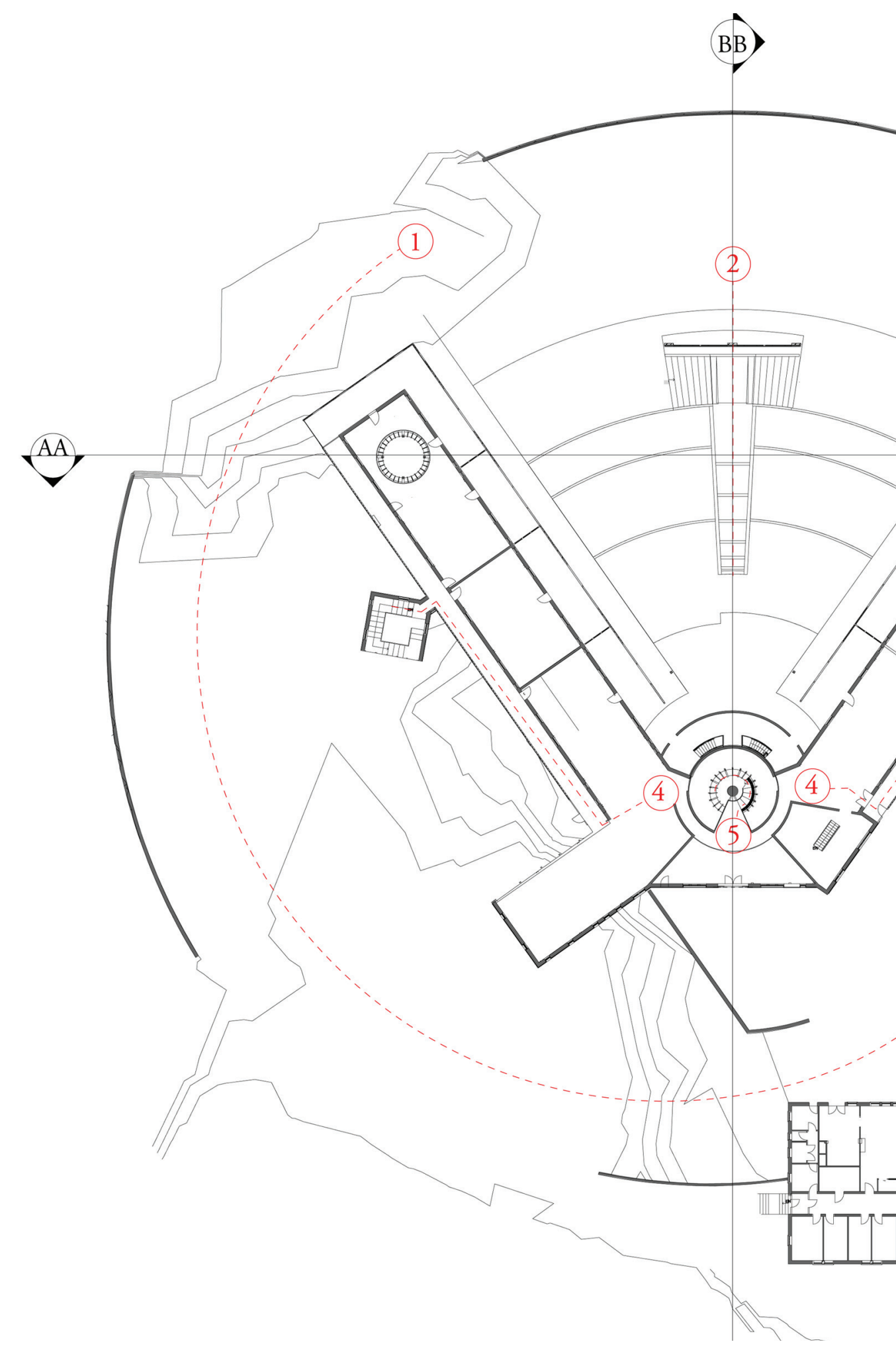



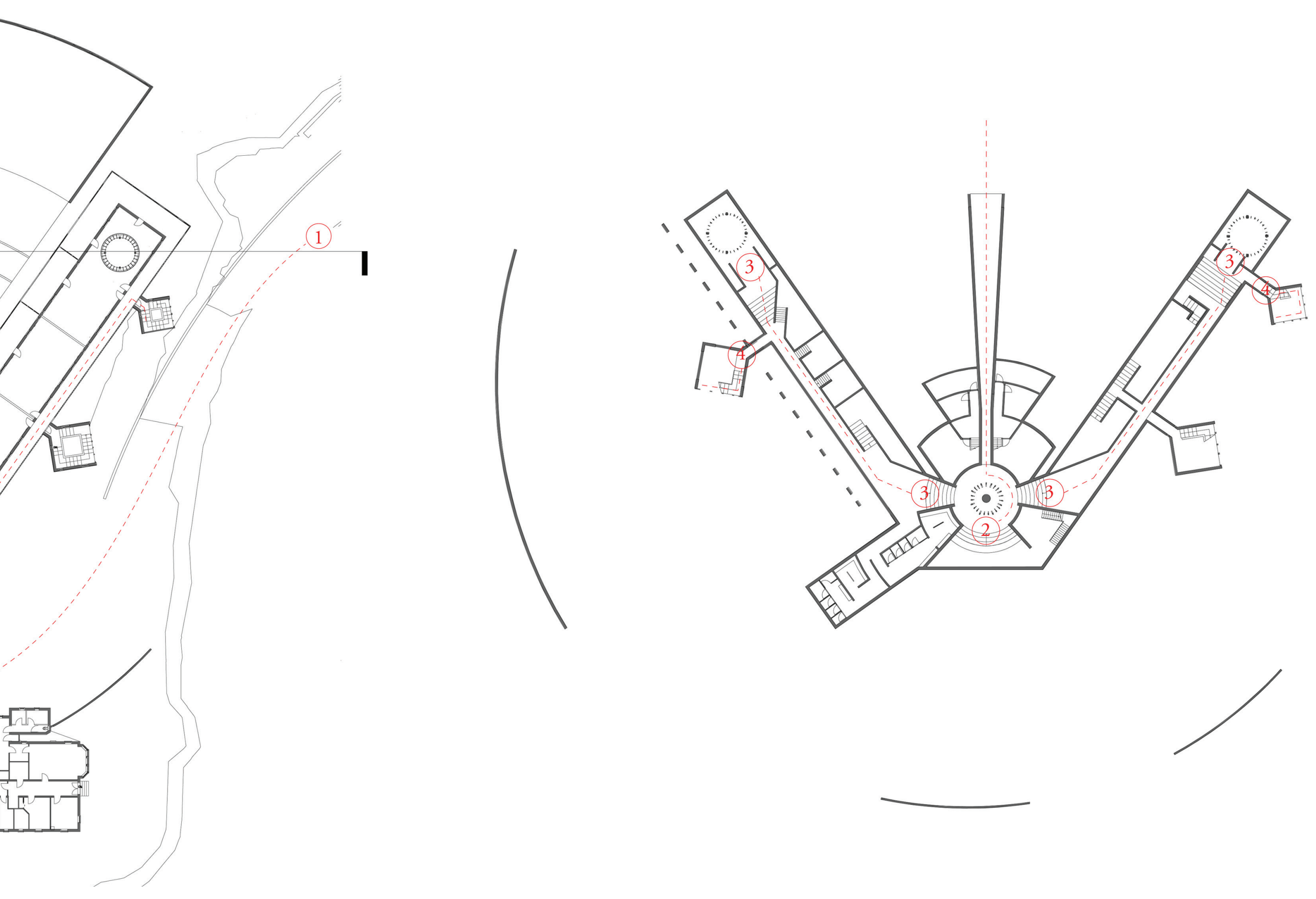


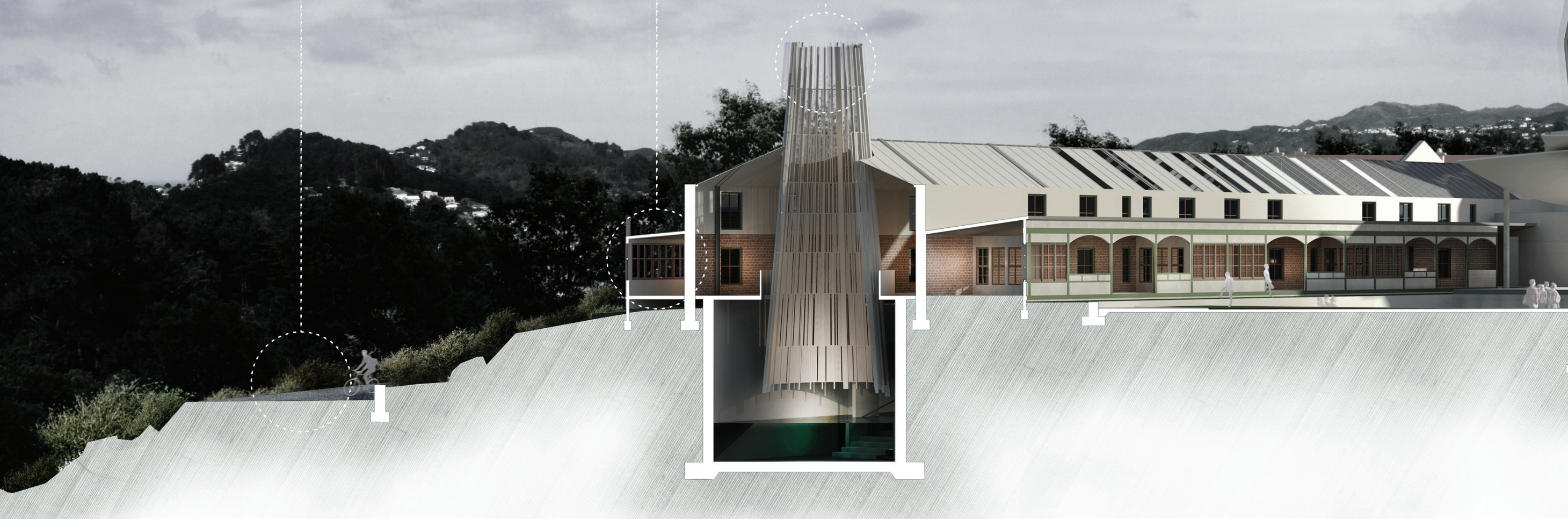



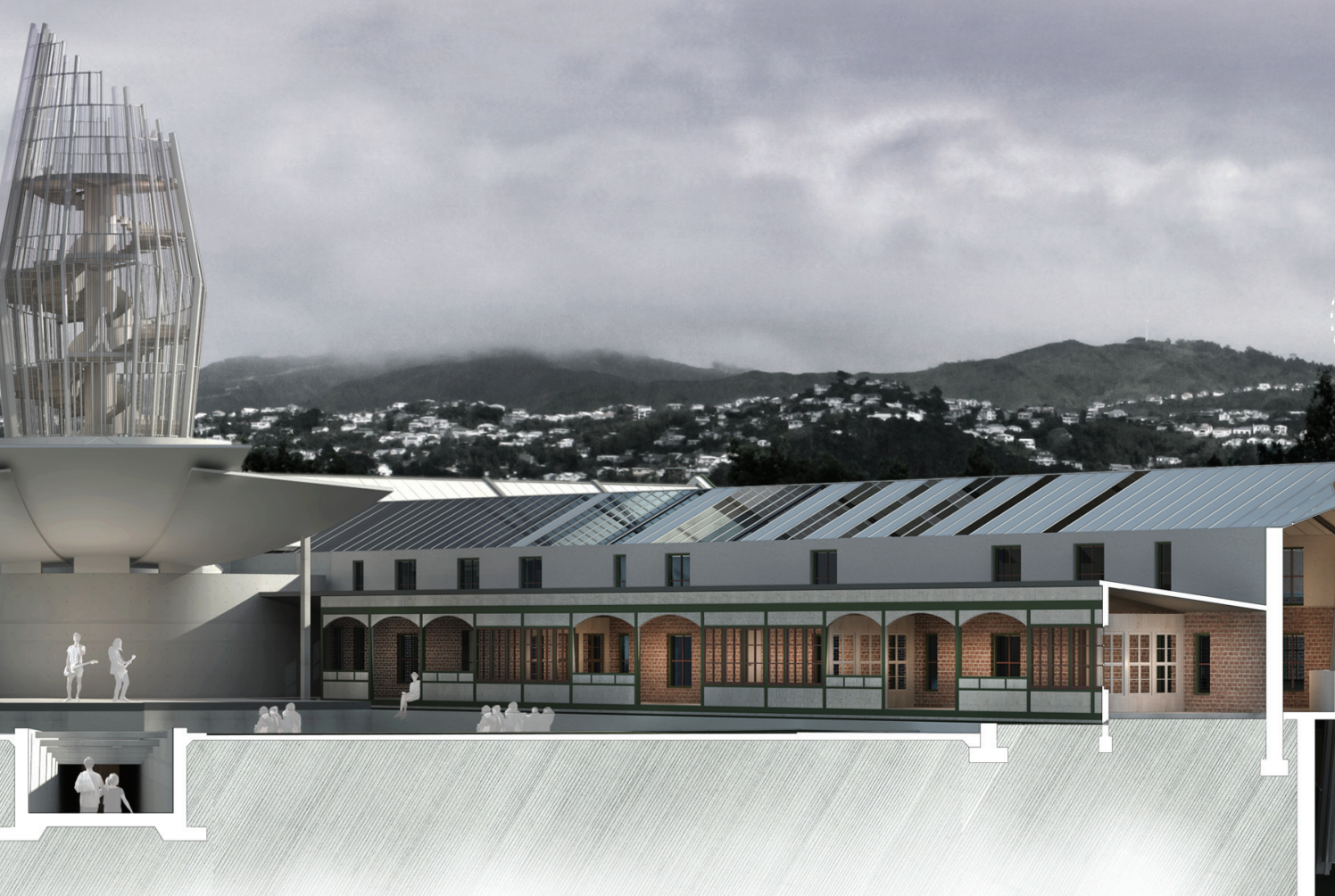

$\frac{1}{4}$

(1) (I)
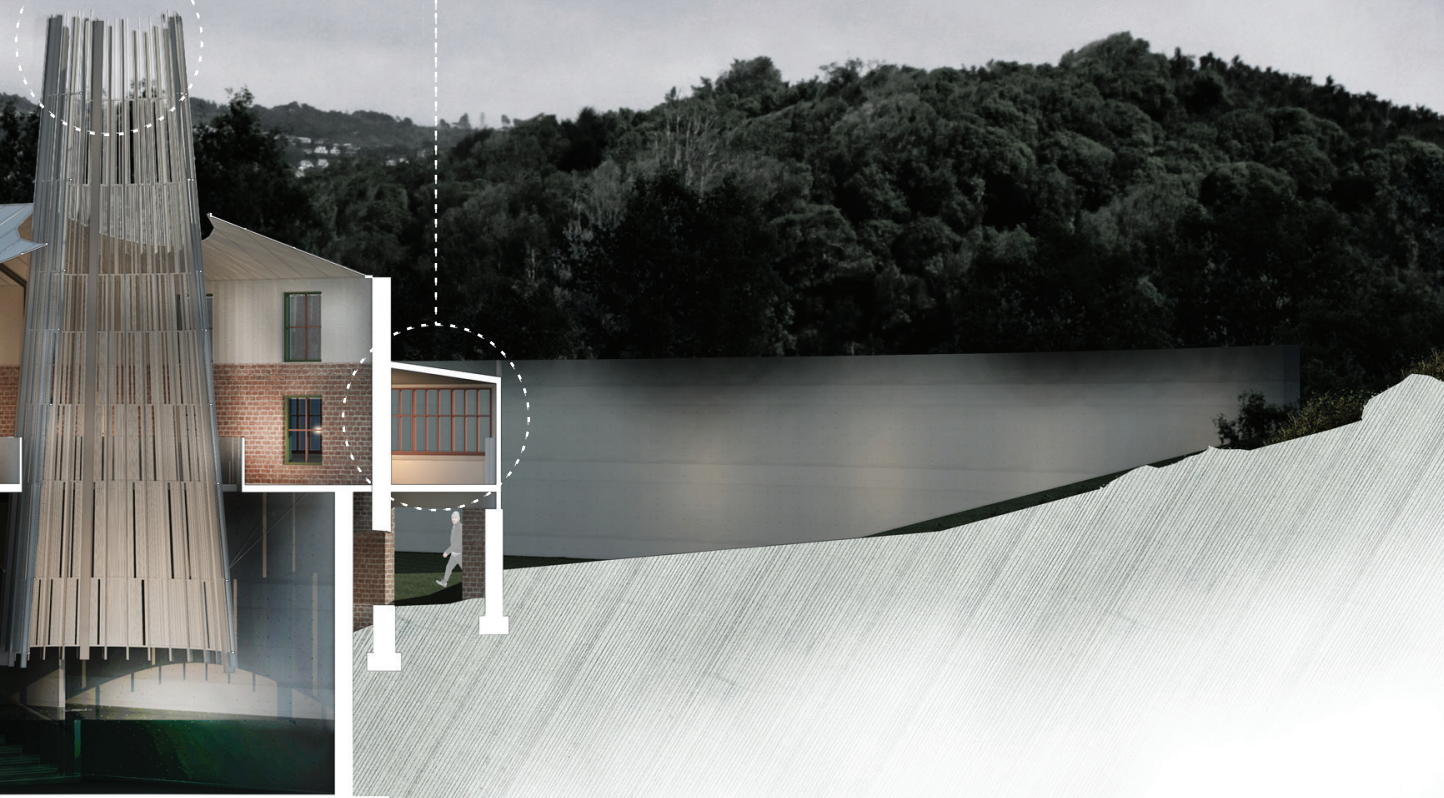

-...-. Act Locations 


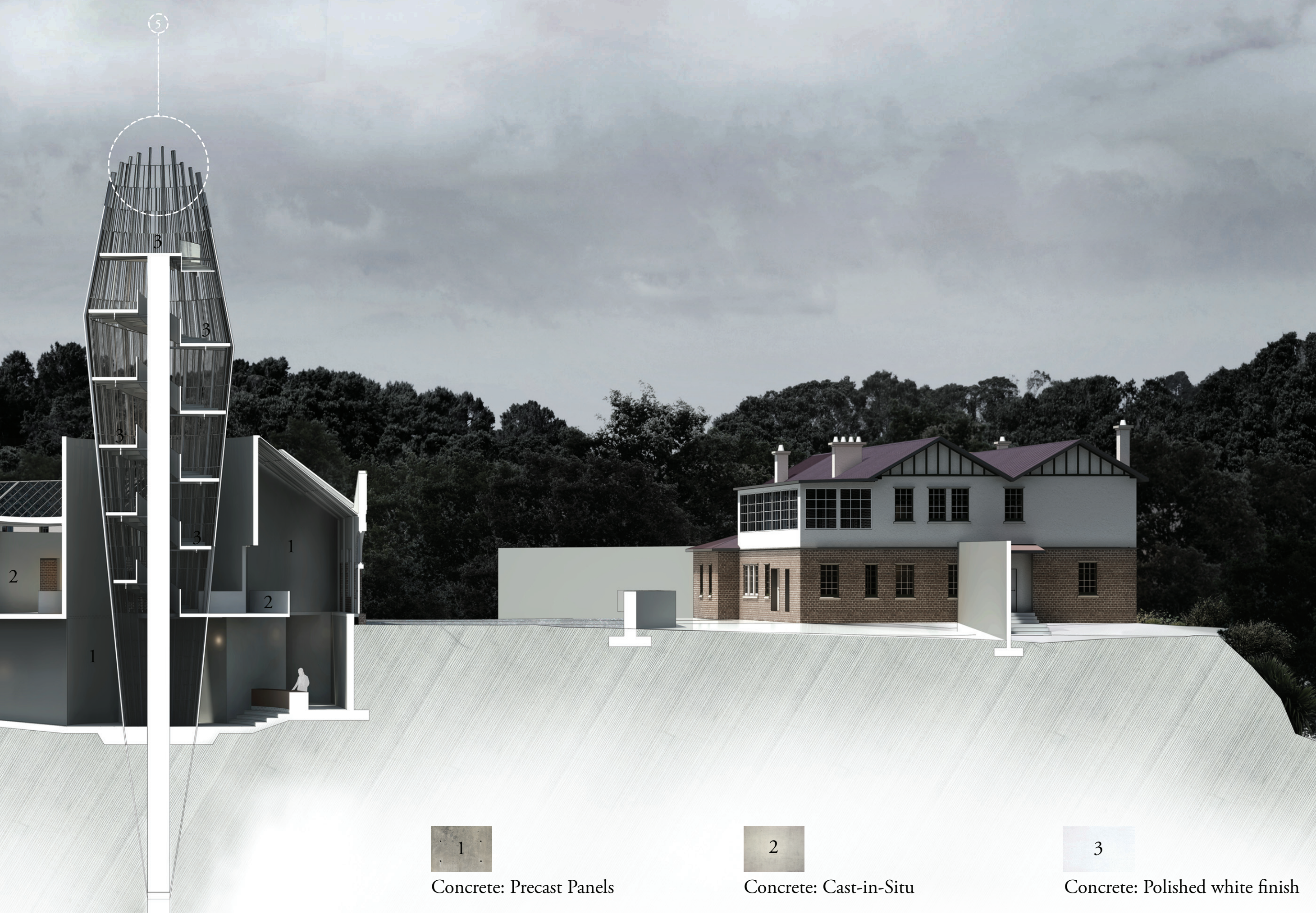




\section{1। Exposition}

"In a classical drama or comedy, the first act provides all of the information necessary for understanding the story. The protagonist, antagonist, and their basic conflict are introduced. This act ends with the so-called inciting moment, the incident that sets the narrative into motion and without which the entire ensuing action would be possible."

Robert Klanten, F. S. (2011). Erratic: visual impact in current design. Berlin: Gestalten, p5

Within this design, the first act provides the user with all of the information necessary for understanding the journey that ensues. This begins as one approaches the site from Alexandra Road. Upon entering, the user follows the existing driveway leading toward and framing the enduring physical traces of the Nurses Home. This progression continues in a circular pattern around the perimeter of the site, communicating the existing and intervening architectural forms as the key actors within this performance. The act ends after the user is directed inward between the wings of the building, incited by the slow descent into below the ground plane.

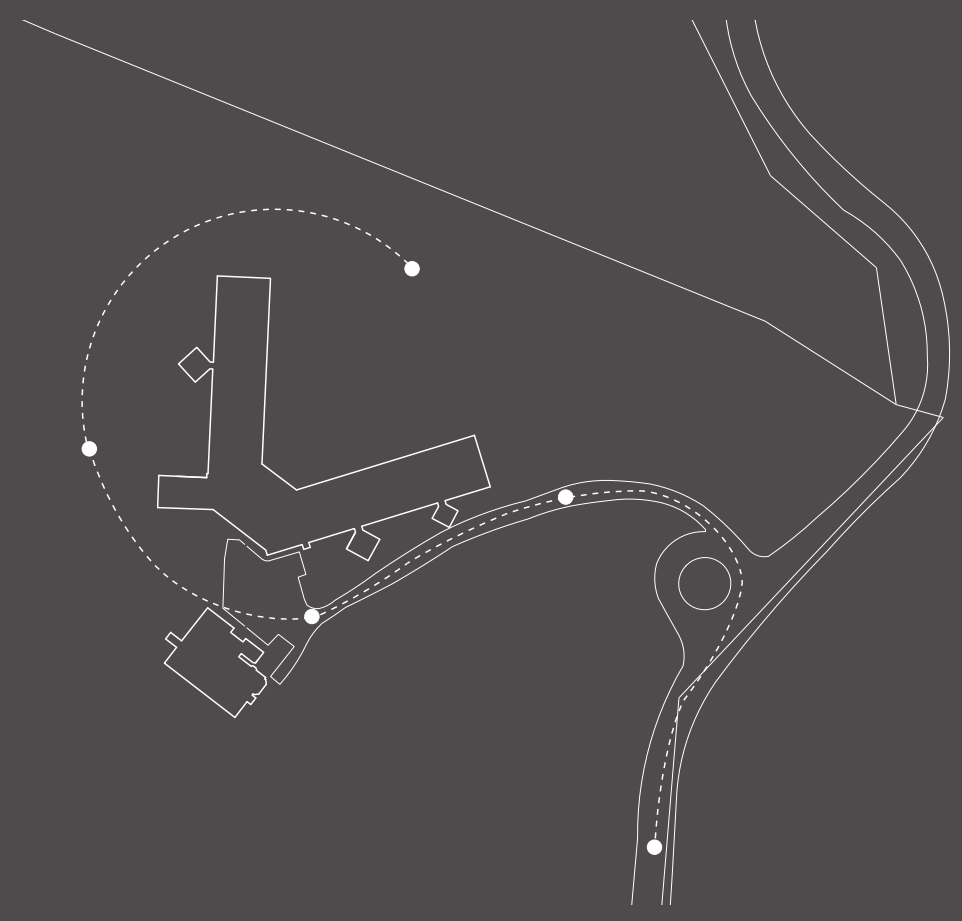




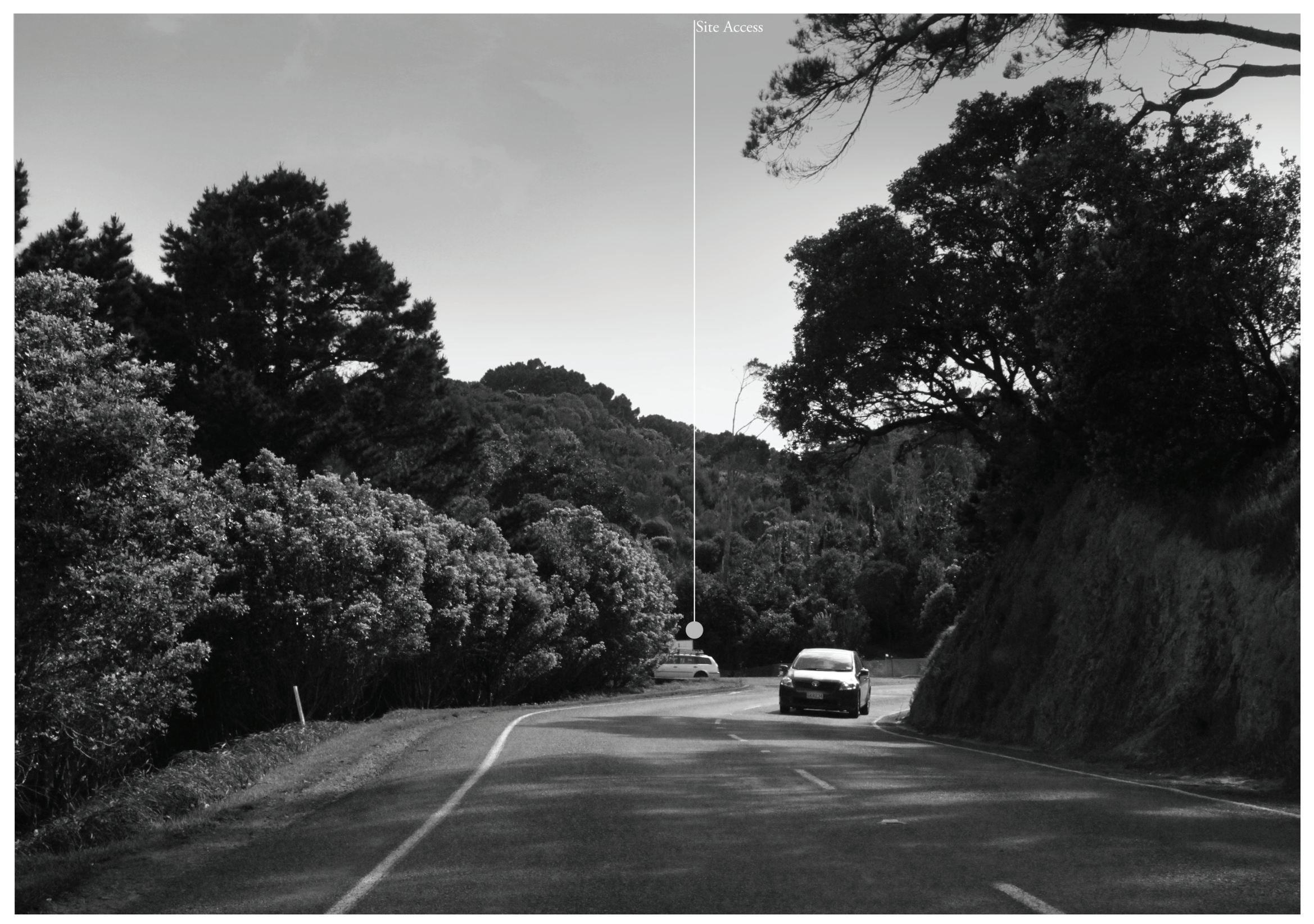



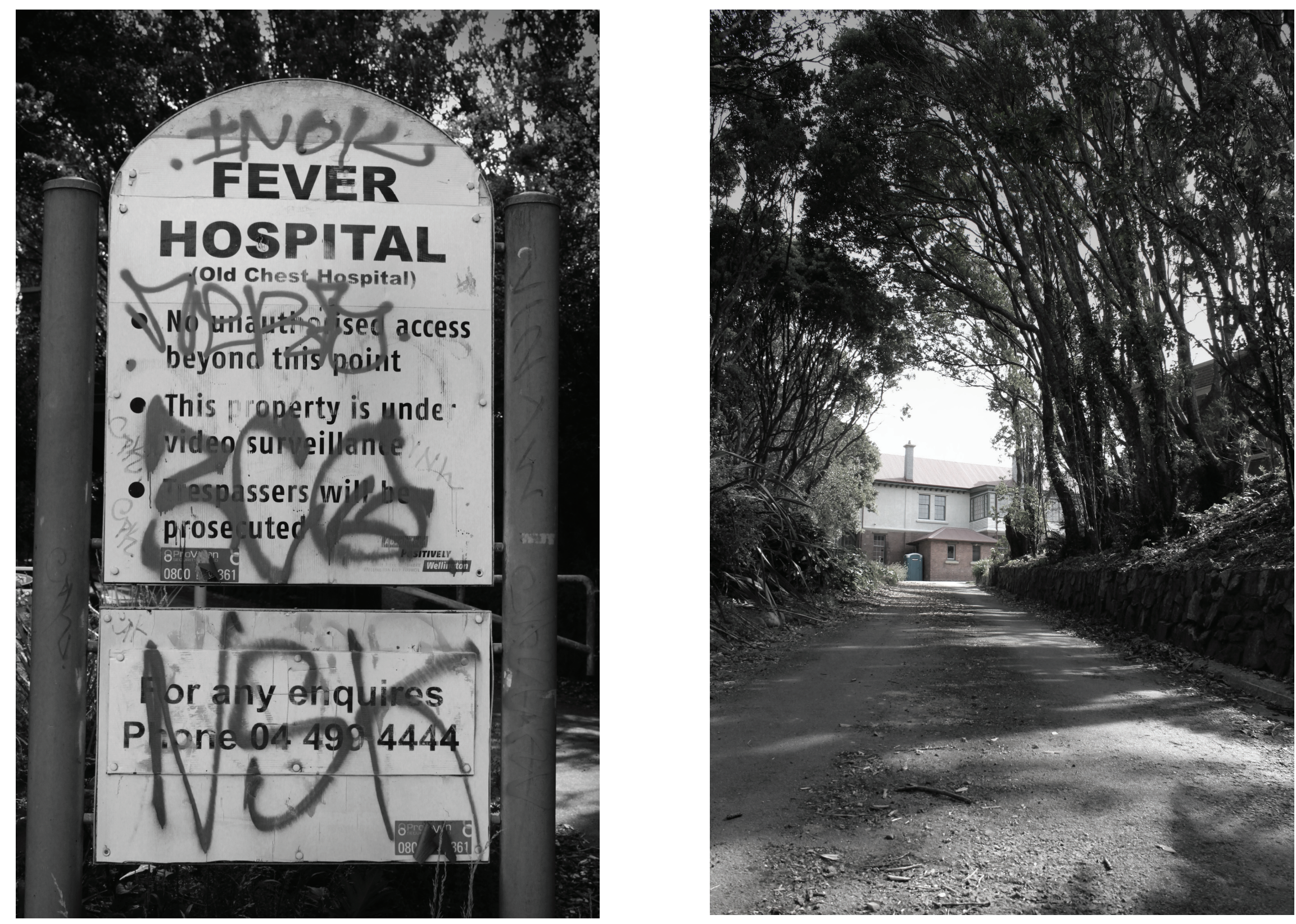

Figure 90: Existing entry sign Figure 91: Driveway approach 

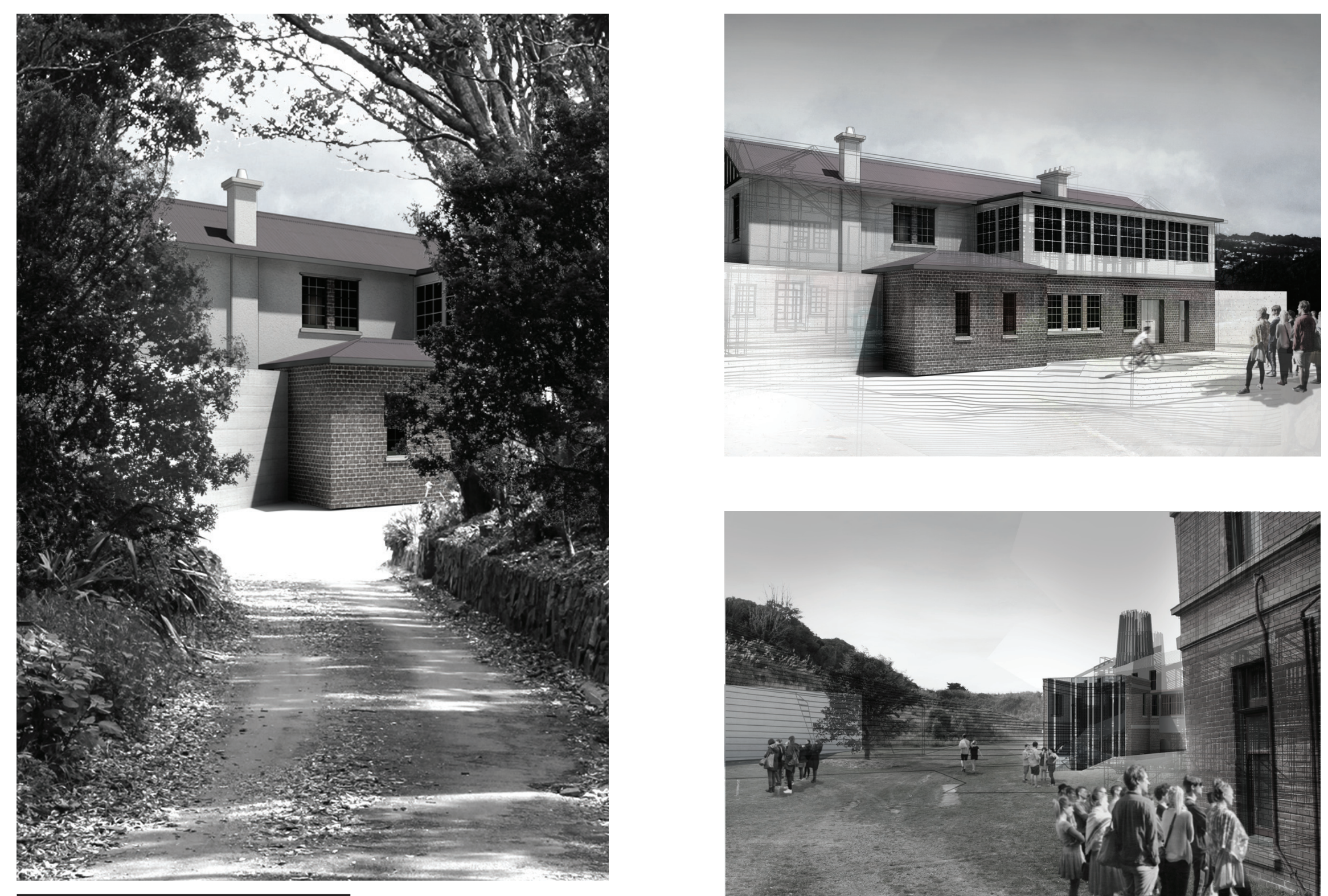

Figure 92: Nurses home approach

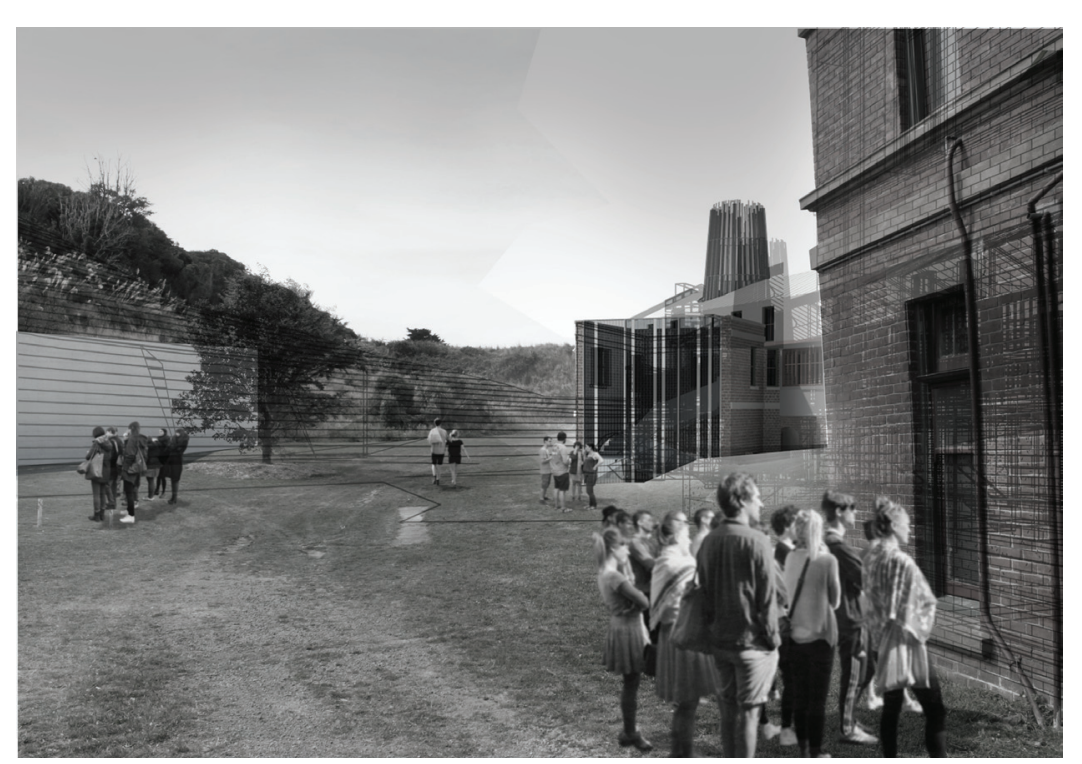

Figure 94: Circulation around building 


\section{Discussion}

Atmosphere

As an external experience, the first act does not introduce the user to the internal atmospheric conditions of the building. Rather, it seeks to introduce the key actors that contribute to this internal environment; the intervening and existing structures. This aims to heighten ones perception of the interrelation and connection between both old and new.

Intangible Heritage

This progression follows the movement patterns within the buildings history of use. This begins at the main entry from Alexandra Road, continuing around the hospital complex and up past the left wing. This access around the left wing was used prior to the construction of Alexandra Road, with patients transported up a path from the main hospital below.

\section{Precedent}

This progression draws from the case study of Libeskind's Jewish $\mathrm{Mu}$ seum. Within his design of the museum, Libeskind makes the presence of the old structure overtly obvious, with users required to walk within it in order to access the contemporary extension. This asserts the relationship between old and new as a connection informed by memory. Similarly, within this design one must first navigate the dominating physical presence of the existing hospital structure before gaining access below its physical remains. 


\section{2। Rising Action}

"During the rising action, the protagonist's basic conflict is complicated by the addition of further conflicts or hurdles. These foil any attempt to reach a conclusion in the second act. ${ }^{2}$

Robert Klanten, F. S. (2011). Erratic: visual impact in current design. Berlin: Gestalten, p5

Within the second act, the user is confronted with a dramatic transition. This begins as they enter the slow descent of the ramp between the two wings of the building. Acting as a mnemonic device, this descent is marked by the preserved facade of the hospitals central addition. As the user descends lower, the atmosphere begins to change; the air becomes thinner, light gives way to shadow, materiality becomes dominated by the cold touch of concrete, and sound from the above social environment begins to fade. The ramp and walls of this descent become markedly more confined as one progressess. Upon entering this subterranean environment the journey becomes further complicated by two pathways, each exiting opposite sides of the circular space. Both lead to public-baths, one wing accomodating small private space, and the other larger and more public bathing pools.

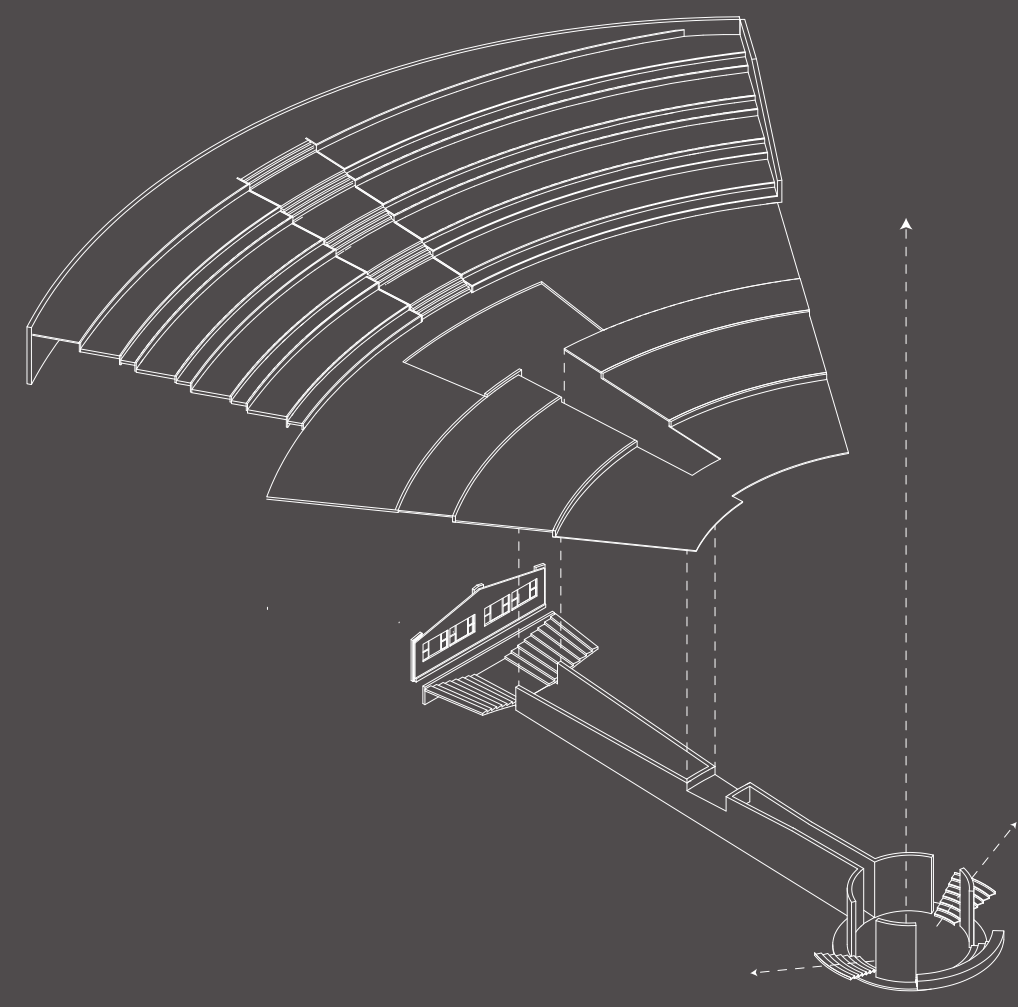



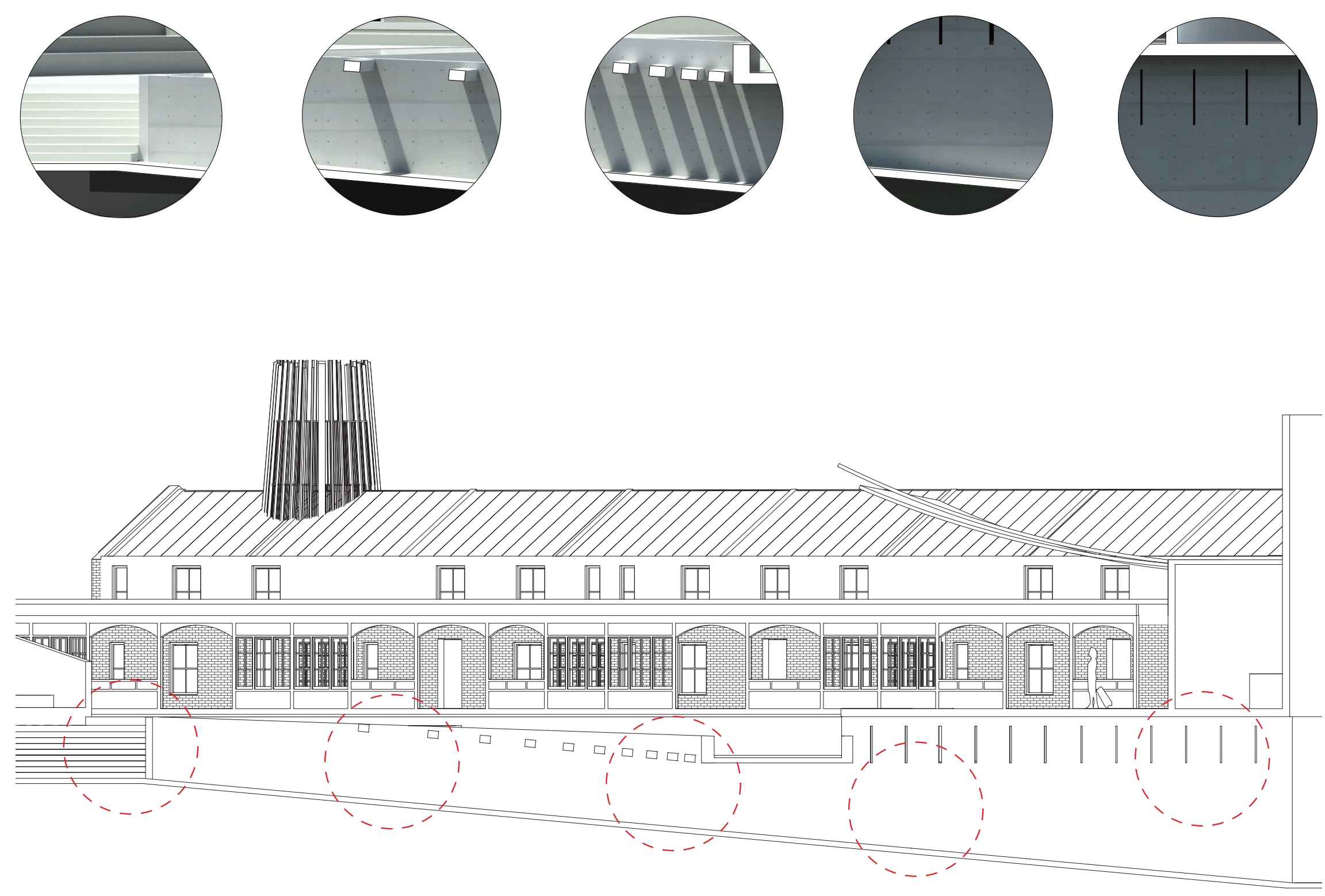


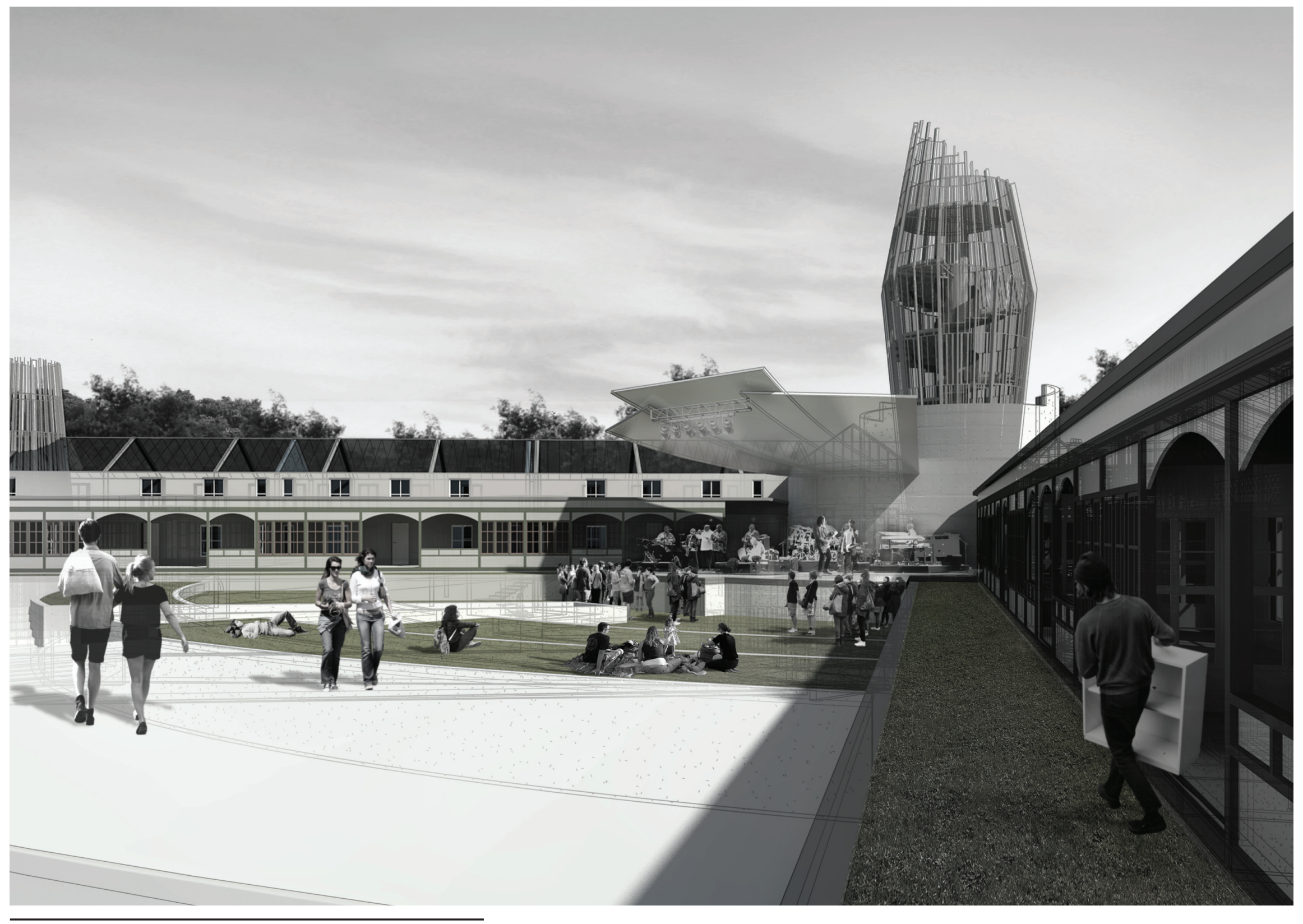

Figure 97: Outdoor performance space - approaching descent pathway 

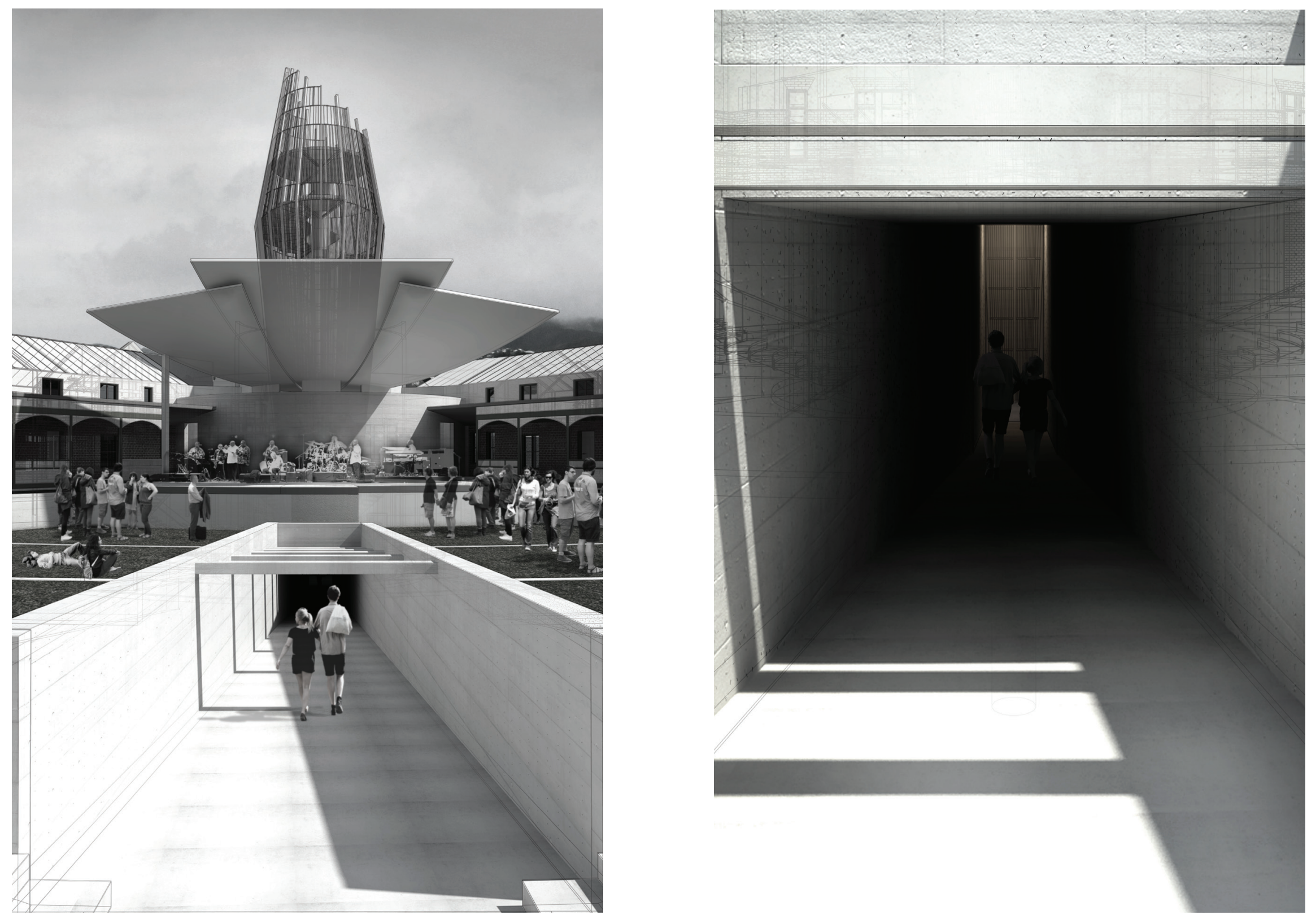


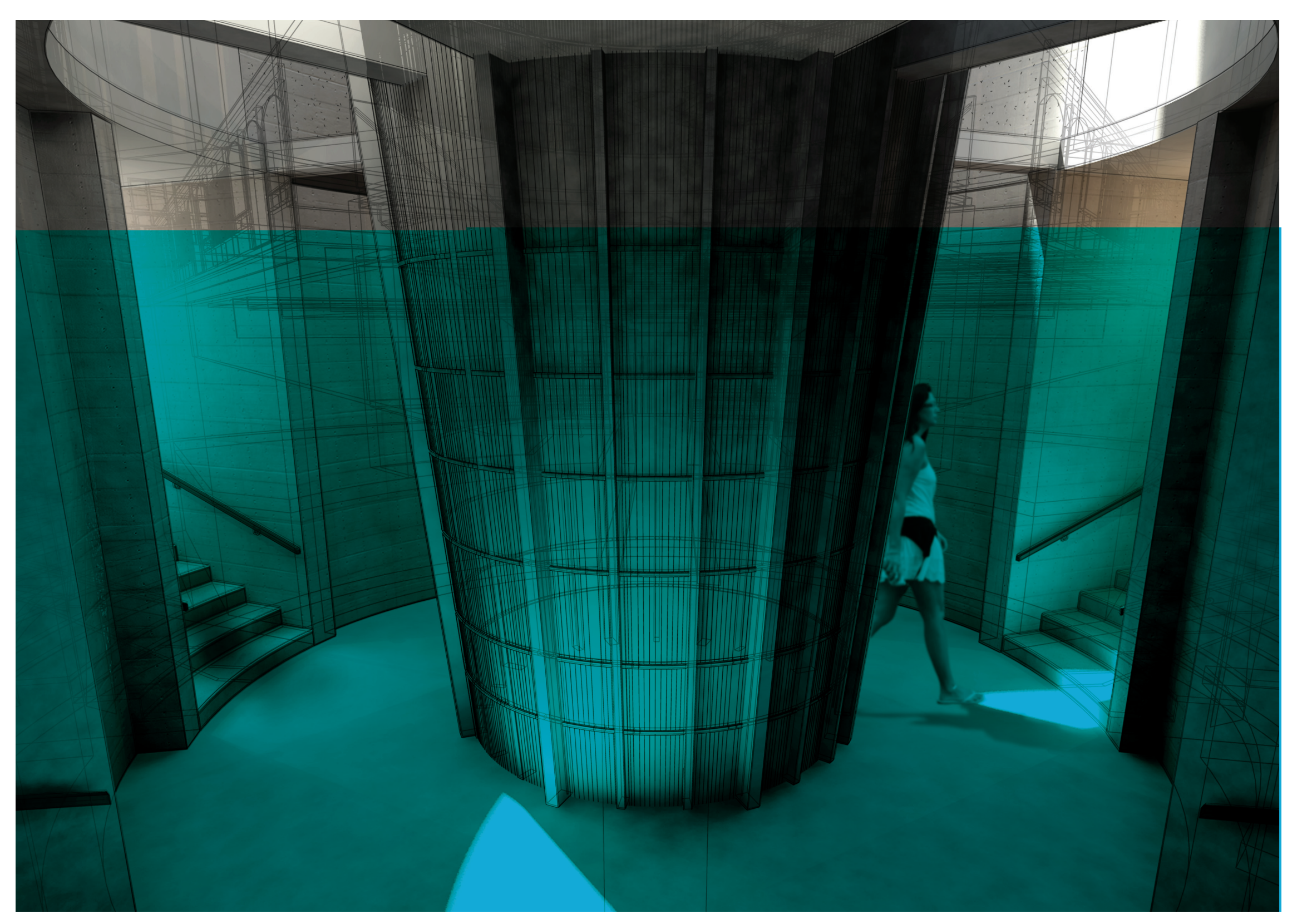

Figure 100: Entry to subterranean space - looking from reception 


\section{Discussion}

Atmosphere

Within this second act the user transitions from an exterior progression of the building to a dramatic internal atmosphere. This is informed by a descent into darkness; as the user slowly moves down the central pathway concrete becomes increasingly dominant and natural light diminishes.

Intangible Heritage

The mnemonic role of the central facade aims to reinforce the presence of memory within the journey, acting as the starting point to ones descent. As the user descends below the ground the noises from the above social environment begin to fade. Only a mere reverberant echo connects the user with their surrounding context, leaving them isolated below the footprint of the building.

\section{Precedent}

This descent within the second act is informed by both the Hedmark and Jewish Museum. The dominating presence of the existing building, acting as a descent below its footprint, is informed by Libeskind's narrative within the jewish Museum. While the confined pathway, constructed of rough concrete, is informed by Fehn's meandering pathways of the Hedmark Museum. 


\section{3| Climax}

"During the third act, a climax is reached in the protagonists circumstances. This turning point brings about a marked change - for the better or for the worse." ${ }^{3}$

Within the third act the user remains beneath the wings of building, emmersed within the sensuous atmosphere of the subterranean bathhouse. The atmosphere of this environment brings about a climactic point within the journey. As one progressess toward the end of the wing visual connectivity to the above space and artificial lighting both begin to fade. The circulation path becomes the primary source of natural light, with penetrations in the floor above allowing zenithal light to filter downwards into a space otherwsie dominated by shadow. The climax is reached as the user approaches the end of the wing. Within this space, the only source of light is provided through a large void that penetrates the entire structure. This void exposes those below to the elements and communicates the surroudning social context of the site as a distant reality, through the faint echo of noise from the performance space above. This aims to reinforce the symbolic and phsycial isolation that underlies the site.

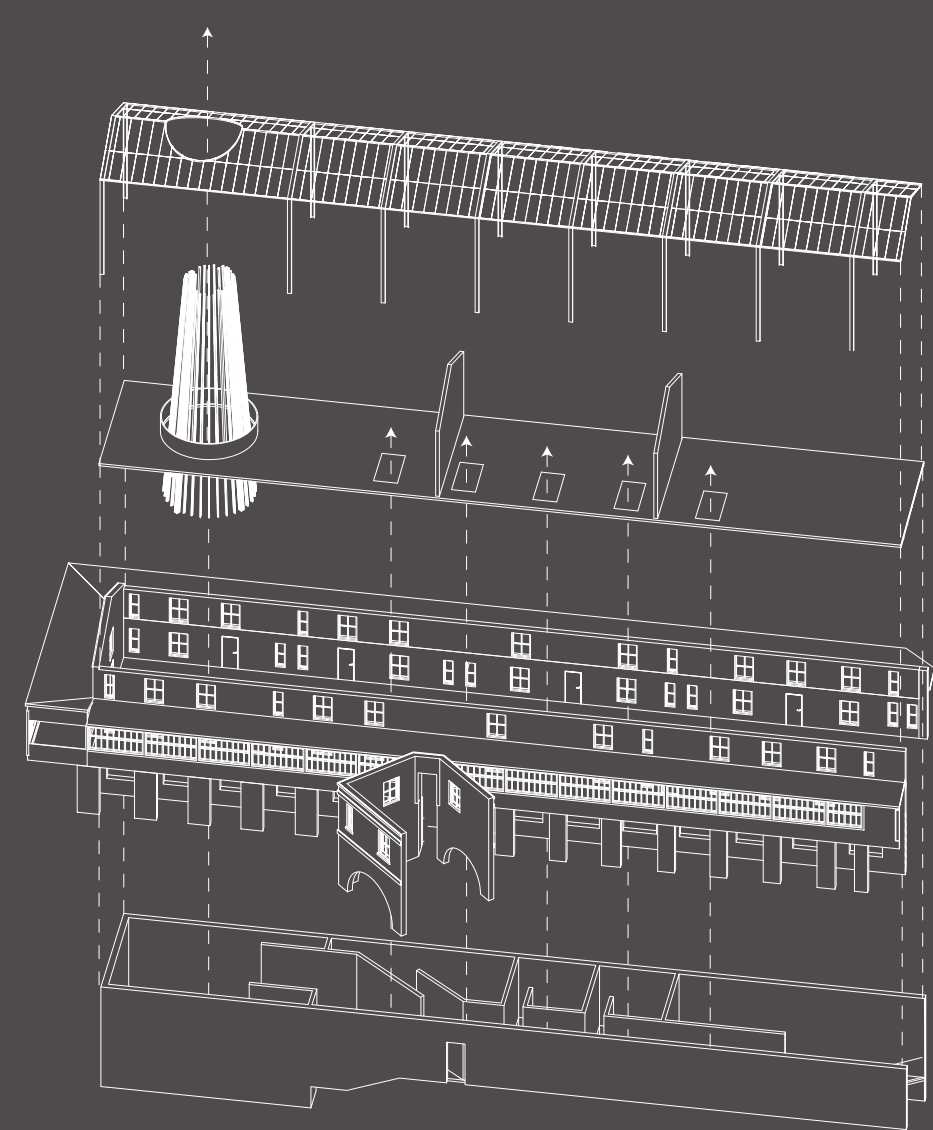

$\overline{\text { Figure 101: Act Three: Subterranean bath-bouse - left wing }}$ 


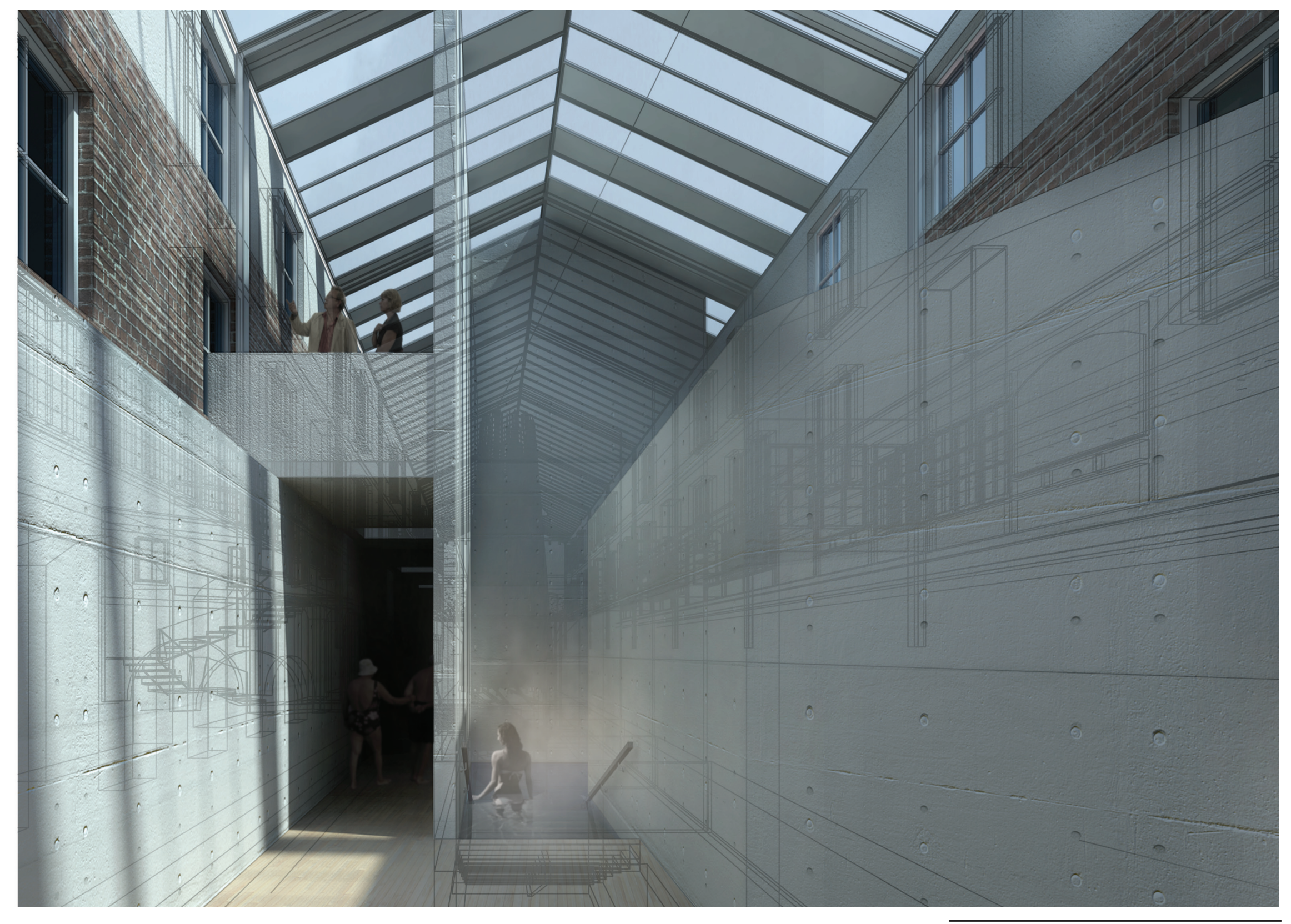

Figure 102: Access to wing - leading from changing rooms 

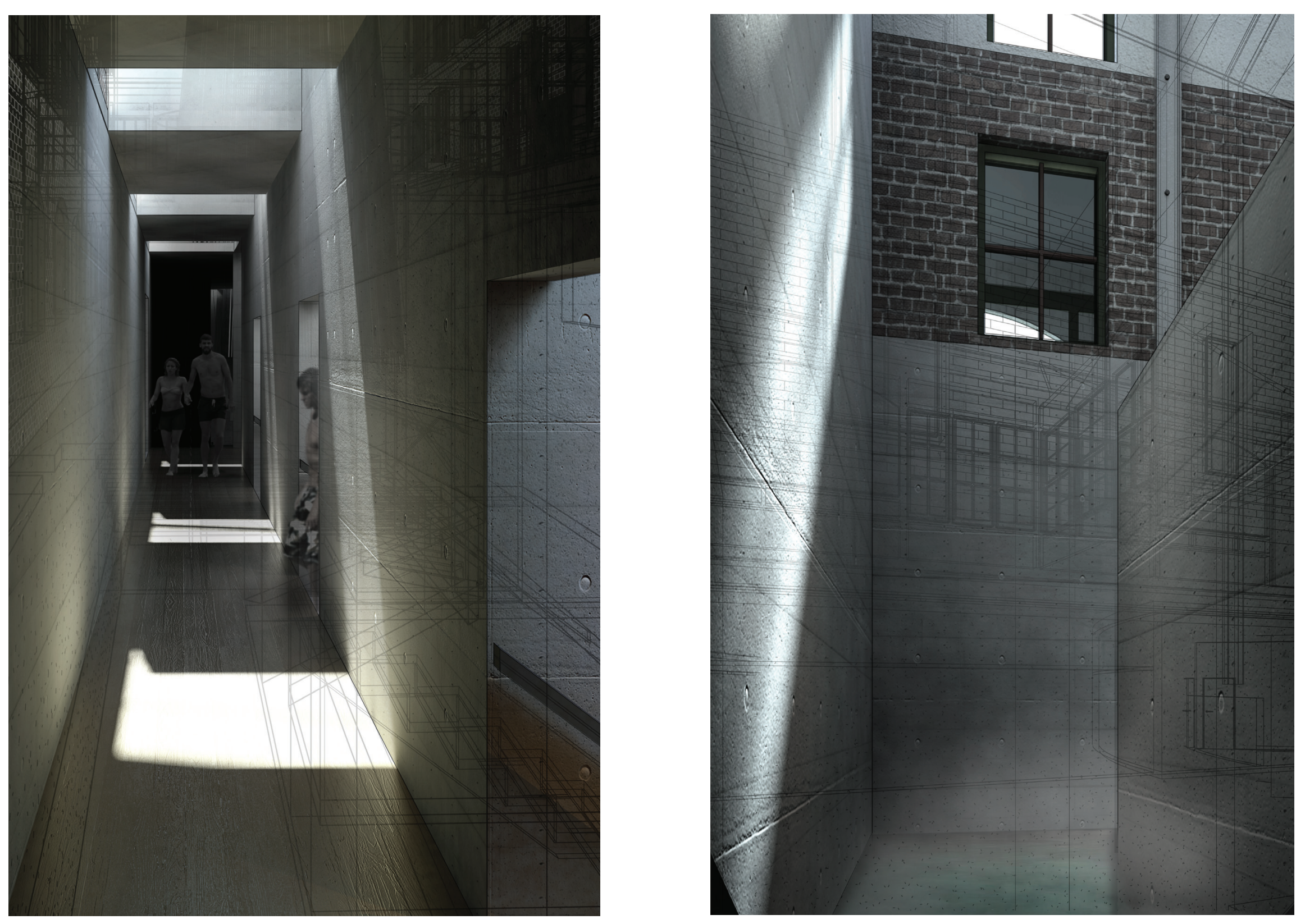


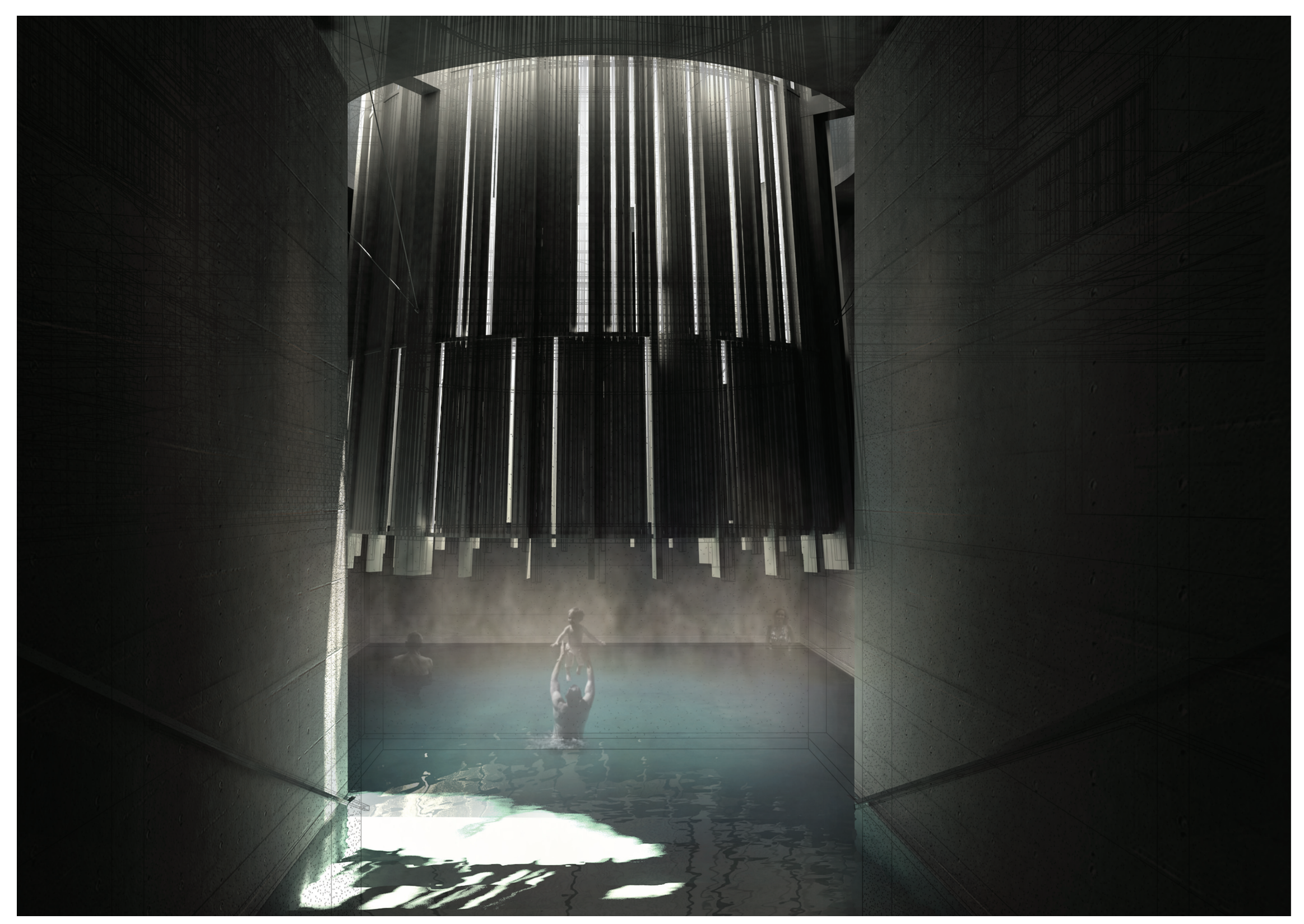




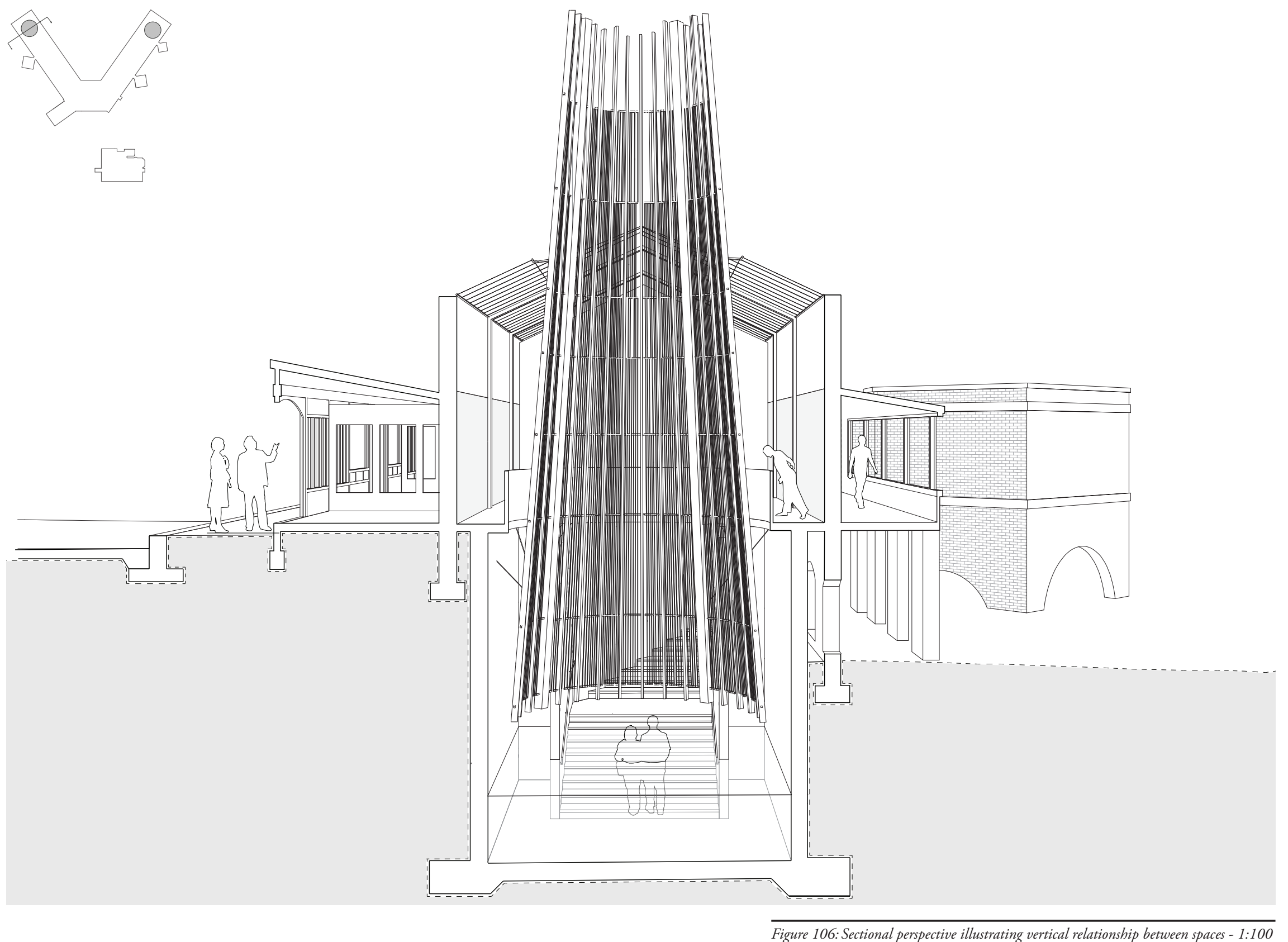



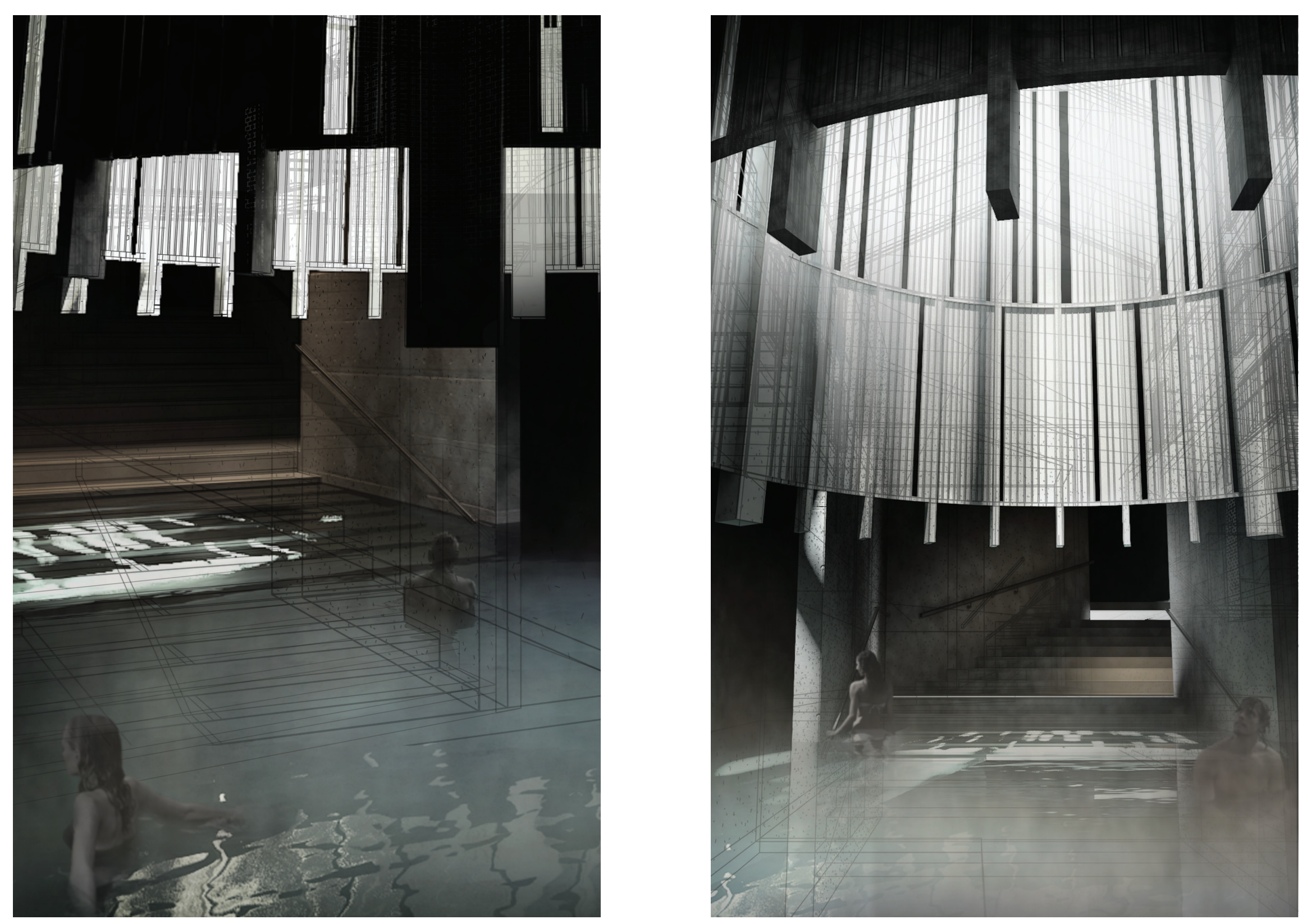


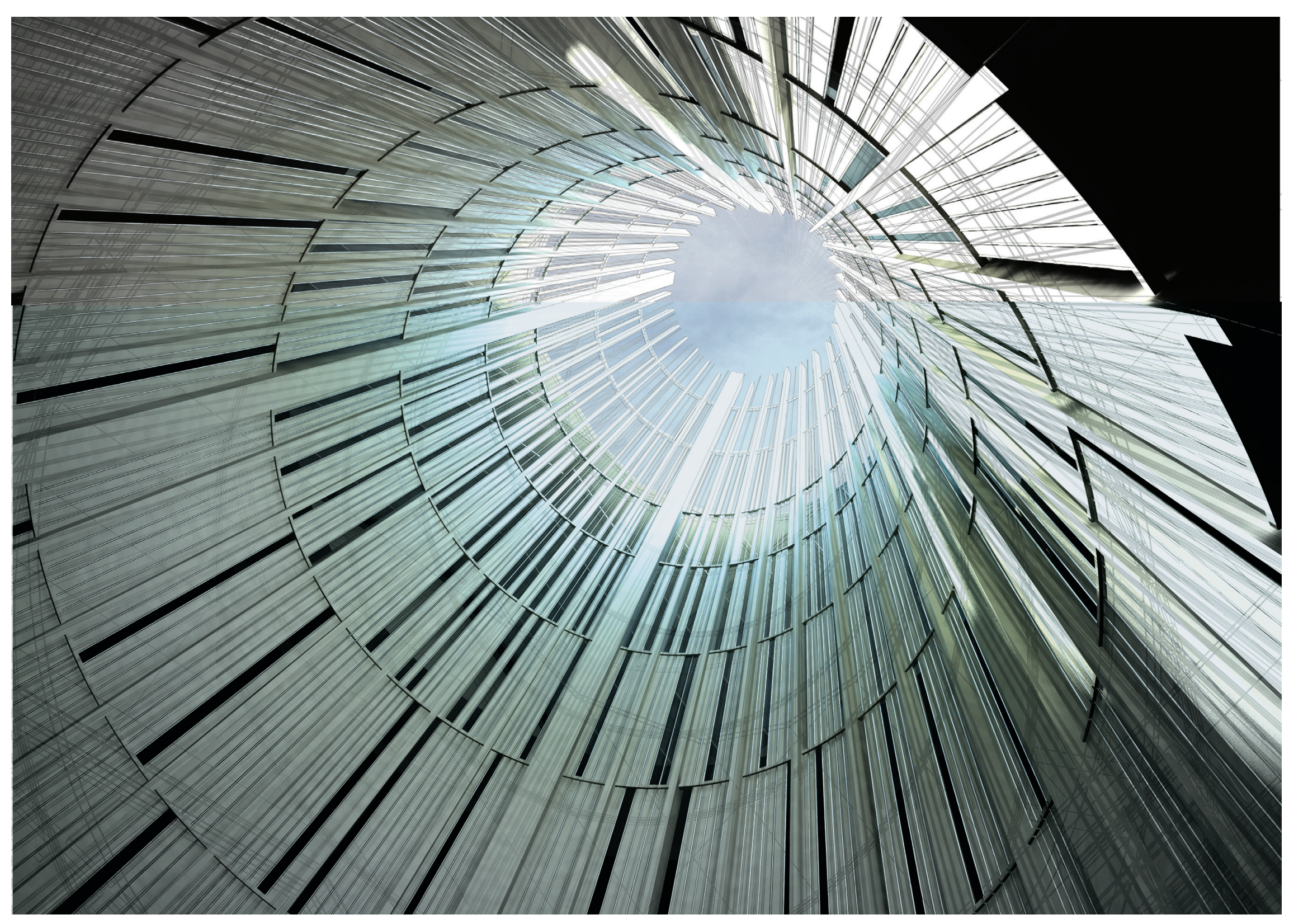

$\overline{\text { Figure 109: view from beneath void }}$ 


\section{Discussion}

Atmosphere

As a result of its subterranean setting, light and shadow have been used as the dominant atmospheric tools within the third act. Natural light falls only from above; through both existing windows and the voids that penetrate vertically. As such, the space is experienced as an isolated environment. The materiality reinforces this spatial seperation. Large pre-cast concrete panels enclose each space, creating small detached bathing spaces. Within these intimate bathing spaces, the user is surrounded by the cold touch of concrete while visually connected to the physicality of the existing building above.

Intangible Heritage

This environment aims to generate reminiscence to qualities of bathing present within the buildings history, structured within an isolated environment that establishes a sense of social seperation from any surrounding context.

\section{Precedent}

The atmosphere within this act draws from aspects within all three case studies. The intimate bathing environment, voids penetrating vertically through the entire structure, and concrete boxes that extend vertically are all reminiscent of charectaristics discussed throughout case-study analysis. 


\section{4| Falling Action}

"In the fourth act, the story moves decidedly toward resolution."4 "The final act is the conclusion of the story. In the denouement, conflicts are resolved.

Robert Klanten, F. S. (2011). Erratic: visual impact in current design. Berlin: Gestalten, p5

In the fourth act, a sense of resolution is reached as one begins their ascent from below ground level. This ascent introduces the user to the existing corridors of the building, lining the exterior of both wings. This is performed through the brick pavilions of the existing building, purpose built as sanitation and bathing sectors for those suffering from infectious diseases. Informed by this historic function, these pavilions create a transition; ascending from the bathing space below to within the enduring physical traces of the building. Upon entering these physical remains, the user progressess along the corridor of the building towards the apex of the two wings. As this act concludes, the user is confronted with a journey leading them above the ruinous physical reamins of the building.

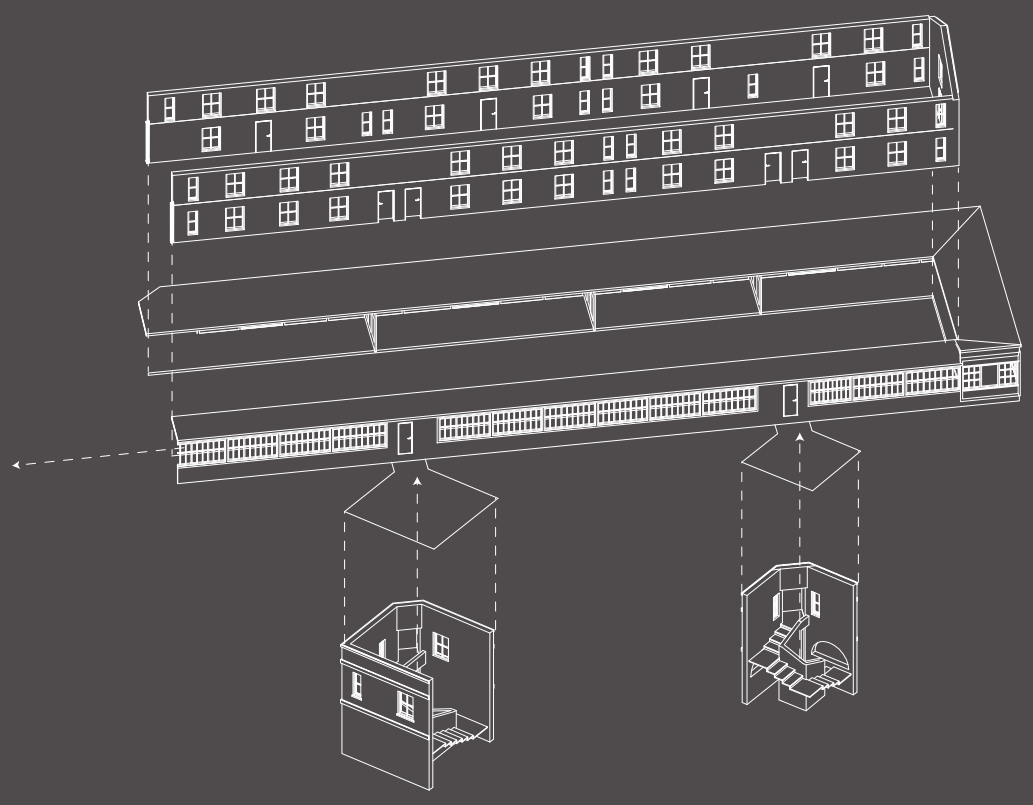




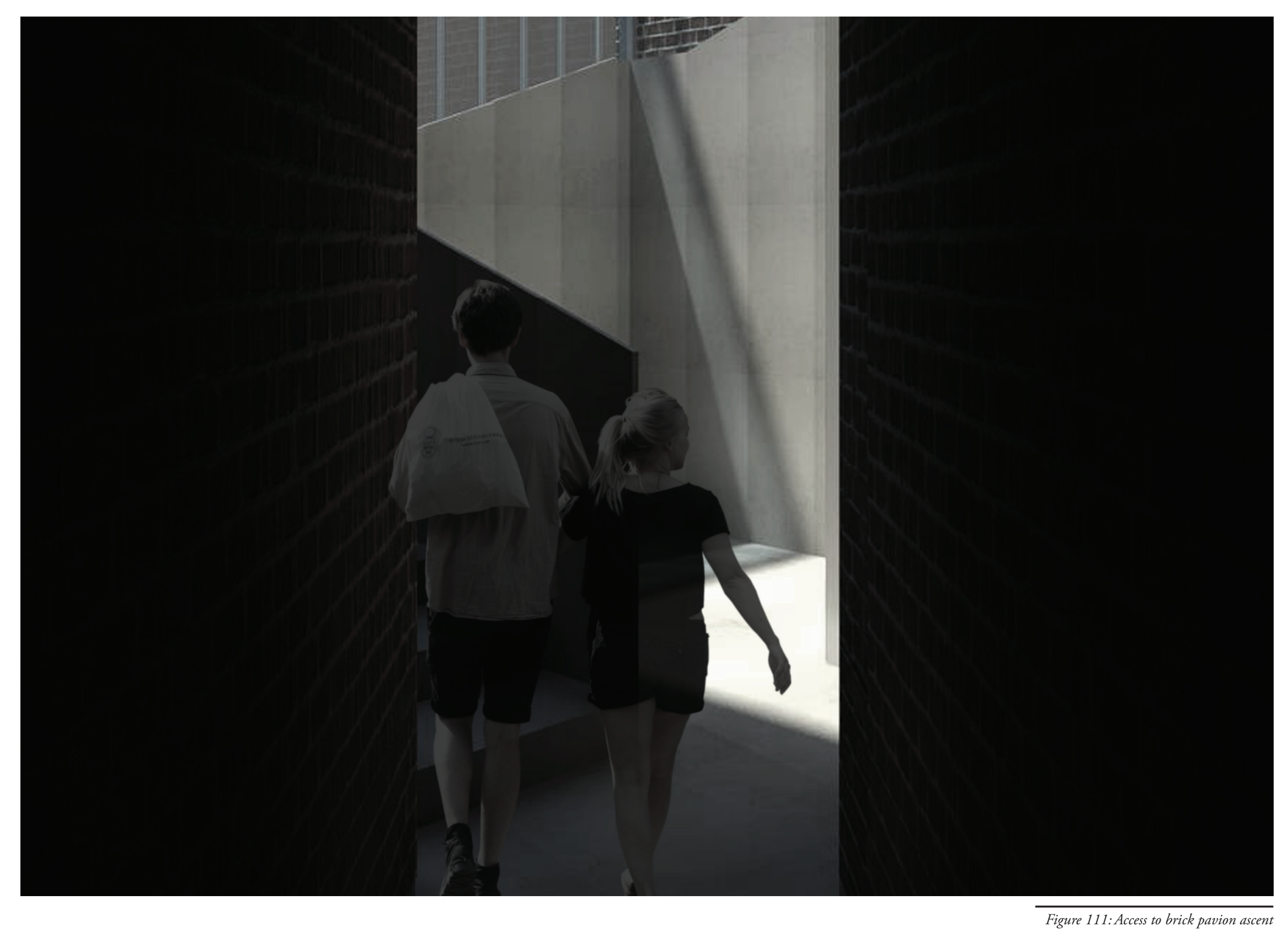



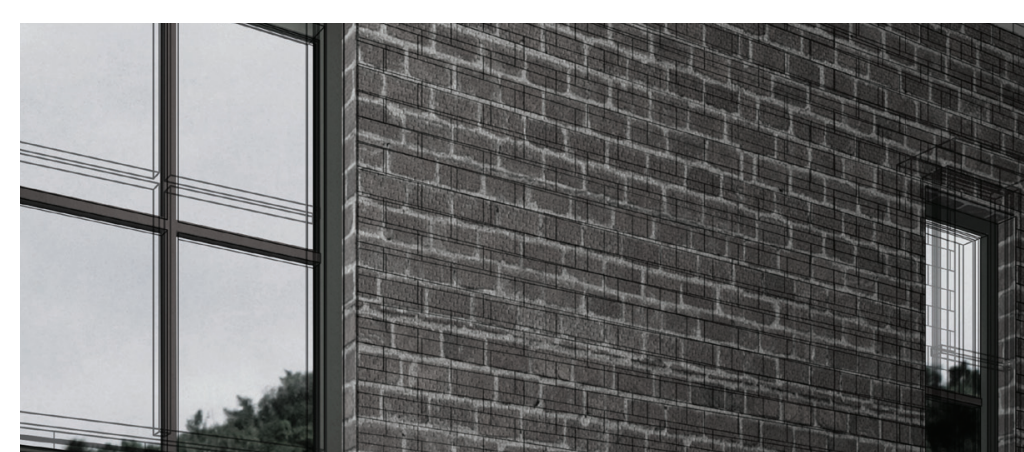

$y+4$ -

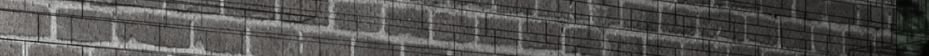

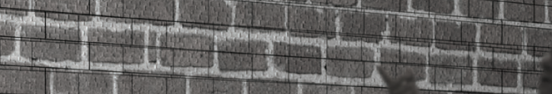

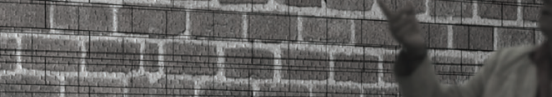

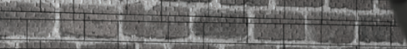

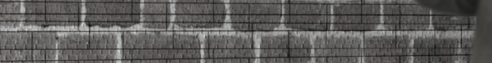

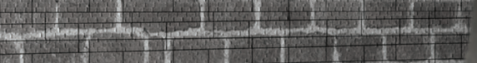

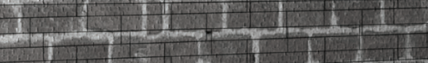

M.

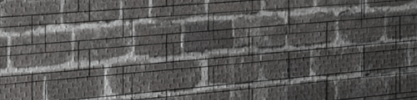

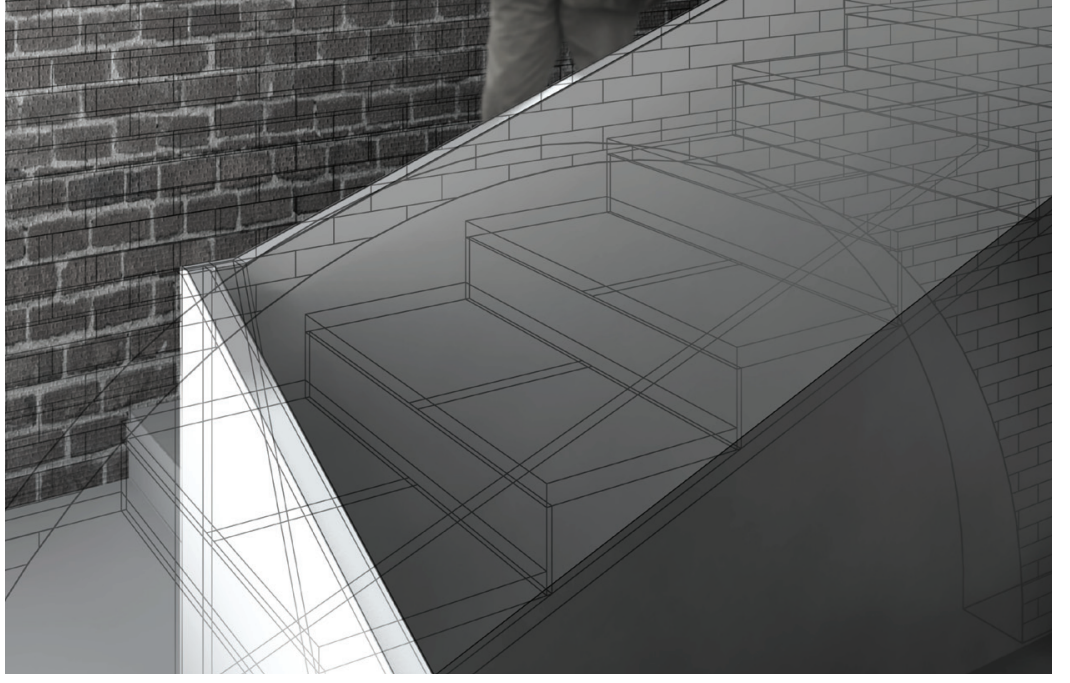

Figure 112: Ascent within existing brick pavilions

Figure 113: Access from external corridor - left wing

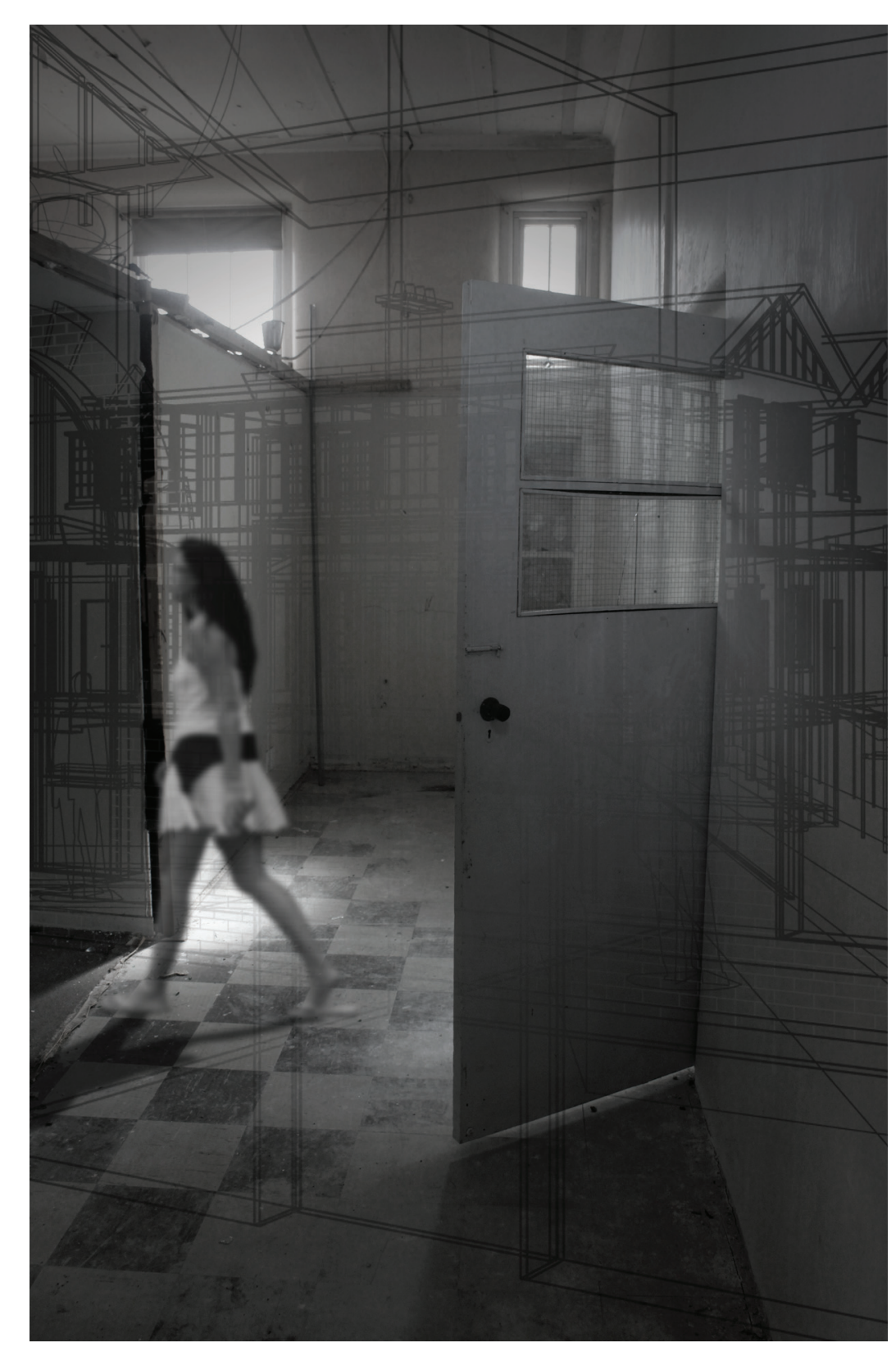




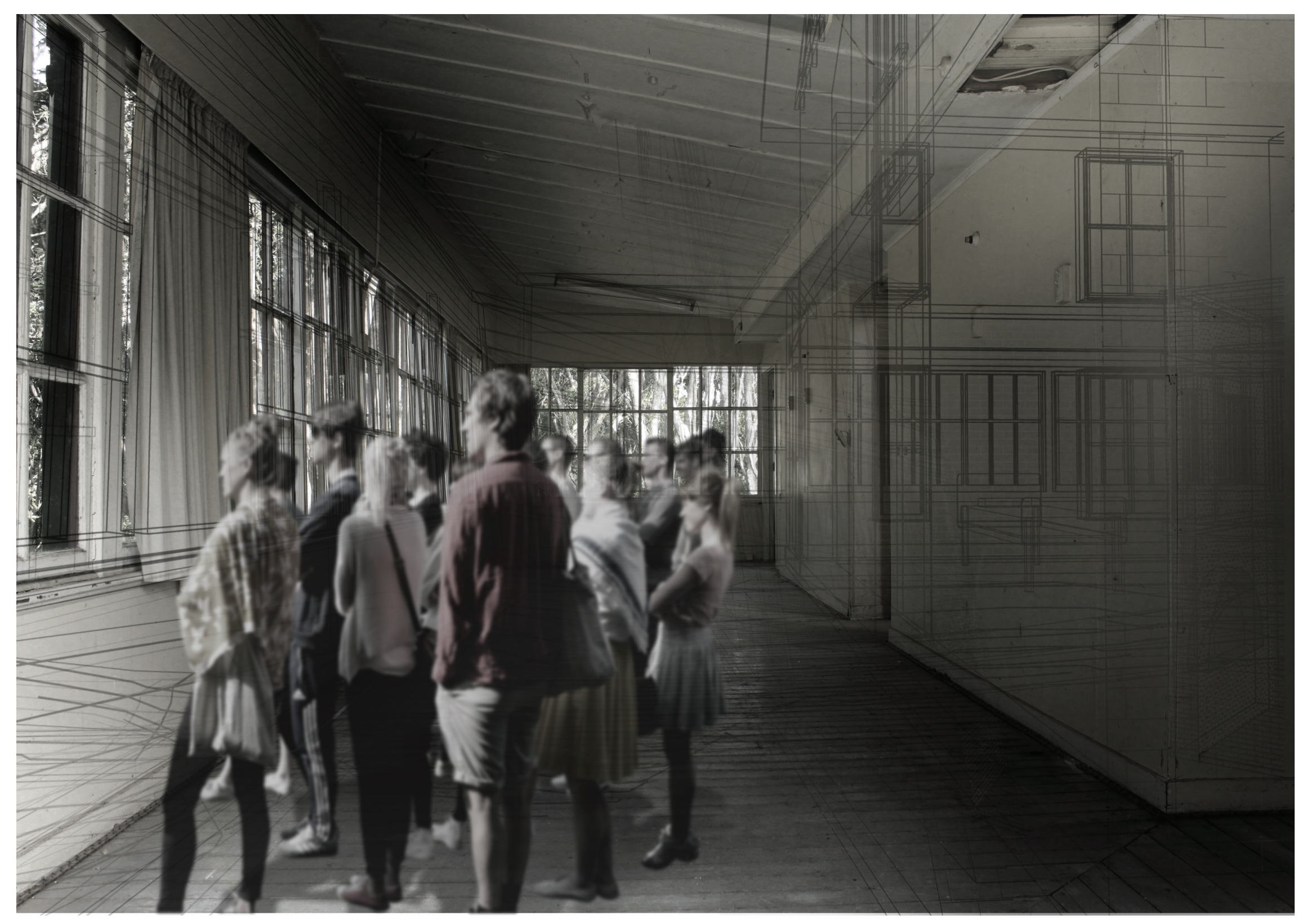




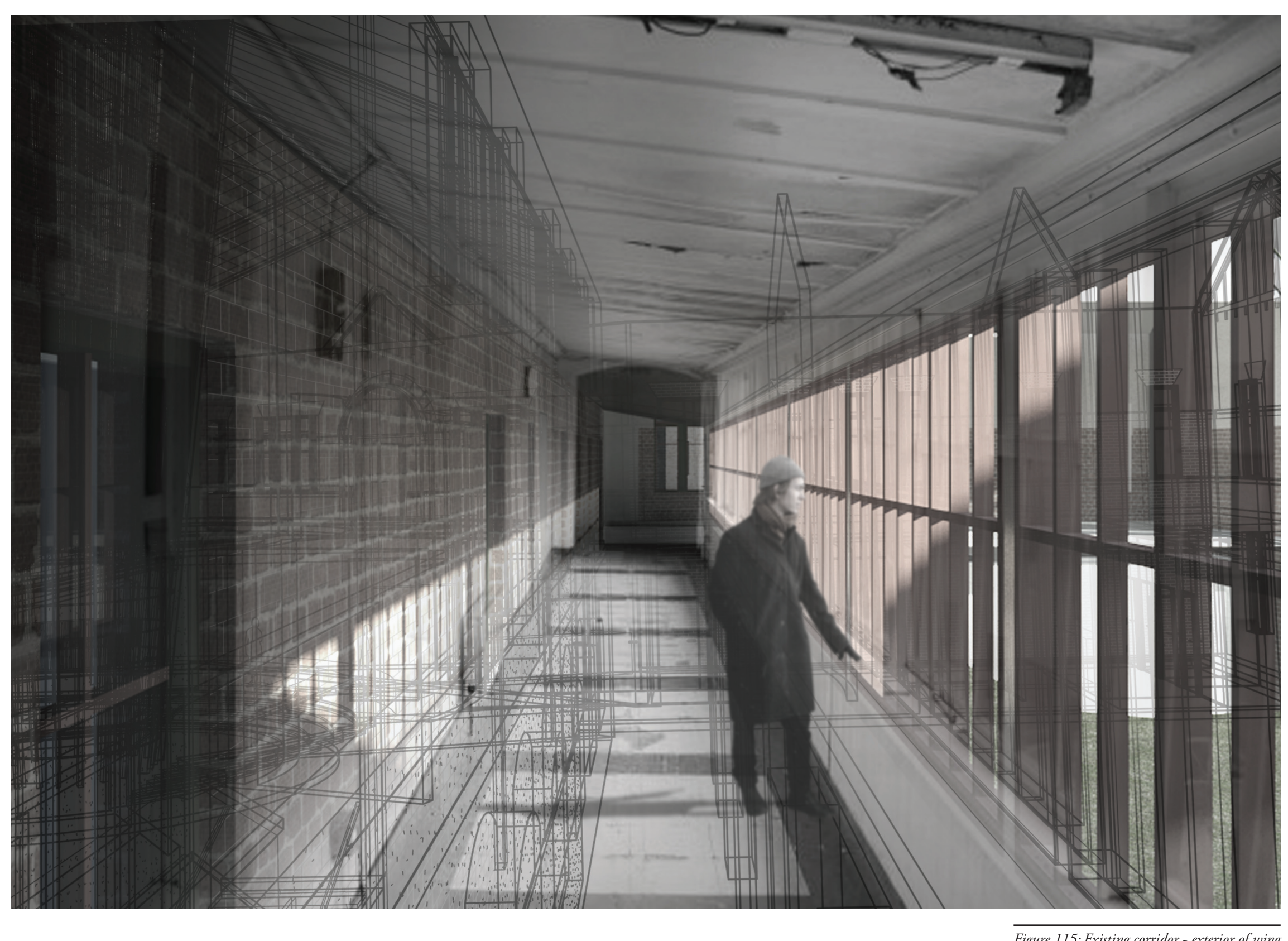




\section{Discussion}

\section{Atmosphere}

As an ascent into the existing building, the fourth act draws attention to the atmospheric conditions presented by the sites state of neglect and abandonement. The materiality of this environment is worn, chipped, and faded. The light is controlled through existing windows that span the length of each wing, lining the external corridor that wraps around the treatment wards, and movement patterns conform to existing paths and doorways.

Intangible Heritage

As the primary bathing spaces during the buildings operation as an isolation hospital, the brick pavilions offer a dramatic transition from the bath-house below into the existing building. 


\section{I denouement}

In some cases, the protagonist is better off than at the narratives outset; in others, the story ends in tragedy. In either case, emotional tension and anxiety are purged."5

$\overline{5}$ Robert Klanten, F. S. (2011). Erratic: visual impact in current design. Berlin: Gestalten, p5

Within the fifth act of this design, a conclusion is reached in the experience of the user. The dominant structure, visible throughout ones progression of the building, is gradually ascended. This ascent begins in darkness, with thin shafts of light penetrating the perforations of the structures exterior. As the user ascends the panels attached to the exterior of the structure begin to dissipate, allowing glimpses outward. These panels continue to fade, allowing increased views of the surroudning environemnt as the user progressess upwards. The conclusive point of this act is reached as one finds themself atop of the structure. From here they are provided a view back toward the city, reinforcing the isolated placement of the site and providing a retrospective understanding of the journey undertaken.

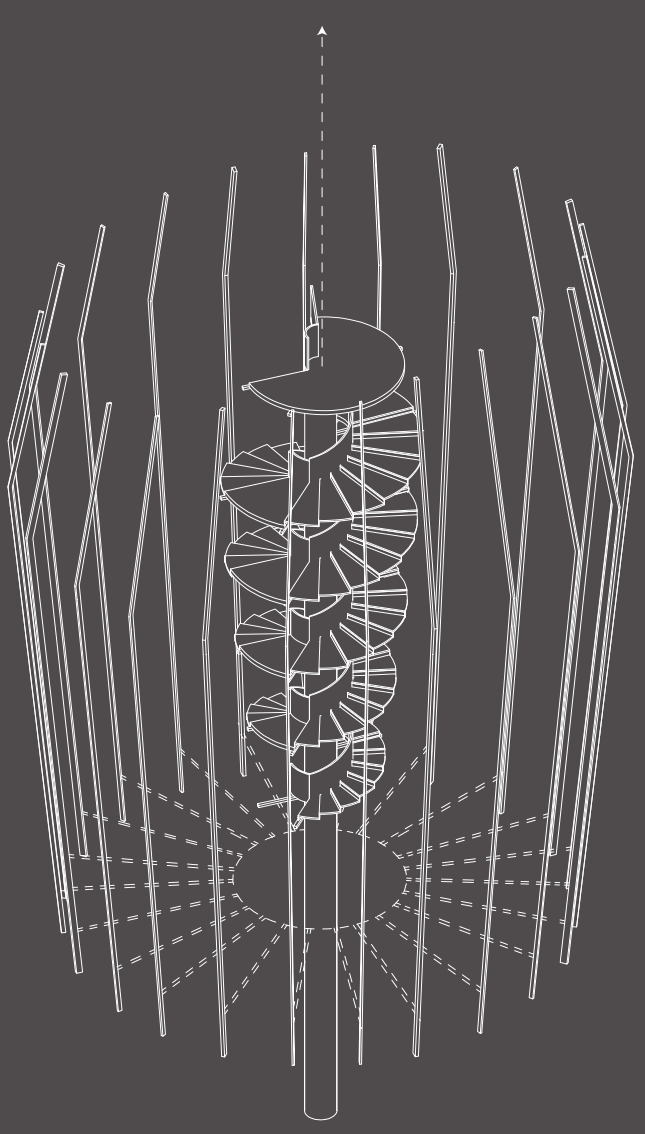

Figure 116: Act Five: Primary structure of viewing tower 


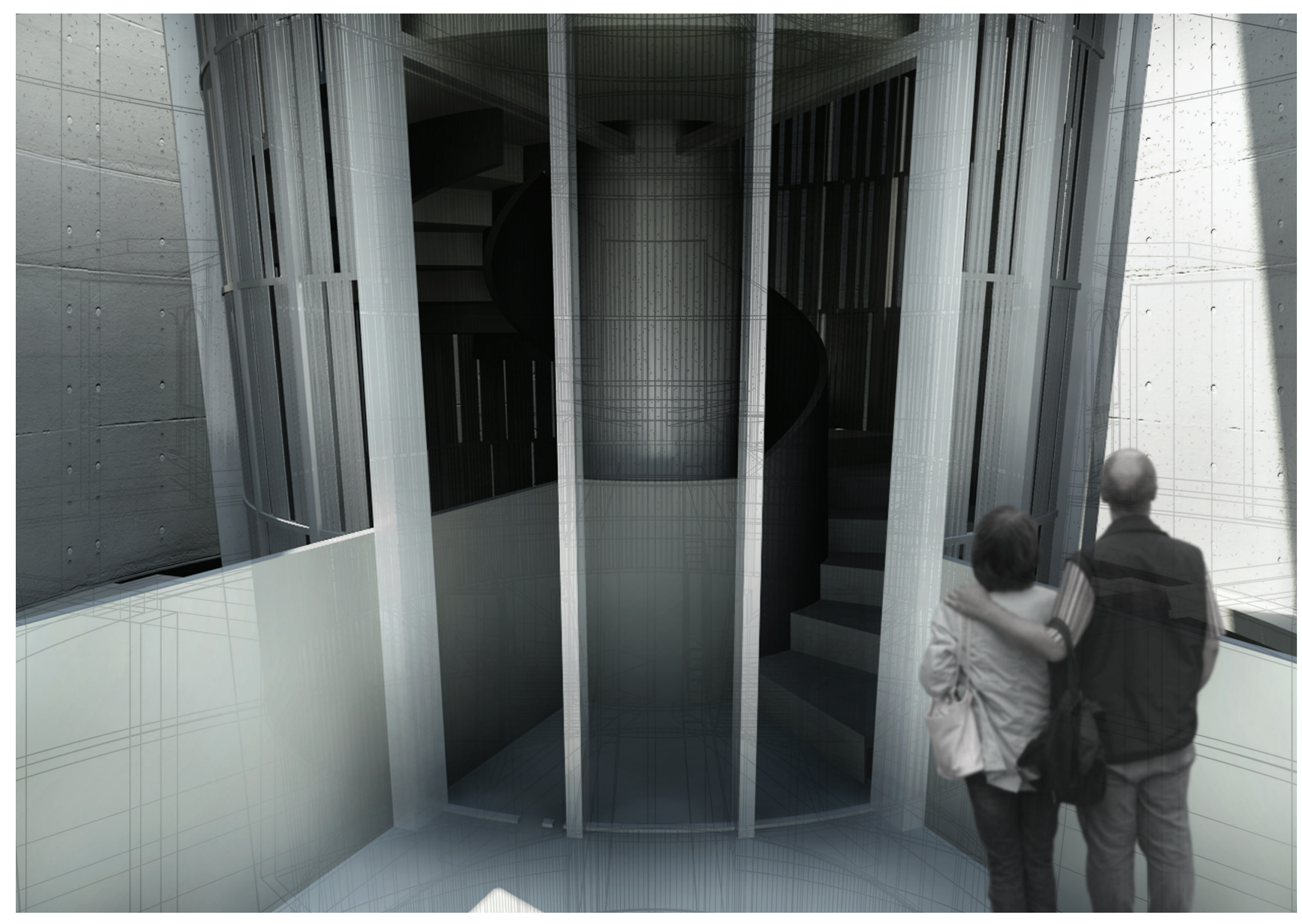



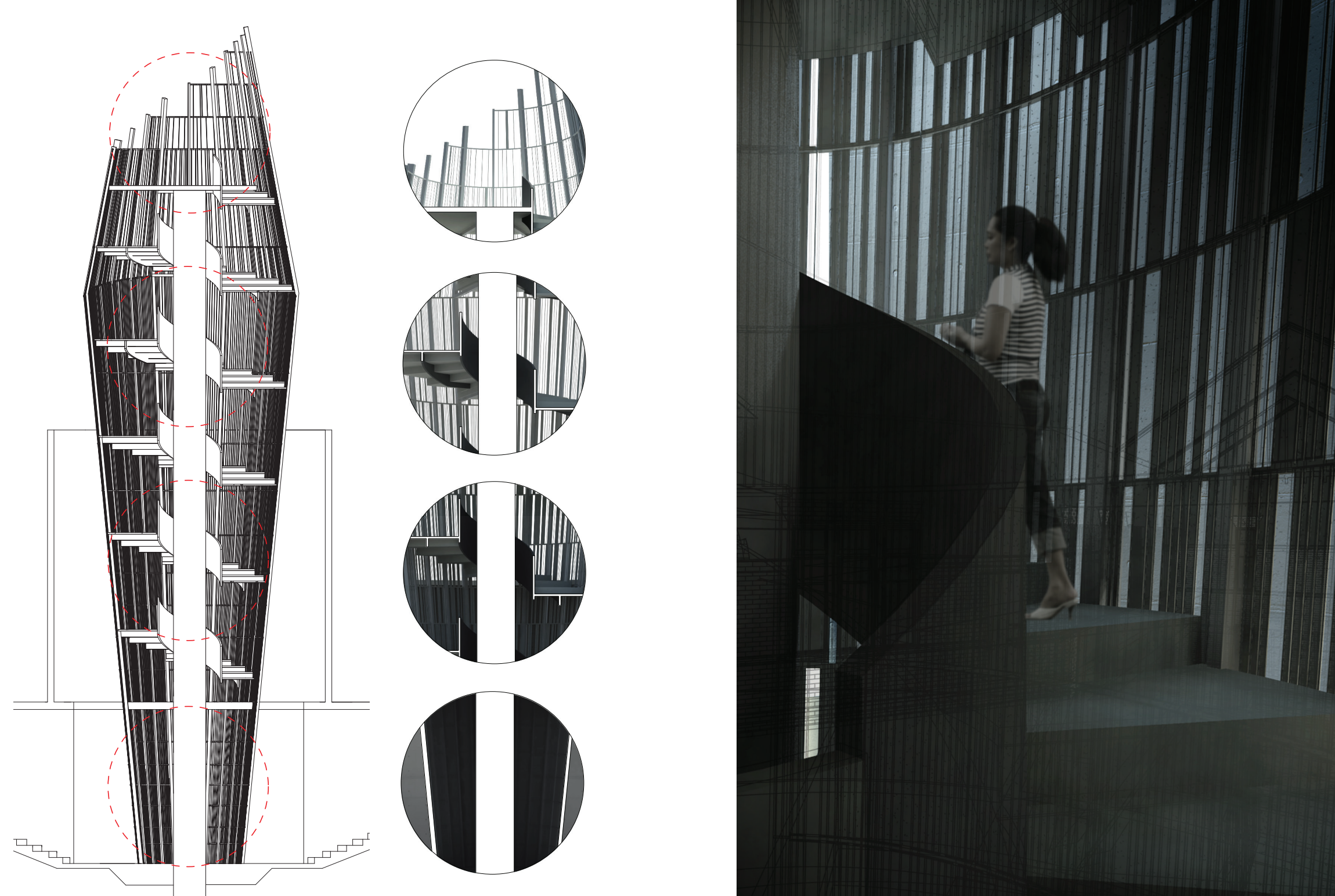

Figure 118: Diagramatic section illustrating ascent from dark to light Figure 119: Ascent one 

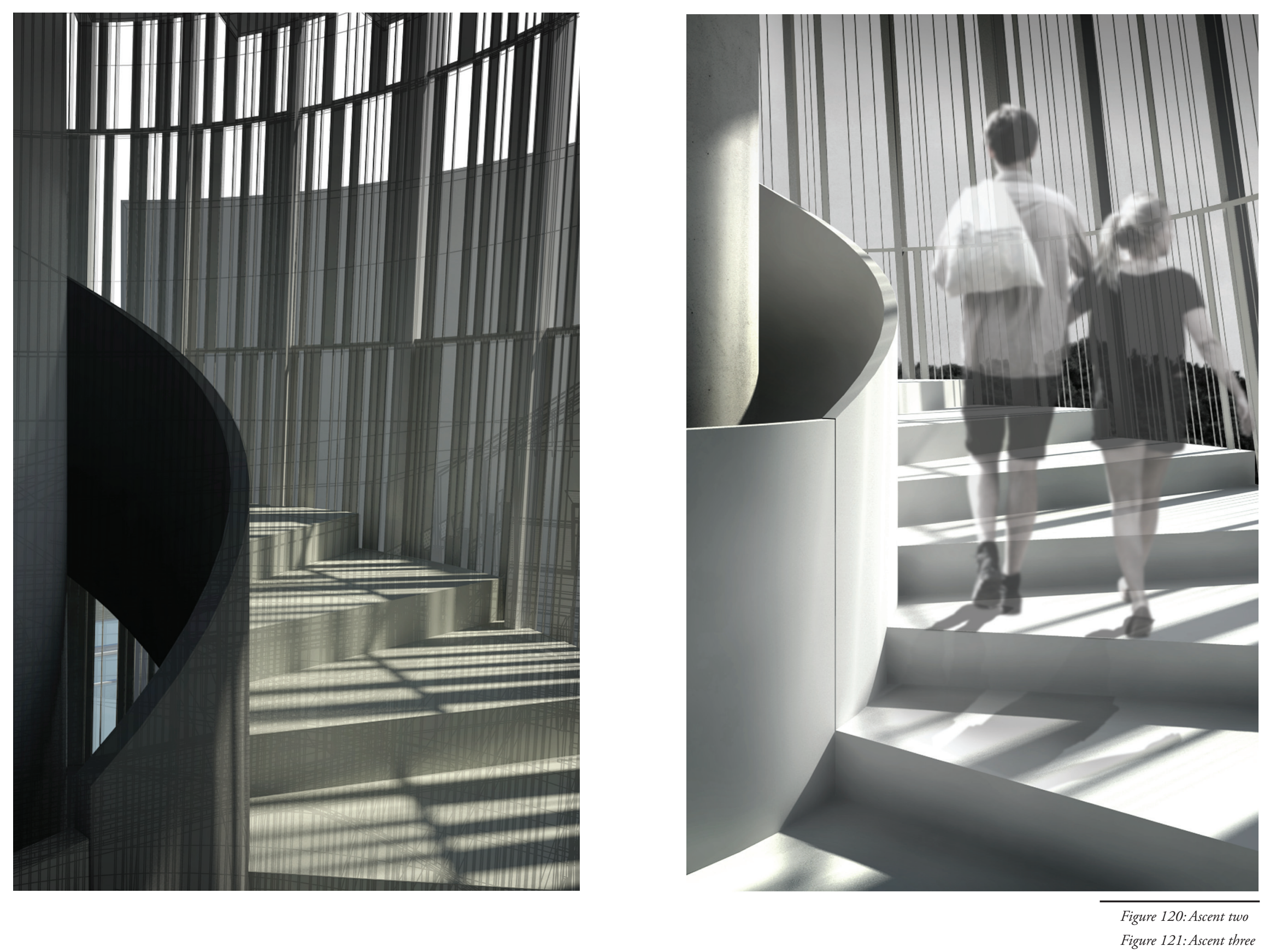


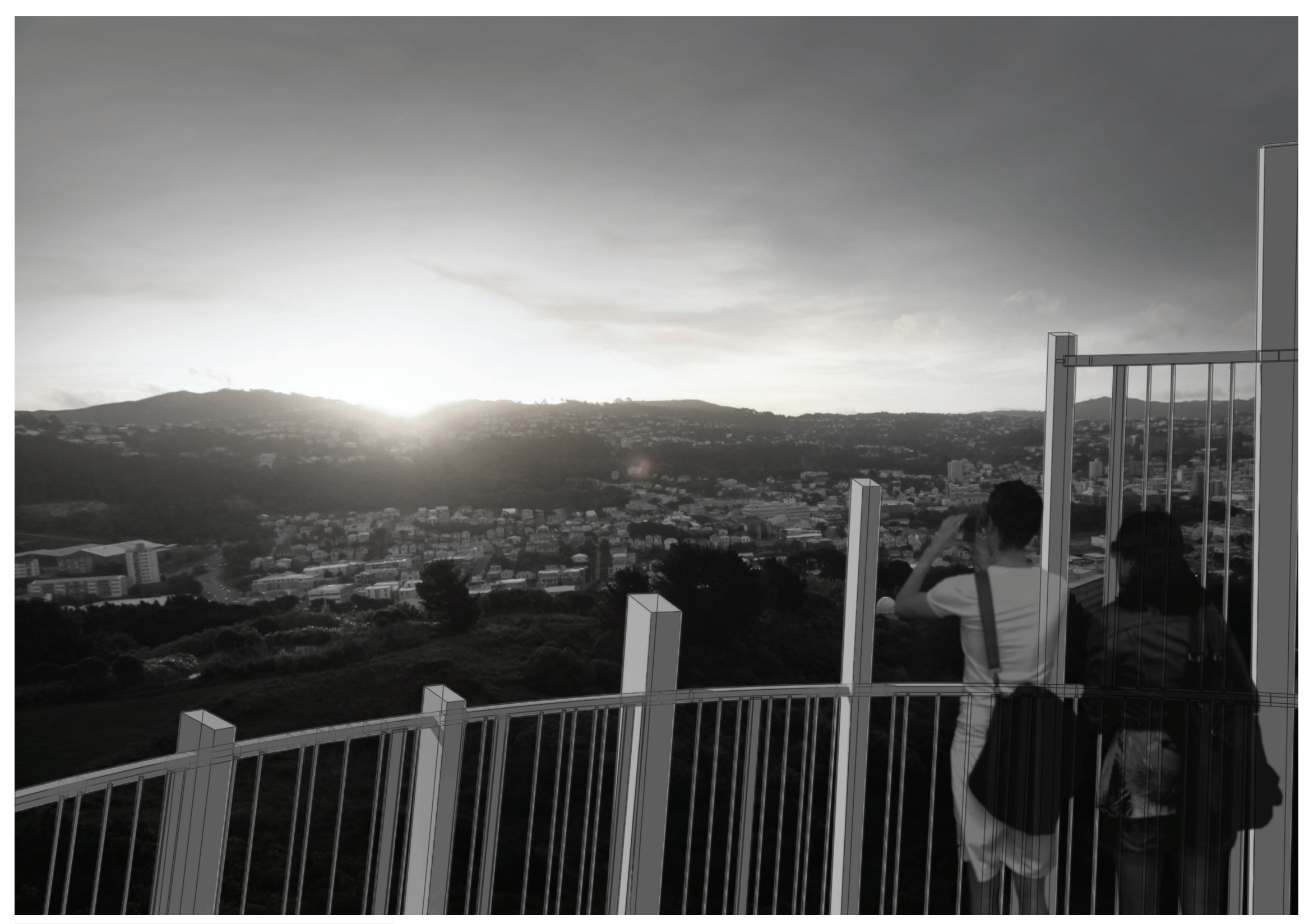




\section{Discussion}

\section{Atmosphere}

Within the fifth act, atmosphere is used to create a dramatic ascent above both buildings. While concrete continues to dominate the material palette, it has a polished white finish which aims to enhance the transition from the dark spaces below. As the user progressess upwards the building appears to soften and the panels of its facade slowly dissipate, giving way to the increasing presence of natural light.

Intangible Heritage

This ascent seeks to resolve the tension raised within the preceding acts. The building opens toward the city, communicating the sites close, yet entirely segregated location. Illustrating its isolated placement while integrating it into public conciusnes. 


\subsection{Design Reflection}

This developed design presents a speculative understanding of architectures capacity to stimulate reminiscence to the intangible heritage present in sites of historic value. The process of site experienced through distinct acts is intended to allow the user to interpret the portrayal of intangible heritage more easily. Within this journey, atmosphere is used to construct dramatic spatial environments and transitions that elicit feelings of reminiscence; informed by the historic functions of bathing, fresh air, and isolation presented by the site. As the outcome of this design-led research, this design symbolises the potential of alternative action within sites that remain seperated from public conciousness due to the strict preservation guidelines outlined by International bodies like ICOMOS. This design presents heritage in a manner that de-centres physical remains as the essence of history, and communicates the past through an imaginative reconstruction of intangible heritage. The architecture of this design creates a journey within the site that amplifies emotions as a means of reminiscence. The individual acts of this design communicate a seperate function and build toward the culmination of the journey, experienced at the conclusion of the final act. Each act employs atmosphere and spatiality in an attempt to construct sensations that assert themselves as witness to the history of the site. This approach argues for heritage as an architectural experience, employing the role of atmopshere and program as pivotal in this activation of intangible heritage.

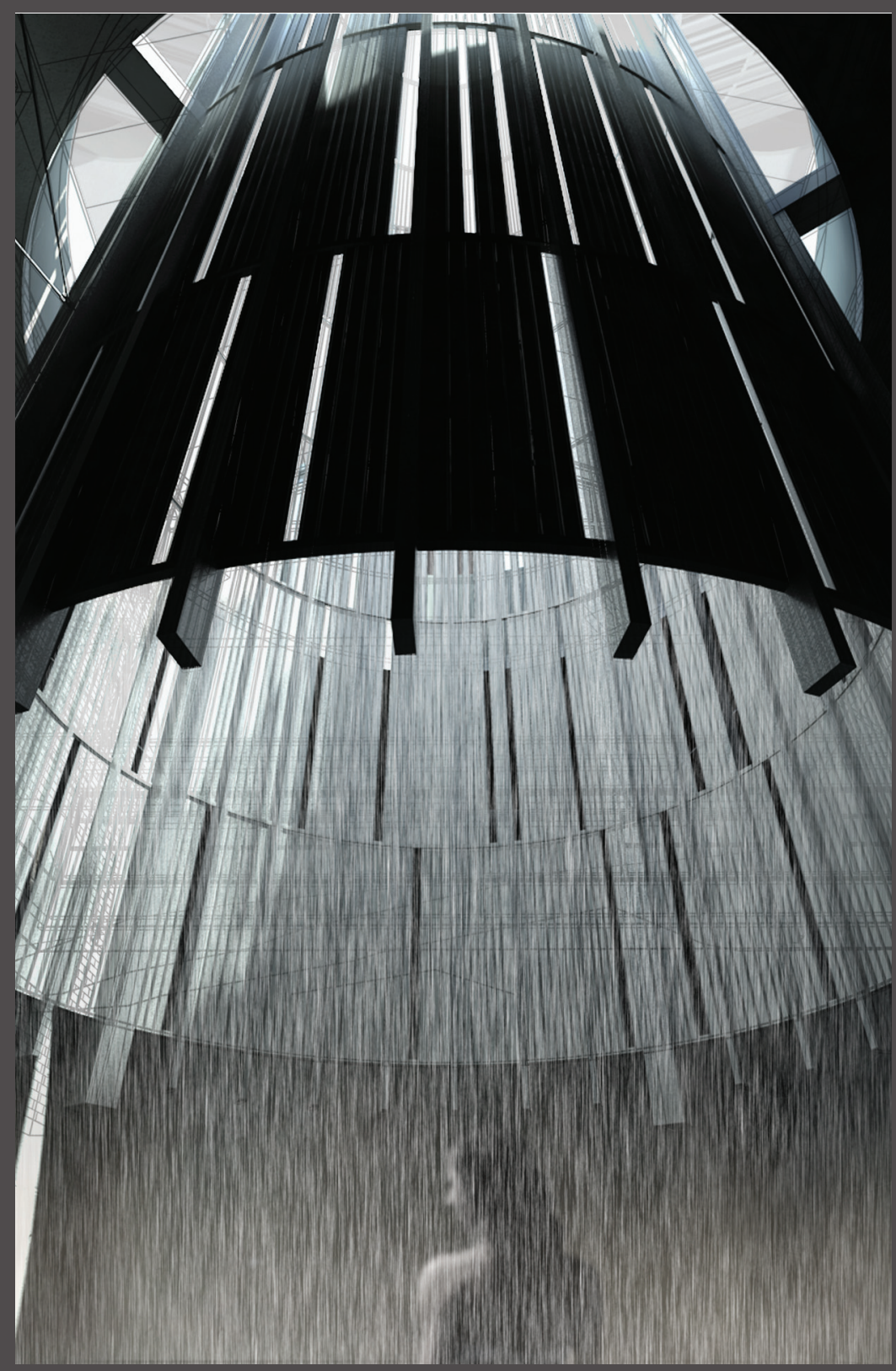

Figure 123: Act Three: Rain filtering downward through void 


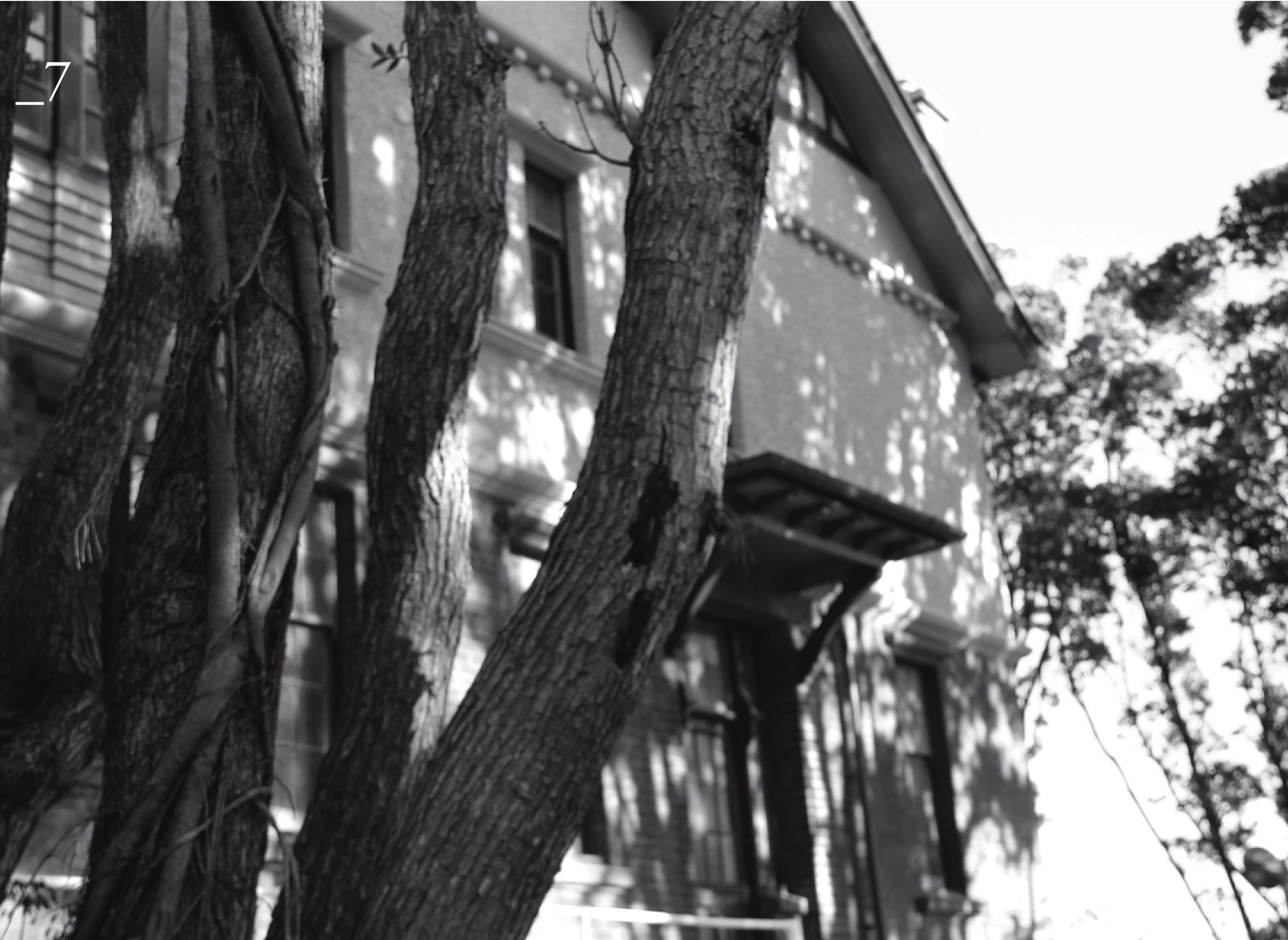




\section{CHAPTER SEVEN CONCLUSIONS}

7.0 Reflection on Design Processes and Outcome

7.1 Limitations and Further Investigations

7.2 To Conclude 


\subsection{Reflection on Design Processes and Outcome}

This thesis has explored heritage as an experience that can be facilitated by, but not limited to enduring physical remains; proposing an approach in which intangible characteristics are privileged. This investigation began with a reconsideration of the definition and role of heritage within contemporary architectural practice, drawing from the work of Smith, Harrison and Pallasmaa who argue for the concept of intangibility. This is a change in direction from the dominant physical understanding of heritage, toward an approach that embodies acts of remembering and memory making. Within this proposition architecture is given the role of conveying the intangible values and history of a site, which would otherwise remain unseen. This architectural investigation has followed an iterative working method, exploring the role of intangible heritage in communicating an active dialogue between past and present that goes beyond the realms of conventional heritage practice that focuses on physical heritage. As an investigation into inherently immaterial elements, this architectural proposition is speculative in nature. As such, the outcome of this design presents an architectural exploration informed by an alternative approach to heritage; symbolizing the potential role of intangible heritage.

By removing existing architectural elements such as the roof and internal walls of the hospital complex, the design of this thesis was able to add to the existing building and create a dialogue between the two; both existing and intervening. The Hedmark Museum provided a case study to approach the hospital complex in this way. While aesthetically contrasting the existing structure, its contemporary and intervening elements became integrated as part of the building. Informed by this case study, the design of this thesis inserts itself within the footprint of the building and conforms to the existing geometries. It sought to disrupt the existing physical shell, while still preserving evidence of its material, form, and plan. The steel moment frames that span between the external walls of each wing reinforce the fragile brickwork of the building, while following the gable forms of the original roof structure. This is intended to create a dialogue between the two; aesthetically distinct, yet intimately connected. This connection between old and new 
aims to enhance the experience of the user, creating an overlay between intangible and physical heritage; the physical remains establish the stage on which intangible heritage is performed.

Within this design the typology of the memorial museum provided insight into architectural mechanisms used to construct a sense of aesthetic remembrance. Through written research and case study analysis atmosphere was identified as a pivotal element; controlling light, shadow, material, and narrative. Within this thesis, these atmospheric mechanisms have been employed in order to convey historic values that could not otherwise be expressed, creating a physical connection to the intangible aspects of history. The spatiality of this environment is intended to allow the occupant to move from knowing, in a factual sense, to experiencing as a witness. The activation of intangible heritage is a complex and multi-layered process. It requires an approach to architecture that privileges the relationships, associations, and functions that underpin the history of a site above its enduring physical remains. It offers a framework for the design of a contemporary intervention; able to imaginatively recreate the historic function, value and meaning of a site through the nuances of architectural form and atmosphere. Above all, the activation of intangible heritage involves a multi-sensory experience of architectural atmosphere; within which reminiscence is formal- ized through a historical narrative of space, visually evoking feelings in regard to the history of place. The five acts were a place to explore this, each offering a separate spatial and atmospheric environment. The implementation of these acts allowed the design to move from a generalized expression of intangible heritage to linear progression, slowly communicating aspects as the user progresses. This provided cohesion between different areas of the building and allowed the design to begin to operate as a whole, compared to earlier iterations that analyzed a particular area within the building.

\subsection{Limitations and Further Investigations}

The iterative working method of this thesis, following a design-led research structure, has allowed theoretical positions to be explored within an architectural setting. While constructional realities have informed design decisions throughout this process, the developed design of this thesis does not focus on structural resolution. This is due to the working method of the thesis, privileging atmosphere and spatiality as primary concerns throughout iterative testing. Through further development, this research would investigate more technical details within the design. This would analyze the programmatic connections and spatiality at a 
more intimate scale, seeking a higher level of structural resolution that enhances the representation of intangible heritage. Further development would also seek resolution within areas of the site that have not been comprehensively addressed and represented within the developed design, specifically the Nurses Home. Due to its intact and unchanged condition, unoccupied since its original use, it remains as it currently exists. The design removes its front entry and porch, creating movement patterns that follow the narrative structure employed. However both side entrances are maintained, opening the building as a preserved mnemonic device to the period in which the hospital was constructed. Through further development, the existing physical state of this building would have been further explored and utilized within the experience of the site.

\subsection{To Conclude}

As presented by Smith, the conventional understanding of heritage tends to be dominated by the assumption that tangible heritage 'just is', and that the history that physical remains represent is simply defined through inherent qualities. ${ }^{1}$ As such, this research proposes that in order for one to understand the history that underlies a site, links to the past must be actively forged and created. Within history-laden heritage sites contemporary architecture hold the potential of being constructed in acknowledgement of the identity of place. The form, atmosphere, and program of a contemporary intervention construct an environment of reminiscence; able to enhance one's ability to understand and read the intangible layers that underlie the history of the site.

It is impossible to provide a precise framework for the activation of intangible heritage applicable to all sites of historic value. The diverse history of each site offers a complex and varied framework, requiring an imaginative architectural response specific to that history. As such, the design-led exploration of this thesis is represented as a site specific investigation. However, the investigation provides insight into the powerful role of atmosphere in communicating the less tangible aspects of history. The use of light, shadow, material, and narrative has been evidenced as a pivotal consideration in the activation of intangible heritage. While this research does not provide a strict set of guidelines, it offers a thought-provoking contribution to existing theories surrounding intangible heritage and illustrates its potential within architecture and heritage practice. 


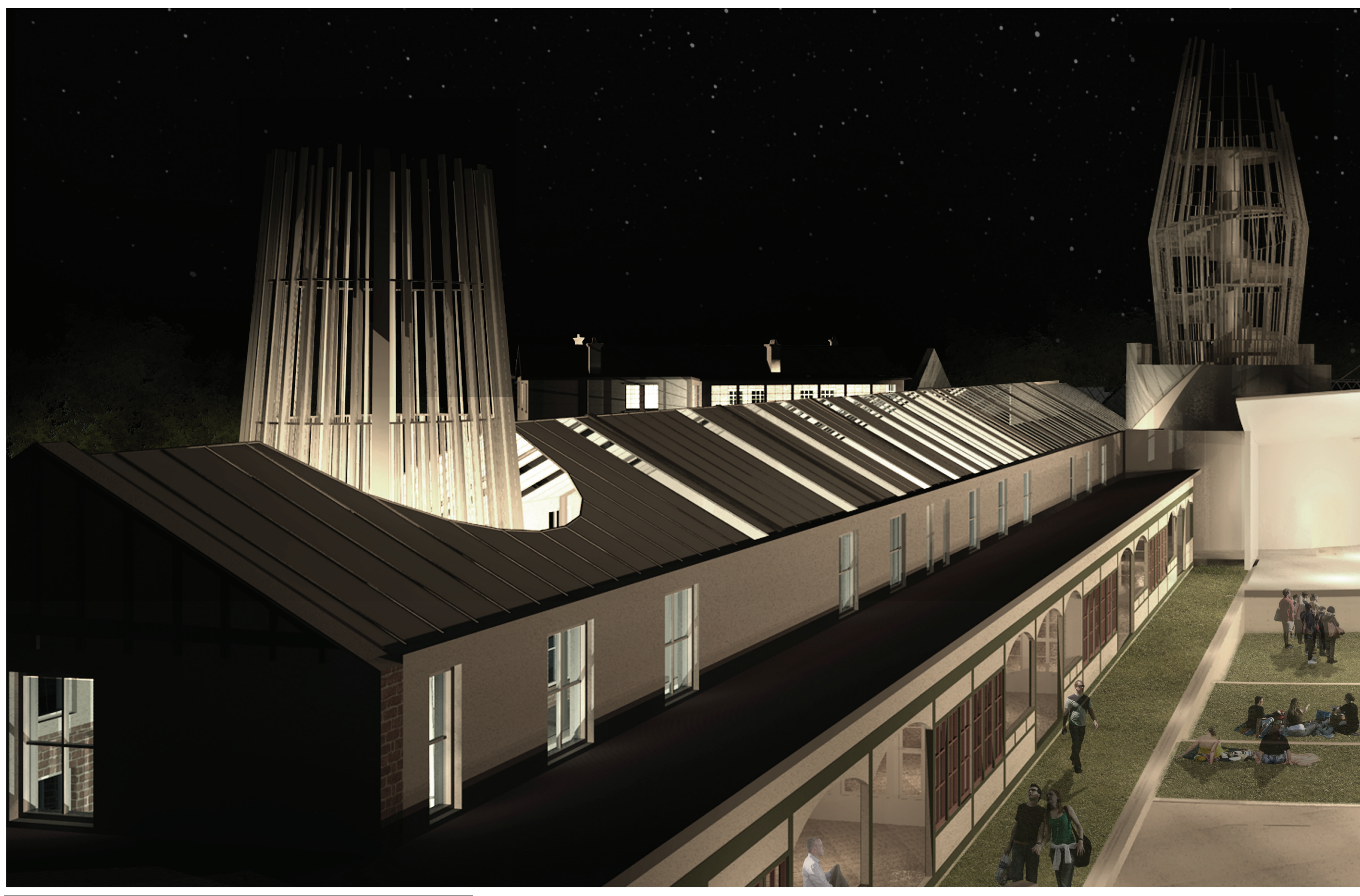




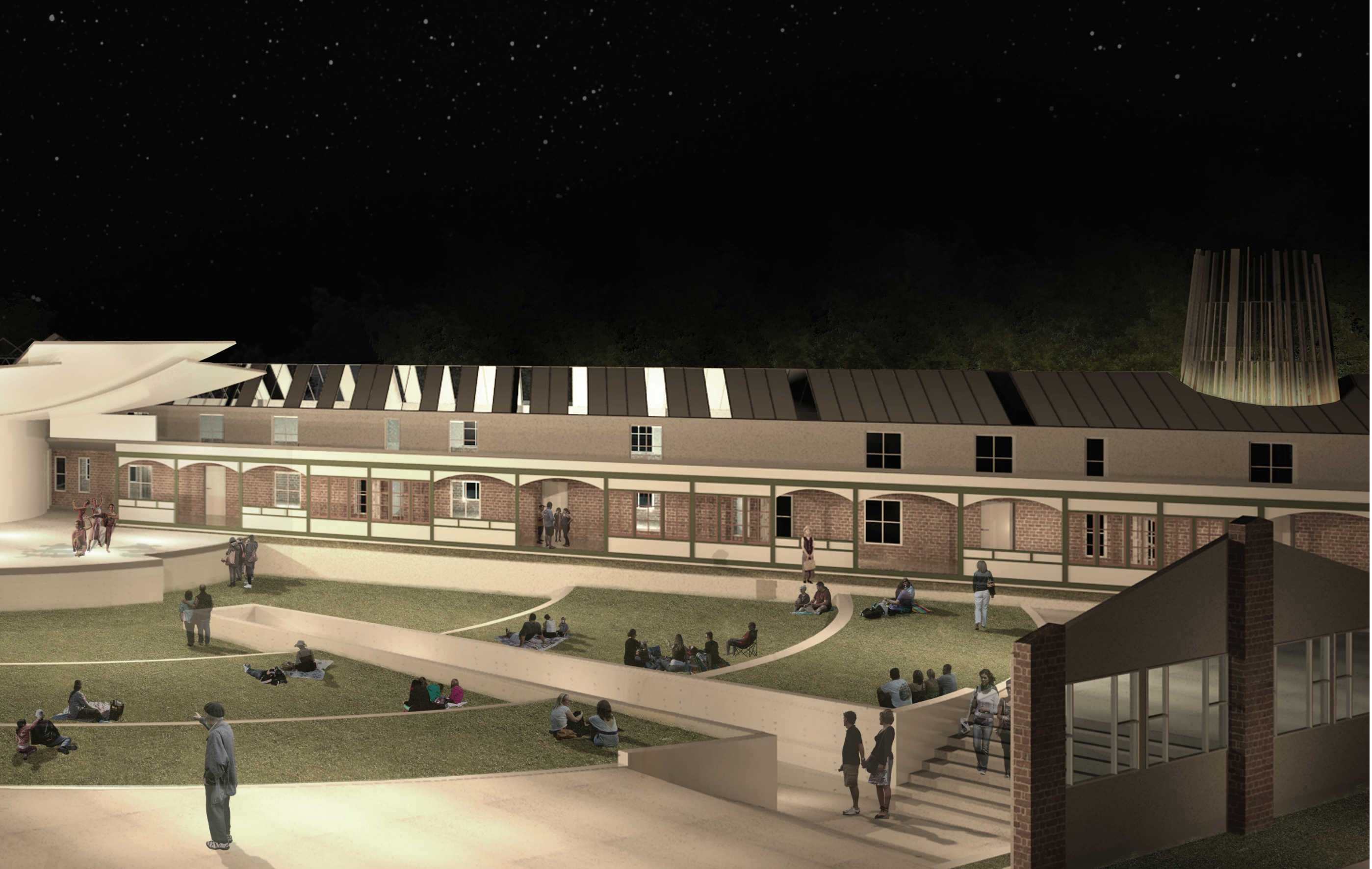




\section{Bibliography}

Akagawa, L. S. (2009). Intangible Heritage. New York: Routledge.

Alivizatou, M. (2012). Intangible Heritage and The Museum. Left Coast Press.

Bagnall, G. (2003). Performance and Performativity at Heritage Sites. Museum and Society, pp. 87-103.

Bastéa, E. (2004). Memory and architecture. University of New Mexico Press.

Bowman, I. (1998). Wellington Hospital for Infectious Diseases Heritage Assessment. Wellington: Wellington City Council.

Casey, E. S. (2000). Remembering: A Phenomenological Study. Indiana Press University.

Charleson, A. (2013). Structure as Architecture. Taylor and Francis.

Chipperfield, D. (1996). Thermal Bath at Vals. AA Exhibition Gallery, 72-75.
Corbusier, L. (1959). Towards a new architecture. London: Architectural Press.

Cubitt, G. (2007). History and Memory. Manchester: Manchester University Press.

Descottes, H. (2011). Architetcural Lighting: Designing with Light and Space. New York: Princeton Architectural Press.

Downton, P. (2003). Design research. Melbourne: RMIT Publishing.

Ellis, E. (1998). Chest / Fever Hospital - Historical Review. Hanorah: Information \& Research Services.

Fehn, S. (1992). The poetry of the straight line. Helsinki: Museum of Finnish Architecture.

Fehn, S. (1993). Blending The Old And The New. Architecture Aujourd Hui, 94-103.

Fehn, S. (1998). The Hedmark Cathedral Museum, Hamar, Norway . Architecture and Urbanism, 106-141. 
Fjeld, P. O. (1994). The workings of Sverre Fehn. Progressive architecture, 50-57.

Fjeld, P. O. (2009). Sverre Fehn : the pattern of thoughts. New York: Monacelli Press.

Frascari, M. (1990). A Secret Semiotic Skiagraphy. VIA 11: Architecture and Shadow, 32-51.

Geden, B. (2004). Chest Hospital Heritage Inventory. Wellington: New Zealand Historic Places Trust.

Glendinning, M. (2013). The Conservation Movement: A history of architectural preservation. New York: Routledge.

Hansen-Glucklich, J. (2010). Evoking The Sacred: Visual Holocaust Narratives In National Museums. Journal of Modern Jewish Studies: Volume 9, No. 2, 209-232.

Harrison, R. (2013). Heritage: Critical Approaches. New York: Routledge.

Hauser, S. (2007). Peter Zumthor therme Vals. Zurich: Scheidegger \& Spiess.
Hawkes, D. (2008). The Environmental Imagination:Technics and poetics of the architectural environment. London: Taylor and Francis.

(2009). Heritage at Risk: Fomer Fever Hospital Building, Wellington. Wellington: New Zealand Historic Places Trust.

Hill, J. (2004). The Double Dimension: Heritage and Innovation. The Royal Australian Institute of Architects.

Huyssen, A. (2003). Present Pasts: urban palimpsests and the politics of memory. Stanford, California: Stanford University Press.

Inventory, H. B. (2001). Former Fever Hospital. Wellington: Wellington City Council.

Jan Smitheram, S. T. (2009). Occupying Atmosphere. Brighton: Victoria University Wellington.

Jokilehto, J. (1999). A History of Architectural Conservation. Butterworth-Heinemann.

Jonas, W. (2007). Design Research and its Meaning to the Methodological Development of the Discipline. In R. Michael, Design Research Now (pp. 187-206). Birkhäuser. 
Lawrence, R. (2009). Sverre Fehn: the architect who built on the horizon. Architectural Research Quarterly, Vol. 13, 11-15.

Libeskind, D. (1992). Extension to the Berlin Museum with Jewish Museum department. Berlin: Ernst \& Sohn.

Libeskind, D. (200). Daniel Libeskind : the space of encounter. New York: Universe.

Libeskind, D. (2008). Daniel Libeskind and the Contemporary Jewish Museum : new Jewish architecture from Berlin to San Francisco . San Francisco: Contemporary Jewish Museum.

Lois Frankel, M. R. (2010). The Complex Field of Research: for Design, through Design, and about design. Design Research Society.

McCarter, R. (2012). Understanding Architecture: a primer on architecture as experience. London: Phaidon Press Limited .

Miyake, R. (1994). Light \& space : modern architecture . Tokyo: A.D.A. EDITA.

Moure, G. (2000). Architecture without shadow . Barcelona: Ediciones Poligrafa.
Norberg-Schulz, C. (1997). Sverre Fehn : works, projects, writings, 19491996. New York: Monacelli Press.

Olgyay, V. (1963). Design with climate: bioclimatic approach to architectural regionalism. Princeton University Press.

Olin, R. S. (2003). Monuments and Memory, Made and Unmade. Chicago: The University of Chicago Press.

Pallasmaa, J. (2000). Hapticity and Time: notes on fragile architecture. The Architectural Review (London). Vol. 207, 78-84.

Parnell, S. (2009). The mediation of Peter Zumthor's Therme Vals. Architects' Journal: Volume 229, 48-49.

Petzet, M. (2003). Place - Memory - Meaning: Preserving Intangible Values in Monuments Sites. ICOMOS 14 th General Assembly and Scientific Symposium.

Plummer, H. (2012). Nordic Light: Modern Scandinavian Architecture. Thames \& Hudson.

Reed, A. (1990). Signifying Shadows. VIA 11: Architecture and Shadow, $12-25$. 
Reuber, P. (2002, June). Therme Vals. The Canadian Architect, p. 25.

Robert Klanten, F. S. (2011). Erratic: visual impact in current design. Berlin: Gestalten.

Rotem, S. S. (2013). Constructing Memory: Architectural Narratives of Holocaust Museums. New York: Peter Lang.

Safdie, M. (2006). Yad Vashem: The Architecture of Memory. Lars Muller Publishers.

Schneider, B. (1999). Daniel Libeskind: Jewish Museum Berlin . Prestel.

Smith, L. (2006). Uses of Heritage. New York: Routledge.

Steane, M. A. (2011). The Architecture of Light: Recent Approaches to Designing with Natural Light. New York: Routledge.

Tanizaki, J. (1977). In Praise of Shadows. Leete's Island Books.

Torres, E. (2005). Zenithal Light. Barcelona: Collegi d'Arquitectes de Catalunya.

Treib, M. (2009). Spatial Recall: memory in architecture and landscape. New York: Routledge.
Wigley, M. (1998). Architecture of Atmosphere. Daidalos 68 , 18-27.

Yerkovich, S. (2006). Linking the Present with the Past through Intangible Heritage in History Museums. International Journal of Intangible Heritage, 45-52.

Young, J. E. (2000). Daniel Libeskind's Jewish Museum in Berlin: The Uncanny Arts of Memorial Architecture. Jewish Social Studies, Volume 6, Number 2, 1-23.

Zumthor, P. (1996). Thermal bath at Vals. London: Architectural Association.

Zumthor, P. (1997). Three concepts : Thermal Bath Vals, Art Museum Bregenz, "Topography of Terror" Berlin. Berlin: Birkhauser Verlag.

Zumthor, P. (1998). Peter Zumthor works : buildings and projects 19791997. Baden, Switzerland : Lars Muller Publishers.

Zumthor, P. (2006). Atmospheres: architectural environmentd; surrounding objects. Birkhäuser.

Zumthor, P. (2006). Atmospheres: architectural environments ; surrounding objects. Basel: Birkhäuser. 


\section{List of Figures}

Within this section, all figures that are not listed as having a source are of the the authors own collection.

Figure 1. Cover photo

Figure 2. Site: Surrounded and eclosed by forest

Figure 3. Diagram illustrating thesis structure and research weight-

ing

Figure 4. Site: Existing brickwork

Figure 5. Site: Syringe on window sill

Figure 6. Site: Window of Nurses Home

Figure 7. Pathway amidst the ruins, Hedmark Museum. Source: http://littlebigfacades.com/wp-content/uploads/2014/02/3.16.jpg. (Accessed 10th April 2014)

Figure 8. Bathing space, Therme Vals. Source: http:I/auxpaysdesmerveilles.wordpress.com/2012/12/13/helene-binet). (Accessed 10th April 2014)
Figure 9. Chaotic struts-cum-beams, Jewish Museum. Source: https://www.flickr.com/photos/manuelasiener/194796045/in/photostream/. (Accessed 10th April 2014)

Figure 10. Suspended walkway into existing building. Source: http:// www.bldgspace.com/post/2648051104/subtilitas-sverre-fehn-hedmarkcounty-museum (Accessed 10th April 2014)

Figure 11. Glazed roofing above concrete blocks containing displays. Source: http:I/farm4.staticflickr.com/3294/2987110747_7fb342ab64_n. jpg. (Accessed 10th April 2014)

Figure 12. Suspended walkway approaching blocks. Source: http:// littlebigfacades.com/wp-content/uploads/2014/02/1.15.jpg. (Accessed 10th April 2014)

Figure 13. Ramp providing access to wings of barn. Source: http:// designlikethis.tumblr.com/post/33993941120/n-architektur-the-hedmarkcathedral-museum. (Accessed 10th April 2014)

Figure 14. Rough exposed concrete of pathway. Source: https://www. fickr.com/photos/44124406151@N01/2987114557. (Accessed 10th April 2014) 
Figure 15. Glulam structure within existing barn. Source: https:// www.fickr.com/photos/pg/2987113463/in/photostream/. (Accessed 10th April 2014)

Figure 16. Central bathing space. Source: http:l/www. latimes.com/entertainment/arts/culturellat-cindy-zumthorla0010763571-20130117,0,564020.photo. (Accessed 14th April 2014)

Figure 17. Light filtering through slit within the roof. Source: http:// blog.thedpages.com/wp-content/uploads/2013/05/peter-zumthor-thermevals-dpages-blog-10.jpg. (Accessed 14th April 2014)

Figure 18. Recessed lights illuminating the pools. Source: http://petitepassport.com/wp-content/uploads/2013/03/thermevals.png. (Accessed 14th April 2014)

Figure 19. Recessed lights illuminating the pools. Source: http://media-cache-ak0.pinimg.com/736x/7c/bble2/7cbbe2f4299bdf149ec9631f7c Od3fef.jpg. (Accessed 14th April 2014)

Figure 20. Plan illustrating progression to raised balcony. Source: http://c1038.r38.cf3.rackcdn.com/group1/building2978/medial tjjj_1288298107thermevalsplan01.jpg. (Accessed 14th April 2014)
Figure 21. Below raised balcony - approaching pools. Source: http:// nagyitas.net/wp-content/uploads/2010/12/Therme_Vals_6.jpg. （Accessed 14th April 2014)

Figure 22. External facade of building. Source: http://genovajoe.files. wordpress.com/2011/03/img_2587.jpg. (Accessed 14th April 2014)

Figure 23. Diagrammatic plan illustrating void placement

Figure 24. Small strip of light within the Holocaust Tower. Source: http:/lykellerman.com/images/second_war/ykellerman_second_war19.jpg. (Accessed 12th April 2014)

Figure 25. Entry from existing building through subterranean tunnel. Source: http://kberry.wordpress.ncsu.edu/fles/2012/11/Jewish-Museum-Section-through-Entrance-Void-and-Main-Staircase.jpg. (Accessed 12th April 2014)

Figure 26. Concrete struts-cum-beams above main stairwell. Source: http://archide.files.wordpress.com/2008/11/berlijn_101.jpg. (Accessed 12th April 2014)

Figure 27. Site: Brickwork - left wing

Figure 28. Wellington, New Zealand 
Figure 29. Site location - isolated from surrounding context

Figure 30. Photograph illustrating sites isolated placement from surrounding context

Figure 31. Context within local Wellington Suburbs

Figure 32. Vehicular access - Alexandra Road

Figure 33. Aerial photograph showing the isolated placement of the hospital complex

Figure 34. Construction begins on central addition (1972). Source: http://www.rehomespca.org.nz/downloads.htm. (Accessed 8th April 2014)

Figure 35. Construction nears completion (1973). Source: http:// www.rehomespca.org.nz/downloads.htm. (Accessed 8th April 2014)

Figure 36. Floor plan following central addition

Figure 37. Floor plan-Fever Hospital. Source: CCDHB (Capital o Coast District Health Board)

Figure 38. Floor plan-School of Music. Source: CCDHB (Capital o. Coast District Health Board)
Figure 39. Isometric illustrating building use - Isolation Hospital

Figure 40. Isometric illustrating building use - School of Music

Figure 41. Photograph of the site as it currently exists

Figure 42. Site: Hospital complex - brickwork and left wing

Figure 43. Physical model 1

Figure 44. Physical model 2

Figure 45. Jeremy Barnard-Danvers State Lunatic Asylum. Source: http://hween.files.wordpress.com/2011/10/screen-shot-2011-10-17-at-1024-10-pm.png. (Accessed 10th April 2014)

Figure 46. Heidi Johnson - former Traverse City State Hospital. Source: http://thumbs.photo.net/photo/1135544-sm.jpg. (Accessed 10th April 2014)

Figure 47. Christopher Payne - Taunton State Hospital, Massachusetts. Source: http://dailycool.net/wp-content/uploads/image/12Febr/Asylumlasylum04.jpg. (Accessed 10th April 2014)

Figure 48. Photographic investigation into atmospherics of abandoned Fever Hospital 
Figure 49. Initial design exploration experimenting with intervening form and geometries: 1

Figure 50. Initial design exploration experimenting with intervening form and geometries: 2

Figure 51. Initial design exploration experimenting with intervening form and geometries: 3

Figure 52. Initial design exploration experimenting with intervening form and geometries: 3

Figure 53. Dotted line outlining test location within existing wing

Figure 54. Physical model exploring perforations in floor: 1

Figure 55. Physical model exploring perforations in floor: 2

Figure 56. Physical model exploring perforations in floor: 3

Figure 57. Cross-section illustrating disconnected programs

Figure 58. Cross-sectional perspective section

Figure 59. Longitudinal perspective section showing journey and cuts

Figure 60. View from detached underground space up to civic envi- ronment

Figure 61. Test location diagram

Figure 62. Floor plans illustrating location of voids

Figure 63. Diagramatic longitudinal section

Figure 64. Longitudinal perspective section - voids penetrating through location of treatment wards

Figure 65. Cross-sectional perspective section showing descent into cimactic space

Figure 66. Climactic point within the journey

Figure 67. Test location diagram

Figure 68. Exploded isometric-fragmentation and voids

Figure 69. Movement patterns - informing progression around building

Figure 70. Diagramatic plan illustrating curvacious walls and access

Figure 71. Descent pathway to subterranean space 
Figure 72. Shadows cast downward by existing building

Figure 73. Access to bathing space

Figure 74. Longitudinal perspective section A - pools below vertical voids

Figure 75. Longitudinal perspective section B - descent stairs leading from changing rooms

Figure 76. Internal perspective within baths

Figure 77. Isometric illustrating programmatic placement

Figure 78. Conceptual development - key points within acts

Figure 79. Conceptual development - Act two: descent below existing building

Figure 80. Isometric diagram illustrating elements removed from existing building

Figure 81. Isometric diagram showing existing and intervening elements

Figure 82. Exploded isometric showing primary elements of structure
- left wing

Figure 83. tical voids

Figure 84. Floor plan outlining acts and progression, Level 00

Figure 85. Floor plan outlining acts and progression, Level-01

Figure 86. Cross-sectional perspective section AA-1:200

Figure 87. Longitudinal perspective section BB - 1:200

Figure 88. Act One: Site access and circulation

Figure 89. Approach-Alexandra Road

Figure 90. Existing entry sign

Figure 91. Driveway approach

Figure 92. Nurses Home approach

Figure 93. Nurses Home

Figure 94. Circulation around building 
Figure 95. Act Two: Descent below building

Figure 96. Longitudinal section diagram - illustrating descent into darkness

Figure 97. Outdoor performance space - approaching descent pathway

Figure 98. Descent pathway - light begins to fade

Figure 99. Confined space beneath stage - light fades entirely

Figure 100. Entry to subterranean space-looking from reception

Figure 101. Act Three: Subterranean bath-house-left wing

Figure 102. Access to wing-leading from changing rooms

Figure 103. Circulation path-natural light shafts

Figure 104. Bathing unit - visually connected to existing building above

Figure 105. Climactic bathing space - end of wing

Figure 106. Sectional perspective illustrating vertical relationship be- tween spaces - 1:100

Figure 107. Climactic bathing space - left wing

Figure 108. Climactic bathing space - right wing

Figure 109. View from beneath void

Figure 110. Act Four: Ascent into existing building - right wing

Figure 111. Access to brick pavilion ascent

Figure 112. Ascent within existing brick pavilions

Figure 113. Access from external corridor - left wing

Figure 114. Existing sun porch - end of wing

Figure 115. Existing corridor-exterior of wing

Figure 116. Act Five: Primary structure of viewing tower

Figure 117. Tower approach

Figure 118. Diagramatic section illustrating ascent from dark to light 
Figure 119. Ascent one

Figure 120. Ascent two

Figure 121. Ascent three

Figure 122. Viewing platform illustrating disconnection from city

Figure 123. Act Three: Rain filtering downward through void

Figure 124. Site: Nurses Home

Figure 125. View of performance space and descent pathway from top of auditorium seating

Figure 126. Jeremy Barnard - photographic investigations. Source: http://www.jeremybarnard.com/jeremy_barnard_photography/Danvers. html. (Accessed 12th April 2014)

Figure 127. Heidi Johnson - photographic investigation. Source: http://photo.net/photodb/folder.tcl.folder_id=179614. (Accessed 12th April 2014)

Figure 128. Christopher Payne-photographic investigations. Source: http://www.bonnibenrubi.com/Christopher-Payne_artwork_Asylum.html. (Accessed 12th April 2014)
Figure 129. Early testing of subterranean bathing - light shafts, 1

Figure 130. Early testing of subterranean bathing - light shafts, 2

Figure 131. Early testing of subterranean bathing - light shafts, 3

Figure 132. Early testing of subterranean bathing - light shafts, 4

Figure 133. Early testing of central auditorium space-cross-sectional perspective

Figure 134. Early testing of central auditorium space-longitudinal perspective section

Figure 135. Early experimentation with fragmentation and shadow

Figure 136. Fragmented view of hospital wing

Figure 137. Fragmented elements of Nurses Home 
Appendices

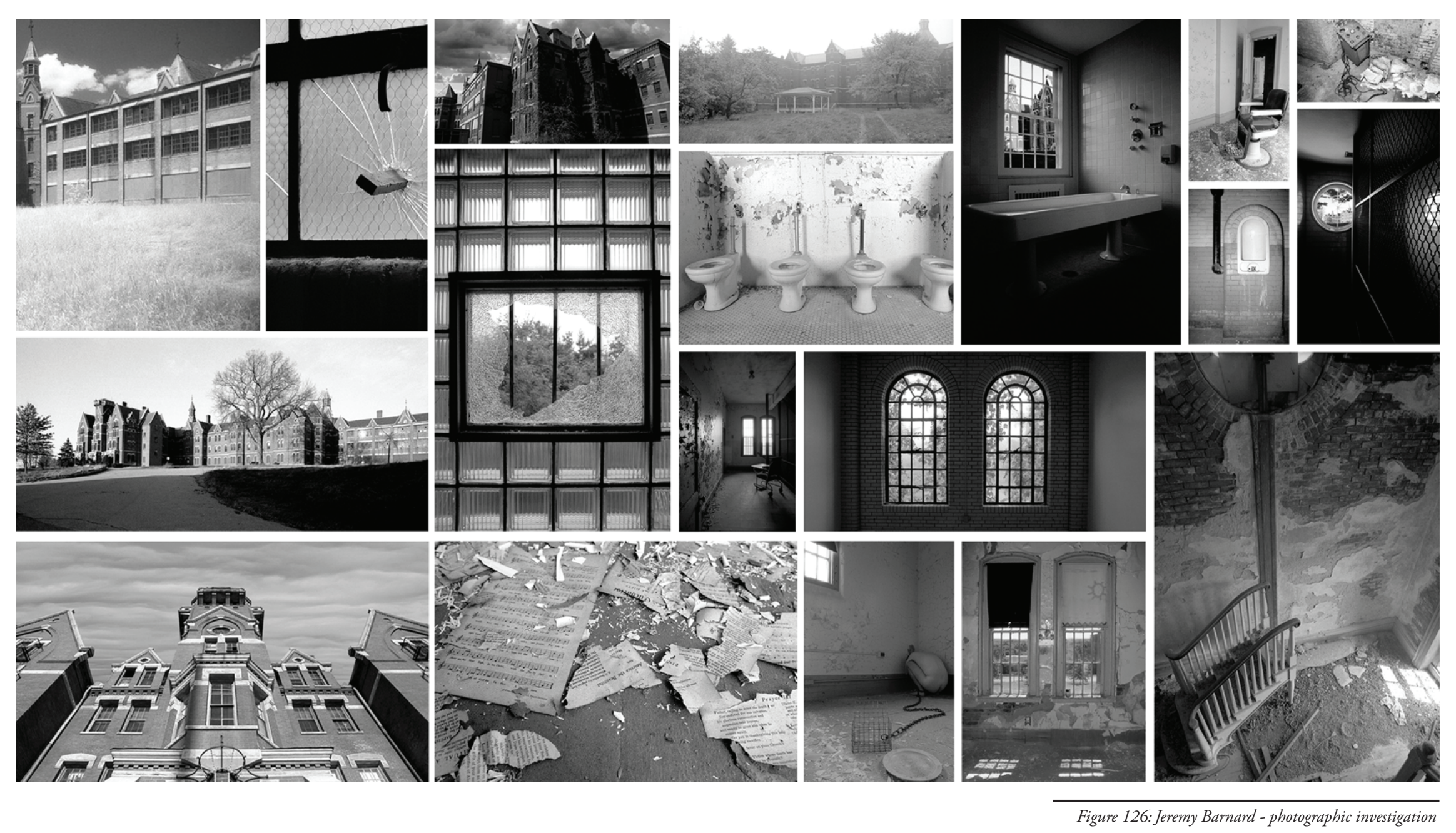



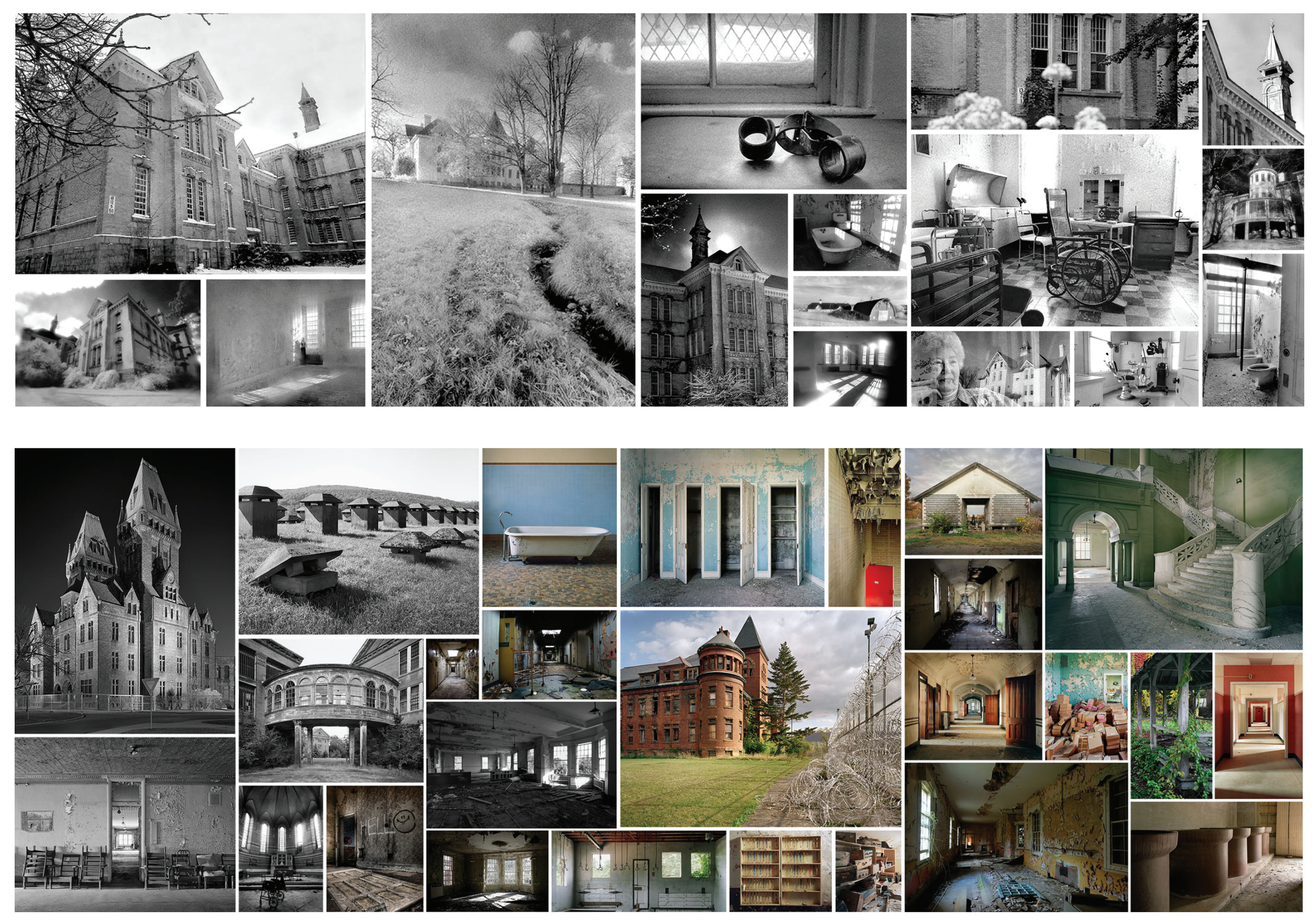

Figure 127: Heidi Johnson - photographic investigation

Figure 128: Christopher Payne - photographic investigation 

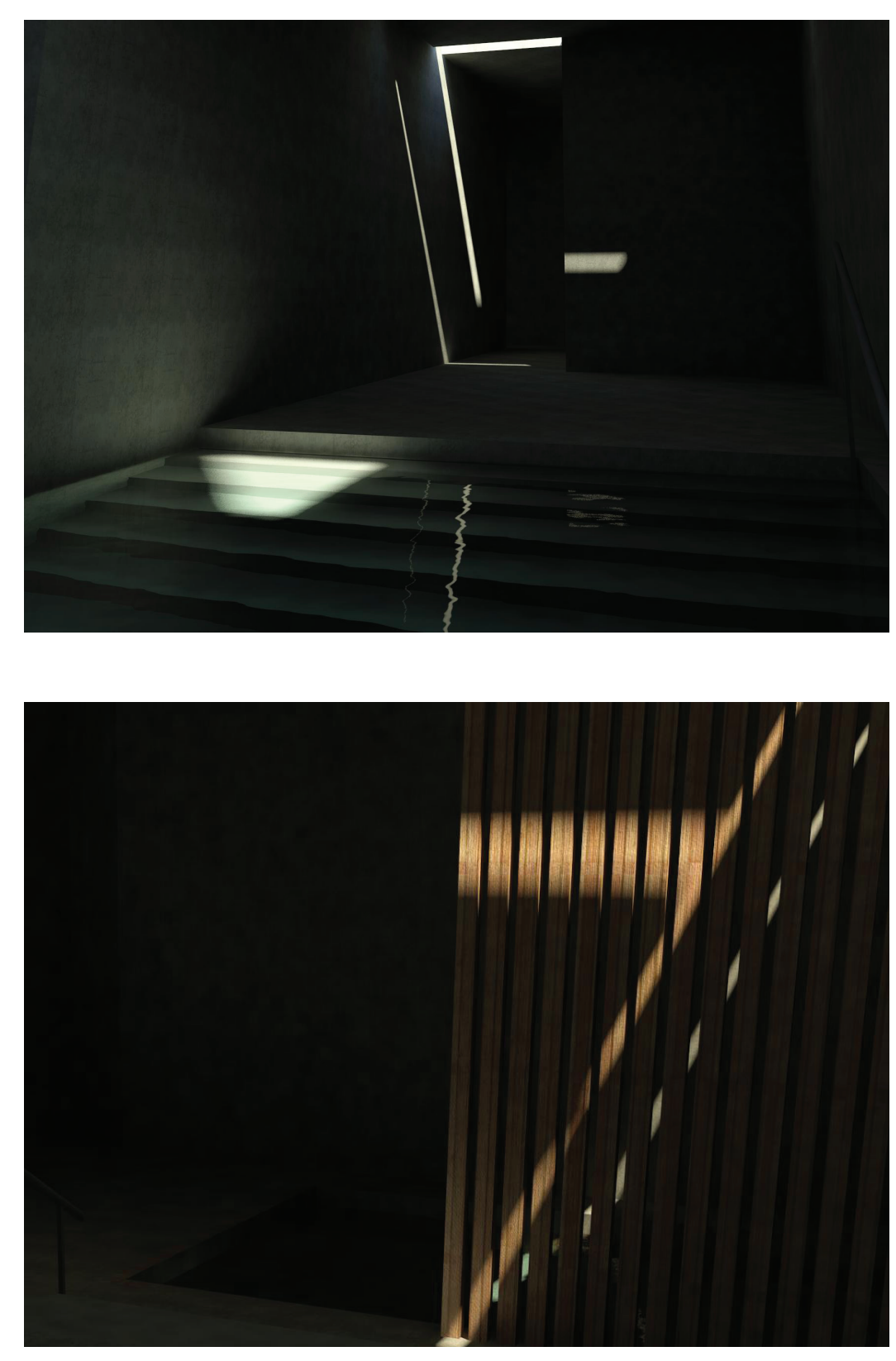

Figure 129: Early testing of subterranean bathing - light shafts, 1 Figure 130: Early testing of subterranean bathing - light shaffs, 2
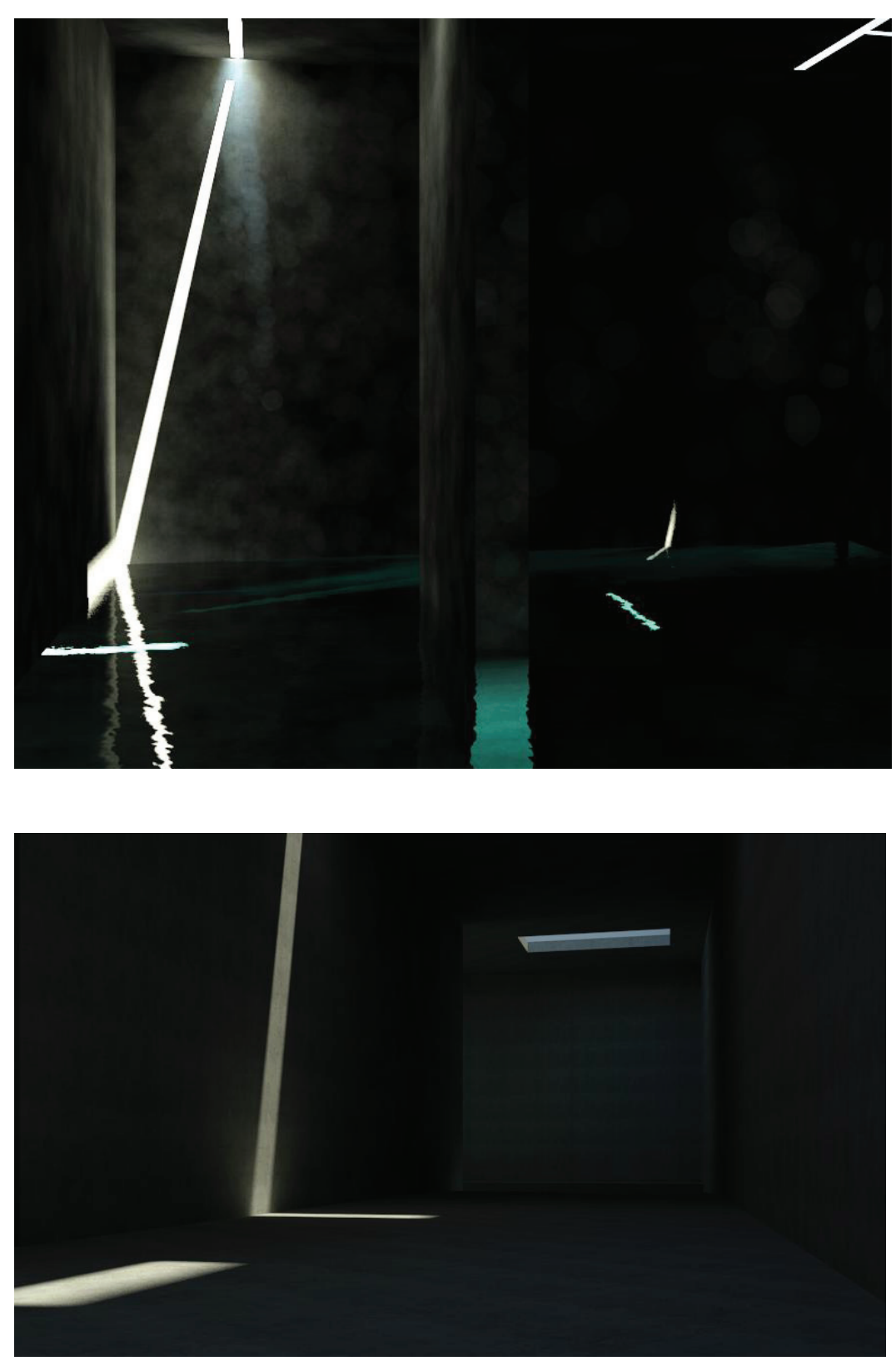

Figure 131: Early testing of subterranean bathing - light shafts, 3 Figure 132: Early testing of subterranean bathing - light shafts, 4 

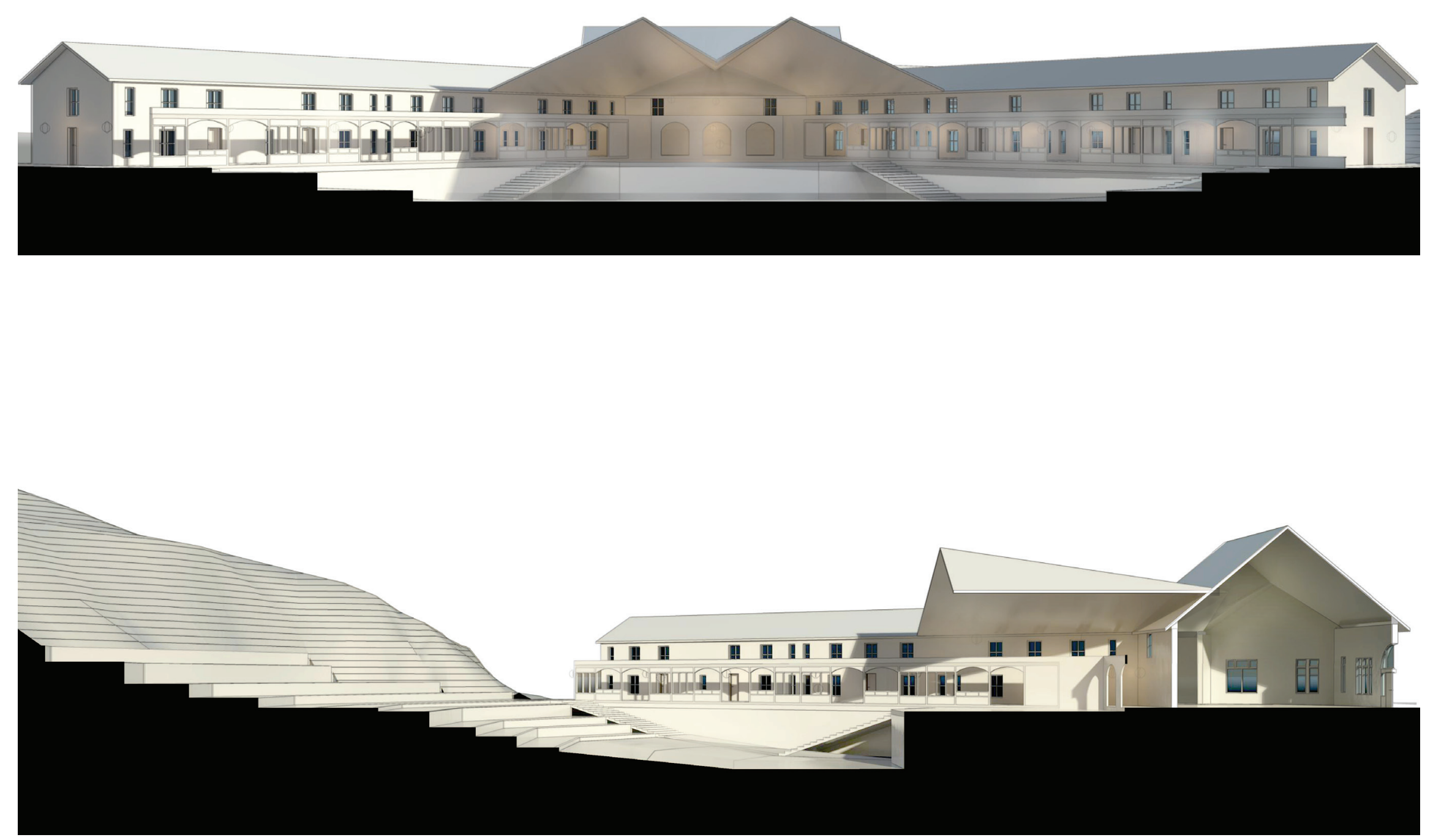

Figure 133: Early testing of central auditoriu space - Cross-sectional perspective

Figure 134: Early testing of central auditoriu space - longitudinal perspective section 

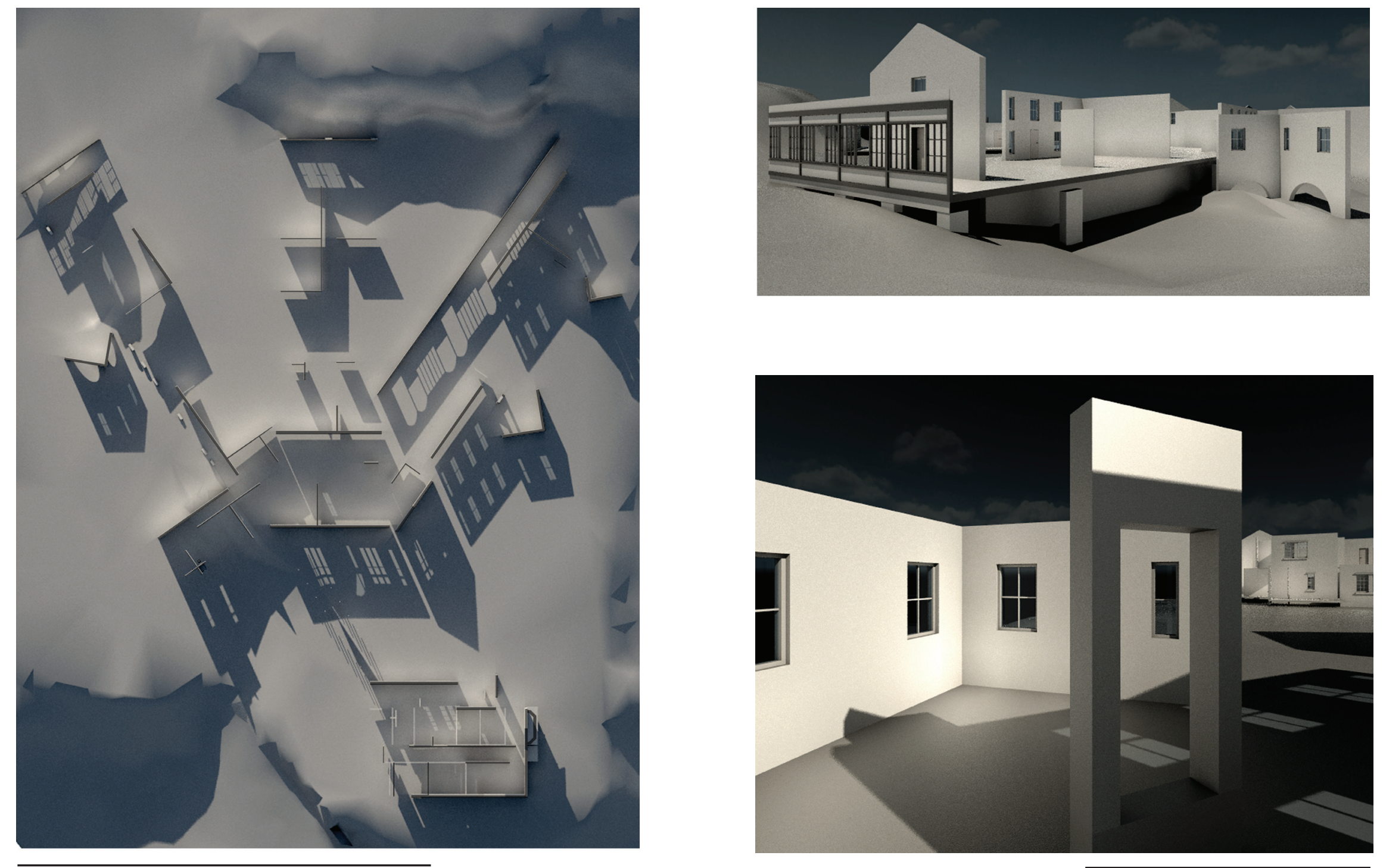


\section{Activating Intangible Heritage}

